\title{
DNA barcoding of arbuscular mycorrhizal fungi
}

Kumulative Dissertation

zur Erlangung des Doktorgrades der Naturwissenschaften

an der Fakultät für Biologie der Ludwig-Maximilians-Universität München

vorgelegt von

Herbert Stockinger

München, Januar 2010 


\section{Ehrenwörtliche Versicherung}

Ich versichere hiermit ehrenwörtlich, dass ich die vorliegende Dissertation von mir selbständig und ohne unerlaubte Hilfe angefertigt ist.

München, am

\section{Erklärung}

Hiermit erkläre ich,

dass die Dissertation nicht ganz oder in wesentlichen Teilen einer anderen

Prüfungskommission vorgelegt worden ist.

dass ich mich anderweitig einer Doktorprüfung ohne Erfolg nicht unterzogen habe.

München, am

Erstgutacher:

Zweitgutachter:

Tag der mündlichen Prüfung:
PD Dr. Arthur Schüßler

Prof. Dr. Martin Parniske

22 April 2010 
Für meine Eltern 



\section{Table of contents}

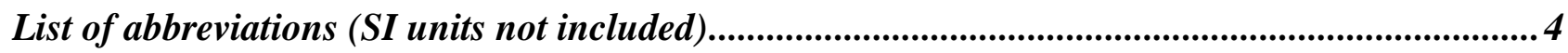

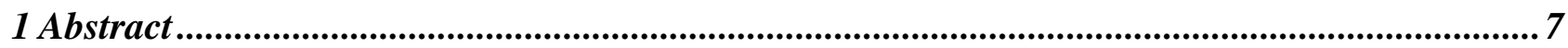

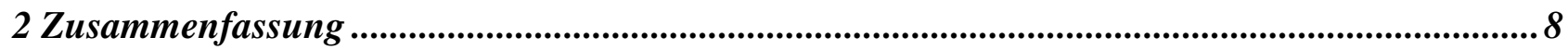

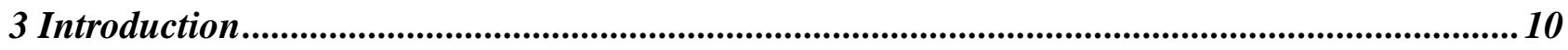

3.1 Arbuscular mycorrhizal fungi (AMF) ......................................................................................................... 10

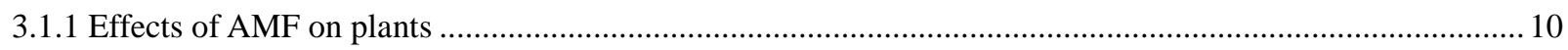

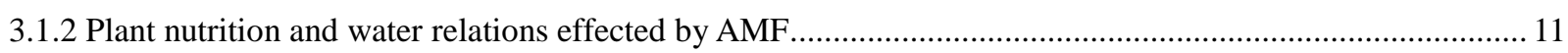

3.1.3 AMF spore characteristics and morphology of root colonization.......................................................... 13

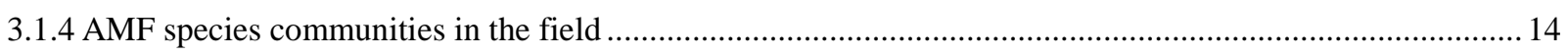

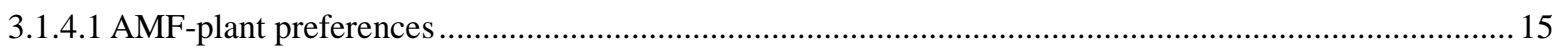

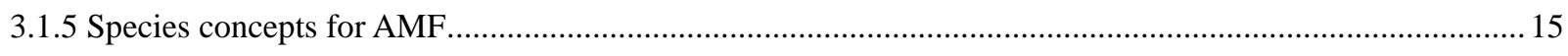

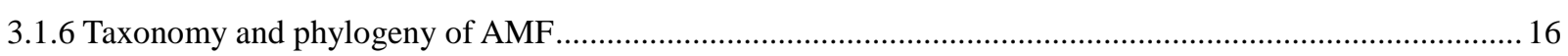

3.2 DNA barcodes and molecular species identification ......................................................................... 18

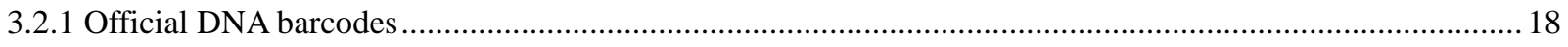

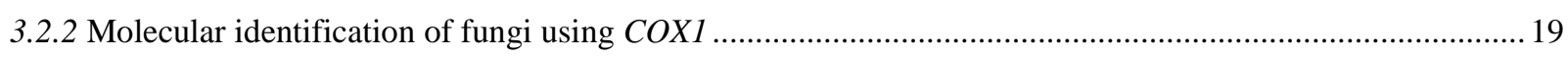

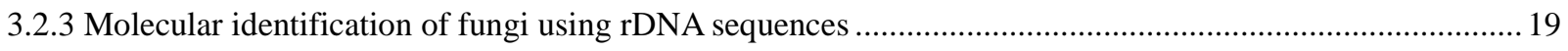

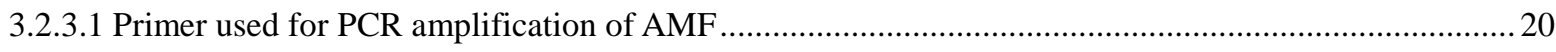

3.3 Aim of this study ................................................................................................................................................... 21

4 Molecular phylogeny and new taxa in the Archaeosporales (Glomeromycota): Ambispora

fennica gen. sp. nov., Ambisporaceae fam. nov., and emendation of Archaeospora and

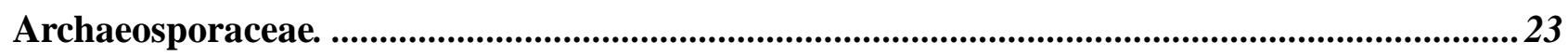

5 DNA-based species level detection of Glomeromycota: one PCR primer set for all arbuscular mycorrhizal fungi..............................................................................................................................43

6 'Glomus intraradices DAOM197198', a model fungus in arbuscular mycorrhiza research, is

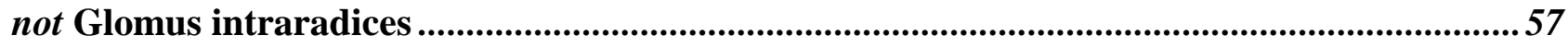

7 DNA barcoding of arbuscular mycorrhizal fungi ........................................................................... 71

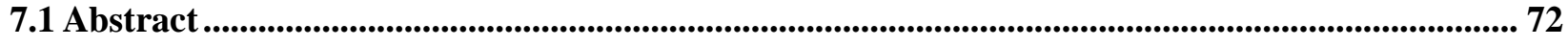

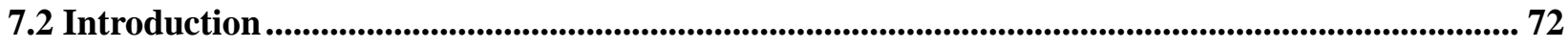

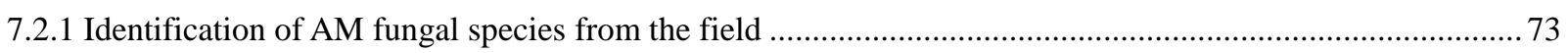

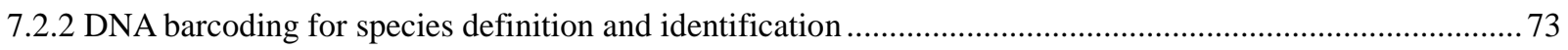

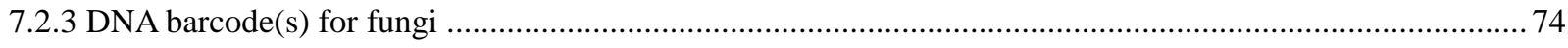




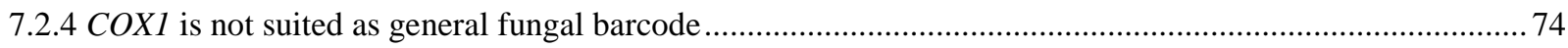

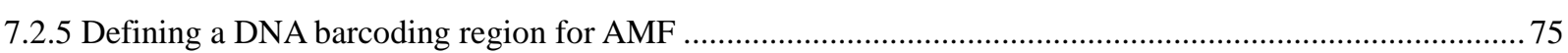

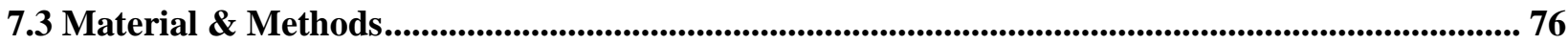

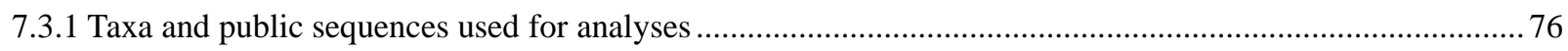

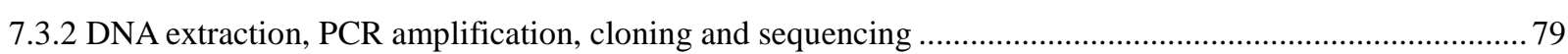

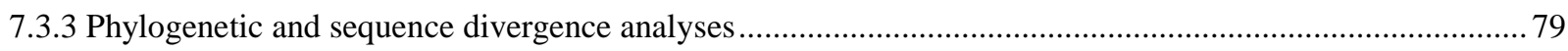

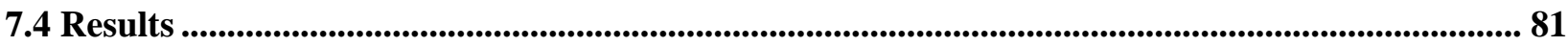

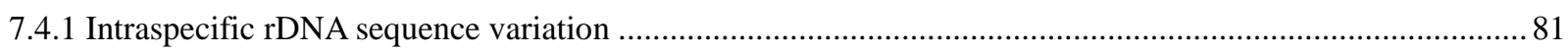

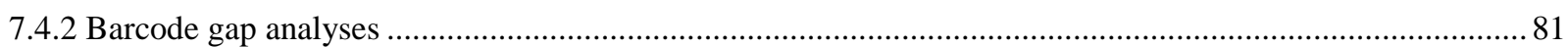

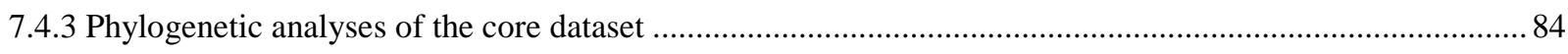

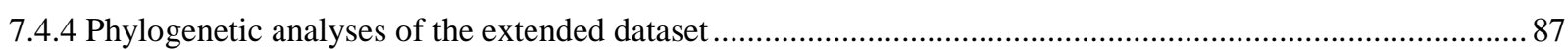

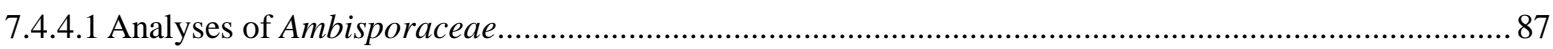

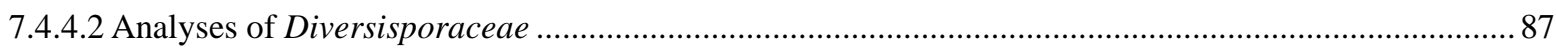

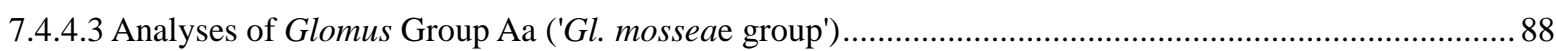

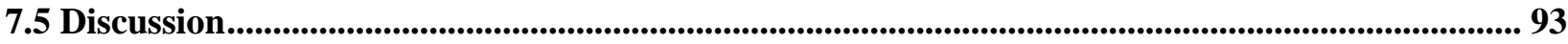

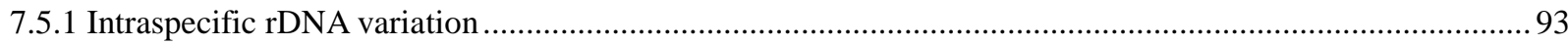

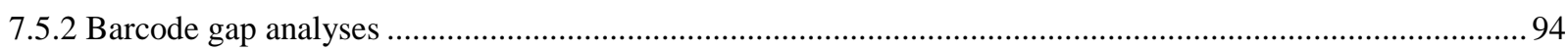

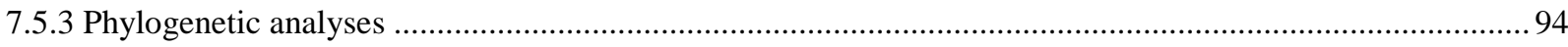

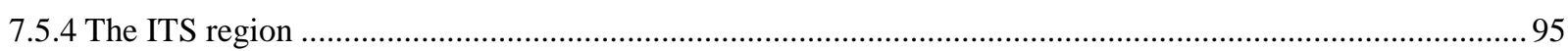

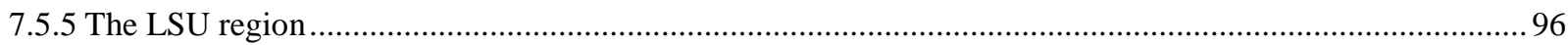

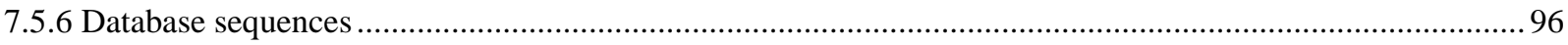

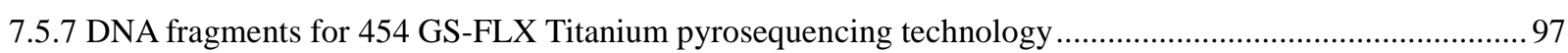

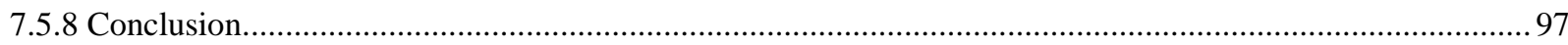

7.6 Acknowledgements ........................................................................................................................................................ 98

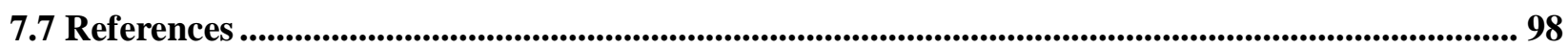

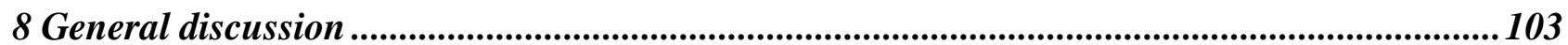

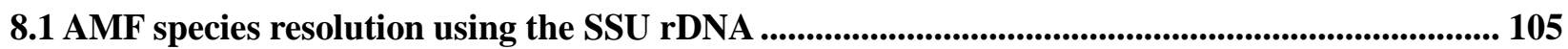

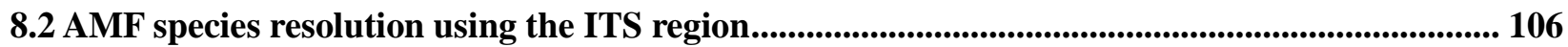

8.3 AMF species resolution using the LSU region ............................................................................................ 107

8.4 Species resolution with ITS region and partial LSU sequences ....................................................... 108

8.5 Evaluation of short rDNA fragments for new sequencing technologies...................................... 109

8.6 Arbuscular mycorrhizal fungi DNA barcoding - a conclusion .........................................................110

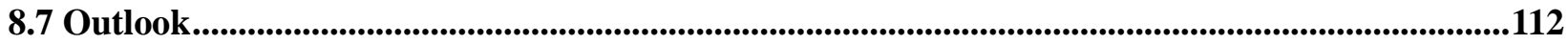

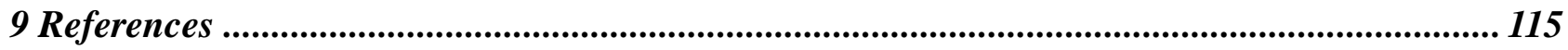




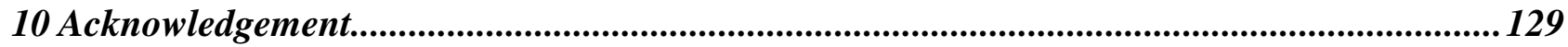

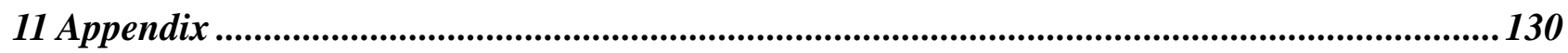

11.1 Supplementary data .............................................................................................................................. 130

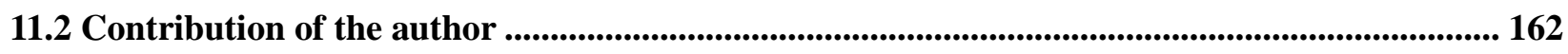

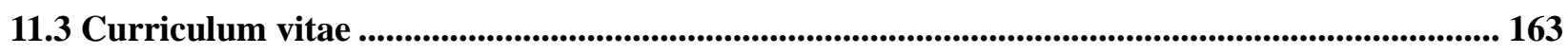




\section{List of abbreviations (SI units not included)}

ac

AFLP

AFTOL

AM

AMF

approx.

Att

BEG

BOLD

bp

BS

CBOL

cf.

CITES

COI

comb. nov.

COX1

CTAB

DAOM

DIC

DNA

dNTP

e.g.

EnvGrA

fam. nov.

gen. nov.

GINCO

GINCO-BEL

g1

GlGrA

GlGrB acaulosporoid

amplified fragment length polymorphism

Assembling the Fungal Tree of Life

English: arbuscular mycorrhiza, Deutsch: Arbuskuläre Mykorrhiza

arbuscular mycorrhiza fungi

approximate(ly)

attempt

International Bank for the Glomeromycota

Barcode of Life Data Systems

base pairs

bootstrap support

Consortium for the Barcode of Life

Latin: confer (English: compare)

Convention on International Trade in Endangered Species of Wild Fauna and Flora

cytochrome c oxidase subunit I (also COXI)

Latin: combinatio nova (English: new combination)

cytochrome oxidase subunit I (also COI)

cetyltrimethylammonium bromide

Agriculture and Agri-Food Canada National Mycological Herbarium

differential interference contrast

deoxyribonucleic acid

deoxynucleotide triphosphate

Latin: exempli gratia (English: for example)

Environmental Group A

Latin: familia nova (English: new family)

Latin: genus novum (English: new genus)

Glomeromycota In Vitro Collection

GINCO-Belgium

glomoid

Glomus Group A

Glomus Group B 


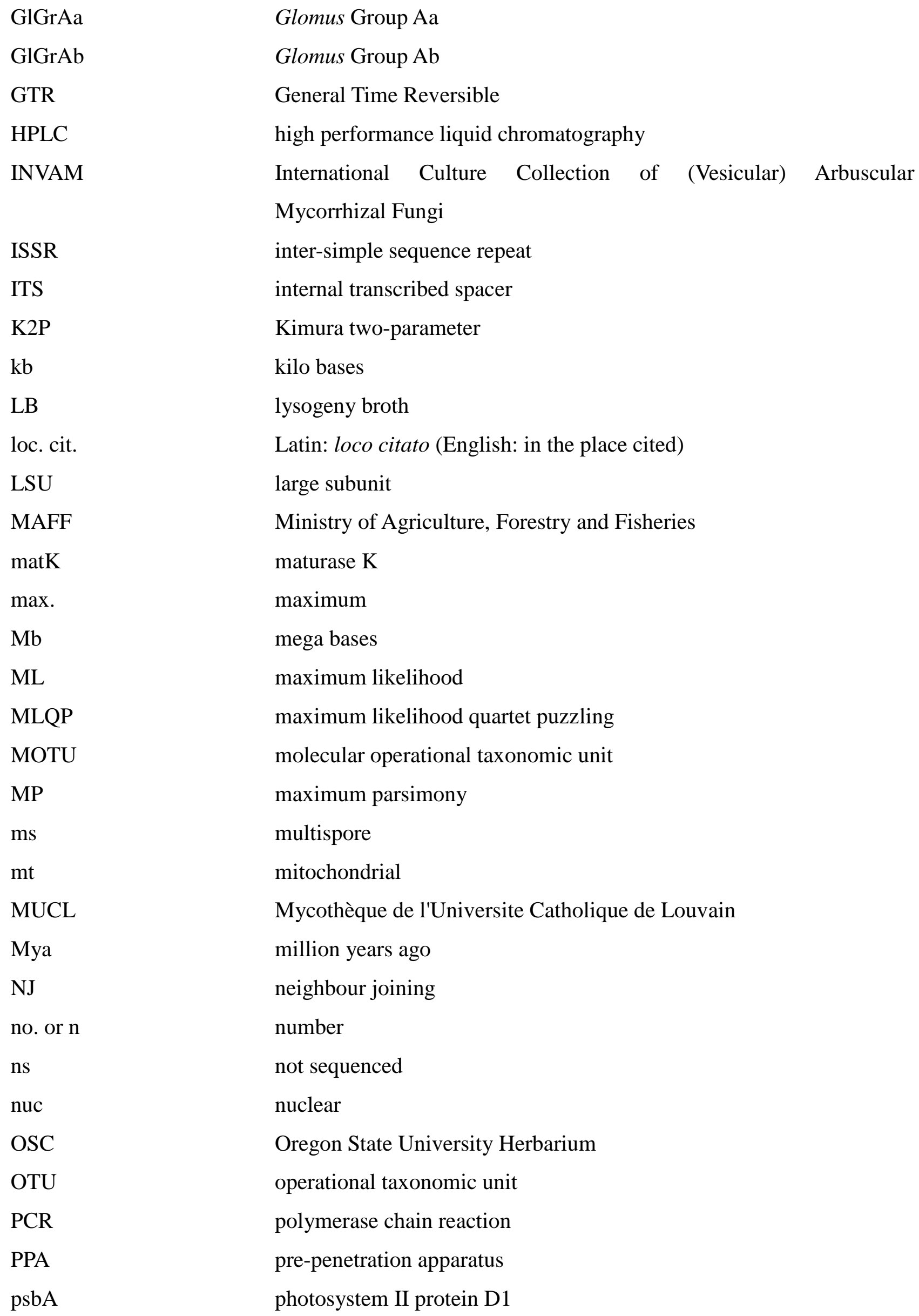


psbI

psbK

PVLG

QP

RAPD

$\mathrm{rbcL}$

rDNA

rf

RFLP

RNA

ROC

rpoB

rpoC1

rRNA

sc

s.d.

SI

SOC

sp. nov.

ss

SSU

Taq

TB

tRFLP

$\operatorname{trnH}$

$\mathrm{U}$

wk photosystem II reaction centre I protein I

photosystem II reaction centre protein $\mathrm{K}$

polyvinyl alcohol lacto-glycerol

quartet puzzles, quartet puzzling

random amplification of polymorphic DNA

ribulose-1,5-bisphosphate carboxylase/oxygenase large subunit

ribosomal DNA

root fragment

restriction fragment length polymorphism

ribonucleic acid

root organ culture

RNA polymerase subunit beta

RNA polymerase subunit gamma

ribosomal RNA

spore cluster

standard deviation

Système International d'unités

super optimal broth with 'catabolite repression'

Latin: species nova (English: new species)

single spore

small subunit

Thermus aquaticus

terrific broth

terminal restriction fragment length polymorphism

tRNA histidine

unit

week 


\section{Abstract}

Plant beneficial microorganisms, such as arbuscular mycorrhiza fungi (AMF), increasingly attract scientific and agronomic attention due to their capacity to increase nutrient accessibility for plants and to reduce inorganic fertilizer requirements. AMF are thought to form symbioses with most land plants, obtaining carbon from the autotrophic host whilst enhancing uptake of poorly available nutrients.

The species of AMF are mainly identified by spore morphology, which is time consuming, requires expertise and is rarely applicable to AMF identification in roots. Molecular tools such as analysis of standardized DNA fragment sequences may allow the recognition of species through a 'DNA barcode', which may partly overcome this problem. The focus of this study was to evaluate different regions of widely used rDNA repeats for their use as DNA barcodes for AMF including the small subunit rRNA gene (SSU), the internal transcribed spacer (ITS) and the large subunit rRNA gene (LSU). Closely related species in the genus Ambispora, members of which have dimorphic spores, could not be separated by analysis of the SSU region, but of the ITS region. Consequently, the SSU was not used for subsequent analysis, but a DNA fragment covering a small part of the SSU, the entire ITS region and about $800 \mathrm{bp}$ of the LSU (SSUmCf-LSUmBr fragment) was analysed, providing phylogenetic resolution to species. New AMF specific primers for these potential barcoding regions were developed and can be applied, without amplification of non-target organisms, for AMF species determination, including identification from field and root samples.

Analyses based on the application of the SSUmCf-LSUmBr fragment showed that the widely used AMF model organism Glomus sp. DAOM197198 (formerly called Glomus intraradices) is not conspecific with $G l$. intraradices. The SSUmCf-LSUmBr fragment clearly provides a much higher species resolution capacity when compared with the formerly preferred ITS and LSU regions.

Further study of several groups of AMF species using different regions of the SSUmCf-LSUmBr fragment revealed that only the complete SSUmCf-LSUmBr fragment allowed separation of all analysed species. Based on these results, an extended DNA barcode covering the ITS region and parts of the LSU region is suggested as a DNA barcode for AMF. The complete SSUmCf-LSUmBr fragment sequences can serve as a database backbone for also using smaller rDNA fragments as barcodes. Although the smallest fragment (approximately $400 \mathrm{bp}$ ) analysed in this study was not able to discriminate among AMF species completely, such short regions covering the ITS2 or LSU D2 regions, respectively, would most likely be suitable for community analyses with 454 GS-FLX Titanium sequencing, providing that the analyses is based on the longer DNA sequences. 


\section{Zusammenfassung}

Arbuskuläre Mykorrhizapilze (AM-Pilze) bilden eine Symbiose mit den meisten Landpflanzen, in welcher sie der Pflanze Nährstoffe bieten und im Austausch Kohlenhydrate erhalten. Sie zählen zu den Mikroorganismen, die einen positiven Einfluss auf Pflanzen ausüben und erwecken zunehmend wissenschaftliche und agronomische Aufmerksamkeit, da sie die Nährstoffzugänglichkeit für Pflanzen erhöhen und damit zum Beispiel die benötigte Menge an Phosphordünger deutlich reduzieren können.

AM-Pilzarten wurden klassischerweise durch morphologische Analysen identifiziert, welche sowohl zeitaufwendig als auch schwierig sind und sich für Artidentifizierung in Pflanzenwurzeln nicht eignen. Die molekularbiologische Analyse eines standardisierten DNA-Fragments, welches für eine Art spezifisch ist und dadurch als „DNA Barcode“ definiert wird, ist ein vielversprechendes Werkzeug für eine verlässliche Artidentifizierung.

Der Fokus dieser Arbeit lag in der Etablierung eines geeigneten DNA-Barcodes für arbuskuläre Mykorrhizapilze. Hierfür wurden verschiedene Abschnitte des in früheren Arbeiten bereits oft verwendeten „,rDNA-Repeats“ analysiert, darunter das „small subunit rRNA gene” (SSU), die „,internal transcribed spacer region” (ITS) und das „large subunit rRNA gene” (LSU).

Nah verwandte Arten der Gattung Ambispora, welche zum Teil dimorphische Sporen aufweisen, konnten nicht durch Analysen der SSU Region aufgetrennt werden, was durch Analysen der ITSRegion aber möglich war. Die SSU-Region wurde folglich für weitere Analysen nicht weiter bearbeitet, sondern ein durch die Primer SSUmCf-LSUmBr amplifiziertes Fragment, das einen kleinen Teil der SSU, die ITS Region und ca. 800 bp der LSU umfasst. Mit Hilfe der SSUmCfLSUmBr Fragmentes konnten alle untersuchten AM-Pilze bis hin zur Artenebene aufgelöst werden. Neue, AM-Pilz spezifische Primer für diese potentielle Barcode-Region wurden entwickelt und können für spezifische AM-Pilz Artbestimmung von Feld- und Wurzelproben benutzt werden.

Analysen basierend auf dem SSUmCf-LSUmBr Fragment ergaben, dass der weit verbreitete Modelorganismus Glomus sp. DAOM197198 (früher Gl. intraradices genannt) nicht zur Art Gl. intraradices gehört. Das SSUmCf-LSUmBr Fragment erlaubt eine deutlich besserer Artauflösung im Vergleich zu der früher oft benutzten ITS und LSU Regionen.

Detaillierte Analysen verschiedener Sequenzabschnitte des SSUmCf-LSUmBr Fragmentes ergaben, dass nur Analysen des kompletten Fragmentes alle analysierten AM-Pilzarten erfolgreich separieren kann. Basierend auf diesen Ergebnissen wird vorgeschlagen, das SSUmCf-LSUmBr Fragment als erweiterten DNA Barcode für AM Pilze zu nutzen. Das SSUmCf-LSUmBr Fragmente kann auch als ,Rückgrat‘ für auf kürzeren Sequenzen basierende Analysen dienen. Die kürzesten hier 
untersuchten rDNA Sequenzen (ca. 400bp) alleine können nicht alle AM-Pilzarten auflösen. Auf Basis von robusten, SSUmCf-LSUmBr Fragment basierten Phylogenien ist es aber wahrscheinlich möglich auch 400 bp Sequenzen verlässlich bestimmten Arten zuzuordnen. Dies wäre für 454 GSFLX Titanium Pyrosequenzierungen zur Bestimmung von AM-Pilz-Gemeinschaften in Ökosystemen ein deutlicher Fortschritt. 


\section{Introduction}

\subsection{Arbuscular mycorrhizal fungi (AMF)}

Arbuscular mycorrhizas (AM) are named from the treelike structures formed inside root cortical cells, called arbuscules ('little bushes'). They are symbioses between plants and a particular group of fungi, the so called arbuscular mycorrhizal fungi (AMF). Such symbioses are generally regarded as mutualistic, with a bidirectional transfer of nutrients (Smith \& Read, 2008). The contact zones of mycorrhiza are in general on the surface or inside the roots of plants, which is reflected in the name mycorrhiza (ancient Greek: $\mu v \kappa \eta \varsigma($ mykes $)=$ fungus and $\rho 1 \zeta \alpha($ rhiza $)=$ root $)($ Frank, 2005). The fungal structures are always surrounded by the plant cell wall (intercellular) or the plant plasma membrane (intracellular). AMF provide the plant with nutrients such as phosphorus, nitrogen, zinc and copper. They receive carbon assimilate from the host plant. Whereas plants may be able to live without AMF, the fungi are thought to be obligate symbionts. It is said that approx. 70-90\% of all land plant species form AM (Brundrett, 2009). Potential host plants range from liverworts, hornworts, ferns and gymnosperms to angiosperms (Harley \& Harley, 1987; Brundrett, 2009; Wang \& Qiu, 2006).

Based on small subunit (SSU) rDNA sequences and their symbiotic lifestyle, the AMF were placed in the separate phylum Glomeromycota (Schüßler et al., 2001). The origin of this phylum may be more than 1000 million years ago. The AM symbiosis is also ancient and AMF may have played an important role during land colonization by plants (Redecker et al., 2000a; Remy et al., 1994; Simon et al., 1993;-Heckman et al., 2001).

\subsubsection{Effects of AMF on plants}

It has long been recognised that AMF have an influence on plant nutrition and growth (Mosse, 1957; Gerdemann, 1965; Daft \& Nicolson, 1966, 1969a, b; Hayman \& Mosse, 1971, 1972; Mosse \& Hayman, 1971). Much of the research on AMF is driven by the desire to improve plant production. Up to $20 \%$ of plant photosynthates can be delivered to the AMF (Jakobsen \& Rosendahl, 1990; Bago et al., 2003). Some AM associations under some circumstances result in increased plant nutrient uptake and growth (Smith et al., 2009), but this is not universal and there are examples in which there is no or even a negative mycorrhizal growth response (Tawaraya, 2003). Graham \& Abbott (2000) noted growth depression by 10 different AMF cultures tested on 
wheat in pot cultures. Different AMF cultured with the same plant gave different growth effects (van der Heijden et al., 2003; Klironomos, 2003). Pringle \& Bever (2008) showed that an early mortality of Rumex seedlings consistently occurred in the laboratory and in a field experiment, when inoculated with Scutellospora pellucida, but it is worth noting that Rumex spp. are considered generally to be non-mycorrhizal (Fransson et al. 2003). Barley showed a similar large growth depression in the presence of Glomus geosporum with $20 \%$ colonization (6 weeks) or in the presence of a $\mathrm{Gl}$. intraradices-like fungus with $72 \%$ colonization (6 weeks) (Grace et al., 2009). The phenomenon of plant growth depression may indicate a potential occurrence of cheating within this symbiosis (Johnson et al., 1997; Smith et al., 2009). However, the plant might benefit from other characteristics of this symbiosis like tolerance against pathogens or drought (Newsham et al., 1995).

The establishment of seedlings (van der Heijden, 2004) and the success of plant invasion (Klironomos, 2002) can be enhanced by AMF through their influence on plant productivity, plant diversity and plant community structure (Grime et al., 1987; Gange et al., 1990; van der Heijden et al., 1998; Hartnett \& Wilson, 1999; Klironomos et al., 2000; Bever et al., 2001; O'Connor et al., 2002). The ability of plants to compete with each other may affect the structure of plant communities. For example, Centauria maculosa and Festuca idahoensis show no positive response to AM when cultivated in separate pots (Marler et al., 1999). However, when cultivated together in the presence of AMF, Centauria maculosa responded more than Festuca idahoensis (Marler et al., 1999). In this instance, no direct effect of AM on the individual plant species growth could be detected, but an indirect benefit from AM occurred when co-cultivating two different species.

The bacterial rhizosphere community also may be influenced by AMF (Marschner \& Baumann, 2003) changing in reaction to different AMF species (Marschner \& Timonen, 2005).

\subsubsection{Plant nutrition and water relations effected by AMF}

It is widely accepted that the main function of the AM symbiosis is the exchange of nutrients between partners. Phosphorus, which occurs in inorganic or organic forms in soil, in many ecosystems is the most important nutrient for which uptake is mediated by AMF. Inorganic phosphorous is held firmly within the soil in insoluble forms such as Al-, Ca-, and Fe-phosphates (Smith \& Read, 2008), whereas organic phosphorous occurs as inositol phosphates (phytate), phospholipids and nucleic acids in the soil. Organic phosphorous is mineralised by desorption, precipitation and with the help of organisms (Smith \& Read, 2008). The available phosphorous 
around roots rapidly becomes exhausted and a depletion zone is formed. AMF can bridge this zone and make additional phosphorous accessible. Furthermore, the small diameter and rapid growth of the AMF hyphae compared with roots can reach smaller soil pores, facilitating phosphorous uptake. This may result in larger plants, which contain higher concentrations of phosphorous in their tissues (Smith \& Read, 2008). Even when mycorrhizal plants do not grow larger, they can receive phosphorus from AMF (Grace et al., 2009; Smith et al., 2009). The increased inflow of phosphorus into mycorrhizal roots was first studied in Allium cepa by Sanders and Tinker (1973), followed by studies in other plants with varying responses and dependencies of the plants (Smith et al., 2003, 2004).

Another main nutrient for plant growth is nitrogen. Nitrogen is a principal component of most fertilizers, on which modern day agriculture depends. Nitrogen production is very energy consuming. Rhizobia in root nodules can fix nitrogen in their natural environments. Additionally AMF hyphae can absorb nitrogen in form of ammonium and nitrate. The contribution of such absorption to plant growth is unclear. Some studies showed, that up to 30-42 \% of total plant nitrogen can be taken up via AMF (Mäder et al., 2000; Govindarajulu et al., 2005), whereas Reynolds et al. (2005) showed no increase of total nitrogen uptake for some perennials plants.

Besides nitrogen and phosphorous, micronutrients, such as copper and zinc are also important for plant growth. AMF can increase copper concentration of different plant species (Mosse, 1957; Gildon \& Tinker, 1983; Kucey \& Janzen, 1987; Gnekow \& Marschner, 1989; Li et al., 1991) and may contribute up to $62 \%$ of total copper uptake of white clover (Li et al., 1991). Zinc, which, like phosphorous, is poorly labile in the soil, can be transported via AMF hyphae to the plant over a distance of at least $14 \mathrm{~cm}$ (Jansa et al., 2003) and therefore reduce zinc deficiency (Thompson, 1990; Bürkert \& Robson, 1994). On the other hand, AMF colonization reduces zinc accumulation in plants growing on soils with high zinc content (Li \& Christie, 2001; Zhu et al., 2001; Burleigh et al., 2003). Although AMF can affect copper and zinc uptake, little is known in respect of other micronutrients (Hart \& Trevors, 2005).

Another fundamental factor for plant growth is the water availability. AMF has an effect on the plant water relations (Augé, 2001, 2004; Augé et al., 2008). For example in the study of Mosse and Hayman (1971), mycorrhizal Allium cepa seedling did not wilt when tranplanted in contrast to nonmycorrhizal controls. Different AMF show different effects on plant water stress (Marulanda et al., 2003; Aroca et al., 2007), however, it remains unclear, if this effect results directly from, or is caused by, the increased phosphorous uptake and therefore by plant size or fitness. The mycelium in the soil changes soil moisture characteristics and improves soil structure by formation of soil aggregates (Rillig, 2004; van der Heijden et al., 2006) and might therefore also effect water 
availability (Augé, 2001, 2004). Augé (2004) showed that mycorrhiza deficient (non-mycorrhizal) mutant plants grown together with mycorrhizal plants in pots with mycorrhiza kept stomata longer open than in soil without AMF.

Although there is considerable evidence that AMF in general enhance the uptake of phosphorous, micronutrients and water, many questions about nutrient uptake of individual AMF species, both singly and in cohorts, remain to be solved.

\subsubsection{AMF spore characteristics and morphology of root colonization}

AMF form large spores, sometimes as big as $1.2 \mathrm{~mm}$ in diameter, containing many storage components and a numerous nuclei (576 to 35000 in different species; Hosny et al., 1998; Viera \& Glenn, 1990), although the highest value is estimated rather than counted (Hosny et al., 1998). It is suggested that nuclei of Gl. sp. DAOM197198, Gl. etunicatum and Sc. castanea are haploid (Bianciotto et al., 1995; Hijri \& Sanders, 2004). The DNA content of one nucleus is between 0.26 and $3.4 \mathrm{pg}$, depending on species and method of assessment (Viera \& Glenn, 1990; Bianciotto \& Bonfante, 1992; Hosny et al., 1998). The genome size of $G l$. sp. DAOM197198 was determined to be approximately 16.54 Mb (Hijri \& Sanders, 2004), but preliminary results of the genome sequencing of a fungus of this name revealed the genome to be approx. five times larger than this (Martin et al., 2008). The Sc. pellucida genome has been calculated to have a size of $1058 \mathrm{Mb}$ (Bianciotto \& Bonfante, 1992). It is still debated whether one spore contains several different nuclei (heterokaryotic; Hijri \& Sanders, 2005) or identical nuclei (homokaryotic; Pawlowska \& Taylor, 2004). This is interesting, in regard to the high genetic diversity for example within the ITS of a single species (Sanders et al., 1995; Lloyd-Macglip et al., 1996; Lanfranco et al., 1999; Jansa et al., 2002b). Variations have been also detected by AFLP analysis of a culture started with 30 spores (Rosendahl \& Taylor, 1997) and in some genes involved in cellular function (Kuhn et al., 2001; Sanders et al., 2003; Pawlowska \& Taylor, 2004). Kuhn et al. (2001) indicated that a nucleus of Sc. castanea contains different numbers of divergent ITS region sequences. This genetic variation within spores may have a significant impact on species definition and on phylogenetic identification. Whether the variation within a single organism influences the interactions of AMF and plants or the colonization of plants in various ecological habitats is still unclear.

AMF preferentially germinate from a spore even in the absence of roots. Plant derived signals such as strigolactones can induce hyphal branching (Akiyama et al., 2005) and change fungal physiology and mitochondrial activity (Besserer et al., 2006). Upon contact with the root, AMF form an 
appressorium, also called hyphopodium (Genre et al., 2008). The plant cell responds to this contact with the formation of a pre-penetration apparatus (PPA). The PPA then determines the path of the fungal growth and seems to form a tunnel. Additionally, the plant root cell triggers AMF growth (Genre et al., 2005, 2008). According to Parniske (2008) the 'pre-infection thread' of legumes most likely evolved from the PPA. This relatedness is also reflected by common plant genes involved in rhizobial symbiosis and AM (Parniske, 2008).

The fungal colonization of the plant root is restricted to the cortical cells. Two distinct structural types of colonization were originally described (Gallaud, 1905): the Arum-type, in which hyphae grow intercellularly and form intracellular arbuscules, and the Paris-type, which exhibits intracellular growth and form hyphal coils cells from which small arbuscules can originate. More recent studies have shown that this differentiation is not so clear and several intermediate forms exist (Dickson, 2004). It remains unclear which factors control the colonization type and it seems it is influenced by both plant and fungus species (Cavagnaro et al., 2001; Dickson, 2004; Kubota et al., 2005; Dickson et al., 2007).

\subsubsection{AMF species communities in the field}

Ecological studies on AMF have been widely performed based on spore identification and colonization intensity of plant. The surveys of different plant species for AM colonization have been summarized in the publications of Harley and Harley (1987), Wang and Qiu (2006), and Brundrett (2009) who gave an overview of the numerous plant hosts. There are many community studies based on spore morphology. In one, about 30 AMF species have been found in a field containing 50 plant species (Bever et al., 2001). Different AMF spore communities were detected in different soil depths (Oehl et al., 2005) and in different farming systems (Oehl et al., 2003), both in cultivated and non-cultivated lands (Li et al., 2007). Trap cultures were furthermore established to allow expression of species not sporulating at the time of sampling. These cultures are influenced by the plant host and age of the culture. Some species start their sporulation in such cultures only after 18 months (Oehl et al., 2005). Furthermore, the spore community may not reflect the active AMF community colonizing roots and soil. Therefore, molecular methods were developed for the identification of AMF colonizing roots and soil. These molecular ecological studies have shown that many AMF phylotypes might correspond to undescribed species (Öpik et al., 2008; Kottke et al., 2008). In addition, Sýkorová et al. (2007a) have detected a bias between the analysis of roots from field, roots from trap cultures, and roots from bait plants. This bias and different methods and DNA 
regions makes the comparison among publications very difficult or even impossible.

\subsubsection{AMF-plant preferences}

Early investigators stated that there is no specificity between AMF taxa and potential host plant taxa. No strict specificity can be expected, as the 214 known AMF species form AM with roughly 250000 host plants species (Fitter, 2005). Some species like Plantago lanceolata, Trifolium subterraneum and Sorghum sudanense are considered to be generalists and therefore are used for cultivation of AMF species in trap cultures (Smith \& Read, 2008). However, recent studies indicate that some preferences exist, e.g. for Acer pseudoplatanus which was only colonized by a fungus determined to be Glomus hoi (Helgason et al., 2002). In addition, mycoheterotrophic plants such as Arachnites, Voria and Voyriella spp. are associated with a limited number of glomeromycotan symbionts possibly because of their narrow specificity to all kinds of fungal associates (Bidartondo et al., 2002). Different plant species used in trap cultures, had also an effect on the sporulation of different AMF (Jansa et al., 2002a). Bever et al. (2009) show that Allium vineale allocated more carbon to the AMF species with greater mutualistic tendencies. This kind of work on specific relationships among host plants and AMF is still in its infancy, and many questions remain unanswered providing opportunities for much future research.

\subsubsection{Species concepts for AMF}

The classical species concept for AMF is mainly based on spore morphology and development. Identifying species from spore morphology is not easy and even specialists do not agree on general characteristics of spores. About 214 AMF species have been described to date (www.amfphylogeny.com), many of which are not in culture. Many, but still not all, new species descriptions include molecular evidence and provide reference cultures, which can be found in BEG (www.kent.ac.uk/bio/beg/), INVAM (http://invam.caf.wvu.edu/), $\quad$ GINCO (http://emma.agro.ucl.ac.be/ginco-bel/) or other available culture collections (e.g. Gamper et al., 2009). Morphological identification of spores can sometimes be misleading. For example, single species with dimorphic spores (Sawaki et al., 1998; Redecker et al., 2000b) have been placed in two different taxa because of their morphological characteristics.

The molecular species concept is mainly based on rDNA sequences such as SSU, internal 
transcribed spacer (ITS) region or partial large subunit (LSU) rDNA. Some new markers have also been used such as the mitochondrial LSU (mtLSU; Raab et al., 2005) and tubulin genes (Corradi et al., 2004a; Corradi et al., 2004b; Msiska \& Morton, 2009) and microsatellites (Croll et al., 2008; Mathimaran et al., 2008). Some of these can differentiate strains within species of AMF.

A biological species concept is not definable within AMF, because no sexual stage, indispensable for this concept, has yet been found. Therefore, it is assumed that AMF are asexual and clonal. Croll et al. (2008) introduced the idea of "non-self fusion compatibility groups" to define species based on anastomosis formation. Such analyses are time-consuming and only one species was analysed up to date. Application of such a concept is also very difficult, because the majority of species is not established in root organ cultures (ROC) or similarly controlled monoxenic systems. Another approach towards species identification utilizes a recombination test. Croll and Sanders (2009) have performed recombination test on 11 polymorphic markers, all showing recombination with 40 clonal isolates from a field, all of which were identified as Gl. intraradices, but which are probably more closely related to a different Glomus sp. DAOM197198, conspecific with, or closely related to Gl. irregulare.

\subsubsection{Taxonomy and phylogeny of AMF}

The most modern higher taxonomy within AMF is based on a combination of morphology and SSU rDNA sequences. The phylogenetic analysis of SSU rDNA sequences has placed the AMF in a separate phylum, the Glomeromycota. This phylum is divided into four orders (Figure 1 Glomerales, Diversisporales, Archaeosporales, Paraglomerales). Within this, 13 families have been defined (Glomeraceae, Diversisporaceae, Acaulosporaceae, Entrophosporaceae, Scutellosporaceae, Gigasporaceae, Racocetraceae, Dentiscutataceae, Pacisporaceae, Geosiphonaceae, Ambisporaceae, Archaeosporaceae and Paraglomeraceae), and 19 genera (Glomus, Diversispora, Otospora, Acaulospora, Kuklospora, Entrophospora, Scutellospora, Gigaspora, Racocetra, Cetraspora, Dentiscutata, Fuscutata, Quatunica, Pacispora, Geosiphon, Ambispora, Archaeospora, Intraspora and Paraglomus; see www.amf-phylogeny.com). Some of these taxa are paraphyletic, and some may by synonyms. In particular, regarding the separation of Scutellospora (personal communication Christopher Walker) many questions are still unanswered about taxonomy and phylogeny. Another example is the genus Glomus still appearing in two different orders. The order Glomerales is divided into at least two major clades, with both being referred to as Glomeraceae. Hence Schwarzott et al. (2001) divided them into two groups, Glomus 
Group A and Glomus Group B. It is likely that these two groups will become separate families as soon as the type of Glomus could be assigned to one of these groups. To clearly understand the relationship within the Glomeromycota it is necessary to have comparable datasets for at least representative species for each clade. However, only one part of the rDNA sequence is available for some species, for example, only the LSU sequence is available for Sc. nigra, and therefore comparisons with other species are not possible. Some species are well covered for different rDNA regions, but the sequences may have originated from different cultures and despite their annotations may not be conspecific because of taxonomic difficulties. Such problems exist in particular when cultures have been lost over time and no voucher had been deposited. Even when taxonomic vouchers have been preserved, they often are not amenable to further DNA extraction. Inadequately prepared vouchers may even lack sufficient characters for verification of the species, or may contain more than one species or heavily parasitized spores (personal communication Christopher Walker). The introduction of an easily and quickly applicable method for species determination would be highly beneficial for reliable and comprehensive identification.

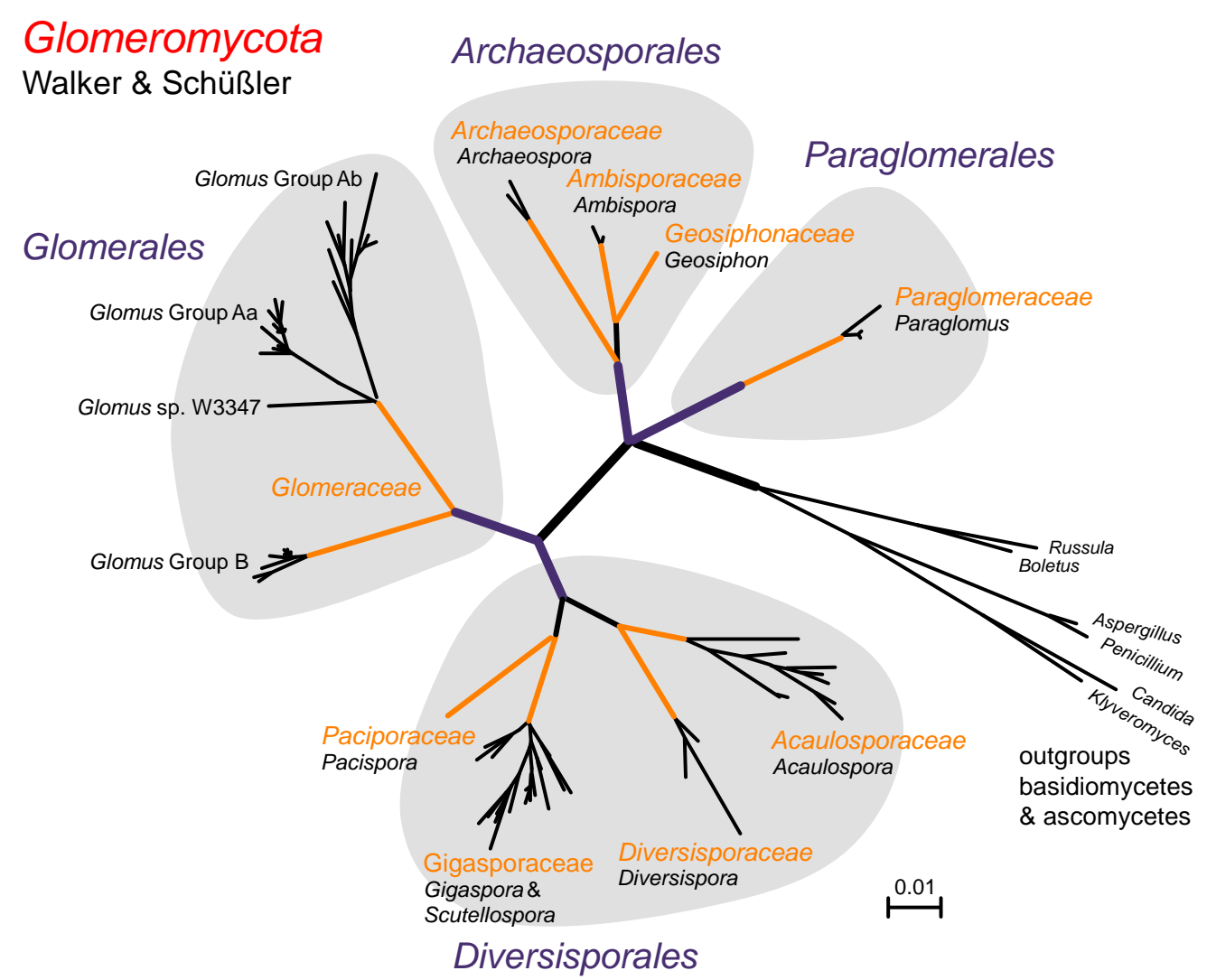

Figure 1: Phylogenetic tree of the AMF showing the organisation within the phylum Glomeromycota. After Schüßler et al. (2001). 


\subsection{DNA barcodes and molecular species identification}

A DNA barcode is defined as a short and easily PCR amplifiable DNA fragment for identification of organisms to species level. DNA barcoding must ideally be feasible for non experts, accurate, rapid, cost-effective, culture-independent and universally accessible (Frézal \& Leblois, 2008). The aim of a barcode system is to be applicable for all kingdoms of eukaryotic life and to simplify recognition of cryptic species. The identification of fragments from organisms or such from different life cycle stages will become possible, where morphological identification is not realizable (Gilmore et al., 2009). This is also a general problem for microorganisms, also such living within other organisms and in the soil. In addition, a genetic barcode can be invaluable for controlling the trade in endangered species (see Convention on International Trade in Endangered Species of Wild Fauna and Flora, CITES) because of its practicality for non experts. Furthermore, it can facilitate the search for new species and may help to protect them before they are lost.

Morphological identification of fungi often requires cultivation of the target organism, which in many cases poses major problems (O'Brien et al., 2005). Therefore molecular methods, such as DNA barcoding, may be the only way to identify such recalcitrant organisms. Of the estimated 1.53.5 million fungal species, about 100.000 are described (Hawksworth, 2001; O'Brien et al., 2005; Kirk et al., 2008). Currently no official DNA barcode is suitable for fungi, although many studies deal with the identification of fungi through molecular markers.

\subsubsection{Official DNA barcodes}

The first official barcode, that is a barcode accepted by the Consortium for the Barcode of Life (CBOL) consists of approx. 640 bp of the cytochrome oxidase subunit I (COX1) in the mitochondrial DNA, and it is mainly used for animal species identification (http://www.barcoding.si.edu/, Hebert et al., 2003). Mitochondrial DNA of plants has a low substitution rate, and a two-locus barcode from the chloroplast region, using the matK and $r b c L$ genes consequently was proposed by the CBOL plant working group (Hollingsworth et al., 2009). These authors have observed a species separation capability of the two-locus barcode to a success rate of approx. $72 \%$, which did not increase significantly when taking in account all seven analysed markers (matK, rbcL, rpoCl, rpoB, psbK-psbI, trnH-psbA, psbK-psbI) together. 


\subsubsection{Molecular identification of fungi using COX1}

COX1 works well for most animal species; however some drawbacks have been detected within fungi. In a case study of species in the genus Penicillium, COXI seems to be a likely candidate for species identification (Seifert et al., 2007), although they have already shown considerable length variations possible within the fungi. The COX1 gene of fungi varies between $1548 \mathrm{bp}$ and $22 \mathrm{~kb}$, similar to the barcoding region within $C O X 1$ gene which ranges from $642 \mathrm{bp}$ to $12.3 \mathrm{~kb}$ (Seifert et al., 2007; Seifert, 2009). Only one COX1 gene is published for just one glomeromycotan species with a length of 2200 bp (based on NC_12056, Lee \& Young, 2009). However the length can vary as seen in other parts of the mitochondrial genome in Glomeromycota. The mitochondrial large subunit (mtLSU) for example has different sizes and introns even among closely related species (Raab et al., 2005; Börstler et al., 2008).

Multiple copies (paralogous) of the COX1 gene have been found in the genus Fusarium and proved inadequate for species level identification (Gilmore et al., 2009). A similar situation was observed within the complex group of Aspergillus niger (Geiser et al., 2007). Lang and Hijri (2009) reported a COX1 intron in Glomus diaphanum with a high sequence similarity to both a plant sequence and a Rhizopus oryzae COX1 intron. This intron may result from a lateral gene transfer from fungi to plant (Vaughn et al., 1995; Seif et al., 2005; Lang \& Hijri, 2009).

\subsubsection{Molecular identification of fungi using rDNA sequences}

Recent studies using molecular markers for species identification of fungi typically use nuclear ribosomal genes such as the small subunit (SSU), the ITS region (ITS1-5.8S-ITS2) or the partial large subunit (including two variable subregions called D1 and D2). For most fungi the ITS has become the default marker for species identification. This led Seifert (2009) to conclude, that "ITS [is] already functioning as de facto barcode". However, yeasts represent an exception, as the LSU is already widely used for species identification (Seifert, 2009). Most sequence data available for members of the Glomeromycota are still only from the SSU.

The fungal ITS is rich in insertions and deletions, rendering it useful for developing taxon-specific primers. The length of the ITS varies within fungi from $270 \mathrm{bp}$ for yeasts to $973 \mathrm{bp}$ for Dothideomycetes, but the indels and the length variations make the ITS difficult to align (Seifert, 2009). 


\subsubsection{Primer used for PCR amplification of AMF}

Several primer combinations were published for the use of PCR amplification for AMF. The resulting DNA fragment varies in their discriminatory power. The most widely used primer combination for AMF is AM1 (Helgason et al., 1998) - NS31 (Simon et al., 1992) ( 550 bp). NS31 amplifies all eukaryotic species, and although supposedly specific to AMF, AM1 excludes the ancestral lineages such as Archaeosporales and Paraglomerales (Redecker et al., 2000b; Schüßler 2001). This primer combination is thus mainly useful for studying Glomerales and Diversisporales. Some of these studies reported additional amplifications even of non-AMF sequences (Helgason $e t$ al., 2002; Douhan et al., 2005; Rodríguez-Echeverría \& Freitas, 2006; Santos-Gonzalez et al., 2007). To solve this, new specific SSU primers known as AML1-AML2, covering the AM1-NS31 fragment, were designed that include species in all the major orders of AMF (Lee et al., 2008; $\sim 800$ bp). Santos-Gonzalez et al. (2007) designed additional new primers (AM2, AM3) based on the AM1 to amplify additional groups, such as the Glomus Group B and Diversisporaceae species. Wubet et al. (2006) also published a new set of primers, specific for different families, amplifying an even longer fragment of about 1130 bp of the SSU (Figure 2).

Several group-specific primers were developed for the amplification of the ITS region (Redecker, 2000). In another approach, Renker et al. (2003) designed primers for both the amplification of the ITS region and partial LSU (SSU-Gom1/LSU-Glom1, Figure 2). They also reported that designing primers suitable for all AMF, but not amplifying other fungi is challenging. In addition, different primers were used on the LSU, wherein most of them cover the first $800 \mathrm{bp}$ of the LSU or at least a part of it (Figure 2). These fragments were amplified using a nested PCR approach. All these different fragments make the comparison of results complicated and difficult.

Sequences of contaminated samples are a serious problem in AM research. Schüßler (1999) and Redecker et al. (1999) reported that some published rDNA sequences of Scutellospora castanea were from ascomycotan origin and even spores with a healthy appearance can contain non glomeromycotan fungi (Hijri et al., 2002). Utilizing AMF specific primers would be an advantage for such contaminated material. 


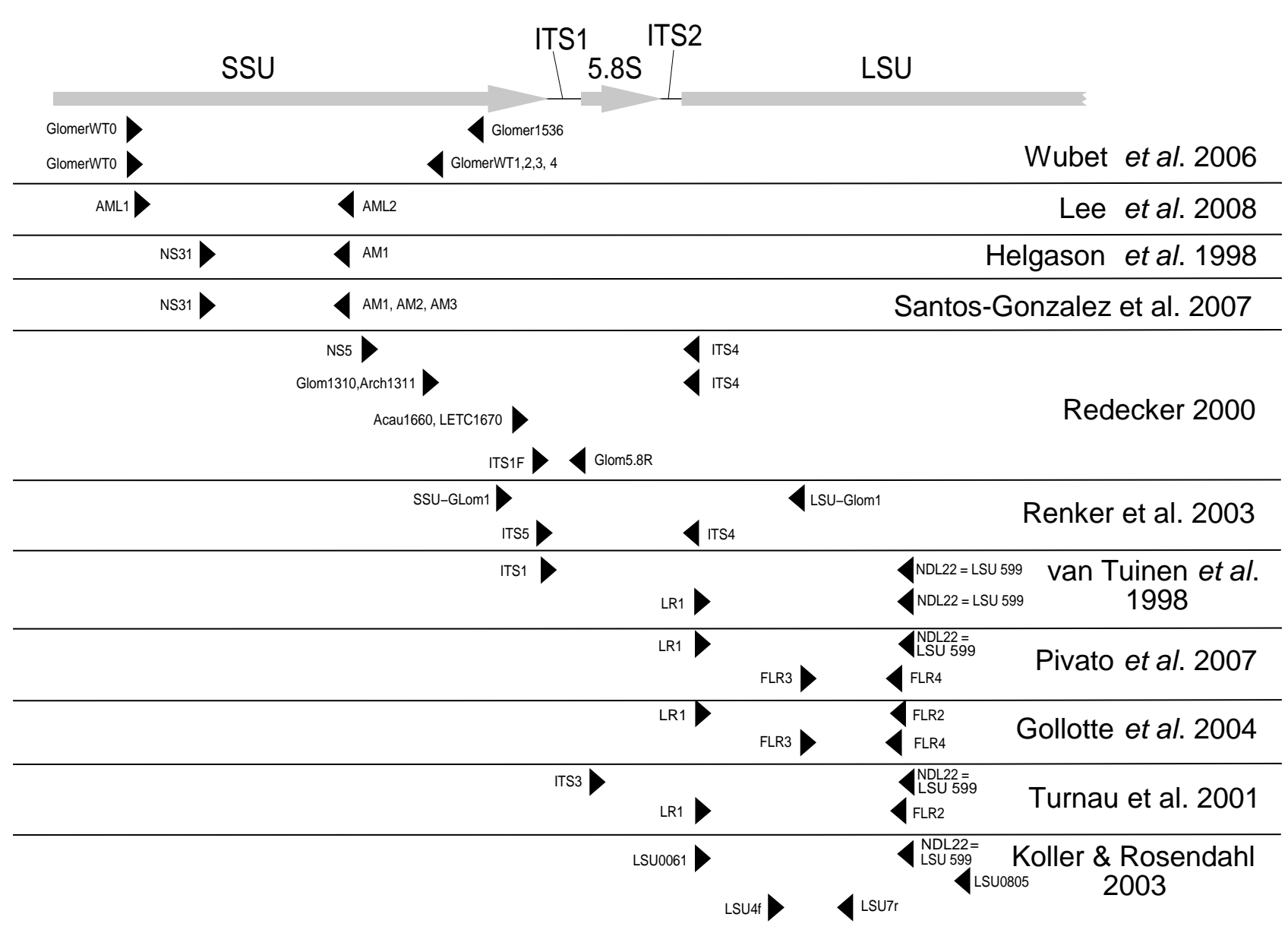

Figure 2: Schematic overview of different primer combinations used in AMF research citing the corresponding publications. A part of the rDNA repeats is illustrated on the top. Grey arrows indicate the genes; thin lines the internal transcribed spacers (ITS1\& ITS2). For clarity, the LSU gene is not shown in full length. Triangles show priming site and direction. Publications showing several primer combinations indicate nested PCR approaches, except for Redecker (2000), who developed AMF subgroup-specific primers.

\subsection{Aim of this study}

The focus of this study was to develop a simple and robust system for the identification to species level of glomeromycotan fungi. The study aimed to contribute to the development of a DNA barcode for fungi and in particular for AMF such as that already established for animals. The identification system must ideally be based on parts of the widely used rDNA such as the SSU, the ITS or LSU region because the largest number of published sequences are available from these regions. In the course of the work, the ITS region was proposed as the possible DNA barcode for fungi. In addition to the ITS region, several other parts of the rDNA region were investigated for their potential DNA barcode suitability. The high variation of the rDNA within one AMF species or 
even a single spore was critically checked for all fragments for successful species identification.

To amplify AMF in roots of plants and to overcome the problem with potential contaminations, new AMF specific primers were designed and tested in anticipation of them being used as AMF barcoding primers. In recognition of new sequencing technologies, such as the 454 GS-FLX Titanium system, approximate $400 \mathrm{bp}$ long fragments were tested for its potential usage in such systems to identify species of AMF. 
4 Molecular phylogeny and new taxa in the Archaeosporales (Glomeromycota): Ambispora fennica gen. sp. nov., Ambisporaceae fam. nov., and emendation of Archaeospora and Archaeosporaceae.

This chapter is identical to the publication:

Walker C, Vestberg M, Demircik F, Stockinger H, Saito M, Sawaki H, Nishmura I, Schüßler A. 2007. Molecular phylogeny and new taxa in the Archaeosporales (Glomeromycota): Ambispora fennica gen. sp. nov., Ambisporaceae fam. nov., and emendation of Archaeospora and Archaeosporaceae. 
Molecular phylogeny and new taxa in the Archaeosporales (Glomeromycota): Ambispora fennica gen. sp. nov., Ambisporaceae fam. nov., and emendation of Archaeospora and Archaeosporaceae. 


\title{
Molecular phylogeny and new taxa in the Archaeosporales (Glomeromycota): Ambispora fennica gen. sp. nov., Ambisporaceae fam. nov., and emendation of Archaeospora and Archaeosporaceae
}

\author{
Christopher WALKER ${ }^{a}$, Mauritz VESTBERG ${ }^{b}$, Filiz DEMIRCIK $^{c}$, Herbert STOCKINGER $^{c}$, \\ Masanori SAITO ${ }^{d}$, Hiromichi SAWAKI ${ }^{e}$, Ibuki NISHMURA ${ }^{f}$, Arthur SCHÜßLER ${ }^{\mathrm{c}, *}$ \\ ${ }^{a}$ Royal Botanic Garden Edinburgh, 21A Inverleith Row, Edinburgh EH3 5LR, UK \\ ${ }^{b}$ MTT Plant Production Research Laukaa, FI-41330 Vihtavuori, Finland \\ 'TU-Darmstadt, FB10 Botanik, Schnittspahnstr. 10, D-64287 Darmstadt, Germany \\ ${ }^{\mathrm{d}}$ National Institute for Agro-Environmental Sciences, Tsukuba, Ibaraki 305-8604, Japan \\ eNational Institute of Livestock and Grassland Science, Nasu-Shiobara, 329-2793, Japan \\ fIbaraki University, Ami, Ibaraki, 300-0393, Japan
}

\section{A R T I C L E I N F O}

\section{Article history:}

Received 22 July 2006

Received in revised form

19 October 2006

Accepted 15 November 2006

Corresponding Editor:

Paola Bonfante

\section{Keywords:}

Arbuscular mycorrhizal fungi

ITS region rDNA

Spore morphology

SSU rDNA

Taxonomy

\begin{abstract}
A B S T R A C T
The AM fungal family Archaeosporaceae and the genus Archaeospora are rendered paraphyletic by the relationship with the Geosiphonaceae. This problem led to a more detailed study of the Archaeosporales. Members of the Archaeosporaceae were described as forming both glomoid and acaulosporoid spores, or solely acaulosporoid spores. However, we found that Glomus callosum fell into the same phylogenetic clade as A. leptoticha and A. gerdemannii, but exclusively formed glomoid spores. To resolve these inconsistencies, a genus, Ambispora gen. nov., typified by Ambispora fennica sp. nov., is erected based on morphological evidence and SSU and ITS region rDNA data. Ambispora contains three species known to produce both acaulosporoid and glomoid spores: A. fennica, A. leptoticha comb. nov. (basionym G. leptotichum), and A. gerdemannii comb. nov. (basionym G. gerdemannii). Another species, A. callosa comb. nov. (basionym G. callosum), is known only from glomoid spores. Ambispora is placed in a new family, the Ambisporaceae fam. nov. The Archaeosporaceae is maintained with the type species, Archaeospora trappei (basionym Acaulospora trappei), along with Intraspora schenckii (basionym Entrophospora schenckii). Acaulospora nicolsonii, known only from acaulosporoid spores, is discussed and is considered likely to belong in the Ambisporaceae, but is retained within its present genus because of inadequate morphological information and a lack of molecular data.
\end{abstract}

(c) 2006 The British Mycological Society. Published by Elsevier Ltd. All rights reserved.

\section{Introduction}

AMs are extremely common in terrestrial ecosystems (Smith \& Read 1997), and their significance has been recognised in a broad range of studies of both basic and practical aspects. Fossils of presumed glomeralean fungal spores date back AM origins at least to the Ordovician, about 460 million years ago (Mya), and from molecular clock estimates,

\footnotetext{
* Corresponding author. Present address: LMU Munich, Genetics Institute, Maria-Ward-Strasse 1a, D-80638 Munich, Germany.

E-mail address: arthur.schuessler@lrz.uni-muenchen.de 0953-7562/\$ - see front matter @ 2006 The British Mycological Society. Published by Elsevier Ltd. All rights reserved. doi:10.1016/j.mycres.2006.11.008
} 
perhaps as far as 600 (Redecker et al. 2000a) or even $>1000$ Mya (Heckman et al. 2001), supporting the theory that the earliest land plants depended upon the symbiosis with AM fungi for their nutrient acquisition (Pirozynski \& Malloch 1975; Schüßler 2002).

Conventional taxonomy of glomeromycotan fungi was mainly dependent upon the relatively simple morphology of their asexual spores with consequent difficulties in finding suitable characters for species determination. For example, it was shown that 'Glomus' lineages, as defined until recently, were clearly non-monophyletic (Schwarzott et al. 2001). Moreover, some AM fungi (AMF) were shown to produce two types of spores, each of which had been placed in a separate genus (Glomus and Acaulospora) in two different families, the Glomeraceae and Acaulosporaceae. This anomalous situation has been discussed several times (Walker 1992; Morton et al. 1997; Murakoshi et al. 1998)

From studies based on SSU ribosomal RNA (rRNA) gene sequences, Sawaki et al. (1998), were the first to show that a dimorphic spore forming fungus named as both Acaulospora gerdemannii and Glomus leptotichum did not belong phylogenetically to any of the AMF families defined at the time. As the latter spore type was said to be morphologically indistinguishable from those of Glomus sensu lato, it is likely that more species placed in Glomus are related to this lineage of AMF.

Further phylogenetic studies showed that several glomeromycotan species should be separated from the existing taxa, as they comprise independent phylogenetic lineages within the AMF (Redecker et al. 2000b). From molecular and morphological data, two new monogeneric families, Archaeosporaceae and Paraglomeraceae, were erected (Morton \& Redecker 2001) to accommodate the new genera Archaeospora and Paraglomus. However, it had already been shown from studies of A. leptoticha (at the time named as Acaulospora gerdemannii) (Schüßler 1999; Kramadibrata et al. 2000), that the 'Archaeospora lineage' also contains Geosiphon pyriformis, a fungus in the Geosiphonaceae that forms an 'AM-like' symbiosis with cyanobacteria. Recently, the new genus Intraspora was erected (Sieverding \& Oehl 2006) to accommodate I. schenckii (basionym Entrophospora schenckii), placed in the Archaeosporaceae as a sister taxon to A. trappei.

There is now a taxonomic conundrum relating to the Archaeosporaceae in the Glomeromycota (Spain 2003; Morton \& Redecker 2001). The AM species A. trappei, A. gerdemannii, and A. leptoticha are presently contained within the same genus, but whereas the last two are closely related, they have little in common with the first, except the production of spores in the neck of an initial, blastic, sporiferous saccule. Similarly, I. schenckii, shares much in common with A. trappei (Ames \& Linderman 1976), but not with the other species presently placed in the family. Moreover, the SSU rDNA phylogeny shows that the Archaeosporaceae is paraphyletic (Schüßler et al. 2001).

We consequently undertook work on the systematics of these fungi, which are widespread in some grassland ecosystems (Murakoshi et al. 1998; Kojima et al. 2004), to understand the relationships among members of the Archaeosporales. We compared the morphology and the SSU and ITS rDNA analyses of new isolates of Archaeospora leptoticha, a fungus from western Finland similar in appearance to A. gerdemannii, and
Japanese isolates of Glomus callosum that produced only glomoid spores.

\section{Materials and methods}

Parts of the work were performed in Finland, Japan, the UK, and Germany. These localities are noted in the following, as the methods used were not identical in each of the different laboratories.

\section{Sampling and isolation}

For the Finnish part of the work, samples of soil were taken on 20 Sep. 1989 from a ley (pasture) field in Kurikka, located in the Ostrobothnia region of western Finland $\left(62^{\circ} 30^{\prime} \mathrm{N} ; 22^{\circ} 20^{\prime} \mathrm{E}\right)$. The plant community consisted of mixed grasses and clover along with the volunteer plants from the seed bank in the soil, but it was not precisely determined because the crop had been harvested and identification of individual species from the remaining stubble was not practical. The soil was silty, with a pH in water of 5.3 , available P $7 \mathrm{mgl}^{-1}$ (ammonium acetate extraction after Vuorinen \& Mäkitie 1955), and conductivity $0.45 \mathrm{mS} \mathrm{cm}^{-2}$. Other available ions were $\mathrm{Ca}^{2+}$ $423 \mathrm{mgl}^{-1}, \mathrm{~K}^{+} 226 \mathrm{mgl}^{-1}$, and $\mathrm{Mg}^{2+} 49 \mathrm{mgl}^{-1}$. Subsamples of soil were used to establish open-pot cultures as soil traps, and from one of these, a single acaulosporoid spore was selected and introduced to the roots of a seedling of Plantago lanceolata (Walker 1999). This was then maintained in a Sunbag® (Sigma, Tufkirchen) to ensure that it was free from contamination by other AM fungi (Walker \& Vestberg 1994). It then was maintained in both Sunbags and open-pot cultures through repeated subcultures in Finland and the UK.

In Japan, four cultures were established initially by soil traps from different parts of the country, followed by singlespore isolation as described in Murakoshi et al. (1998). The fifth culture was a multi-spore single species culture. Cultures were maintained in sealed Sunbag systems at the Soil Ecology Laboratory, National Institute of Livestock and Grassland Science. Examination of the resultant spores followed standard methods for morphological study of members of the Glomeromycota (e.g., Walker 1983, 1986; Walker et al. 1993; Morton 1988).

For molecular analyses, spores for DNA extraction were isolated by centrifugation and sugar-floatation (Walker et al. 1982) or by swirling with water and decanting through a fine sieve. For analyses done in Germany, spores were selected under a dissecting microscope and individually placed in Eppendorf $^{\circledR}$ vials. They were carefully checked for fresh and undamaged appearance, and to verify that there was no obvious contamination from other fungi. For the Japanese work, one to ten spores were selected in a similar manner for later DNA extractions.

\section{Morphological studies}

Extracted spores were initially examined in water under a dissecting microscope, and then through a compound microscope after mounting in polyvinyl alcohol lacto-glycerol (PVLG) with or without the addition of Melzer's reagent 
(Walker et al. 1993). Measurements were made with a calibrated eyepiece graticule. Records were kept in a database in which pot culture attempts are given attempt (Att) numbers and herbarium voucher collections given ' $\mathrm{W}$ numbers' (Walker \& Vestberg 1998). For consistency, such numbers are given to all specimens examined, regardless of the collector (Table 1), including type material. Vouchers are deposited, where relevant, in the herbaria designated in their protologues or in the Walker collection lodged at the Herbarium at the Royal Botanic Garden Edinburgh (E).

Because of the different opinions regarding wall structure of spores in the Glomeromycota, we need to define the terminology used in the descriptions herein. There are no controlled developmental studies of the acaulosporoid propagules of members of the group of organisms under discussion, and the light microscope with pot-cultured specimens cannot provide the resolution needed to reconcile different layers and walls in these complex structures. We therefore applied the terminology of Walker (1983), modified by Walker \& Vestberg (1998), in which the wall structure, as seen through a compound microscope, is described as having individual components which, when they remain adherent or close together on crushed specimens, are referred to as being in groups.

Samples of roots were stained in trypan blue or ink (Phillips \& Hayman 1970; Walker 2005) to examine mycorrhizas, mounted in PVLG, and examined under a compound microscope.

\section{Molecular studies}

DNA extraction, cloning, and sequencing

Cultures, isolates, and spore morphs used, clone numbers, and sequence accession numbers are listed in Table 1. Whereas the morphological methods used were the same regardless of the origins of the fungi, the molecular studies were carried out at different times and locations. Consequently, the details of materials and methods are different for each laboratory. The 'Japanese fungi' were initially investigated in Japan, and later also in Germany, whereas the 'European fungi' were studied only in Germany, where the final analysis was carried out.

For the European AM fungi, DNA was extracted, PCR-amplified, and cloned from individual spores (stored at $-80^{\circ} \mathrm{C}$ ) sampled from the cultures Att200-11 (sampled Jan. 2001; cloned May 2005 and Mar. 2006), Att200-21 (sampled Feb. 2002; cloned Mar. 2002), Att200-23 (sampled Sep. 2005, cloned Dec. 2005). Isolation of DNA from cleaned single spores and methods used for cloning and sequencing were as described in Schwarzott \& Schüßler (2001). Primers and conditions for PCR of the SSU rDNA were also as described in that paper, except that in many of the PCR reactions the Phusion proofreading polymerase (Finnzymes, Espoo) was used. The ITS region rDNA was amplified using the primers SSU-Glom1 (Renker et al. 2003) and LSU-Glom1b (TCGTTTCCCTTTCAACAATTTC $A C$, designed for the present study). PCR was run with the Phusion proofreading polymerase with the following programme: $99^{\circ} \mathrm{C}$ denaturation for $2 \mathrm{~min}$; 35 cycles of $99^{\circ} \mathrm{C}$ for $10 \mathrm{~s}, 65^{\circ} \mathrm{C}$ for $30 \mathrm{~s}, 72^{\circ} \mathrm{C}$ for $60 \mathrm{~s}$; final elongation $72^{\circ} \mathrm{C}$ for $5 \mathrm{~min}$. After cloning and plasmid isolation, fragments were sequenced with vector primers and ITS4 (White et al. 1990), and sequences assembled with the program SeqAssem (http:// science.do-mix.de/software.php).

For the Japanese cultures and isolates, DNA was extracted for amplification of rDNA as described in Sawaki et al. (1998). SSU rRNA gene fragments were PCR amplified using the primers EcoNS1 (GTAAAACGACGGCCAGTGAATTCGTAGTC ATATGATTGTCTC) and NS8KX (GTACCTCGAGGTACCTAATG ATCCTTCCGC), containing restriction sites for cloning, by a proofreading DNA polymerase (Takara, Kyoto, Japan). The PCR was performed with the following programme: $95^{\circ} \mathrm{C}$ denaturation for $3 \mathrm{~min}$; 41 cycles of $95^{\circ} \mathrm{C}$ for $30 \mathrm{~s}, 53^{\circ} \mathrm{C}$ for $45 \mathrm{~s}$, $70^{\circ} \mathrm{C}$ for $3 \mathrm{~min}$; final elongation $72^{\circ} \mathrm{C}$ for $10 \mathrm{~min}$. DNA was purified (QIAquick; QIAGEN, Hilden) and digested with EcoRI and XhoI. After agarose gel electrophoresis (1 \%) DNA was extracted from gels and fragments were ligated into Uni-ZAP XR (Stratagene, La Jolla, CA) and packaged in vitro. Several clones containing appropriate inserts were screened from each phage fraction with plaque-direct PCR, using P7 and P8 universal primers flanking the cloning sites. DNA of each clone was rescued with in vivo excision protocol. ITS rDNA was amplified from the spore DNA with ITS1 and ITS4 primers (White et al. 1990) by using a hot-start Taq DNA polymerase (Applied Biosystems, Foster City, CA). PCR was performed as follows: $95^{\circ} \mathrm{C}$ denaturation for $10 \mathrm{~min}$; 40 cycles of $94^{\circ} \mathrm{C}$ for $45 \mathrm{~s}, 50^{\circ} \mathrm{C}$ for $45 \mathrm{~s}, 72{ }^{\circ} \mathrm{C}$ for $45 \mathrm{~s} ; 72^{\circ} \mathrm{C}$ for $10 \mathrm{~min}$ final elongation. DNA fragments were purified and cloned into pCR2.1 plasmid vector (Invitrogen, Carlsbad, CA). Templates for DNA sequencing were generated from phagemid plaque by PCR with Taq DNA polymerase (Nippon Gene, Tokyo) and universal primers (Sawaki \& Saito 2001). The products were purified and used as templates for sequencing with T3 and T7 universal primers and the SSU rRNA gene specific primers NS2, NS3, NS4, and NS5 (White et al. 1990). Plasmid DNA was used as templates for sequence reaction with M13 primers. Sequences for SSU rDNA were compared and assembled with the program Sequencher (Hitachi, Tokyo, Japan).

\section{Phylogenetic analyses}

Sequence alignment was carried out manually, with the program Align (http://science.do-mix.de/software.php), taking secondary structure into account (Wuyts et al. 2000). The SSU rDNA alignment comprised all archaeosporalean near full-length sequences available in the databases (http://srs. ebi.ac.uk/); database sequences from the same isolate were composed to majority rule consensus sequences. The sequences from the two spore morphs from the Finnish fungus (Att200), described here as Ambispora fennica gen. sp. nov., were analysed as individual sequences or as consensus sequences, both, and sequences from members of the Paraglomerales were used as outgroups (Table 1). The ITS1, $5.8 \mathrm{~S}$ rDNA, ITS2 alignment consisted of 77 sequences. The new rDNA sequences derived from this study were deposited in the EMBL/GenBank/DDBJ databases (Table 1) with the accession numbers AM268192-AM268203, AB047302-AB047309, and AB259840-AB259846. The alignments are deposited at the EMBL database (http://srs.ebi.ac.uk/srsbin/cgi-bin/ wgetz?-id+2Mjb01SgNM8+EMBLALIGN) under accession number ALIGN_001112 and ALIGN_001113.

From the aligned SSU rDNA dataset 1704 sites and for the ITS rDNA dataset 339 sites could be used for the phylogenetic 


\section{Table 1 - Sequences and cultures used in this study}

Species and culture identity Voucher/culture-no.

Outgroup SSU rDNA sequences from the database:

Paraglomus brasilianum BR105

W3086/Att260-4

P. occultum CL700

P. occultum IA702-3

P. occultum HA771

Archaeosporales SSU rDNA sequences

Ambispora callosa OK1

MAFF520057 (ss, gl)

A. callosa V1 MAFF520058 (ms, g])

A. fennica (ms, ac)

A. fennica (ms, ac)

A. fennica (ss, ac)

A. fennica (ms, gl)

A. fennica (ss, gl)

A. gerdemannii AU215

A. leptoticha F3b MAFF520055 (ss, ac)

A. leptoticha NC176

\section{A. leptoticha FL130}

A. leptoticha WL1

Archaeospora trappei

A. trappei AU219

A. trappei NB112

Geosiphon pyriformis GEO1

W3179/Att186-1

W3619/Att754-6

Archaeosporales ITS-region rDNA sequences

Ambispora callosa OK-m (ss, gl)

A. callosa OK-m (ss, gl)

A. callosa OK-m (ss, gl)

A. callosa OK-m (ss, gl)

A. callosa HZ-6K (ss, gl)

A. callosa HZ-6K (ss, gl)

A. callosa $\mathrm{HZ}-6 \mathrm{~K}$ (ss, gl)

A. fennica (ss, gl)

A. fennica (ms, gl)

A. fennica (ms, gl)

A. fennica (ms, gl)

A. fennica (ms, ac)

A. fennica (ms, ac)

A. fennica (ms, ac)

A. leptoticha F3b (ss, ac, gl)

W4768/Att1321-4 W4768/Att1321-4 W4768/Att1321-4 W4768/Att1321-4 W4772/Att1322-4 W4772/Att1322-4 W4772/Att1322-4 W4752/Att200-23 W4752/Att200-23 W3569/Att200-11 W3569/Att200-11 W3569/Att200-11 W3569/Att200-11 W3569/Att200-11 W4770/Att315-11

A. callosa OK1 MAFF520057 (ss, gl)

W4769/Att1323-7

A. callosa V1 MAFF520058 (ms, gl)

W4771/Att321-10

A. gerdemannii AU215

A. leptoticha NC176

A. leptoticha FL130

A. sp. from Plantago lanceolata roots

A. sp. from Prunus africana roots

A. sp. from Taxus baccata roots
OK-m18e

OK-m18f

OK-m18i

OK-m8

HZ-6K2

$\mathrm{HZ}-6 \mathrm{~K} 7$

HZ-6K5

pFD120-6

pFD120-13

pFD120-7

pFD120-10

pFD114-12

pFD114-5

pFD114-6

F3bA15,A25-26,A32,A313,

A411,A414,A43,A49,A51,

G1,G8,G12-15,G17,A311+G16

(identical),A16+A36+A54

(identical), G18+G3 (identical),

G7+G9 (identical)

OK113,17,33,222,313,

$322+44$ (identical), $38+411$

(identical), 41,415,418,42,

$320+321$ (identical)

V113-15,21-23,32-34,422-24

2v34.2

Pa110+111+112 (identical)

201, 208, 210, 214, 224,

$216+212+217$ (identical)
AJ301862

AJ006798

consensus AJ276081-82, DQ322629

AJ006799

consensus AB047305-07

consensus AB047308-09

AM268192

AM268193

AM268194

AM268195

AM268196

AJ012202

consensus AB015052, AB047302-04

consensus AJ301861, AJ006466,

AJ006794-97

AJ006793

AB220172

Y17634

AJ006801

AJ006800

consensus X86686, Y17831, Y15904-05, AJ276074, AM183923

AB259840

AB259841

AB259842

AB259843

AB259844

AB259846

AB259845

AM268203

AM268198

AM268199

AM268197

AM268200

AM268201

AM268202

AB048630, AB048632-33, AB048635-36,

AB048638-42, AB048644-48, AB048650,

$\mathrm{AB} 048654, \mathrm{AB} 048634+\mathrm{AB} 048649$ (identical),

$\mathrm{AB} 048631+\mathrm{AB} 048637+\mathrm{AB} 048643$ (identical),

AB048651-52 (identical), AB048653+

AB048655 (identical)

AB048656-59, AB048663, AB048662+

$\mathrm{AB} 048670$ (identical), $\mathrm{AB} 048664+$

AB048666 (identical), AB048665, AB048667,

$\mathrm{AB} 048668, \mathrm{AB} 048669$,

$\mathrm{AB} 048660+\mathrm{AB} 048661$ (identical)

AB048671-82

AJ012111

AJ012109, AJ012110

AJ012201

AJ567807

AY236277-79 (identical)

AY174701-3, AY174707, AY174710,

AY174705+AY174708-09 (identical)

Spore morphs are indicated as acaulosporoid (ac) or glomoid (gl) and cultures as single spore isolate (ss) or multi spore culture (ms). 
analyses. PHYLIP 3.6a3 (Felsenstein 1989) was used for NJ, ML and MP analyses (Kumar \& Gadkar 2000) and consensus tree computations. ML quartet puzzling (MLQP) analyses were performed with TREE-PUZZLE 5.2 (based on HKY, KN, as well as TN models; gamma distributed heterogeneous rates were estimated from the dataset). Although having a different base, QP analysis support values can be interpreted in much the same way as BS values. Transition:transversion ratios (1.8 for SSU; 1.65 for ITS) and nucleotide frequencies were estimated from the dataset with TREE-PUZZLE. The input order of species was always randomised. For the SSU rDNA and ITS region phylogenies, majority rule consensus trees were constructed from 1000-fold bootstrapped NJ (based on distances computed with F84 parameters) or MP analyses and 100-fold bootstrapped ML analyses. Trees were viewed, assembled and edited with the programs TREEME (http://science.do-mix.de/software.php), TreeView (http://taxonomy.zoology.gla.ac.uk/rod/treeview. html) and Microsoft PowerPoint.

\section{Results}

Molecular phylogenetic analyses

As expected due to the intraspecific sequence variability of AMF, many sequences of clones (derived from a single spore) were not identical but closely related (Figs 1-2). Clones that resulted in identical sequences were submitted as one sequence only, with the exception of SSU rDNA sequences AM268193 and AM268193, which were identical but derived from different spores with different morphs (but from the same culture) and were therefore submitted individually.

\section{SSU rDNA analyses}

NJ, MP, ML and MLQP analyses (Fig 1) together with the archaeosporalean near full-length sequences available in the databases revealed that the sequences from Ambispora fennica, derived from spores of both morphs, cluster within the Archaeosporales with high support. All phylogenetic methods applied gave the same result, showing that A. fennica belongs in a sister clade of the Geosiphonaceae, together with Archaeospora gerdemannii, A. leptoticha, and Glomus callosum. Based on the SSU rDNA, Ambispora fennica can be separated from the other species with good support. For the principal topology there was no difference among MLQP, NJ, ML, and MP trees. The distances shown in the phylogenetic trees were derived from a TREE-PUZZLE MLQP analysis.

\section{ITS region and $5.8 \mathrm{~S}$ rDNA analyses}

The ITS1/ITS4 primer set used in Japan amplified DNA fragments of approximately $570 \mathrm{bp}$ in length. The region sequenced in Germany ranged from $800 \mathrm{bp}$ (partially sequenced) up to $1100 \mathrm{bp}$. Phylogenetic analysis (Fig 2) of the new sequences (Table 1) together with sequences from Archaeospora leptoticha NC176, FL130, A. gerdemannii AU215, and from Prunus africana, Taxus baccata (Wubet et al. 2003a, 2003b) and Plantago lanceolata (Börstler et al. 2006) mycorrhizas showed that the related species could be divided into two subgroups with good support. The sequences from A. leptoticha FL130 (AJ012101), NC176 (AJ012109-AJ012110) and F3b (Japanese isolate) generated an individual clade. The two different spore morphs were sequenced separately for F3b, and neither morph could be separated into subclades in the analysis. The sequences of Glomus callosum HZ-6K, OK1, OK-m, and V1 formed another cluster, also not separating into subclades. The A. gerdemannii sequence (AJ012111) (Redecker et al.

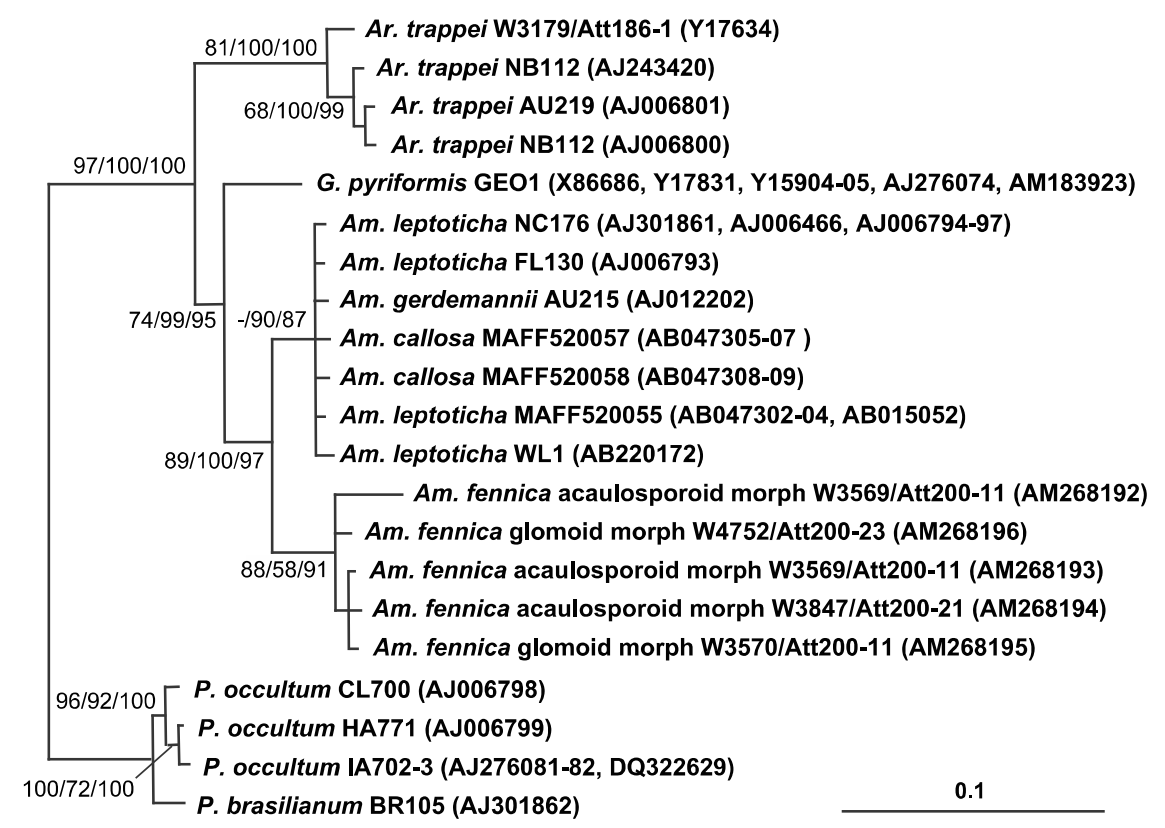

Fig 1 - Phylogenetic tree (SSU rDNA) of the Archaeosporales with Paraglomerales as outgroup. The support values shown at the branches are from MLQP/NJ (1000 BS)/ML (100 BS) analyses. Distances are derived from a MLQP analysis. 


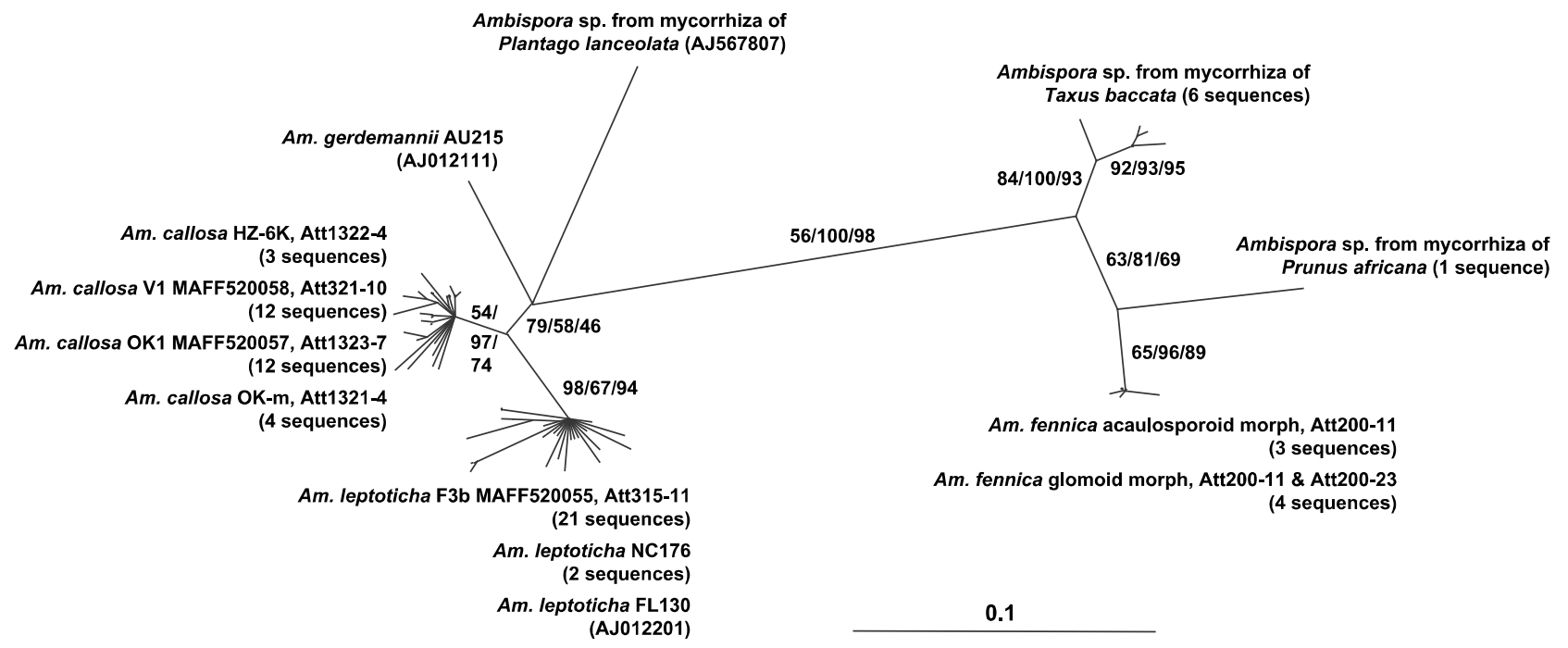

Fig 2 - Phylogenetic tree (ITS region rDNA, unrooted) of the sequences representing Ambispora gen. nov. (Ambisporaceae, Archaeosporales). The support values shown at the branches are from MLQP/NJ (1000 BS)/MP (100 BS) analyses. Distances are derived from a MLQP analysis. Sequence AJ567807 was originally assigned to the species Archaeospora leptoticha in the public database. The numbers of individual sequences included in the analysis (identical sequences were excluded) are shown.

$2000 \mathrm{~b}$ ) is separated from both clades, but with relatively low BS support. The same is true for a sequence (AJ567807) from a $P$. lanceolata root that was annotated as A. leptoticha (Börstler et al. 2006). A better sequence sampling perhaps could resolve this situation of low support, but it seems that these sequences represent separate taxa, probably at the level of species.

Based on the ITS region phylogeny, Ambispora fennica is clearly separated from the defined Archaeospora gerdemannii (AU215) and A. leptoticha isolates, and also from G. callosum, but relatively closely related to sequences from $T$. baccata and $P$. africana roots. Ambispora fennica therefore belongs in a monophyletic clade together with Archaeospora gerdemannii, A. leptoticha, G. callosum, and Geosiphon pyriformis (Geosiphonaceae) to which the clade containing A. trappei represents a sister lineage (Fig 1). A. trappei is the type species of Archaeospora and the Archaeosporaceae. The genus Archaeospora and the family Archaeosporaceae sensu Morton and Redecker consequently are paraphyletic.

\section{Morphological studies}

Having established the need for new taxa to rationalise the systematic position of the organisms within the Archaeosporales, the morphological characteristics were assessed for comparison with existing species. The lengths and widths of spores measured, and similar information from published descriptions, are listed in Table 2. Our results are mainly incorporated into the new descriptions and new combinations in the taxonomic section below. We did not see germination of any of the spores examined, though specific germination studies were not undertaken.

Ambispora fennica sp. nov. (Fig 3)

We concluded, from the measurements, wall structure, and morphological details of the Finnish fungus (from Att200), that it was undescribed, and describe it herein as Ambispora fennica sp. nov.

The spores of A. fennica were either glomoid or acaulosporoid (Fig 3A). The latter were hyaline to white at first, becoming pale ochraceous with age (Fig 3, A-B). Each spore was formed on a large (199-248 $\mu \mathrm{m}$ diam) saccule (Fig 3C) that collapsed and became detached at maturity. Some spores were sessile (Fig 3E), but others had a persistent pedicel, similar to the subtending hypha of a Glomus spore (Fig 3D, I). The wall structure was complex, consisting of three groups (Fig 3F-K). Group 1 is formed by budding of the saccule neck, and consists of two components, a granular, evanescent outer component, often with adherent fine soil particles, overlaying a semi-flexible, hyaline to lightly pigmented (probably laminated) component. Component 1 reacts rapidly to become pink or red in Melzer's reagent (Fig 3I-K). Wall group 2 appears to develop separately and consists of a single, hyaline component that splits and fractures on crushing (Fig 3H-J), slightly yellowing in Melzer's reagent. Wall group 3 also develops independently and is of a single, relatively thick, semi-flexible component.

The glomoid spores were hyaline and varied in shape, from globose to subglobose to ellipsoid, with occasional obovoid or irregular specimens (Fig 3L-N). The wall structure was of two components in a single group. The outer component was thin, and often difficult to see, but with fine soil particles adherent (Fig 3L), indicating that it was sticky. The second component was finely laminated, and pliable, making it difficult to crush spores on microscope slides to see the detail of wall structure. Many of these spores were open-pored (lacking any occlusion), but where they were closed, it was by the formation of a septum from the laminated inner wall component (Fig $3 \mathrm{~N}$ ). They did not react to Melzer's reagent.

Mycorrhizas stained weakly in ink, producing arbuscules and hyphal coils and occasional vesicles (Fig 30). 
Table 2 - Lengths and widths of spores $(\mu \mathrm{m})$ in the Ambisporaceae from new measurements (with voucher numbers) and published measurements

\begin{tabular}{|c|c|c|c|c|c|c|c|c|c|}
\hline Identifier/voucher or source & $\begin{array}{l}\text { Min } \\
\text { length }\end{array}$ & $\begin{array}{l}\text { Max } \\
\text { length }\end{array}$ & $\begin{array}{l}\text { Min } \\
\text { width }\end{array}$ & $\begin{array}{c}\text { Max } \\
\text { width }\end{array}$ & $\begin{array}{l}\text { Mean } \\
\text { length }\end{array}$ & $\begin{array}{l}\text { Mean } \\
\text { width }\end{array}$ & $\begin{array}{l}\text { S.D. } \\
\text { length }\end{array}$ & $\begin{array}{l}\text { S.D. } \\
\text { width }\end{array}$ & $\begin{array}{l}\text { No. } \\
\text { measured }\end{array}$ \\
\hline \multicolumn{10}{|l|}{ Glomoid spores } \\
\hline Ambispora callosa OK-m/W4768 & 77 & 319 & 68 & 291 & 223 & 213 & 37.4 & 35.4 & 100 \\
\hline A. callosa OK1/W4769 & 87 & 245 & 95 & 257 & 174 & 172 & 29.2 & 30.0 & 100 \\
\hline A. callosa V1/W4771 & 84 & 316 & 84 & 270 & 172 & 170 & 40.4 & 36.9 & 100 \\
\hline A. callosa HZ6-K/W4772 & 93 & 270 & 93 & 248 & 192 & 186 & 32.7 & 28.4 & 100 \\
\hline Glomus callosum type/W4819 & 112 & 285 & 108 & 288 & 222 & 223 & 27.5 & 28.4 & 104 \\
\hline G. callosum/protologue ${ }^{a}$ & 84 & 319 & 84 & 300 & - & - & - & - & - \\
\hline G. leptotichum/protologue ${ }^{\mathrm{b}}$ & 48 & 262 & 48 & 262 & - & - & - & - & - \\
\hline G. fecundisporum/protologue $\mathrm{e}^{\mathrm{b}}$ & 60 & 155 & 60 & 207 & - & - & - & - & - \\
\hline G. leptotichum type/W945 & 62 & 257 & 62 & 254 & 154 & 151 & 47.4 & 47.3 & 63 \\
\hline Ambispora leptoticha F3b/W4770 & 45 & 215 & 42 & 213 & 106 & 102 & 47.8 & 46.2 & 69 \\
\hline Archaeospora leptoticha/combination ${ }^{c}$ & 60 & 250 & 60 & 250 & - & - & - & - & - \\
\hline A. gerdemannii AU215A/combination ${ }^{c}$ & 40 & 120 & 40 & 120 & 80 & 80 & - & - & 142 \\
\hline Ambispora fennica sp. nov. glomoid/W4816 & 38 & 130 & 38 & 117 & 71 & 73 & 14.8 & 15.5 & 100 \\
\hline \multicolumn{10}{|l|}{ Acaulosporoid spores } \\
\hline G. gerdemannii/protologue ${ }^{d}$ & 140 & 198 & 149 & 230 & - & - & - & - & - \\
\hline $\begin{array}{l}\text { Archaeospora gerdemannii AU215A/ } \\
\text { combination }^{c}\end{array}$ & 160 & 260 & 160 & 260 & 212 & 212 & - & - & 110 \\
\hline Acaulospora gerdemannii/protologue $\mathrm{e}^{\mathrm{e}}$ & 200 & 250 & 200 & 250 & - & - & - & - & - \\
\hline Archaeospora leptoticha/combination ${ }^{c, g}$ & $>160$ & $>200$ & $>160$ & $>200$ & - & - & - & - & - \\
\hline Acaulospora appendicula/protologue ${ }^{\mathrm{f}}$ & 170 & 390 & 170 & 390 & - & - & - & - & - \\
\hline Ambispora leptoticha F3b/W4770 & 195 & 288 & 186 & 298 & 236 & 235 & 18.0 & 19.6 & 100 \\
\hline A. fennica sp. nov./W4815 & 124 & 201 & 134 & 201 & 168 & 166 & 14.0 & 13.5 & 100 \\
\hline
\end{tabular}

Ambispora leptoticha (Fig 4)

Our Japanese isolate produced acaulosporoid and glomoid spores within the size range given for Acaulospora appendicula by Schenck et al. (1984) (Fig 4). From the molecular evidence, we move this species from Archaeospora to Ambispora as A. leptoticha comb. nov. (see below). Mycorrhizas stained weakly in trypan blue. They had arbuscules, hyphal coils, and occasional vesicles (Fig 40).

Ambispora callosa (Figs 5-6)

All collections formed only glomoid spores, singly or in loose clusters in the soil, and there were neither sporocarps nor dense clusters of spores. There was no evidence of spores produced in roots. Spore dimensions from formaldehyde-preserved type material (Table 2) had a slightly narrower range than was given in the species description. Measurements of the Japanese material all were within the range for the species.

The wall structure of all the Glomus callosum material examined was interpreted differently from the protologue description. It consists of an outer, somewhat granular, evanescent component, overlaying a laminated component that has a tendency to be loosely adherent towards the interior of the spore Figs $5-6 \mathrm{~N}-0$ ). The Japanese fungi studied here could not be distinguished morphologically from $G$. callosum. The molecular evidence shows them to belong to Ambispora, and so we transfer the species as A. callosa comb. nov. Mycorrhizas stained weakly in trypan blue and ink, and no vesicles were observed.

\section{Taxonomy}

\section{Archaeosporaceae J. B. Morton \& Redecker 2001.}

Differs from other families in the Glomeromycota by possession of small, hyaline spores formed laterally or centrally within the neck of a sporiferous saccule, that lack any distinctive reaction to Melzer's reagent. With rDNA phylogeny (Figs 1-2) and sequences differing from those of members of the Geosiphonaceae and Ambisporaceae.

Included genera:

Typus: Archaeospora J. B. Morton \& Redecker 2001.

Intraspora Oehl \& Sieverd (2006).

Archaeospora J. B. Morton \& Redecker 2001.

Typus: Archaeospora trappei (R. N. Ames \& Linderman) J. B. Morton \& Redecker 2001.

Spores formed in the soil, rarely in roots, in the neck of a sporiferous saccule, hyaline, globose to subglobose to irregular, tending to remain suspended in water when extracted from substrate. Lacking amyloid or dextrinoid reaction to Melzer's reagent. Forming faintly staining arbuscular mycorrhizas.

Ambisporaceae C. Walker, Vestberg \& Schuessler, fam. nov. MycoBank no.: MB 510208

A familiis aliis in Archaeosporalibus ob sporas glomoideas, acaulosporoideas vel ambas formans et a characteribus rDNA differt.

Typus: Ambispora C. Walker, Vestberg \& Schuessler 2007. 

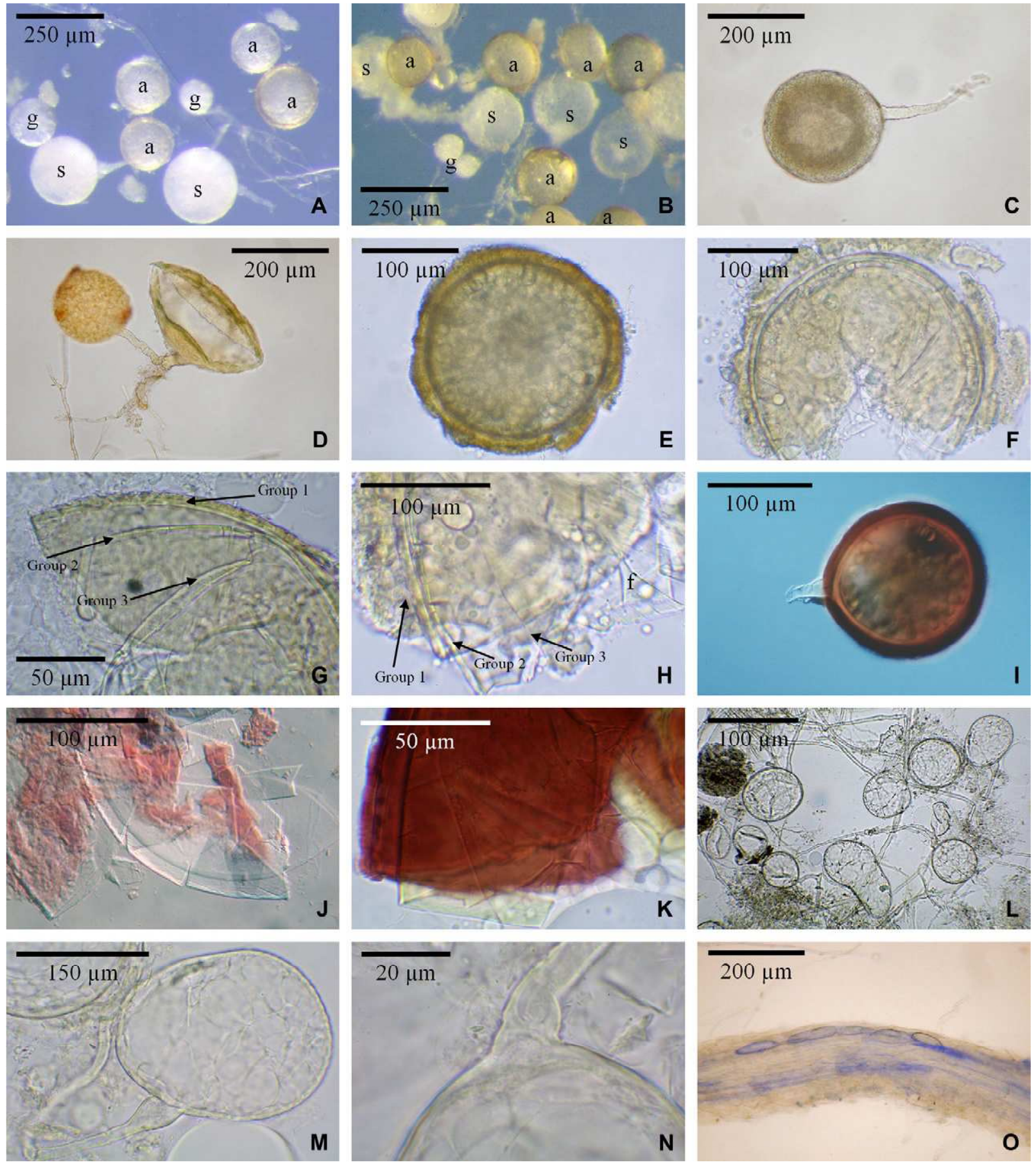

Fig 3 - Spores of Ambispora fennica from various subcultures of Att200 with single spore origin (brightfield microscopy except I and J, which are Nomarski DIC images). A-B. Spores in water. Saccules (s), acaulosporoid spores (a), and glomoid spores (g). A. The saccules still have their white contents, and one acaulosporoid spore is showing some pigmentation, though most are immature and lack pigmentation. B. Mature acaulosporoid spores are more pigmented and the saccules are empty. C. Saccule without development of an acaulosporoid spore. D. Collapsed saccule with the acaulosporoid spore attached by a long pedicel, giving the erroneous impression of a glomoid spore. E. Acaulosporoid spore detached from the saccule and lacking any pedicel. F. Acaulosporoid spore crushed in PVLG. The evanescent outer component has fragmented on crushing. G-H. Wall structure of acaulosporoid spores crushed in PVLG, showing the wall groups. G. Component 1 has either not yet developed or has disintegrated. H. Granular nature of component 1 (left), and the fractures (f) in component 4 (right). I-K. Reaction of acaulosporoid spores to PVLG with Melzer's reagent. Note pedicel in I, giving the spore a glomoid appearance. Component 1 reacts to become pink or red. The other components do not react, other than a slight yellowing in component 3. L-N. Glomoid spores in a loose cluster $(\mathrm{L})$ showing different shapes, and singly showing funnel-shaped subtending hypha (M) and occlusion by formation of a septum from the laminated component (N). O, mycorrhiza stained with trypan blue showing vesicles. 

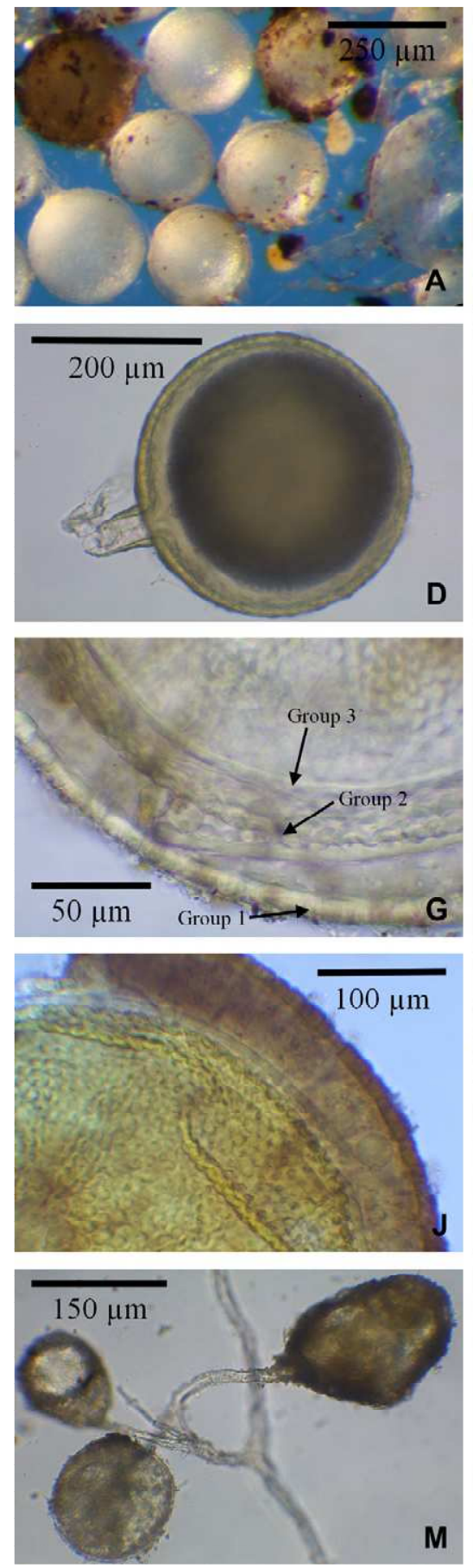
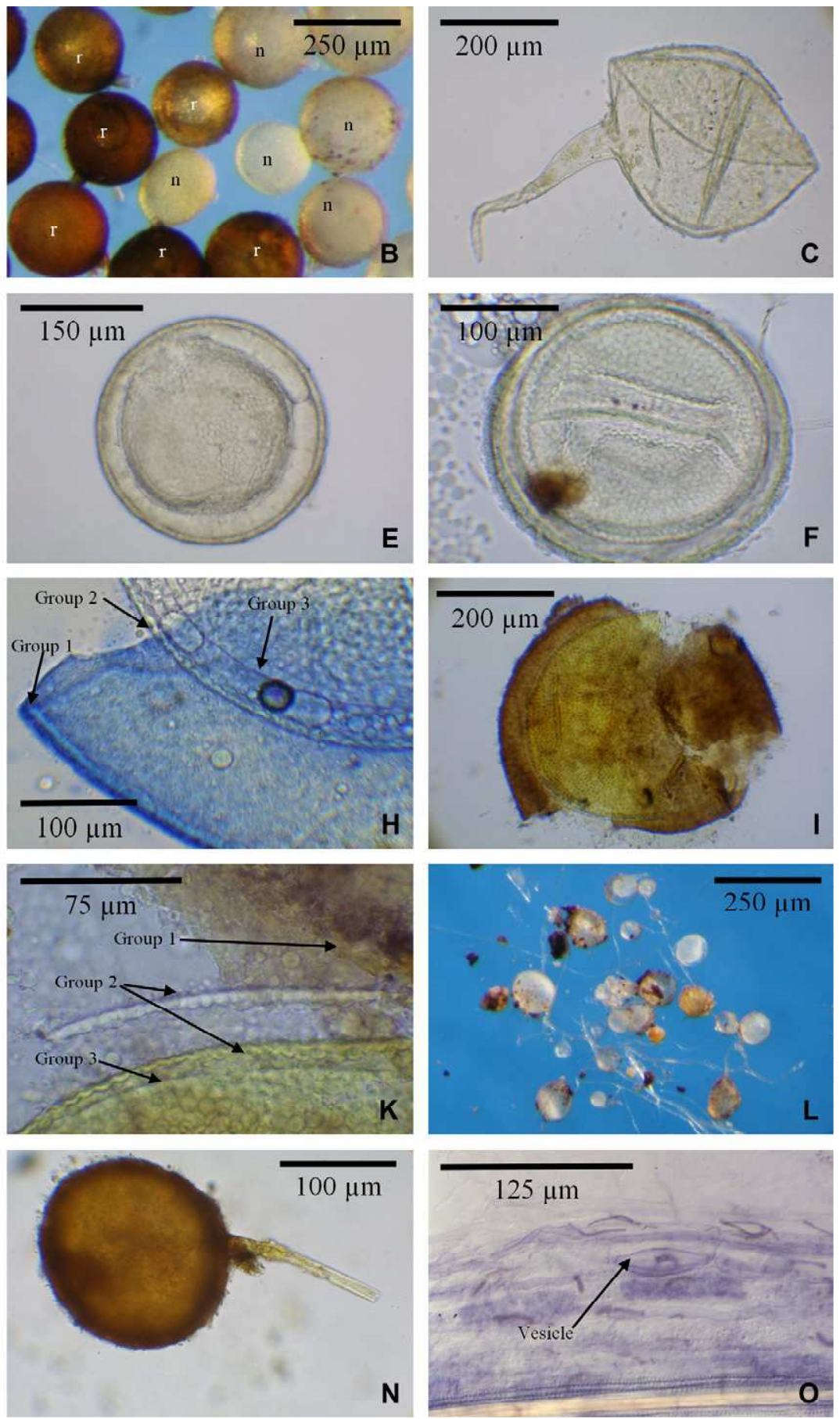

Fig 4 - Spores of Ambispora leptoticha from Att315-11, of single spore origin (brightfield microscopy). A-K. Acaulosporoid spores. L-O. Glomoid spores. A. Spores in water showing the range of pigmentation. The majority of spores are white to ivory, but some may be coloured due to age. B. Spores before $(n)$ and after $(r)$ immersion in Melzer's reagent. C. A collapsed, empty saccule after detachment of the spore. D-E. Intact spores with (D) and without (E) a pedicel. F. Wrinkling of a freshly squashed spore resulting from the pliable nature of the wall components. The scalloped nature of the components in group 2 appears as ornamentation. G. Lightly crushed spore showing wall groups. The two interlocking, scalloped components of group 2 have separated slightly at lower left. H. Spore crushed in PVLG with blue ink, showing the staining of the outer wall components. The components of wall groups 2 and 3 are only lightly stained. I. Reaction to Melzer's reagent of a lightly crushed spore, showing the rust-brown reaction of the outer wall group. J-K. Spores crushed in PVLG with Melzer's reagent, showing the brown reaction of outer components, and the yellow reaction of the innermost scalloped component of group 2. L. Glomoid spores, showing the large size range and the variation in colour. M. A cluster of three spores with adherent soil particles. N. A spore reacting to become brown after immersion in Melzer's reagent. 0 . Mycorrhiza stained with trypan blue showing a vesicle. 

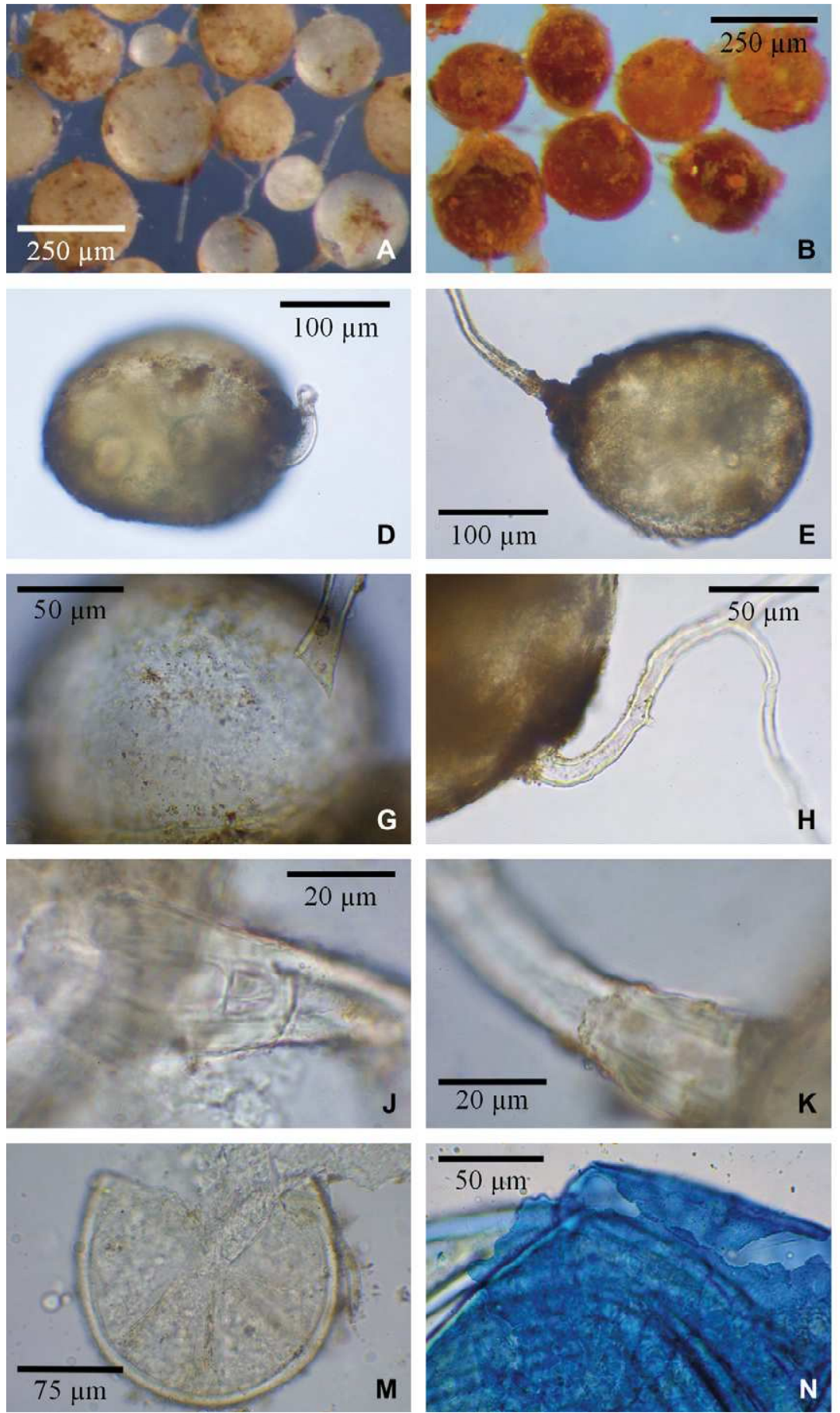
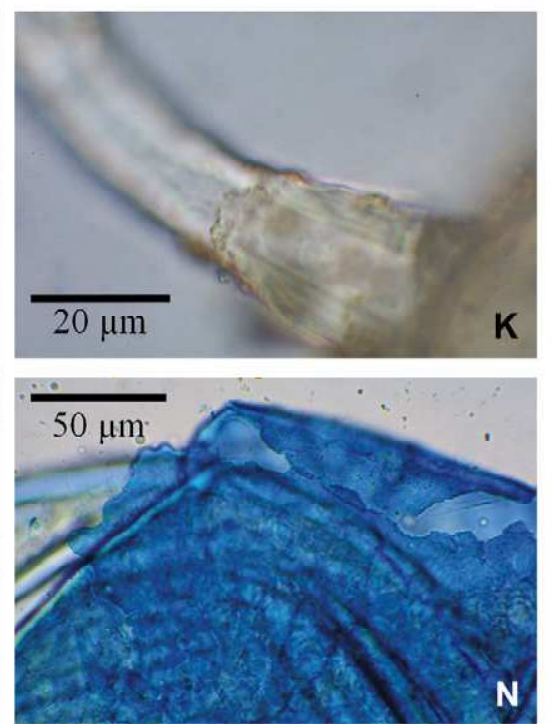
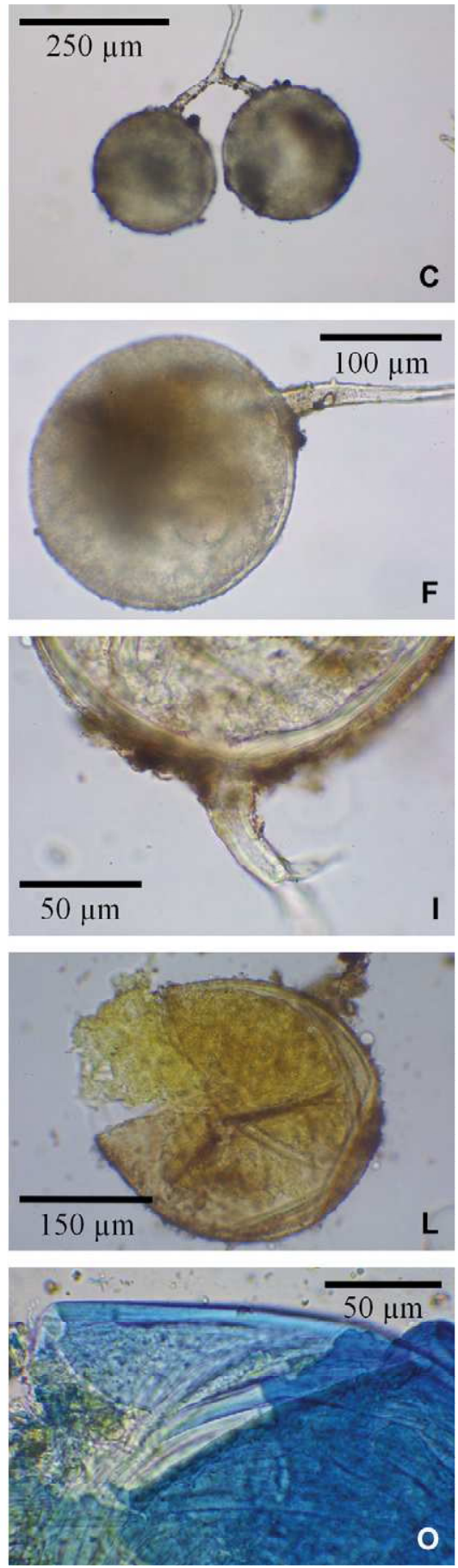

Figs 5-6 - Comparison of spores of the type material (Fig 5) of Ambispora callosa (basionym Glomus callosum) and Japanese isolate from Att1323-7 of single spore origin (Fig 6) (brightfield microscopy except J, which is a Nomarski DIC image). A. Spores in water showing the attached soil particles on some spores giving an erroneous impression of pigmentation. B. Spores in water after immersion in Melzer's reagent. Note the change in colour. C. Pair of attached spores, uncrushed in PVLG. D-F. Individual spores, uncrushed in PVLG, showing differences in shape. G. Surface view of a spore in PVLG, showing the false impression of a warty ornamentation due to the granular nature of the outer wall component and attached fine soil particles. H-K. Subtending hyphae, showing shape differences (cylindrical to funnel-shaped) and occlusion by formation of a septum. L. Spore crushed in PVLG with Melzer's reagent, showing the rust-coloured reaction of the outer wall component, the yellow reaction of the contents exuded through the break, and the creasing resulting from the pliable nature of the wall components. M. Spore crushed in PVLG, also showing creasing. N-O. Wall structure of spores in PVLG with blue ink, showing the outer component staining more heavily than the laminated inner component. 0 . The loose, laminated nature of component 2 is evident, giving an erroneous impression of individual inner flexible components. 

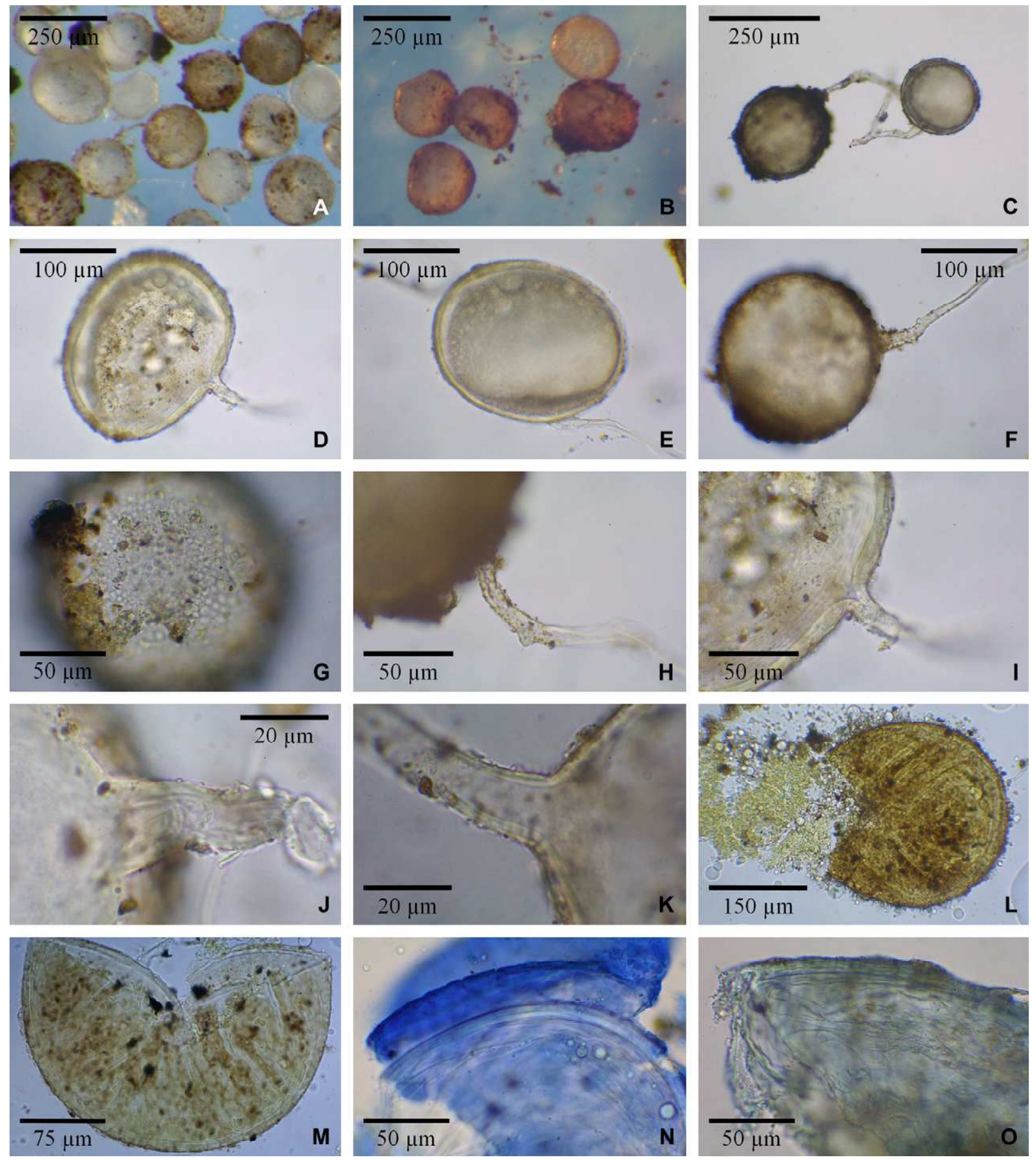

Figs 5-6 (continued)

Arbuscular mycorrhizal fungi forming glomoid spores, acaulosporoid spores, or both glomoid and acaulosporoid spores. Glomoid spores almost lacking in pigmentation, and with a soft, pliable nature resulting in wrinkling and resistance to fracturing when crushed. Acaulosporoid spores formed in the neck of a hyaline to subhyaline to whitish sporiferous saccule, often but not exclusively on a short pedicel resulting in a glomoid appearance once detached from the collapsed saccule. Separated from other families in the Archaeosporales by its rDNA characteristics (Figs 1-2)
Ambispora C. Walker, Vestberg \& Schuessler, gen. nov. MycoBank no.: MB 510209

Etym.: Latin 'ambispora' referring to the capability of some organisms in the genus to produce two different kinds of propagules, acaulosporoid and glomoid.

Sporae alterutrae glomoideae, acauosporoideae vel ambae. A generibus aliis in Archaeosporalibus differt a ordinatione SSU rDNA sequenti: CAAAACCAATCTCGTCTTCGGGC.

Typus: Ambispora fennica C. Walker, Vestberg \& Schuessler, 2007. 
Spores formed in the soil, either as glomoid spores only, or both acaulosporoid and glomoid spores. Glomoid spores formed singly in the soil or in loose clusters, pliable, differing from the normally brittle nature of such spores in the genus Glomus; open-pored or sealed by a septum formed from the inner wall component. Sporiferous saccule initially similar in appearance to the glomoid spores, with a soft, pliable nature, formed blastically from a hyphal tip, and becoming sealed by a septum. Acaulosporoid spores formed, usually laterally, in the neck of the sporiferous saccule; spore wall structure complex is of two or three groups. Outermost wall group continuous with the saccule wall, enclosing a distinct and separate entity with a wall structure of more than one flexible component in two groups. Forming arbuscular mycorrhizas. Separated from other genera in the Archaeosporales by its rDNA characteristics (Figs 1-2), e.g. the SSU rDNA sequence motif CAAAACCAATCT CGTCTTCGGGC.

Ambispora fennica C. Walker, Vestberg \& Schuessler, sp. nov.

MycoBank no.: MB 510210

Etym.: 'fennica' (of Finland) referring to the country in which the species was first isolated.

Sporae acaulosporoideae et glomoideae ambae formantes. Sporae acaulosporoideae 124-201 × 134-201 $\mu \mathrm{m}$, hyalinae vel pallide ochaceae, turmis tribus parietum: turma prima partibus duabus, pars exterior asperula; turma secunda parte una, in solutione Melzeri lutescenti; turma tertia usque ad $3 \mu \mathrm{m}$ crassa. Sporae glomoideae 38-130 $\times 38-117 \mu \mathrm{m}$, turma una partibus duabus: paries primus $<1 \mu \mathrm{m}$ crassus; paries secundus usque ad $3 \mu \mathrm{m}$ crassus, laminatus.

Typus: Finland: Kurikka, $62^{\circ} 30^{\prime} \mathrm{N} ; 22^{\circ} 20^{\prime} \mathrm{E}$, from a pot culture on Plantago lanceolata, 7 Jun. 2002, C. Walker W3887 (E-holotypus)

Acaulosporoid spores formed singly in the soil, laterally in the neck of a sporiferous saccule that collapses and may detach at maturity; hyaline to pale ochraceous, globose to subglobose to pyriform, 124-201 $\times 134-201 \mu \mathrm{m}(n=100)$, attached to the saccule [199-248 $\mu \mathrm{m}$ diam $(n=15)]$ by a slightly raised collar or by a thickened stalk. Wall components in three groups. Wall group 1 with two adherent components, with a roughened, granular outer component (up to $4 \mu \mathrm{m}$ thick) that tends to disintegrate with time, overlaying a semi-rigid, inner structural component up to $4 \mu \mathrm{m}$ thick. Outermost component expanding to up to $15 \mu \mathrm{m}$ thick on crushing in PVLG, reacting to Melzer's reagent to become rust-brown or red; wall group 2 apparently with a single component, relatively thick (up to $4 \mu \mathrm{m}$ ) and more or less rigid, fracturing and splitting on crushing, becoming yellow in Melzer's reagent. Wall group 3 thin, semi-flexible, up to $3 \mu \mathrm{m}$ thick. Glomoid spores $38-130 \times 38-117 \mu \mathrm{m}(n=100)$, with a thin, wall of two components in a single group. Outer component evanescent, $<1 \mu \mathrm{m}$ thick, adherent to an inner component that is up to $3 \mu \mathrm{m}$ thick and laminated. Subtending hypha rarely cylindrical, normally funnel-shaped, often with a slight constriction at the spore base. Pore open or occluded by a distal septum formed by the laminated wall component. Separated from other species in the Archaeosporales by its rDNA characteristics (Figs 1-2), e.g. the SSU rDNA sequence motif GGAGAGTCGGCATGTCCTTTGTTGGGTGTGCC.

Additional specimens examined: Finland: Kurikka, from a pot culture with Plantago lanceolata established with several glomoid spores taken from a trap pot culture with Trifolium repens started with soil from the root zone of pasture grasses and possibly T. pratense, 1 Nov. 1991, M. Vestberg (Att200-0, W1586) (E); loc. cit. from a pot culture with $P$. lanceolata of single acaulosporoid spore origin, 6 Feb. 2002, M. Vestberg [Att200-8, W3011 (acaulosporoid morph) and W3012 (glomoid morph), 6 Feb. 1998] (E); loc. cit. from a pot culture with $P$. lanceolata of single acaulosporoid spore origin, 14 Jan. 2001, C. Walker [Att200-11, W3570 (acaulosporoid morph) and W3569 (glomoid morph)] (E); loc. cit. from a pot culture with P. lanceolata of single acaulosporoid spore origin, 27 Feb. 2002, C. Walker [Att200-21, W3847 (both morphs)] (E);; loc. cit. from a pot culture with P. lanceolata of single acaulosporoid spore origin, 28 Sep. 2005, C. Walker [Att200-23, W4752 (both morphs), 7 Jun. 2002] (E).

Ambispora gerdemannii (S. L. Rose, B. A. Daniels \& Trappe) C. Walker, Vestberg \& Schuessler, comb. nov.

MycoBank no.: MB 510211

Basionym: Glomus gerdemannii S. L. Rose, B. A. Daniels \& Trappe, Mycotaxon 8: 297 (1979).

Synonym: Archaeospora gerdemannii (S.L. Rose, B.A. Daniels \& Trappe) J. B. Morton \& Redecker, Mycologia 93: 186 (2001).

A species description can be found in Morton \& Redecker (2001). Separated from Archaeospora trappei (Archaeosporaceae) and other species in the genus Ambispora by its rDNA characteristics (Figs 1-2).

Ambispora leptoticha (N.C. Schenck \& G.S. Sm.) C. Walker, Vestberg \& Schuessler, comb. nov. Fig 4

MycoBank no.: MB 510212

Basionym: Glomus leptotichum N. C. Schenck \& G. S. Sm., Mycologia 74: 82-83 (1982).

Synonyms: Acaulospora gerdemannii N. C. Schenck \& T.H. Nicolson, Mycologia 71: 193 (1979).

Acaulospora appendicula Spain, Sieverd. \& N. C. Schenck, Mycologia 76: 686 (1984).

Glomus fecundisporum N.C. Schenck \& G.S. Sm. Mycologia 74: 81 (1982).

Archaeospora leptoticha (N.C. Schenck \& G.S. Sm.) J. B. Morton \& Redecker, Mycologia 93: 184 (2001).

A species description can be found in Morton \& Redecker (2001). Separated from Archaeospora trappei (Archaeosporaceae) and other species in the genus Ambispora by its rDNA characteristics (Figs 1-2).

Specimens examined: Japan: Tochigi, Nishinasumo, Fujinitayama, from a pot culture with Sorghum bicolor, T. repens, M. sativa and Dactylis glomerata, established with soil sievings containing roots of D. glomerata and Zoysia sinensis, 1 Nov. 1994, T. Murakoshi (Att315-0, W1974) (E); loc. cit. from a multi-spore pot culture established with $S$. sudanense, $T$. repens and Miscanthus sinensis from a pot culture with Att315-0 in its ancestry, 1 Dec. 1996, M. Saito, culture F3b, MAFF520055, (Att315-4, W2875) (E) and from a subsequent pot culture, 31 Jan. 2005, M. Saito (Att315-11, W4770) (E).

Ambispora callosa (Sieverd.) C. Walker, Vestberg \& Schuessler, comb. nov.

Figs 5-6

MycoBank no.: MB 510213

Basionym: Glomus callosum Sieverd., Angew. Bot. 62, 374 (1988).

Sporocarps unknown. Spores sub-hyaline to white to ivory, yellowing somewhat with age or storage in preservative, borne singly or in loose clusters in the soil. Acaulosporoid spores unknown. Glomoid spores globose to subglobose to broadly 
ellipsoid, sometimes ovoid or obovoid, sometimes eccentrically produced from the subtending hypha; very variable in size, 84-319 $\times 84-300 \mu \mathrm{m}$, often with immature (open-pored) spores closely attached to mature (occluded) spores. Subtending hypha straight to funnel-shaped, open-pored or occluded by a septum formed from the laminated wall component. Wall structure continuous with that of the sporogenous mycelium, consisting of two components, an inner, laminated structural component and an outer, unit component, roughened on the surface, which may disintegrate with time. Spores sometimes covered by a sticky mucilaginous coat, appearing as a separate wall component. Adherent fine soil particles giving the impression of pigmentation. Lacking brittle or rigid wall components. Components pliable and thus creasing and rather difficult to break open on crushing. In Melzer's reagent, or PVLG with Melzer's reagent, spores rapidly becoming deep yellow to orange, the reaction being mostly in the roughened outer wall component and the mucilaginous component. Melzer's reaction fading within a few days of preparation of PVLG-Melzer's slide mounts. Separated from the Glomerales but not the Archaeosporales at the ordinal level, and from Archaeospora trappei at the family and genus levels by rDNA nucleotide sequence data (Figs 1-2). Differing from other described members of the Ambisporaceae by production only of glomoid spores.

Specimens examined: Japan: Sakurajima Island, Kagoshima, from a subculture with $\mathrm{T}$. repens with a single spore isolate (Att1323-5, host unknown) in its lineage, 3 Jan. 2006, M. Saito, isolate OK1, MAFF520057, (Att1323-7, W4769) (E); Morioko, Iwate, Tohoku National Agricultural Experiment Station, from a subculture with a multi spore culture (Att321-0, on S. bicolor) in its lineage, 31 Jan. 2005, M. Saito culture V1, MAFF520058 (Att321-1 on T. repens, W1980 and Att321-9 with P. notatum and T. repens, W4771) (E); Hokkaido, Sapporo, from a subculture with $P$. notatum with a single spore isolate (Att1322-2, host unknown) in its lineage, 7 Dec. 2004, M. Saito, isolate HZ-6K (Att1322-4, W4772) (E); Miyakejima Island, grassland (predominantly M. sinensis) on volcanic soil, from a subculture with $P$. notatum, with a single spore isolate (Att1321-2, host unknown) isolate OK-m in its lineage, 7 Dec. 2004, M. Saito, (Att1321-4, W4768) (E) - Zaire: South Kivu Province, near Bukavu, Agricultural School Mushweshwe, from a multi-spore subculture with Sorghum bicolor, 15 May 1988, E. Sieverding, culture GTZ-21, (Att1324-0, W4819; Holotype; GOET).

\section{Discussion}

\section{Molecular phylogenetic analyses}

Our molecular and morphological data and the sequences from roots indicate a substantial diversity within this deeply branched glomeromycotan lineage, the Archaeosporales, providing further phylogenetic and taxonomic insights into this poorly studied group of AM fungi. The formation of spores within the neck of a sporiferous saccule is shared by members of the genus Acaulospora, which is genetically very distant from the Archaeosporales. Analysis of SSU rDNA phylogeny showed the Archaeosporaceae sensu Morton \& Redecker (2001) to be composed of three clades, one containing Archaeospora trappei and the second containing A. leptoticha and A. gerdemannii. The latter forms a sister clade with Geosiphon pyriformis (Geosiphonaceae), rendering the Archaeosporaceae paraphyletic (Schüßler et al. 2001). No molecular analysis of Intraspora
(Sieverding \& Oehl 2006) is available, but its morphological and developmental characteristics suggest that I. schenckii is likely to belong in the same clade as A. trappei, and therefore can remain in the Archaeosporaceae.

The analysis of SSU rDNA shows that three main clades, resolved at the taxonomic level of family, can be defined within the Archaeosporales: the Geosiphonaceae, the Archaeosporaceae, and the Ambisporaceae. Ambispora gerdemannii clearly is related to A. fennica (Fig 1) and is non-monophyletic (family level) with Archaeospora trappei (Archaeosporaceae). An alignment of ITS region sequences between the Ambisporaceae, the Geosiphonaceae, and the Archaeosporaceae is not possible due to the large molecular distances. Based on the ITS region, the species within the Ambisporaceae can clearly be separated (Fig 2). Among the main clades in the Archaeosporales, two (typified by Archaeospora trappei and G. pyriformis, respectively) already were defined as the families Archaeosporaceae and Geosiphonaceae. The third clade comprises the Ambispora fennica lineage. The situation of paraphyly for the Archaeosporaceae, which contained A. leptoticha and A. gerdemannii, could have been resolved by placing this clade into the Geosiphonaceae, or by erecting a new family. In our opinion, the latter is most appropriate and this clade is herein described as a new family, the Ambisporaceae. Two putative species sequenced from Taxus (from Germany) and Prunus (from Africa) roots (Wubet et al. 2003a, 2003b) also belong to this clade.

The resolution of the SSU rDNA analysis within the Ambisporaceae is not sufficiently discerning to distinguish the species investigated unless used in concert with the ITS region. With respect to the ITS region, A. leptoticha strain FL130 and NC176 are well characterized, and from the ITS data, isolate F3b from Japan can be considered to belong to the same species (Fig 2). Similarly, A. callosa HZ-6K, OK-m, OK1, and V1 are clearly separated from the other species and sufficiently close to each other to be considered conspecific. A. fennica is well separated from all other species in the clade and unequivocally separated from Archaeospora gerdemannii AU215 (AJ012202). Although the latter is very closely related to A. leptoticha based on the SSU rDNA data (Fig 1), the single ITS sequence published does not give sufficient resolution for a complete phylogenetic analysis. However, it is well separated from the other species in the clade.

The sequence AJ567807, derived from Plantago roots, is labelled in the public database as A. leptoticha, but it is more probably another, undescribed, species in Ambispora. This shows that care should be taken when annotating environmental sequences with species names, as in many instances, the database is not yet sufficiently large to be discerning at this level.

\section{Morphology}

\section{Archaeospora trappei and Intraspora schenckii}

The original species description of Archaeospora trappei was modified first by Morton \& Redecker (2001) and later by Spain (2003). The differences in these descriptions cannot be reconciled without more detailed study, but whichever author is followed, the species is different in most respects from other species in the genus. The wall structure, when examined in 
PVLG, appears simple (Morton \& Redecker 2001), consisting of an outer component (probably a continuation of the wall of the sporiferous saccule) enclosing two adherent components making up a separate wall group. The spores are very small (40-48 $\times 50-72 \mu \mathrm{m})$, and have neither pigmentation nor a reaction to Melzer's reagent. The emendation by Spain (2003) described a much more complex wall structure, and indicated that the species is capable of forming glomoid spores. This work was carried out with a completely different approach from the established methods. Without further examination and comparison of all other species with the same methods, it is not possible to make the necessary morphological comparisons. Our own examination of pot cultured material did not reveal a glomoid phase as described in Spain (2003), and thus we suggest there is a need for independent verification of this aspect.

The molecular data show some differences among different cultures and origins of this fungus, which has few characteristics that can be used to distinguish species. We have noted differences among SSU signatures in organisms determined as A. trappei (Fig 1). It is possible that cryptic species exist that can be defined only or mainly through molecular analysis. The combination of morphological and molecular characteristics set A. trappei apart from the other organisms included by Morton \& Redecker (2001) within the Archaeosporaceae. For Intraspora schenckii, there is no molecular evidence to show how closely it is related to A. trappei, but the two organisms are certainly very similar morphologically, differing only in the topological position of the spore within the neck of the sporiferous saccule, and it is retained within our concept of the family Archaeosporaceae.

\section{Ambispora fennica and A. gerdemannii}

These are very close morphologically, but the rDNA phylogenies clearly set them apart and show that they cannot be the same species (Fig 1). The type material of the former Glomus gerdemannii was unavailable for us to examine. Consequently, the comparison has to be made from the detailed illustrations and descriptions in the literature.

Ambispora gerdemannii has cream to orange-brown to dark orange-brown acaulosporoid spores that are much darker in colour than the hyaline to pale ochraceous spores (Fig 3A-B) of A. fennica They are described as having a 'pedicel' with a minimum length of $50 \mu \mathrm{m}$ that gives a somewhat glomoid appearance. A similar pedicel is present in some, but not all, spores of A. fennica. The spores and saccules of the former are generally larger than those of the latter (Table 2). The acaulosporoid spores have an outer group that is probably continuous with the saccule wall, consisting of a more or less evanescent mucilaginous component that reacts to become pink to red in Melzer's reagent (often with adherent particles from the soil) overlaying a 'semi-flexible' component. The outermost component of A. gerdemannii fractures into angular fragments, whereas that of A. fennica disintegrates into fine granules. For both species, within this outer envelope, a second wall group develops which has an apparently brittle nature, fracturing when crushed to give the impression of 'polygonal shards' (Fig 3N, J). A third wall group of a single somewhat flexible component finally develops.
The glomoid spores of A. gerdemannii are white to pale cream, and those of A. fennica colourless, both are similar in size (Table 2). Their subtending hyphae differ somewhat. For A. gerdemannii, they are cylindrical to slightly flared and 6-12 $\mu \mathrm{m}$ wide at the spore base, and occluded by spore wall thickening. For A. fennica, they are cylindrical to distinctly funnelshaped, often a little constricted at the base, up to $20 \mu \mathrm{m}$ wide at the widest point, and open pored, or sealed by a distal septum formed by the inner wall component. The glomoid spore wall structures are similar, consisting of an evanescent outer component overlaying a somewhat flexible, finely laminated structural component. In contrast to A. leptoticha, glomoid spores of A. fennica have no reaction to Melzer's reagent.

There is some confusion in the redescription of A. gerdemannii, with regard to its origins. It is described as having been collected from 'Tasmania, Kakadu National Park' in Australia by C. Gazey (Morton \& Redecker 2001). Kakadu National Park is in the Northern Territory, not Tasmania, and Chris Gazey (personal communication) has not collected organisms from the Northern Territory or Tasmania. The Australian collection at UWA is all carefully catalogued and numbered, but in the re-description, only an INVAM number is given, and there is no detail in the website (as of Jan. 2006), either as an accession, or as an available culture of AU215, at http:// invam.caf.wvu.edu. It has proved impossible to obtain further information by direct contact with INVAM. Consequently, there must remain some doubt as to the precise origins of the fungus, when it was isolated, and by whom.

\section{Ambispora leptoticha}

This discussion refers to the interpretation of the former Acaulospora appendicula, A. gerdemannii, Glomus leptotichum and $G$. fecundisporum combined as conspecific. The morphologies of the organisms concerned are described in Morton \& Redecker (2001). Although there can be some debate as to the correctness of combining $A$. gerdemannii and $A$. appendicula into a single species, their acaulosporoid spores are clearly different from those of Ambispora fennica because of their scalloped interlocked inner wall components. The acaulosporoid spores of the isolate F3b (A. leptoticha from Japan) correspond well in all aspects with the description of Acaulospora appendicula, and therefore with the concept of Archaeopora leptoticha sensu Morton \& Redecker.

Similarly, the combination of heterotypic synonyms for the glomoid morphs, represented by $G$. leptotichum and G. fecundisporum, into A. leptoticha may be debated, but the glomoid spores of Ambispora fennica, are smaller, have a much smaller size range (38-130 × 38-117 compared with 48-262 × 48-262 $\mu \mathrm{m}$, respectively), and show no reaction to Melzer's reagent.

There are still some fundamental questions that must be addressed eventually with regard to the synonymisation of four organisms and the choice of the epithet to represent them. For example, the sample of the type material of G. leptotichum examined during this study appeared to be very close morphologically to G. callosum, and showed no evidence of production of acaulosporoid spores as mentioned by Morton et al. 1997. Further examination of living material re-isolated from type localities might provide molecular evidence, and may be the only way to address this matter fully. Until then, the status quo is best maintained. 
Ambispora callosa

Except for minor size differences, the type material of $G$. callosum is indistinguishable from the Japanese fungi $\mathrm{OK}-\mathrm{m}$, HZ-6K, OK1 and V1 (Figs 5-6). We are confident of our morphological species determination and the molecular evidence (Fig 1) in transferring this species to Ambispora. Spores of A. callosa are similar to the glomoid spores of A. leptoticha sensu Morton \& Redecker (2001), but are generally larger.

The outer mucilaginous coating on spores of this species can give the impression of ornamentation. This was referred to in the species protologue as ornamentation formed of crowded minute warts. Examination of the type material shows this to be a misinterpretation (Figs 5G, 6G) of soil particles adherent to the sticky outer wall component. A similar effect was reported from G. viscosum (Walker et al. 1995).

In the protologue, the species in Archaeosporaceae are described as forming dimorphic or monomorphic spores (Morton \& Redecker 2001). In the description, it is made clear that when spores produced are monomorphic, only the acaulosporoid form is found. A. callosa Att321 was established in 1989 (Saito \& Vargas 1991), and the same species from Att1323 was isolated in 1993. For more than a decade these isolates, repeatedly sub-cultured with several different host plants and various soil conditions, have not produced acaulosporoid spores. It is impossible to prove that such spores do not exist, but Morton et al. (1997) themselves also described some cultures (from FL184) that exclusively form glomoid spores. It can thus be concluded that organisms with only glomoid spores do exist in the genus Archaeospora sensu Morton \& Redecker (2001). The species description of G. callosum is of a fungus, from pot culture, that forms only glomoid spores. Incidentally, the same is true of G. leptotichum and G. fecundisporum, and questions might still be raised as to whether or not the evidence that these organisms should be synonymised (Morton \& Redecker 2001) with the acaulosporoid-producing species was correct.

\section{Acaulospora nicolsonii}

The type material of Acaulospora nicolsonii was re-examined with a view to revising its systematic position. Re-examination of the type material suggests that there are three wall groups, the first with two components resolvable by light microscopy, and the second and third with one component each, rather than that shown in the protologue's murograph as four distinct walls in three groups (Walker et al. 1984). The outer component has a roughened appearance due to gradual disintegration, and can be considered as evanescent, in that some spores appear to have lost it completely. This is similar to the outer component of acaulosporoid spores of Ambispora fennica, but the outer wall of the A. fennica reacts with Melzer's reagent, whereas for Acaulospora nicolsonii, there is no such reaction. Although no fresh material of the latter species was available to check this, specimens were soaked from a polyvinyl alcohol lactophenol slide and re-tested, and no Melzer's reaction occurred. A similar exercise was carried out for spores of Ambispora fennica from a PVLG mount in which the reaction had faded, and the reaction was refreshed. The second component, which is inseparable by crushing from the first, is laminated and relatively rigid. Contained within this outer envelope is a separate and slightly flexible component, and within this a third group consisting of a very thin, flexible component. The appearance and structure of these inner wall components is similar to those of A. fennica and A. gerdemannii, though lacking the fracturing and splitting nature of those species.

No glomoid morph was recognised in the original species description of A. nicolsonii, though because the cultures from which it was derived were not pure, such spores at the time would have been recognised as belonging to the genus Glomus, and would not have been associated as belonging to the same organism. It is likely that Acaulospora nicolsonii belongs in Ambispora, but there is insufficient evidence to merit moving it at this time. The fungus was originally obtained in mixed pot culture from a farm owned and operated by the University of Leeds. Consequently, the prospects of re-isolating the organism in due course must be relatively good. It would then be possible to confirm the correct taxonomic position based on both morphological and molecular evidence.

It is increasingly clear that similar spore morphologies may not always be sufficient evidence for conspecificity (or sometimes even a close phylogenetic relationship at any level), and that molecular data are becoming a requirement for determining the correct phylogenetic position of members of the Glomeromycota. We clearly have cryptic species in this phylum, implying that defining species solely on morphological grounds is risky, though not impossible if the characteristics used to define them are sufficiently different from those of existing species. In some circumstances, it may not be possible to obtain molecular evidence, but where possible, the combination of molecular and morphological evidence is needed to be confident of the existence of new genera or species. For example, here Ambispora fennica and A. gerdemannii have similar morphologies, but are clearly well separated by molecular evidence, and cannot be conspecific. This raises some questions about the validity of using the Australian organism to re-define the North American G. gerdemannii. These doubts can only be reconciled if the latter is re-isolated from its type locality and examined for both molecular and morphological characteristics. We are in a similar dilemma with the Japanese species that we have determined as A. callosa. Morphologically, the characteristics of the Japanese isolates agree with those of the type material from Zaire, but until new living material is obtained from somewhere close to the type locality, there must always remain an element of doubt. However, the type material of G. callosum is in excellent condition and shows all the characteristics described in the protologue, in contrast to the type of G. gerdemannii, which was described by Morton \& Redecker (2001) as being in poor condition.

According to the previous descriptions of mycorrhizas formed by members of the more ancient clades in the Glomeromycota, these do not form vesicles. This characteristic was considered to have important phylogenetic implications. However, staining of mycorrhizas of both A. fennica and A. leptoticha proved the existence of vesicles. It seems that there must be some doubt as to the value of this as a taxonomic character, and further research is needed to assess its value. 
Therefore we remove the emphasis on mycorrhizal morphology from our formal descriptions.

The combination of near full-length SSU rDNA and ITS region analyses is proving to be a valuable strategy for resolving taxonomic and evolutionary questions about AM fungal species. SSU rDNA sequences often do not allow the separation of species in the Glomeromycota. The ITS region sequences help to uncover the diversity hidden within such SSU rDNA sequences, which in biodiversity studies often are grouped as 'sequence types'. It is likely that the real species diversity is much higher than that revealed by studies based on SSU rDNA sequence types, as here shown for the A. leptoticha-A. gerdemannii-A. callosa clade. The addition of data from LSU rDNA, and perhaps also other genes, may further enhance resolution, but the combination of the SSU and ITS rDNA regions seems to be well suited to define species in the Glomeromycota at the molecular level.

\section{Acknowledgements}

Thanks to Hiroake Okabe, Japan, and Joyce L. Spain, USA for generously providing specimens, James M. Trappe (Oregon, USA) for assistance with the Latin. The curators of OSC and GOET loaned specimens of the type of Glomus leptotichum and Glomus callosum. Funding, provided by the German Research Foundation (DFG Schu1203/8) and by the Biooriented Technology Research Advancement Institution, Japan (Promotion of Basic Research Activities for Innovative Biosciences PROBRAIN), is gratefully acknowledged. Part of this research project has been supported by a Marie Curie Early stage Research Training Fellowship of the European Community's Sixth framework Programme under contract number MEST-CT-2005-021016.

\section{R E F E R E N C E S}

Ames RN, Linderman RG, 1976. Acaulospora trappei sp. nov. Mycotaxon 3: $565-569$

Börstler B, Renker C, Kahmen A, Buscot F, 2006. Species composition of arbuscular mycorrhizal fungi in two mountain meadows with differing management types and levels of plant biodiversity. Biology and Fertility of Soils 42: 286-298.

Felsenstein J, 1989. PHYLIP: phylogeny inference package (version 3.2). Cladistics 5: 164-166.

Heckman DS, Geiser DM, Eidell BR, Stauffer RL, Kardos NL, Hedges SB, 2001. Molecular evidence for the early colonization of land by fungi and plants. Science 293: 1129-1133.

Kojima T, Sawaki H, Saito M, 2004. Detection of arbuscular mycorrhizal fungi, Archaeospora leptoticha, and related species colonizing plant roots by specific PCR primer. Soil Science and Plant Nutrition 50: 95-101.

Kramadibrata K, Walker C, Schwarzott D, Schüßler A, 2000. A new species of Scutellospora with a coiled germination shield. Annals of Botany 86: 21-27.

Kumar S, Gadkar SR, 2000. Efficiency of the neighbour-joining method in reconstructing deep and shallow evolutionary relationships in large phylogenies. Journal of Molecular Evolution 51: 544-553.
Morton JB, 1988. Taxonomy of VA mycorrhizal fungi: classification, nomenclature and identification. Mycotaxon 32: 267-324.

Morton JB, Bever JD, Pfleger FL, 1997. Taxonomy of Acaulospora gerdemannii and Glomus leptotichum, synanamorphs of an arbuscular mycorrhizal fungus in Glomales. Mycological Research 101: 625-631.

Morton JB, Redecker D, 2001. Two families of Glomales, Archaeosporaceae and Paraglomaceae, with two new genera Archaeospora and Paraglomus, based on concordant molecular and morphological characters. Mycologia 93: 181-195.

Murakoshi T, Motoaki T, Walker C, Saito M, 1998. Arbuscular mycorrhizal fungi on adjacent semi-natural grasslands with different vegetation in Japan. Mycoscience 39: 455-462.

Nicolson TH, Schenck NC, 1979. Endogonaceous mycorrhizal endophytes in Florida. Mycologia 71: 178-198.

Pirozynski AH, Malloch DW, 1975. The origin of land plants. A matter of mycotrophism. Biosystems 6: 153-154.

Phillips JM, Hayman DS, 1970. Improved procedures for clearing roots and staining parasitic and vesicular-arbuscular mycorrhizal fungi for rapid assessment of infection. Transactions of the British Mycological Society 55: 158-160.

Redecker D, Kodner R, Graham LE, 2000a. Glomalean fungi from the Ordovician. Science 289: 1920-1921.

Redecker D, Morton JB, Thomas D, Bruns TD, 2000b. Ancestral lineages of arbuscular mycorrhizal fungi (Glomales). Molecular Phylogenetics and Evolution 14: 276-284.

Renker C, Heinrichs J, Kaldorf M, Buscot F, 2003. Combining nested PCR and restriction digest of the internal transcribed spacer region to characterize arbuscular mycorrhizal fungi on roots from the field. Mycorrhiza 13: 191-198.

Rose S, Daniels BA, Trappe JM, 1979. Glomus gerdemannii sp. nov. Mycotaxon 3: 297-301.

Saito M, Vargas R, 1991. Vesicular-arbuscular mycorrhizal fungi in some humus-rich Ando soils of Japan. Soil Microorganisms 38: 3-15.

Sawaki H, Saito M, 2001. Expressed genes in the extraradical hyphae of an arbuscular mycorrhizal fungus Glomus intraradices, in the symbiotic phase. FEMS Microbiology Letters 195: 109-113.

Sawaki H, Sugawara K, Saito M, 1998. Phylogenetic position of an arbuscular mycorrhizal fungus, Acaulospora gerdemannii, and its synanamorph Glomus leptotichum, based upon $18 \mathrm{~S}$ rRNA gene sequence. Mycoscience 39: 477-480.

Schenck NC, Smith GS, 1982. Additional new and unreported species of mycorrhizal fungi (Endogonaceae) from Florida. Mycologia 74: 77-92.

Schenck NC, Spain JL, Sieverding E, Howeler RH, 1984. Several new and unreported vesicular-arbuscular mycorrhizal fungi (Endogonaceae) from Colombia. Mycologia 76: 685-699.

Schüßler A, 1999. Glomales SSU rRNA gene diversity. New Phytologist 144: 205-207.

Schüßler A, 2002. Molecular phylogeny, taxonomy, and evolution of Geosiphon pyriformis and arbuscular mycorrhizal fungi. Plant and Soil 244: 75-83.

Schüßler A, Schwarzott D, Walker C, 2001. A new fungal phylum, the Glomeromycota: phylogeny and evolution. Mycological Research 105: 1413-1421.

Schwarzott D, Schüßler A, 2001. A simple and reliable method for SSU rRNA gene DNA-extraction, amplification, and cloning from single AM fungal spores. Mycorrhiza 10: 203-207.

Schwarzott D, Walker C, Schüßler A, 2001. Glomus, the largest genus of the arbuscular mycorrhizal fungi (Glomales) is nonmonophyletic. Molecular Phylogenetics and Evolution 21: 190-197.

Sieverding E, 1988. Two new species of vesicular arbuscular mycorrhizal fungi in the Endogonaceae from tropical highlands in Africa. Angewandte Botanik 62: 372-380.

Sieverding E, Oehl F, 2006. Revision of Entrophospora and description of Kuklospora and Intraspora, two new genera in the 
arbuscular mycorrhizal Glomeromycetes. Journal of Applied Botany and Food Quality 80: 69-81.

Smith SE, Read DJ, 1997. Mycorrhizal Symbiosis, 2nd edn. Academic press, San Diego.

Spain JL, 2003. Emendation of Archaeospora and of its type species, Archaeospora trappei. Mycotaxon 57: 109-112.

Vuorinen J, Mäkitie O, 1955. The method of soil testing in Finland. Agrogeological Publication 63: 1-44.

Walker C, 1983. Taxonomic concepts in the Endogonaceae: spore wall characteristics in species descriptions. Mycotaxon 18: 443-455.

Walker C, 1986. Taxonomic concepts in the Endogonaceae: II. A fifth morphological wall type in endogonaceous spores. Mycotaxon 25: 95-99.

Walker C, 1992. Systematics and taxonomy of the arbuscular endomycorrhizal fungi (Glomales) - a possible way forward. Agronomie 12: 887-897.

Walker C, 1999. Methods for culturing and isolating arbuscular mycorrhizal fungi. Mycorrhiza News 11: 2-3.

Walker C, 2005. A simple blue staining technique for arbuscular mycorrhizal and other root-inhabiting fungi. Inoculum 56 : 68-69.

Walker C, Gianinazzi-Pearson V, Marion-Espinasse H, 1993. Scutellospora castanea, a newly described arbuscular mycorrhizal fungus. Cryptogamie, Mycologia 14: 279-286.

Walker C, Giovannetti M, Avio L, Citernes AS, Nicolson TH, 1995. A new fungal species forming arbuscular mycorrhizas: Glomus viscosum. Mycological Research 99: 1500-1506.

Walker C, Mize CW, McNabb HS, 1982. Populations of endogonaceous fungi at two localities in central Iowa. Canadian Journal of Botany 60: 2518-2529.
Walker C, Reed LE, Sanders FE, 1984. Acaulospora nicolsonii, a new endogonaceous species from Great Britain. Transactions of the British Mycological Society 83: 360-361.

Walker C, Vestberg M, 1994. A simple and inexpensive method for producing and maintaining closed pot cultures of arbuscular mycorrhizal fungi. Agricultural Science in Finland 3: 233-240.

Walker C, Vestberg M, 1998. Synonymy amongst the arbuscular mycorrhizal fungi: Glomus claroideum, G. maculosum, G. multisubstensum and G. fistulosum. Annals of Botany 82: 601-624.

White TJ, Bruns TD, Lee S, Taylor J, 1990. Amplification and direct sequencing of fungal ribosomal RNA genes for phylogenetics. In: Innis MA, Gelfand DH, Sninsky JJ, White T (eds), PCR Protocols: A Guide to Methods and Applications. Academic Press, San Diego, pp. 315-322.

Wubet T, Weiß M, Kottke I, Oberwinkler F, 2003a. Morphology and molecular diversity of arbuscular mycorrhizal fungi in wild and cultivated yew (Taxus baccata). Canadian Journal of Botany 81: 255-266.

Wubet T, Weiß M, Kottke I, Teketay D, Oberwinkler F, $2003 \mathrm{~b}$. Molecular diversity of arbuscular mycorrhizal fungi in Prunus africana, an endangered medicinal tree species in dry Afromontane forests of Ethiopia. New Phytologist 161: 517-528.

Wuyts J, De Rijk P, Van de Peer Y, Pison G, Rousseeuw P, De Wachter $R, 2000$. Comparative analysis of more than 3000 sequences reveals the existence of two pseudoknots in area V4 of eukaryotic small subunit ribosomal RNA. Nucleic Acids Research 28: 4698-4708. 
Molecular phylogeny and new taxa in the Archaeosporales (Glomeromycota): Ambispora fennica gen. sp. nov., Ambisporaceae fam. nov., and emendation of Archaeospora and Archaeosporaceae. 

mycorrhizal fungi.

\section{DNA-based species level detection of Glomeromycota: one PCR primer set for all arbuscular mycorrhizal fungi.}

This chapter is identical to the publication:

Krüger M, Stockinger H, Krüger C, Schüßler A. 2009. DNA-based species level detection of Glomeromycota: one PCR primer set for all arbuscular mycorrhizal fungi. New Phytologist 183: 212-223.

The definitive version is available at http://www.blackwell-synergy.com/loi/nph 


\title{
DNA-based species level detection of Glomeromycota: one PCR primer set for all arbuscular mycorrhizal fungi
}

\author{
Manuela Krüger, Herbert Stockinger, Claudia Krüger and Arthur Schüßler \\ Ludwig-Maximilians-University Munich, Dept Biology I, Genetics, Großhaderner Strasse 4, D-82152 Planegg-Martinsried, Germany
}

Author for correspondence:

Manuela Krüger

Tel: +4989218074714

Email: manuela.krueger@/rz.uni-

muenchen.de

Received: 12 December 2008

Accepted: 23 February 2009

New Phytologist (2009) 183: 212-223

doi: 10.1111/j.1469-8137.2009.02835.x

Key words: arbuscular mycorrhizal fungi (AMF), DNA barcoding, ITS region, LSU rRNA gene, molecular community analyses, rDNA, species level resolution, specific primers.

\section{Summary}

- At present, molecular ecological studies of arbuscular mycorrhizal fungi (AMF) are only possible above species level when targeting entire communities. To improve molecular species characterization and to allow species level community analyses in the field, a set of newly designed AMF specific PCR primers was successfully tested. - Nuclear rDNA fragments from diverse phylogenetic AMF lineages were sequenced and analysed to design four primer mixtures, each targeting one binding site in the small subunit (SSU) or large subunit (LSU) rDNA. To allow species resolution, they span a fragment covering the partial SSU, whole internal transcribed spacer (ITS) rDNA region and partial LSU.

- The new primers are suitable for specifically amplifying AMF rDNA from material that may be contaminated by other organisms (e.g., samples from pot cultures or the field), characterizing the diversity of AMF species from field samples, and amplifying a SSU-ITS-LSU fragment that allows phylogenetic analyses with species level resolution.

- The PCR primers can be used to monitor entire AMF field communities, based on a single rDNA marker region. Their application will improve the base for deep sequencing approaches; moreover, they can be efficiently used as DNA barcoding primers.

\section{Introduction}

Arbuscular mycorrhizal fungi (AMF) are associated with $70-90 \%$ of land plants (Smith \& Read, 2008) in a symbiosis called arbuscular mycorrhiza (AM), that has existed for $>400$ million yr (Parniske, 2008; Schüßler et al., 2009). The economic and ecological importance of these ancient biotrophic plant symbionts is therefore obvious. Arbuscular mycorrhizal fungi transfer inorganic nutrients and water to the plant and receive carbohydrates in exchange. By driving this bidirectional nutrient transport between soil and plants, they are highly relevant for global phosphorus $(\mathrm{P})$, nitrogen $(\mathrm{N})$ and $\mathrm{CO}_{2}$ cycles. Moreover, they affect directly and indirectly the diversity and productivity of land-plant communities (van der Heijden et al., 1998) by their central role at the soil-plant interface (van der Heijden et al., 2008). They can also improve host plant pathogen resistance (Vigo et al., 2000; de la Pena et al., 2006) and drought stress tolerance (Michelson \& Rosendahl, 1990; Aroca et al., 2007).

Despite the enormous role of AMF in the entire terrestrial ecosystem, their biodiversity in relation to functional aspects is little understood. Most of the 214 currently described species (www.amf-phylogeny.com) are characterized only by spore morphology and the majority have not yet been cultured. Moreover, from molecular ecological studies we know that the species described represent only a small fraction of the existing AMF diversity (Kottke et al., 2008; Öpik et al., 2008). Problems with identification of AMF result from their hidden, biotrophic lifestyle in the soil, few morphological characters, and the potential formation of dimorphic spores. This led to many AMF species, phylogenetically belonging to different orders, being placed in one genus (Glomus) and, conversely, individual species forming different spore morphs being described as members of different orders.

Another drawback of morphologically monitoring AMF by their resting spores (Oehl et al., 2005; Wang et al., 2008) is that the presence of spores may not reflect a symbiotically active organism community. Furthermore, many species cannot be reliably identified at all from heterogeneous field samples, and when identifying described species (likely to represent less than $5 \%$ of the existing species diversity) similar morphotypes may be erroneously determined as a single species. 
To reveal functional and ecological aspects of distinct AMF communities associated with different plants and/or under different environmental conditions it is essential to detect AMF communities in the field on the species level. However, there are as yet no unbiased methods for this purpose, not only for morphological identification but also for molecular methods. Principally, DNA sequence based methods are most useful for detecting organisms at different community levels, but for ecological work they also depend on reliable baseline databases and tools. For example, fingerprinting methods such as random amplification of polymorphic DNA (RAPD), inter-simple sequence repeat PCR (ISSR) and amplified fragment length polymorphism (AFLP) are expected to be error prone in uncharacterized environments because of too many 'unknowns' in the background, which hampers interpretation of specificity (Mathimaran et al., 2008). A similar problem exists for DNA array techniques. Nevertheless, suitable molecular methods are crucial to overcome the limitations of morphological identification (Walker \& Schüßler, 2004; Walker et al., 2007; Gamper et al., 2009; Stockinger et al., 2009).

But how are DNA or RNA sequence data for community analyses obtained and how can the current limitations of molecular tools be overcome? Molecular characterization of AMF is in most cases achieved by PCR on DNA from roots of host plants, spores or soil samples. Several primers targeting the rDNA regions as molecular marker were claimed to be AMF specific. Most of these amplify only a restricted number of glomeromycotan taxa or DNA of nontarget organisms. The most comprehensive taxon sampling for the Glomeromycota covers the small subunit (SSU) rDNA region (Schüßler et al., 2001a,b), for which a new, AMF specific primer pair was recently published (AML1 and AML2; Lee et al., 2008). Unlike the often used AM1 primer (Helgason et al., 1998) it is perhaps suitable to amplify sequences from all AMF taxa, but the SSU rDNA is inadequate for species resolution of AMF. Inclusion of the internal transcribed spacer (ITS) and the large subunit (LSU) rDNA region allows both robust phylogenetic analyses and species level resolution (Gamper $e t$ al., 2009; Stockinger et al., 2009).

The available public database sequences are scattered through SSU, ITS and LSU rDNA subsets with varying lengths, often only $500-800 \mathrm{bp}$. In most cases this does not allow species level analyses, and short sequences obtained with primers that have inaccurately defined specificity may result in errors. For example, some short database sequences labelled as Gigaspora (Jansa et al., 2003) cluster with those of Glomus versiforme BEG47 (Diversisporaceae) (Gamper et al., 2009). Because of the relatively few LSU sequences in the public databases, the design of improved primers is challenging or even impossible. We therefore sequenced the ITS region and the $5^{\prime}$ part of the LSU rDNA of a set of well-characterized, but phylogenetically diverse AMF, and designed new primers from the resulting database. These primers are suited to amplify DNA from members of all known glomeromycotan lineages and, by allowing elaboration of a more accurate baseline dataset, could be a breakthrough for molecular community analyses of AMF.

\section{Materials and Methods}

\section{Fungal and plant material for primer tests}

We first tested different samples as DNA templates for PCR to confirm the specificity of the newly designed primers. These included plasmid inserts (Table 1), DNA extractions from single AMF spores and root samples from the Andes (Ecuador) and the Spessart Mountains (Germany). Primers were tested for specificity by PCR with plasmids carrying rDNA fragments with known sequences. All these plasmids had been amplified from single spore DNA extracts with the SSU rDNA primer SSUmAf, described here, and the LSU rDNA primer LR4+2 (modified from LR4; www.aftol.org). The specificity of SSUmAf could therefore not be investigated directly.

\section{DNA extraction for primer tests}

All vials, tips, beads, solutions, and other equipment used were sterile and DNA free.

From cleaned, single AMF spores DNA was extracted with the Dynabead DNA DIRECT Universal Kit (Invitrogen, Karlsruhe, Germany) as described in Schwarzott \& Schüßler (2001).

Roots potentially colonized by AMF were cut into ten $0.5 \mathrm{~cm}$ pieces and collected in a single $1.5 \mathrm{ml}$ Eppendorf tube containing one tungsten carbide bead (diameter $3 \mathrm{~mm}$; Qiagen, Hilden, Germany). They were immediately frozen in liquid $\mathrm{N}_{2}$ within the closed tube, placed in liquid $\mathrm{N}_{2}$ precooled Teflon holders, and ground to a fine powder in a MM2000 bead-mill (Retsch, Haan, Germany). Extraction was done by either an innuPREP Plant DNA Kit (Analytik Jena, Jena, Germany) following the instructions of the manufacturer, or a cetyltrimethylammonium bromide (CTAB) protocol modified from Allen et al. (2006). For the CTAB protocol, prewarmed extraction buffer $(750 \mu \mathrm{l}$ for $75 \mathrm{mg}$ tissue) was added to each sample of frozen, ground tissue, followed by incubation at $60^{\circ} \mathrm{C}$ for $30 \mathrm{~min}$. Next, one volume of a chloroform-isoamylalcohol mixture $(24: 1)$ was added. The samples were centrifuged for $5 \mathrm{~min}$ at $2570 \mathrm{~g}$ and the upper phase was transferred into a new tube. After addition of $2.5 \mu \mathrm{l}$ RNase $\mathrm{A}\left(10 \mathrm{mg} \mathrm{ml}^{-1}\right)$ this was incubated at $37^{\circ} \mathrm{C}$ for $30 \mathrm{~min}$. One volume chloroform-isoamylalcohol $(24: 1)$ was then added and the tube was centrifuged as above. The supernatant was collected and two-thirds volumes of isopropanol added. The samples were incubated at $4^{\circ} \mathrm{C}$ for $15 \mathrm{~min}$. After centrifugation $(10290 \mathrm{~g}$ for $10 \mathrm{~min})$ the pellet was washed in $70 \%$ ethanol, air dried, and eluted in $100 \mu$ of molecular biology grade $\mathrm{H}_{2} \mathrm{O}$. Volumes of $2-5 \mu$ of each DNA extract were used as PCR template. 
Table 1 Plasmids used to test primer specificity and their origin

\begin{tabular}{|c|c|c|c|c|c|c|}
\hline Species (order) & $\begin{array}{l}\text { Plasmid } \\
\text { no. }\end{array}$ & $\begin{array}{l}\text { Spore } \\
\text { no. }\end{array}$ & $\begin{array}{l}\text { Attempt number } \\
\text { (culture code) }\end{array}$ & Voucher & $\begin{array}{l}\text { Source } \\
\text { (collector) }\end{array}$ & Origin \\
\hline Glomus luteum (Glomerales) & pMK020.1 & 2 & Att 676-5 (SA101) & W3184 & INVAM & Saskatchewan, Canada \\
\hline Glomus intraradices (Glomerales) & pHS051.14 & 283 & $\begin{array}{l}\text { Att } 1102-12 \\
\text { (MUCL49410) }\end{array}$ & W5070 & GINCO (Nemec) & Orlando, USA \\
\hline Glomus sp. (Glomerales) & pMK010.1 & 11 & Att 15-5 (WUM3) & W2940 & Walker (Mercer) & Merredin, Australia \\
\hline Acaulospora sp. (Diversisporales) & pMK005.1 & 19 & Att 869-3 (WUM18) & W2941 & Walker (Mercer) & Nedlands, Australia \\
\hline Pacispora scintillans (Diversisporales) & pMK027.1 & 190 & Field collected & W4545 & Walker (Schüßler) & Griesheim, Germany \\
\hline Gigaspora sp. (Diversisporales) & pMK003.1 & 14 & Field collected & W2992 & Walker (Cabello) & Tres Arroyos, Argentina \\
\hline $\begin{array}{l}\text { Scutellospora heterogama } \\
\text { (Diversisporales) }\end{array}$ & pMK029.3 & 72 & Att 334-16 (BEG35) & W3214 & Walker (Miranda) & $\begin{array}{l}\text { exact location unknown, } \\
\text { North America }\end{array}$ \\
\hline Glomus versiforme (Diversisporales) & pHSO36.4 & 262 & Att 475-45 (BEG47) & W5165 & Walker (Bianciotto) & Corvallis, USA \\
\hline Kuklospora kentinensis (Diversisporales) & pHS098.16 & 310 & Att 1499-9 (TW111A) & W5346 & INVAM & Tainan, Taiwan \\
\hline Geosiphon pyriformis (Archaeosporales) & pMK044.1 & 8 & GEO1 & W3619 & Schüßler & Bieber, Germany \\
\hline
\end{tabular}

Single spores from which the cloned amplicons (amplified with primers SSUmAf-LR4+2) originated and the geographic origin of the respective arbuscular mycorrhizal fungi (AMF) are shown.

\section{PCR conditions}

The Phusion High-Fidelity DNA polymerase $2 \times$ mastermix (Finnzymes, Espoo, Finland) was used for PCR with the SSUmAf-LSUmAr or SSUmCf-LSUmBr primer pairs. SSUmCf and LSUmBr were also applied as nested primers (see Fig. 1c). The final concentration of the reaction mix contained $0.02 \mathrm{U} \mathrm{ul}^{-1}$ Phusion polymerase, $1 \times$ Phusion HF Buffer with $1.5 \mathrm{~mm} \mathrm{MgCl} 2,200 \mu \mathrm{M}$ of each dNTP and $0.5 \mu \mathrm{M}$ of each primer. Thermal cycling was done in an Eppendorf Mastercycler Gradient (Eppendorf, Hamburg, Germany) with the following conditions for the first PCR: 5 min initial denaturation at $99^{\circ} \mathrm{C} ; 40$ cycles of $10 \mathrm{~s}$ denaturation at $99^{\circ} \mathrm{C}, 30 \mathrm{~s}$ annealing at $60^{\circ} \mathrm{C}$ and $1 \mathrm{~min}$ elongation at $72^{\circ} \mathrm{C}$; and a $10 \mathrm{~min}$ final elongation. The same conditions were used for the nested PCR primers except that the annealing temperature was $63^{\circ} \mathrm{C}$ and only 30 cycles were carried out. The PCR products were loaded on $1 \%$ agarose gels (Agarose NEEO; Carl Roth, Karlsruhe, Germany) with $1 \times$ sodium borate buffer (Brody \& Kern, 2004) at $220 \mathrm{~V}$, and visualized after ethidium bromide staining $\left(1 \mu \mathrm{g} \mathrm{ml}^{-1}\right)$.

\section{Cloning, restriction fragment length polymorphism (RFLP) and sequencing}

Polymerase chain reaction products were cloned with the Zero Blunt TOPO PCR Cloning Kit (Invitrogen) following the instructions of the manufacturer, except that to reduce costs only one-third of the specified volume of all components was used. Only SOC medium for initial bacterial growth after transformation was used in the volume as per the instructions. From each cloning we analysed up to 48 clones for correct length of plasmid inserts. In some instances fewer clones were available because of low cloning efficiency. Colony-PCR was performed with the GoTaq DNA Polymerase $\left(5 \mathrm{U} \mathrm{\mu l}^{-1}\right.$; Promega, Mannheim, Germany) and modified M13F and M13R primers. To roughly detect intrasporal and intersporal sequence variability in the clones, RFLP was performed in $10 \mu \mathrm{l}$ reaction volume, containing $5 \mu \mathrm{l}$ colony-PCR product, one of the restriction enzymes Hinf I ( $1 \mathrm{U})$, RsaI (1 U), or $\mathrm{MboI}(0.5 \mathrm{U})$ and the specific buffer. One or two clones for each restriction pattern were sequenced, using M13 primers, by the LMU Sequencing Service Unit on an ABI capillary sequencer with the BigDye v3.1 (Applied Biosystems, Foster City, CA, USA) sequencing chemistry. The sequences were assembled and edited in SEQASSEM (www.sequentix.de) and deposited in the EMBL/GenBank/DDBJ databases with the accession numbers FM876780 to FM876839.

\section{Primer design}

For the design of new AMF specific primers a sequence alignment was established with the programs ALIGN (www.sequentix.de) and ARB (Ludwig et al., 2004). The alignments contained all AMF sequences present in the public databases and our new data. In total > 1000 AMF sequences, covering all known phylogenetic lineages, were analysed to design the SSU and LSU rDNA primers. To allow comparison to the existing SSU rDNA datasets the primers were designed to overlap (approx. $250 \mathrm{bp}$ ) with the SSU rDNA. We used BLAST against the public databases and the probe match tool in ARB to test the specificity of the newly designed primers in silico. For the alignment in the ARB database a combination of our new dataset and the 94th release version of the SILVA database (Pruesse et al., 2007, www.arb-silva.de) was used. The oligonucleotides were then synthesized as standard primers $(25 \mathrm{nmol}$, desalted) by Invitrogen. 
New

Phytologist

(a) SSUmAf1

G1. Caledonium BEG20 Y17635

G1. mosseae UT101 AY635833, GI. geosporum BEG11 AJ132664

Gl. sp. 'intraradices' DAOM197198 AY635831

G1. Claroideum BEG14 AJ301851

G1. Iuteum SA101 AJ276089

Ac. laevis AU211 AJ250847

AC. Iongula W3302 AJ306439, AC. rugosa WV949 Z14005

AC. Scrobiculata BEG33 AJ306442, AC. spinosa WV860 Z14004

AC. sp. W3424 AJ306440

Ku. Colombiana WV877 Z14006

Di. spurca ex-type W3239 AJ276077

GI. versiforme BEG47 X86687, G. sp. W2423 AJ301863

G1. eburneum AZ420 AM713405

GI. eburneum AM713406, Gl. fulvum AM418548, Ot. bareai AM905318

Gi. candida BEG17 AJ276091

Gi. Cf. margarita W2992 AJ276090

Gi. Cf. margarita W2992 AJ2760
Gi. rosea DAOM194757 X58726

Gi. Cerradensis MAFF520056 AB041345

SC. heterogama FL225 AY635832

Pac. Scintillans W3793 AJ619940

Ge. pyriformis AM183923

Am. fennica W3847 AM268194, W4752 AM268196

Am. Ieptoticha MAFF520055 AB047304, NC176 AJ006466

Ar. trappei NB112 AJ243420

In. schenkii CL401 AM743189

Pa. brasilianum WV219 AJ012112, Pa. occultum IA702 AJ276081

Ichthyophonus hoferi U25637

Neurospora crassa x04971

Parasitella parasitica AF157149

Penicillium notatum M55628

Peridermium/Endocronartium harknessii M94339

Peziza badia L37539

Russula compacta U59093

Saccharomyces cerevisiae J01353

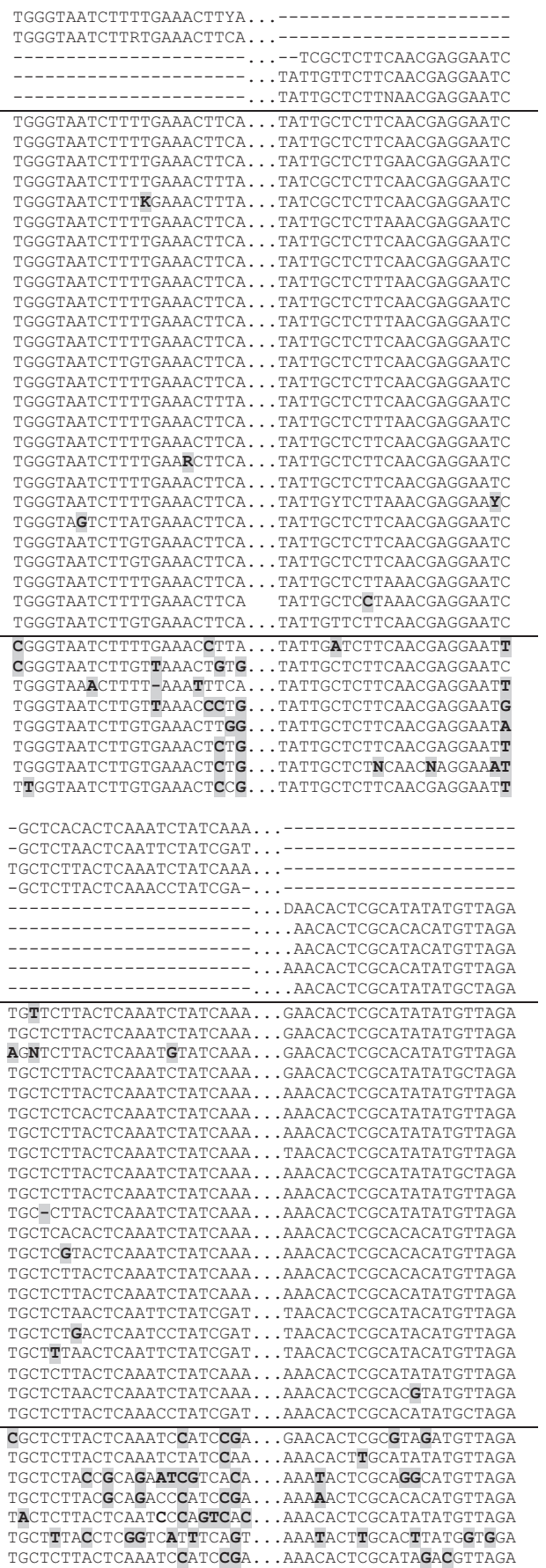

(b) $\quad$ LSUmAr1

LSUMAr3

LSUMAr3
LSUmAr4

LSUmBr1

LSUmBr2

LSUmBr 3
LSUmBr 4

LSUmBr4
LSUmBr5

G1. etunicatum BEG92 AF145749

G1. etunicatum AJ623309

GI. Iuteum SA101 FM876809, GI. Sp. W3349 FM876804

G1. Sp. WUM3 FM876813

G1. Coronatum W3582 FM876794, BEG28 AF145739

GI. Coronatum BEG49 AF145740, GI. mosseae BEG25 AF145735

Gl. sp. 'intraradices' DAOM197198 DQ273790

Gl. claroideum BEG14 AF235007

G1. constrictum BEG130 AF145741

G1. fragilistratum BEG05 AF145747

AC. laevis WUM11 FM876787

AC. sp. WUM18 FM876792

AC. Scrobiculata BEG33 FM876788

Di. celata BEG231 AM713417, GI. versiforme BEG47 FM876814

Gi. SP. W2992 FM876803, SC. heterogama BEG35 FM876837

SC. heterogama FL225 DQ273792

SC. Sp. W3009 FM876833

Pac. Scintillans W4545 FM876831

Ge. pyriformis GEO1 AM183920

Pa. Occultum IA702 DQ273827

Aspergillus niger AM270051

Endogone pisiformis DQ273811

Laccaria bicolor DQ071702

Malassezia cf. restricta HN312 DQ789978

Mortierella sp. MS-6 DQ273786

Mucor racemosus M26190

Saccharomyces cerevisiae 273326

TGCTCTTACTCAAATCCATCCGA... AAACACTCGCATAGACGTTAGA

(c)

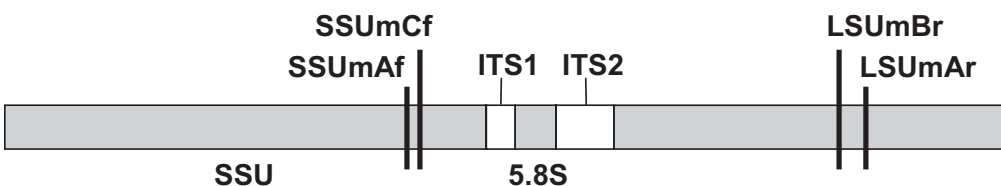

LSU

Fig. 1 Forward and reverse primers designed in this study ( $5^{\prime}-3^{\prime}$ direction), compared with their annealing sites in sequences from representative members of all main AMF taxa and some non-AMF species. Variable sites not represented in any primer mixture are shaded. When no culture identifiers are known, voucher (W) numbers are given behind the species name. (a) Forward primers SSUmAf (mixture SSUmAf1-2) and SSUmCf (mixture SSUmCf1-3). (b) Reverse primers LSUmAr (mixture LSUmAr1-4) and LSUmBr (mixture LSUmBr1-5). (c) Small subunit (SSU) rDNA, internal transcribed spacer (ITS) region and large subunit (LSU) rDNA (5465 bp) of Glomus sp. 'intraradices' DAOM197198 (AFTOL-ID48, other culture/voucher identifiers: MUCL43194, DAOM181602; accession numbers: AY635831, AY997052, DQ273790) showing the binding sites of the newly designed forward and reverse primer mixtures. 
Table 2 Polymerase chain reaction primer mixtures designed for amplification of arbuscular mycorrhizal fungi (AMF)

\begin{tabular}{|c|c|c|c|}
\hline Primer & Nucleotide sequence $\left(5^{\prime}-3^{\prime}\right)$ & nt & Target taxa (mainly) \\
\hline SSUmAf1 & TGG GTA ATC TTT TGA AAC TTY A & 22 & $\begin{array}{l}\text { Acaulosporaceae, Archaeosporaceae, Diversisporaceae, Geosiphonaceae, } \\
\text { Gigasporaceae, Glomeraceae (GIGrA \& GlGrB), Pacisporaceae }\end{array}$ \\
\hline SSUmAf2 & TGG GTA ATC TTR TGA AAC TTC A & 22 & Ambisporaceae, Diversisporaceae, Geosiphonaceae, Paraglomeraceae \\
\hline SSUmAf & Mix SSUmAf1-2 (equimolar) & 22 & All AMF lineages \\
\hline SSUmCf1 & T CGC TCT TCA ACG AGG AAT C & 20 & $\begin{array}{l}\text { Archaeosporaceae (indirect evidence by amplification } \\
\text { of Ambispora fennica), Glomeraceae (mainly GlGrB) }\end{array}$ \\
\hline SSUmCf2 & TAT TGT TCT TCA ACG AGG AAT C & 22 & Paraglomeraceae \\
\hline SSUmCf3 & TAT TGC TCT TNA ACG AGG AAT C & 22 & $\begin{array}{l}\text { Acaulosporaceae, Ambisporaceae, Archaeosporaceae, Diversisporaceae, } \\
\text { Geosiphonaceae, Gigasporaceae, Glomeracea (mainly GlGrA), Pacisporaceae }\end{array}$ \\
\hline SSUmCf & Mix of SSUmCf1-3 (equimolar) & $20-22$ & All AMF lineages \\
\hline LSUmAr1 & GCT CAC ACT CAA ATC TAT CAA A & 22 & Acaulosporaceae \\
\hline LSUmAr2 & GCT CTA ACT CAA TTC TAT CGA T & 22 & Gigasporaceae \\
\hline LSUmAr3 & T GCT CTT ACT CAA ATC TAT CAA A & 23 & $\begin{array}{l}\text { Acaulosporaceae, Diversisporaceae, Geosiphonaceae, Gigasporaceae, } \\
\text { Glomeraceae (GIGrA and GIGrB), Pacisporaceae }\end{array}$ \\
\hline LSUmAr4 & GCT CTT ACT CAA ACC TAT CGA & 21 & Paraglomeraceae \\
\hline LSUmAr & Mix of LSUmAr1-4 (equimolar) & $21-23$ & All AMF lineages \\
\hline LSUmBr1 & DAA CAC TCG CAT ATA TGT TAG A & 22 & Acaulosporaceae, Archaeosporaceae, Glomeraceae (GlGrA), Pacisporaceae \\
\hline LSUmBr2 & AA CAC TCG CAC ACA TGT TAG A & 21 & Acaulosporaceae \\
\hline LSUmBr3 & AA CAC TCG CAT ACA TGT TAG A & 21 & Gigasporaceae \\
\hline LSUmBr4 & AAA CAC TCG CAC ATA TGT TAG A & 22 & $\begin{array}{l}\text { Diversisporaceae, Geosiphonaceae, Glomeraceae, Paraglomeraceae, } \\
\text { (primer sequence was also found in amplicons from Ambispora } \\
\text { fennica and an Archaeospora sp.) }\end{array}$ \\
\hline LSUmBr5 & AA CAC TCG CAT ATA TGC TAG A & 21 & Gigasporaceae, Glomeraceae (GlGrB) \\
\hline LSUmBr & Mix of LSUmBr1-5 (equimolar) & $21-22$ & All AMF lineages \\
\hline
\end{tabular}

Variable sites among primers of an individual mixture are shaded. Target taxa most likely amplified, according to known binding site sequences, are listed. Comments in parentheses indicate that the primer was successfully used to amplify the given taxon, although the binding site sequences were not known.

\section{Results}

\section{Primer design}

Potentially suited binding sites for primers that match AMF sequences but discriminate against plant and non-AM fungal (non-AMF) sequences were identified for the SSU rDNA and LSU rDNA. They were located at positions 1484 and 1532 on the SSU, and at positions 827 and 928 on the LSU rDNA (based on Glomus sp. 'intraradices' DAOM197198 sequence; Fig. 1c). Sequence variation made it impossible to derive individual primer sequences that specifically amplify all Glomeromycota. Thus, a set of four primer mixtures was designed, each targeting one binding site (Table 2, Fig. 1). Certain non- $3^{\prime}$ located mismatches that only slightly altered melting temperature and some mismatches (Glomus etunicatum) that were perhaps caused by low sequence quality were accepted for primer design (Fig. 1). To discriminate against nontarget organisms mismatches at the $3^{\prime}$ end of the primers were included. BLAST searches indicated high specificity of the new primer pairs for AMF.
Glomeromycota sequences that represent the known variability at the primer binding sites are shown in Fig. 1. We aimed to include as many main phylogenetic lineages (Fig. 2) for primer design as possible. However, the following taxa could not be included for LSU rDNA binding sites analyses: Entrophosporaceae, containing only two species lacking sequence data; Archaeosporaceae, because available sequences did not cover the LSU rDNA binding sites; Otospora for which only two nonoverlapping partial SSU rDNA sequences are known; Intraspora, represented by only one SSU rDNA database sequence.

\section{Primer specificity - discrimination against plants}

The discrimination of primer SSUmAf1 against 'lower' plants is weak and exemplified by only one mismatch to database sequences from mosses (Polytrichastrum, Leptodontium and Pogonatum), a liverwort (Trichocoleopsis), a hornwort (Phaeoceros) and a clubmoss (Selaginella). Burmannia, one Phaseoleae sp. and some other plant sequences also showed only one mismatch. All other plant sequences had a minimum 
New

Phytologist

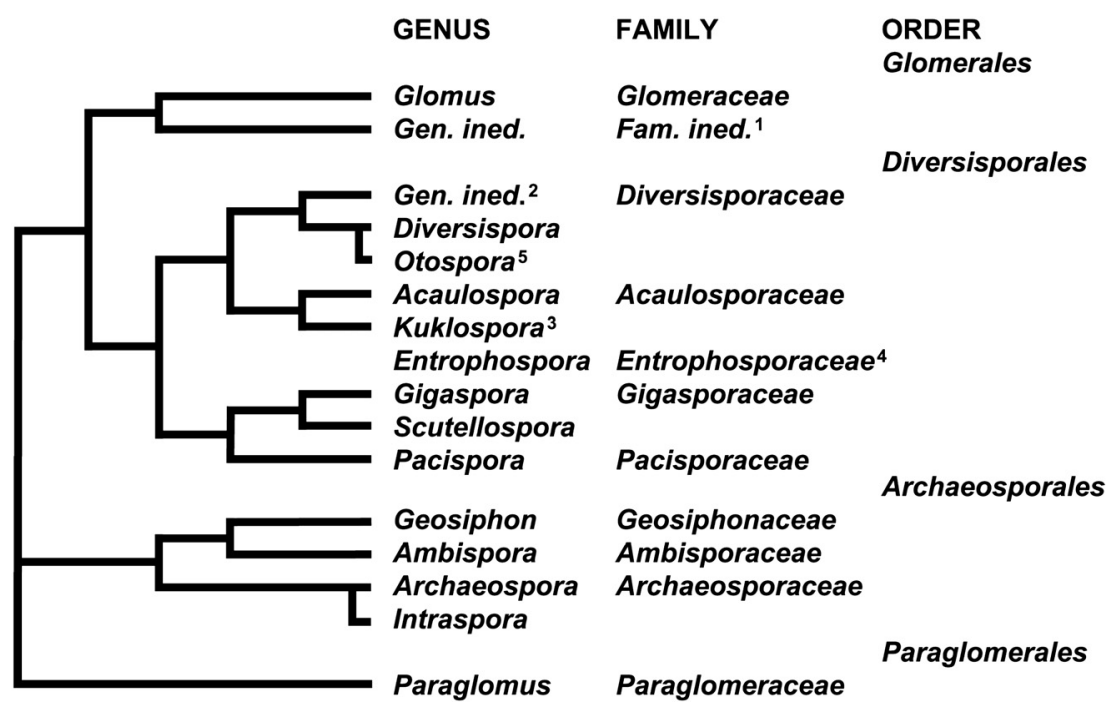

Fig. 2 Phylogenetic relationships of taxa in the Glomeromycota (Schüßler et al., 2001b; Walker et al., 2007). ${ }^{1}$ Species currently named Glomus. One of the main Glomus clades (GlGrA or GlGrB) will represent the Glomeraceae, once the phylogenetic affiliation of the type species of Glomus is known; ${ }^{2}$ contains Glomus fulvum, Gl. megalocarpum, Gl. pulvinatum; ${ }^{3}$ contains Kuklospora colombiana and Ku. kentinensis (formerly Entrophospora) (Sieverding \& Oehl, 2006); ${ }^{4}$ contains one genus with two species, Entrophospora infrequens and En. baltica (Sieverding \& Oehl, 2006), neither of which is phylogenetically characterized; ${ }^{5}$ Otospora (Palenzuela et al., 2008) contains one species, Otospora bareai. Based on small subunit (SSU) rDNA sequences and from a phylogenetic viewpoint this genus is congeneric with Diversispora.

of two mismatches, mainly at the $3^{\prime}$ end of the primer. For SSUmAf2 there were at least two mismatches to all plant sequences, except for a moss (Archidium) with only one mismatch. For the nested forward primer SSUmCf1 a minimum of three mismatches for all plants, except for one environmental Phaseoleae sequence with two mismatches, were observed. SSUmCf2 mismatched at one site to the same Phaseoleae sequence and to liverworts (Radula, Ptilidium and Porella), a hornwort (Anthoceros) and a Taxus species. Other plant sequences displayed a minimum of two mismatches, at least one at the 3' end. For SSUmCf3 the above mentioned sequence of Phaseoleae showed no mismatch, but all other environmental Phaseoleae sequences had at least one mismatch at the $3^{\prime}$ region of the primer. SSUmCf3 also showed only one mismatch for sequences of liverworts (Radula, Ptilidium and Porella), a hornwort (Anthoceros) and for one Liliopsida and Taxus sequence. The remaining вLAST hits displayed two mismatches (several Taxus spp., Pinus and the liverwort Haplomitrium) or more. These results show that for primer mixtures SSUmAf and SSUmCf the discrimination against 'lower' plants is less than for vascular plants.

The LSU rDNA primers had at least two mismatches to plant sequences. The minimum for LSUmAr1 was four mismatches to a Brassica sequence. LSUmAr2 and LSUmAr3 showed four mismatches for a Medicago sequence, in the case of LSUmAr2 this holds also true for Vitis vinifera and Oryza sativa. All other plant sequences showed more mismatches to LSUmAr1, LSUmAr2 and LSUmAr3. For LSUmAr4, which was designed to target Paraglomeraceae, two mismatches were found for Solanum lycopersicum followed by at least three for all other plant sequences. The LSUmBr primer set had a minimum of three mismatches to plant sequences. LSUmBr1 shows more than three mismatches to a Lotus and a Brassica sequence. At least three mismatches (to Ephedra and Larix) occurred for LSUmBr2. There were three mismatches for LSUmBr3 to Selaginella, followed by a liverwort (Trichocoleopsis) and a moss (Bryum) species with four. LSUmBr4 had three mismatches for $V$. vinifera and at least five for all other plant sequences. LSUmBr5 displayed more than four mismatches to any plant sequence.

Primer specificity - discrimination against nontarget fungi

The primer mixture SSUmAf should partly exclude amplification of nontarget fungi, whereas SSUmCf poorly discriminates non-AMF (Fig. 1a). Therefore, the highly specific amplification of AMF $\mathrm{rDNA}$ results mainly from the LSU primers. The primer mixture LSUmAr discriminates well against most non-AMF. An exception is LSUmAr1 with only one mismatch to a group of sequences from uncultured soil fungi (Basidiomycota related) from a Canadian forestry centre. For all other known non-AMF sequences more than four mismatches to LSUmAr1 and three to LSUmAr2 were observed. The primer LSUmAr3 shows only one mismatch with several chytrid sequences. For all other non-AMF LSUmAr3 as well as LSUmAr4 mismatched with at least two sites, mainly at the $3^{\prime}$ end. 
For the (nested) LSUmBr primer mixture the specificity is lower; for example, LSUmBr1 showed no mismatch to some fungi in the more ancestral lineages, namely Endogone lactiflua and Mortierellaceae species, chytrids (Rhizophlyctis and Gonapodya), an uncultured alpine tundra soil fungus and matched one ascomycete sequence (Catenulostroma). For LSUmBr2, no mismatches occurred for sequences of some basidiomycetes (Bulleribasidium, Paullicorticium and Russula) and a zygomycete (Spiromyces minutus). Only one mismatch was observed for sequences including basidiomycetes (Calocera, Calostoma and Ramaria) and ascomycetes (Pyxidiophora, Eremithallus and Phaeococcus), and some other fungi. LSUmBr3 discriminates well against other fungi with at least three mismatches, except for one uncultured soil fungus sequence (Cryptococcus related) that matched completely. The primer LSUmBr4 showed no mismatch to Clavulina griseohumicola and only one to some fungal sequences including ascomycetes (Pyxidiophora and Phaeococcus) and basidiomycetes (Cryptococcus spp.). LSUmBr5 showed only one mismatch to fungal sequences of Mortierella spp., a chytrid (Rhizophlyctis rosea), and some ascomycetes (Schizosaccharomyces, Verrucocladosporium, Passalora and Catenulostroma). In general the LSUmAr primers discriminate better against non-AMF than the nested primers LSUmBr.

Primer efficiency - tests on plasmids and DNA extracts from single spores

The new primer pairs were designed to amplify fragments of approx. $1800 \mathrm{bp}$ (SSUmAf-LSUmAr) and $1500 \mathrm{bp}$ (SSUmCf-LSUmBr). In a first PCR amplification test, samples were chosen to encompass divergent phylogenetic lineages of the Glomeromycota. Cloned rDNA of the AMF species Acaulospora sp. and Kuklospora kentinensis (Acaulosporaceae), Glomus luteum, Gl. intraradices and a Glomus sp. (Glomeraceae), Pacispora scintillans (Pacisporaceae), and Scutellospora heterogama (Gigasporaceae) were used (Table 1, Fig. 3a). In addition, rDNA fragments were amplified from single spore DNA extracts from Geosiphon pyriformis (Geosiphonaceae), Gl. mosseae (Glomeraceae), Gl. eburneum and Gl. versiforme (Diversisporaceae), a Paraglomus sp. (Paraglomeraceae), and a Gigaspora sp. (Gigasporaceae) (not shown). All tested AMF species were successfully amplified with the new primer set.

To test the potential sensitivity of the new primers, the same plasmids as in the first PCR test and additional plasmids carrying inserts of a Gigaspora sp., Gl. versiforme and Ge. pyriformis (Table 1, Fig. 3b) were used. They were diluted over several magnitudes to contain $100 \mathrm{pg}, 10 \mathrm{pg}, 1 \mathrm{pg}$, $100 \mathrm{fg}, 10 \mathrm{fg}, 1 \mathrm{fg}, 0.1 \mathrm{fg}$ and $0.01 \mathrm{fg}$ DNA $\mu^{-1}$. One microlitre was used as template for PCR, whereas the four lowest concentrations correspond with 5000, 500, 50 and 5 plasmid molecules in the $20 \mu \mathrm{l}$ PCR reaction volume. Both primer sets were tested independently. Differences between specificity of the first and nested primer sets were observed for Pacispora,
Kuklospora, and Geosiphon. For Pacispora the PCR with SSUmAf and LSUmAr yielded, even with the lowest DNA concentration, a clearly visible band, whereas PCR with SSUmCf and LSUmBr yielded weaker bands, indicating lower specificity. Weaker bands were also observed for the rDNA amplification of $K u$. kentinesis with the primers SSUmCf-LSUmBr and for Ge. pyriformis with SSUmAfLSUmAr. However, these differences may be within the error-range of photometric DNA concentration measurement of the plasmid stock-solutions. Only slight or no differences occurred between the other plasmid templates, when comparing the intensity of the bands, except for Gl. versiforme. Here, clearly visible bands were only found for the higher DNA concentrations, but with the same pattern for both primer pairs. However, this was an artefact caused by low template DNA integrity. Later dilution series with fresh plasmid preparations (also from other Diversisporaceae) were indistinguishable from those obtained with the other species shown in Fig. 3(b). For Ku. kentinensis no amplicon could be observed after PCR with the primers SSUmAf-LSUmAr, because the cloned fragment was originally amplified with the nested primers. The plasmid therefore serves only as a negative control in the first PCR and as positive control for the PCR with the nested primers.

Primer efficiency - tests on field and nursery sampled roots and spores

To test whether the newly designed primers discriminate against nonglomeromycotan fungi and plants, we used them on DNA extracted from single spores from pot cultures, environmental root samples, and root samples from a tree nursery, in nested PCR approaches. We observed not a single non-AMF contaminant sequence in the 12 environmental root and 40 single spore samples processed. The discrimination against plants was tested with DNA extracts from roots of potential AMF hosts. The species collected comprised Poa cf. annua, Ranunculus cf. repens, and Rumex acetosella from a field site in Germany, and Podocarpus cf. macrostaqui, Heliocarpus americanus and Cedrela montana tree seedlings from a tree nursery in Ecuador. From a large number of nested PCR approaches, on just one occasion, three identical clones carrying a plant sequence $(R$. acetosella) were obtained. The Rumex related database sequence (AF189730, 630 bp) covers the ITS region, but not the binding sites for the nested primers. The new primers were also used successfully on DNA extractions from single AMF spores from pot cultures and a root organ culture (ROC). This demonstrates PCR amplification with a broad phylogenetic coverage of AMF, while efficiently discriminating against non-AMF and plants (Table 3).

The results show that the new primers are suitable to amplify DNA from members of the whole Glomeromycota and can be used for species level analyses of AMF communities in the field. 
New

Phytologist

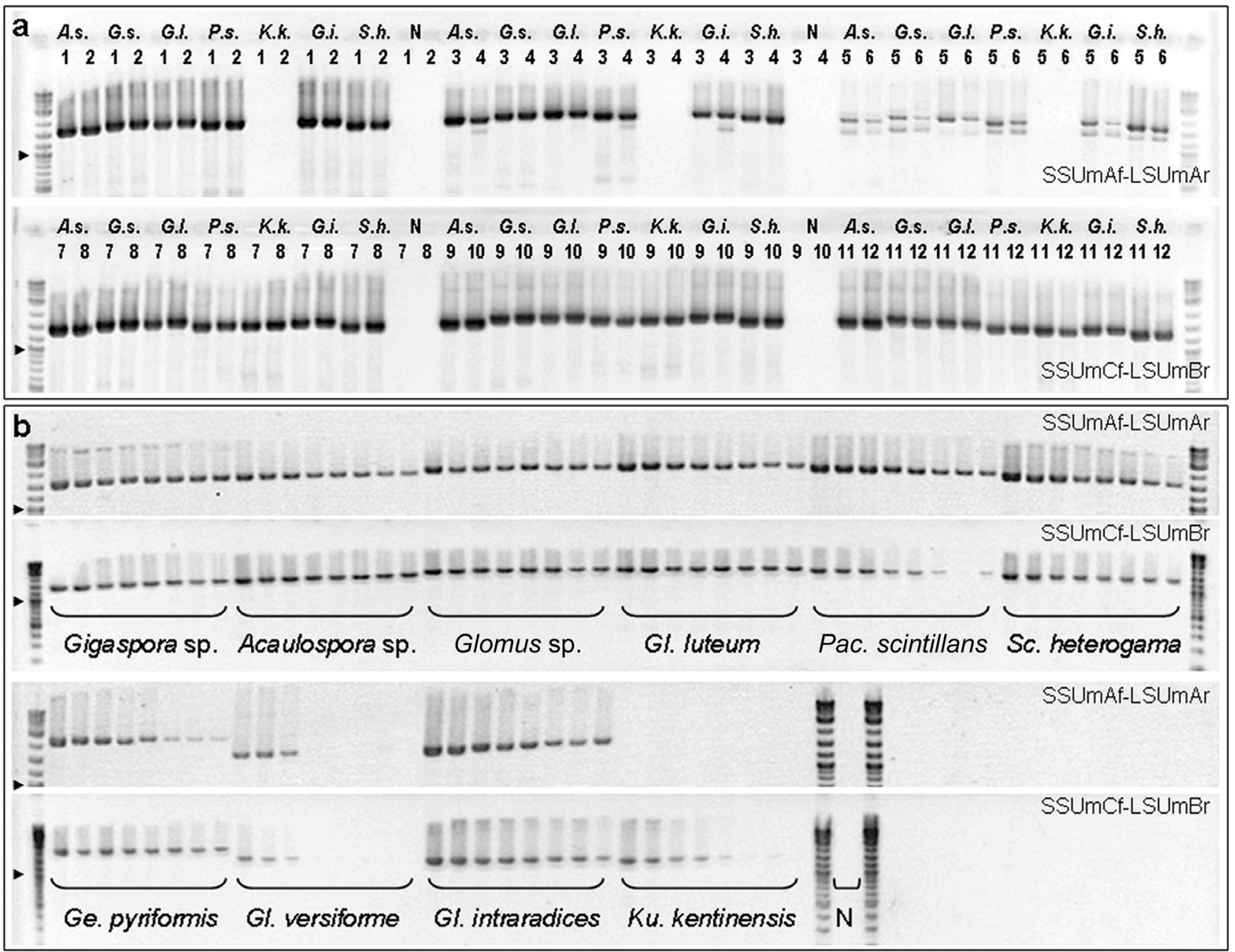

Fig. 3 Polymerase chain reaction amplification with primers SSUmAf-LSUmAr (approx. 1800 bp amplicons) and SSUmCf-LSUmBr (approx. 1500 bp amplicons). (a) PCR on cloned DNA fragments, using different annealing temperatures and a template concentration of $1 \mathrm{ng} \mu^{-1}$. A.s., Acaulospora sp.; G.s., Glomus sp.; G.I., Glomus luteum; P.s., Pacispora scintillans; K. K., Kuklospora kentinensis; G.i., Glomus intraradices; S.h., Scutellospora heterogama; $\mathrm{N}$, negative control. Annealing temperatures: $1,55^{\circ} \mathrm{C} ; 2,55.7^{\circ} \mathrm{C} ; 3,57.8^{\circ} \mathrm{C} ; 4,60.5^{\circ} \mathrm{C} ; 5,63.1^{\circ} \mathrm{C} ; 6,65^{\circ} \mathrm{C} ; 7,55.2^{\circ} \mathrm{C}$; $8,56.6^{\circ} \mathrm{C} ; 9,59.1^{\circ} \mathrm{C} ; 10,61.8^{\circ} \mathrm{C} ; 11,64.2^{\circ} \mathrm{C} ; 12,65.5^{\circ} \mathrm{C}$. (b) PCR using $1 \mu \mathrm{l}$ of a 10 -fold plasmid dilution $\left(100 \mathrm{pg}-0.01 \mathrm{fg} \mu \mathrm{l}^{-1}\right)$ as template, corresponding to $5 \times 10^{7}$ to 5 plasmid molecules in $20 \mu \mathrm{l} \mathrm{PCR}$ reaction volume. Annealing temperatures: SSUmAf-LSUmAr $60^{\circ} \mathrm{C} ; \mathrm{SSUmCf}-\mathrm{LSUmBr}$ $63^{\circ} \mathrm{C}$. N, negative control; Marker, NEB 2-Log DNA Ladder (bp: 10 000, 8000, 6000, 5000, 4000, 3000, 2000, 1500, 1200, 1000 (arrowhead), $900,800,700,600,500,400,300,200,100)$.

\section{Discussion}

There have been numerous efforts to design PCR primers generally applicable for detection of the whole group of AMF (Simon et al., 1992; Helgason et al., 1998), but later studies showed that they do not amplify DNA of all Glomeromycota or they also amplify ascomycetes, basidiomycetes or plant DNA (Clapp et al., 1995, 1999; Helgason et al., 1999). Other primers were successfully used for certain groups of the Glomeromycota (Kjøller \& Rosendahl, 2000; Redecker, 2000; Turnau et al., 2001; Wubet et al., 2003, 2006; Gamper \& Leuchtmann, 2007).

Many of the approaches require different primer pairs and independent PCR attempts for distinct target taxa.
Comparison of such studies can be difficult since the distinct primer binding sites may behave very different in PCR and do not allow semiquantitative approaches. A single primer set for PCR amplification that covers all groups of the Glomeromycota and allows the identification of AMF at the species level was not available.

We have chosen the strategy of mixed primer sets to cover the defined sequence variability, instead of using fully degenerated primers. This reduces the degree of degeneration and results in a higher ratio of efficiently binding primers. The approach also allows adjustment of the concentrations of individual primers in future attempts. At the beginning of the study we speculated that the exonuclease activity of the proofreading DNA polymerase used could hamper discrimination 
Table 3 PCR amplification with the new primer pairs; DNA extracted from roots or spores

\begin{tabular}{|c|c|c|c|c|}
\hline Environmental samples & $\begin{array}{l}\text { Sample } \\
\text { or culture }\end{array}$ & $\begin{array}{l}\text { First } \\
\text { PCR }\end{array}$ & $\begin{array}{l}\text { Nested } \\
\text { PCR }\end{array}$ & Clones sequenced, most likely genus (BLAST hits for full length and partial sequences) \\
\hline Cedrela montana roots (tree nursery pot) & N1 & - & + & pCK011.1-7 Ambispora (uncultured Archaeospora LSU) \\
\hline
\end{tabular}

N3

Cedrela montana roots (tree nursery pot)

Heliocarpus americanus roots (tree nursery pot)

Podocarpus cf. macrostaqui root without nodules PO (seedling from forest)
Podocarpus cf. macrostaqui root nodules only
Podocarpus cf. macrostaqui root with nodules (seedling from forest)

Podocarpus cf. macrostaqui root nodules only (seedling from forest) (seedling from forest)

Ranunculus repens roots (field sample) Ranunculus repens roots (field sample) Ranunculus repens roots (field sample) Ranunculus repens roots (field sample)

Poa annua roots (field sample) Poa annua roots (field sample) Plantago lanceolata roots (pot culture, inoculated with C. montana roots)

Plantago lanceolata roots (pot culture, inoculated with $H$. americanus roots) AMF ss (ss pot culture)

P1

AMF ss (ss pot culture)

AMF ss (ss pot culture)

AMF ss (ss pot culture)

AMF ss (ss pot culture)

AMF ss morphotype 1 (ms pot culture)

AMF ss morphotype 2 (ms pot culture)

Glomus intraradices spore cluster (ROC)
MUCL43206 LSU); nested PCR: pCK016.1-3, pCK017.1 Glomus (uncultured AMF clone Glom3524.1 SSU; symbiont of M. foliacea SSU, ITS, LSU; Glomus sp. MUCL43206 LSU, MUCL43194, LSU; Glomus sp. 'intraradices' AFTOL-ID845 LSU)

+ (ns) pCK010.1,2 Gigaspora and/or Scutellospora (uncultured Gigasporaceae clone S2R2 SSU, ITS, LSU; Gi. rosea SSU, ITS, LSU; Sc. heterogama AFTOL-ID138 LSU)

pCK012.2-4 Archaeospora and Glomus (Ar. trappei NB112 SSU, ITS, LSU; Glomus sp. 'intraradices' AFTOL-ID845 LSU)

(ns) pCK018.1 Acaulospora (Ac. alpina clone 1060/33 SSU, ITS; uncultured Acaulospora clone:

A3-68-c LSU)

+(ns) pCK020.1-13 Acaulospora (Ac. alpina clone 1060/33 SSU, ITS; Acaulospora clone: A3-68-c LSU)

pCK006.1,2 Glomus (GI. diaphanum clone 3.3 SSU, ITS, LSU; GI. coronatum BEG28 LSU; symbiont of $M$. foliacea SSU, ITS1; uncultured Glomus LSU)

pCK007.1,3,4 Glomus (Glomus sp. 0171 SSU, ITS; uncultured Glomus clone K7-10 SSU, ITS; Glomus clone K31-1 LSU; uncultured Glomus clone 1298-21 SSU, ITS, LSU; uncultured glomeromycete 2-09 LSU); pCK007.5,6 pCK008.1,3-7 Glomus (uncultured Glomus clone S1R2 + S2R1/2 SSU, ITS, LSU; Glomus sp. MUCL43206 LSU, MUCL43207 LSU; symbiont of M. foliacea SSU, ITS1; uncultured Glomus clone: A10-28 LSU) pMK078.1-3 Acaulospora (uncultured Acaulospora SSU; LSU)

pMK083.2,3,5 Acaulospora (Acaulospora sp. ZS2005 SSU, ITS; Ac. paulinae clone 2.2 LSU )

pMK077.1-5 Glomus (uncultured Glomus clones S1R2 + 850-23 SSU, ITS; uncultured Glomus clone H5-2 LSU) pMK080.1-5 Diversispora (Gl. aurantium SSU, ITS, LSU; Gl. versiforme BEG47 LSU, uncultured Glomus LSU); pMK080.6.7 Glomus (uncultured Glomus clone S1R2 SSU, ITS; uncultured Glomus LSU) pMK082.1,4,6,9-17 Acaulospora (uncultured Acaulospora SSU, ITS, LSU; uncultured Acaulospora LSU) pMK081.1,3-5 Acaulospora (uncultured Acaulospora SSU, ITS, LSU; Ac. laevis BEG13 LSU)

pCK024.1,3,4 Glomus (uncultured Glomus clone S2R2 SSU, ITS, LSU; uncultured Glomus clone S1R2 SSU,

ITS, LSU; Glomus sp. 'intraradices' AFTOL-ID845 LSU, Glomus sp. MUCL43206 LSU; Glomus sp. MUCL43203 LSU)

pCK025.1-4 Glomus (uncultured Glomus clone S1R2 SSU, ITS, LSU; Glomus sp. MUCL43203 LSU)

Att 1456-1 -

Att 1449-5 - $\quad+\quad$ pCK022.1-3 Diversispora (Gl. aurantium SSU, LSU; Gl. versiforme BEG47 LSU)

Att 1450-1 - + $\quad+\quad$ pCK023.1-4 Acaulospora (Ac. colossica clones 15.1+15.4 SSU, ITS, LSU; uncultured Acaulospora clone H1-1 LSU)

Att 1456-7 - $\quad+\quad$ pCK026.1,2-6 Archaeospora (uncultured Archaeospora clone 1400-71 SSU, ITS, clone R8-37 LSU; Ar. trappei SSU, ITS, LSU)

pCK027.1-3 Glomus (Gl. claroideum clone 57.10 SSU, ITS, LSU)

pCK028.2-5.7-12 Glomus (Gl. claroideum clone 57.10 SSU, ITS, LSU)

Att $1456-11-$

Att $1451-6++$

first PCR: PCK029.1 Glomus (GI claroideum clone 57.10 SSU, ITS, LSU); nested PCR: pCK030.1-6

Glomus (uncultured Glomus clone Pa127 SSU, ITS, LSU; uncultured Glomus clone S1R2 SSU, ITS, LSU;

Gl. etunicatum LSU; Glomus sp. MUCL43203 LSU)

Att 1451-6 - + pCK031.1,2 Gigaspora (Gi. rosea clone Gr8.2 SSU, ITS, LSU; Sc. heterogama AFTOL-ID138 LSU)

Att 4-64 - + $\quad+\quad$ pHS099.3,6,8,11,14,16,25,32,36,40,41,47 Glomus (uncultured Glomus clone S2R2 SSU, ITS, LSU; Glomus sp. (from FL208) MUCL43203 LSU, Glomus sp. MUCL43206 LSU, MUCL43207 LSU, Glomus sp. 'intraradices' AFTOL-ID845 LSU)

First PCR, SSUmAf-LSUmAr; nested PCR, SSUmCf-LSUmBr. PCR reactions are given as positive when a PCR product of the expected size was visible. The closest BLAST hits are shown for the first and/or nested PCR derived sequences. Att, culture attempt; ITS, internal transcribed spacer; LSU, large subunit; ms, multi spore; ns, not sequenced; ROC, root organ culture; sS, single spore; SSU, small subunit. 
by terminal $3^{\prime}$ primer mismatches, but no such problems were detected.

\section{Primer specificity}

The primers designed show some mismatches to AMF sequences at the $5^{\prime}$ end (Fig. 1), which do not hinder PCR amplification (Bru et al., 2008). Primer mismatches such as $\mathrm{C}-\mathrm{T}, \mathrm{T}-\mathrm{C}$ and $\mathrm{T}-\mathrm{G}$ do not impair amplification strongly even when situated at the $3^{\prime}$ end of the primer (Kwok et al., 1990). The forward primers SSUmAf as well as the reverse primers LSUmBr mismatched once with Ge. pyriformis, but did not hamper amplification. The LSU rDNA primers show sufficient sequence similarity to the target organisms, as the mismatches are either in the middle or at the $5^{\prime}$ end. LSUmAr primers displayed individual mismatches to sequences of Scutellospora spp., Gl. etunicatum, and one Acaulospora sp. (Fig. 1). Nevertheless, DNA of these species was successfully amplified from environmental samples and in the primer efficiency test (Fig. 3). Ambisporaceae and Archaeosporaceae species could not be included in the design of the LSU primers, but Ambispora fennica DNA from a single spore extraction (not shown) and Archaeospora sp. from single spores and roots of an Ecuadorian tree seedling (Table 3) could be amplified with the new primers, indicating well matching binding sites. Sequences from Otospora (Diversisporaceae; Palenzuela et al., 2008; matching the SSU primers), Intraspora (closely related to Archaeospora), and Entrophospora (sensu Oehl \& Sieverd.; with two species only) are either not or only partly characterized and therefore could not be included in several aspects of primer design. Otospora and Intraspora are very closely related to their sister genera (maybe congeneric), so the lack of LSU rDNA sequences was therefore interpreted as a minor limitation.

We could successfully amplify all AMF tested with the new primers, but because of the lower number of LSU rDNA sequences available for AMF an optimization of the LSU primers might be reasonable in future. The discrimination against non-AMF and plant DNA is excellent, as shown on DNA extracts from environmental samples and spores from pot cultures. To discriminate against non-AMF, LSUmAr works much better than the nested primers LSUmBr. The cloned plant (Rumex) rDNA fragment that originated from root material can be interpreted as an 'outlier'. The primer binding sites could not be investigated for Rumex, because of lacking sequence coverage. It should be indicated in this context that we did not use HPLC-purified primers. This means a certain fraction of primers may not be fully synthesized and could result in less specific amplification. All plasmids used in the plasmid test carried inserts that were originally amplified with SSUmAf. Therefore, the efficiency of this primer could not be validated, but because of the high number of SSU rDNA sequences known, it can be stated that the binding sites in the cloned fragments correspond to a realistic situation. The efficient amplification from spore DNA extracts was, moreover, confirmed in numerous former PCR.

\section{Advantages over previously used PCR primer sets}

In most former field studies SSU rDNA phylotypes were analysed for molecular detection of AMF. However, this region does not allow species resolution and each defined phylotype, irrespective of the used distance threshold value or phylogenetic analysis method, may hide a number of species (Walker et al., 2007). In general, the LSU rDNA region allows species resolution, and thus the LSU primer pair FLR3-FLR4 (Gollotte et al., 2004) was used for specieslevel community analyses. However, in particular, FLR4 is not phylogenetically inclusive (Gamper et al., 2009) and discriminates many lineages, including Diversisporales, Archaeosporales and Paraglomerales, which results in a strong bias in community analyses towards the Glomeraceae. The primer FLR3 binds to DNA of many nontarget fungi as it shows no mismatch to $>1300$ basidiomycete sequences and some ascomycete sequences in the public databases. Such problems obviously may bias tRFLP community analyses (Mummey \& Rillig, 2008) and seminested PCR approaches (Pivato et al., 2007) using FLR3 and/or FLR4. The primer pair SSUGlom1-LSUGlom1 (Renker et al., 2003) amplifies many non-AMF and plants. Combined with the primers ITS5-ITS4 in a nested PCR (Hempel et al., 2007) this resulted in a $5.8 \mathrm{~S}$ rDNA phylogenetic analysis, which resolved only the genus level. Even the ITS region does not always resolve species for AMF (Stockinger et al., 2009).

In some cases, species-specific detection tools are available for individual species or certain well-defined and closely related species. The three closely related AM fungi Gl. mosseae, Gl. caledonium and Gl. geosporum were detected by using LSU primers in field studies (Stukenbrock \& Rosendahl, 2005; Rosendahl \& Matzen, 2008), but these primers were designed to only amplify subgroups or certain taxa in the Glomeromycota. For the well-studied Gl. intraradices related AMF (e.g. DAOM197198), which are, however, not conspecific with Gl. intraradices (Stockinger et al. 2009), microsatellite markers are available for their detection in the field (Croll et al., 2008; Mathimaran et al., 2008). Some mtLSU region markers were also studied (Börstler et al., 2008), but because of the high length variation observed (1070-3935 bp) and the difficulty in amplifying this region it is not very promising for community analyses. Thus, such markers cannot be used for general AMF community analyses.

The new primers described in the present study were used to amplify efficiently and specifically target rDNA from environmental samples of the main phylogenetic groups in the Glomeromycota. For the first time, this will allow molecular ecological studies covering all AMF lineages to be carried out with only one primer set. Furthermore, the long sequences allow robust phylogenetic analyses and species level resolution 
by inclusion of the variable ITS and LSU rDNA region (Walker et al., 2007; Gamper et al., 2009; Stockinger et al. 2009), whereas formerly used primers mainly amplified rDNA fragments of up to 800 bp (Helgason et al., 1999; Redecker, 2000; Lee et al., 2008).

\section{Potential application as DNA barcoding primers}

The new primers are suited to amplify the most likely primary DNA barcode region for fungi, the ITS region (already online at the Barcode of Life Data Systems (BOLD) website; www.barcodinglife.org). In general 'barcode primers' should amplify short fragments and for the ITS region the amplicons generated by our primers are in fact too long. However, the main criterion for DNA barcodes is the resolution at species level. Since for Glomeromycota this is difficult or impossible to achieve with the ITS region only (Stockinger $e t$ al., 2009), the inclusion of the $5^{\prime}$ LSU rDNA fragment is strongly recommended. Our new primer set (SSUmAf, SSUmCf, LSUmAr and LSUmBr) appears to be well suited as barcoding primers for Glomeromycota. The primers will be helpful for the molecular characterization of AMF, including species descriptions (Gamper et al., 2009), resulting in a sequence database that allows the design of further primers for the detection of AMF from field samples. LSUmAr and LSUmBr, located approximately at positions $930-950$ and $830-850$ on the LSU rRNA gene, may be used in combination with new forward LSU primers for amplification of fragments within the variable D1/D2 LSU regions. Based on such amplicons, deep sequencing approaches with the now feasible longer reads of the new 454 FLX-titanium chemistry will allow species level detection of the 'unknown' AMF community, in future molecular ecological studies.

\section{Acknowledgements}

The grants for M.K., C.K. and A.S. were financed by the German Research Foundation (DFG). The grant for H.S. was funded by the Marie Curie Early Stage Research Training Fellowship of the European Community's Sixth framework Programme (MEST-CT-2005-021016).

\section{References}

Allen GC, Flores-Vergara MA, Krasnyanski S, Kumar S, Thompson WF. 2006. A modified protocol for rapid DNA isolation from plant tissues using cetyltrimethylammonium bromide. Nature Protocols 1: 2320-2325.

Aroca R, Porcel R, Ruiz-Lozano JM. 2007. How does arbuscular mycorrhizal symbiosis regulate root hydraulic properties and plasma membrane aquaporins in Phaseolus vulgaris under drought, cold or salinity stresses? New Phytologist 173: 808-816.

Börstler B, Raab PA, Thiery O, Morton JB, Redecker D. 2008. Genetic diversity of the arbuscular mycorrhizal fungus Glomus intraradices as determined by mitochondrial large subunit rRNA gene sequences is considerably higher than previously expected. New Phytologist 180 : 452-465.
Brody JR, Kern SE. 2004. Sodium boric acid: a Tris-free, cooler conductive medium for DNA electrophoresis. Biotechniques 36: 214-215.

Bru D, Martin-Laurent F, Philippot L. 2008. Quantification of the detrimental effect of a single primer-template mismatch by real-time PCR using the $16 \mathrm{~S}$ rRNA gene as an example. Applied and Environmental Microbiology 74: 1660-1663.

Clapp JP, Fitter AH, Young JPW. 1999. Ribosomal small subunit sequence variation within spores of an arbuscular mycorrhizal fungus, Scutellospora sp. Molecular Ecology 8: 915-922.

Clapp JP, Young JPW, Merryweather JW, Fitter AH. 1995. Diversity of fungal symbionts in arbuscular mycorrhizas from a natural community. New Phytologist 130: 259-265.

Croll D, Wille L, Gamper HA, Mathimaran N, Lammers PJ, Corradi N, Sanders IR. 2008. Genetic diversity and host plant preferences revealed by simple sequence repeat and mitochondrial markers in a population of the arbuscular mycorrhizal fungus Glomus intraradices. New Phytologist 178: 672-687.

De la Pena E, Rodriguez Echeverria S, van der Putten WH, Freitas H, Moens M. 2006. Mechanism of control of root-feeding nematodes by mycorrhizal fungi in the dune grass Ammophila arenaria. New Phytologist 169: 829-840.

Gamper H, Leuchtmann A. 2007. Taxon-specific PCR primers to detect two inconspicuous arbuscular mycorrhizal fungi from temperate agricultural grassland. Mycorrhiza 17: 145-152.

Gamper H, Walker C, Schüßler A. 2009. Diversispora celata sp. nov.: molecular ecology and phylotaxonomy of an inconspicuous arbuscular mycorrhizal fungus. New Phytologist 182: 495-506.

Gollotte A, van Tuinen D, Atkinson D. 2004. Diversity of arbuscular mycorrhizal fungi colonising roots of the grass species Agrostis capillaris and Lolium perenne in a field experiment. Mycorrhiza 14: 111-117.

Helgason T, Daniell TJ, Husband R, Fitter AH, Young JPW. 1998. Ploughing up the wood-wide web? Nature 394: 431.

Helgason T, Fitter AH, Young JPW. 1999. Molecular diversity of arbuscular mycorrhizal fungi colonising Hyacinthoides nonscripta (bluebell) in a seminatural woodland. Molecular Ecology 8: 659-666.

Hempel S, Renker C, Buscot F. 2007. Differences in the species composition of arbuscular mycorrhizal fungi in spore, root and soil communities in a grassland ecosystem. Environmental Microbiology 9: 1930-1938.

Jansa J, Mozafar A, Kuhn G, Anken T, Ruh R, Sanders IR, Frossard E. 2003. Soil tillage affects the community structure of mycorrhizal fungi in maize roots. Ecological Applications 13: 1164-1176.

Kjøller R, Rosendahl S. 2000. Detection of arbuscular mycorrhizal fungi (Glomales) in roots by nested PCR and SSCP (single stranded conformation polymorphism). Plant and Soil 226: 189-196.

Kottke I, Haug I, Setaro S, Suárez JP, Weiß M, Preußing M, Nebel M, Oberwinkler F. 2008. Guilds of mycorrhizal fungi and their relation to trees, ericads, orchids and liverworts in a neotropical mountain rain forest. Basic and Applied Ecology 9: 13-23.

Kwok S, Kellogg DE, McKinney N, Spasic D, Goda L, Levenson C, Sninsky JJ. 1990. Effects of primer-template mismatches on the polymerase chain reaction: human immunodeficiency virus type 1 model studies. Nucleic Acids Research 18: 999-1005.

Lee J, Lee S, Young JPW. 2008. Improved PCR primers for the detection and identification of arbuscular mycorrhizal fungi. FEMS Microbiology Ecology 65: 339-349.

Ludwig W, Strunk O, Westram R, Richter L, Meier H, Yadhukumar, Buchner A, Lai T, Steppi S, Jobb G et al. 2004. ARB: a software environment for sequence data. Nucleic Acids Research 32: 1363-1371.

Mathimaran N, Falquet L, Ineichen K, Picard C, Redecker D, Boller T, Wiemken A. 2008. Microsatellites for disentangling underground networks: Strain-specific identification of Glomus intraradices, an arbuscular mycorrhizal fungus. Fungal Genetics and Biology 45: 812-817.

Michelson A, Rosendahl S. 1990. The effect of VA mycorrhizal fungi, phosphorus and drought stress on the growth of Acacia nilotica and Leucaena leucocephala seedlings. Plant and Soil 124: 7-13. 
New

Mummey DL, Rillig MC. 2008. Spatial characterization of arbuscular mycorrhizal fungal molecular diversity at the submetre scale in a temperate grassland. FEMS Microbiology Ecology 64: 260-270.

Oehl F, Sieverding E, Ineichen K, Ris EA, Boller T, Wiemken A. 2005. Community structure of arbuscular mycorrhizal fungi at different soil depths in extensively and intensively managed agroecosystems. New Phytologist 165: 273-283.

Öpik M, Moora M, Zobel M, Saks Ü, Wheatley R, Wright F, Daniell T. 2008. High diversity of arbuscular mycorrhizal fungi in a boreal herb-rich coniferous forest. New Phytologist 179: 867-876.

Palenzuela J, Ferrol N, Boller T, Azcon-Aguilar C, Oehl F. 2008. Otospora bareai, a new fungal species in the Glomeromycetes from a dolomitic shrub land in Sierra de Baza National Park (Granada, Spain). Mycologia 100: 296-305.

Parniske M. 2008. Arbuscular mycorrhiza: the mother of plant root endosymbioses. Nature Reviews Microbiology 6: 763-775.

Pivato B, Mazurier S, Lemanceau P, Siblot S, Berta G, Mougel C, van Tuinen D. 2007. Medicago species affect the community composition of arbuscular mycorrhizal fungi associated with roots. New Phytologist 176: 197-210.

Pruesse E, Quast C, Knittel K, Fuchs BM, Ludwig W, Peplies J, Glöckner FO. 2007. SILVA: a comprehensive online resource for quality checked and aligned ribosomal RNA sequence data compatible with ARB. Nucleic Acids Research 35: 7188-7196.

Redecker D. 2000. Specific PCR primers to identify arbuscular mycorrhizal fungi within colonized roots. Mycorrhiza 10: 73-80.

Renker C, Heinrichs J, Kaldorf M, Buscot F. 2003. Combining nested PCR and restriction digest of the internal transcribed spacer region to characterize arbuscular mycorrhizal fungi on roots from the field. Mycorrhiza 13: 191-198.

Rosendahl S, Matzen HB. 2008. Genetic structure of arbuscular mycorrhizal populations in fallow and cultivated soils. New Phytologist 179: 11541161.

Schüßler A, Gehrig H, Schwarzott D, Walker C. 2001a. Analysis of partial Glomales SSU rRNA gene sequences: implications for primer design and phylogeny. Mycological Research 105: 5-15.

Schüßler A, Krüger M, Walker C. 2009. Phylogeny, evolution and origin of the 'plant-symbiotic' phylum Glomeromycota. In: Wöstemeyer J, Martin W, eds. The Mycota XIV - evolution of fungi and fungal-like organisms. Berlin, Germany: Springer-Verlag, in press.

Schüßler A, Schwarzott D, Walker C. 2001b. A new fungal phylum, the Glomeromycota: phylogeny and evolution. Mycological Research 105: 1413-1421.

Schwarzott D, Schüßler A. 2001. A simple and reliable method for SSU rRNA gene DNA extraction, amplification, and cloning from single AM fungal spores. Mycorrhiza 10: 203-207.
Sieverding E, Oehl F. 2006. Revision of Entrophospora and description of Kuklospora and Intraspora, two new genera in the arbuscular mycorrhizal Glomeromycetes. Journal of Applied Botany and Food Quality 80: 69-81.

Simon L, Lalonde M, Bruns TD. 1992. Specific amplification of 18 S fungal ribosomal genes from vesicular-arbuscular endomycorrhizal fungi colonizing roots. Applied Environmental Microbiology 58: 291-295.

Smith SE, Read DJ. 2008. Mycorrhizal symbiosis. Cambridge, UK: Academic Press.

Stockinger H, Walker C, Schüßler A. 2009. 'Glomus intraradices DAOM197198', a model fungus in arbuscular mycorrhiza research, is not Glomus intraradices. New Phytologist, in press.

Stukenbrock EH, Rosendahl S. 2005. Development and amplification of multiple co-dominant genetic markers from single spores of arbuscular mycorrhizal fungi by nested multiplex PCR. Fungal Genetics and Biology 42: 73-80.

Turnau K, Ryszka P, Gianinazzi-Pearson V, van Tuinen D. 2001. Identification of arbuscular mycorrhizal fungi in soils and roots of plants colonizing zinc wastes in southern Poland. Mycorrhiza 10: 169-174.

Van der Heijden MGA, Bardgett RD, van Straalen NM. 2008. The unseen majority: soil microbes as drivers of plant diversity and productivity in terrestrial ecosystems. Ecology Letters 11: 296-310.

Van der Heijden MGA, Klironomos JN, Ursic M, Moutoglis P, Streitwolf-Engel R, Boller T, Wiemken A, Sanders IR. 1998. Mycorrhizal fungal diversity determines plant biodiversity, ecosystem variability and productivity. Nature 396: 69-72.

Vigo C, Norman JR, Hooker JE. 2000. Biocontrol of the pathogen Phytophthora parasitica by arbuscular mycorrhizal fungi is a consequence of effects on infection loci. Plant Pathology 49: 509-514.

Walker C, Schüßler A. 2004. Nomenclatural clarifications and new taxa in the Glomeromycota. Mycological Research 108: 981-982.

Walker C, Vestberg M, Demircik F, Stockinger H, Saito M, Sawaki H, Nishmura I, Schüßler A. 2007. Molecular phylogeny and new taxa in the Archaeosporales (Glomeromycota): Ambispora fennica gen. sp nov., Ambisporaceae fam. nov., and emendation of Archaeospora and Archaeosporaceae. Mycological Research 111: 137-153.

Wang YY, Vestberg M, Walker C, Hurme T, Zhang XP, Lindström K. 2008. Diversity and infectivity of arbuscular mycorrhizal fungi in agricultural soils of the Sichuan Province of mainland China. Mycorrhiza 18: 59-68.

Wubet T, Weiß M, Kottke I, Oberwinkler F. 2003. Morphology and molecular diversity of arbuscular mycorrhizal fungi in wild and cultivated yew (Taxus baccata). The Canadian Journal of Botany 81: 255-266.

Wubet T, Weiß M, Kottke I, Teketay D, Oberwinkler F. 2006. Phylogenetic analysis of nuclear small subunit rDNA sequences suggests that the endangered African Pencil Cedar, Juniperus procera, is associated with distinct members of Glomeraceae. Mycological Research 110: 1059-1069. 
DNA-based species level detection of Glomeromycota: one PCR primer set for all arbuscular mycorrhizal fungi. 


\section{6 'Glomus intraradices DAOM197198', a model fungus in arbuscular mycorrhiza research, is not Glomus intraradices}

This chapter is identical to the publication:

Stockinger H, Walker C, Schüßler A. 2009. 'Glomus intraradices DAOM197198', a model fungus in arbuscular mycorrhiza research, is not Glomus intraradices. New Phytologist 183: 1176-1187.

The definitive version is available at http://www.blackwell-synergy.com/loi/nph 


\title{
'Glomus intraradices DAOM197198', a model fungus in arbuscular mycorrhiza research, is not Glomus intraradices
}

\author{
Herbert Stockinger ${ }^{1}$, Christopher Walker ${ }^{2}$ and Arthur Schüßler ${ }^{1}$ \\ ${ }^{1}$ LMU Munich, Dept. Biology I, Genetics, Großhaderner Str. 4, D-82152 Planegg-Martinsried, Germany; ${ }^{2}$ Royal Botanic Garden Edinburgh, 20A Inverleith \\ Row, Edinburgh EH3 5LR, UK
}

\section{Summary}

Author for correspondence: Arthur Schüßler

Tel: +49 218074730

Email: arthur.schuessler@lmu.de

Received: 18 February 2009

Accepted: 1 April 2009

New Phytologist (2009) 183: 1176-1187 doi: 10.1111/j.1469-8137.2009.02874.x

Key words: DNA barcoding, Glomus intraradices, Glomus irregulare, internal transcribed spacer (ITS) region rDNA, intraspecific rDNA variability, large subunit (LSU) rDNA, molecular phylogeny, species definition.
- Glomus intraradices-like fungi are the most intensely studied arbuscular mycorrhizal (AM) fungi. However, there are several AM fungi named as $G$. intraradices that may not be conspecific. Therefore, the hypothesis was tested that DAOM197198 and similar AM fungi, such as BEG195, correspond to the type of G. intraradices.

- The G. intraradices isotype material, a descendant (INVAM FL208) of the type culture, and a morphologically corresponding AM fungus (MUCL49410) isolated from the type locality were studied and compared with several cultures of DAOM197198 and BEG195.

- Phylogenetic analyses of the partial small subunit (SSU), complete internal transcribed spacer (ITS) and partial large subunit (LSU) nuclear rDNA regions revealed two clades, one including G. intraradices FL208 and MUCL49410, the other containing DAOM197198 and BEG195.

- The two clades were clearly separated by sequence analyses, despite the high intraspecific and intrasporal ITS region sequence divergence of up to $>23 \%$. We conclude that the AM fungi with the identifiers DAOM197198 and BEG195 are not $G$. intraradices, but fall in a clade that contains the recently described species G. irregulare.

\section{Introduction}

About $70-90 \%$ of land plant species form arbuscular mycorrhiza (Smith \& Read, 2008), so it is obvious that the interaction of plants and the obligate symbiotic arbuscular mycorrhizal (AM) fungi of the Glomeromycota (Schüßler et al., 2001) is of major importance for the entire terrestrial ecosystem. In research on AM fungi (hereafter AMF), a fungus named Glomus intraradices is the most frequently used member of the Glomeromycota. To date, $>1200$ publications refer to this species, $>130$ of which have the name in the title. This wide use resulted from the first AMF established in in vitro root organ culture (ROC) being determined as $G$. intraradices (Chabot et al., 1992). The descendants of this ROC established in Canada, often referred to as DAOM197198 (or DAOM181602, another voucher number for the same fungus), are extensively used in basic research (e.g. for a genome sequencing project; Martin et al., 2008) and to demonstrate transient genetic transformation (Helber \& Requena, 2008). It also is a component of some commercial plant growthenhancing products (Corkidi et al., 2004; http://www.promixbas.com).
However, a very basic question still remains to be resolved: does the DAOM197198 fungus indeed correspond to Glomus intraradices? It is possible that more than one species may have been identified with this name.

Despite the large body of published work, including recent publications dealing with genetic recombination and anastomoses compatibility between isolates of AMF that are closely related to DAOM197198 (Croll \& Sanders, 2009; Croll et al., 2009), the definition of ' $G$. intraradices' is far from clear. The species was described by Schenck \& Smith (1982) from a citrus orchard in Florida. The type specimens came from a pot culture established from root fragments of a Citrus sp., a descendant of which was donated to the INVAM collection (http://www.invam.caf.wvu.edu) where it was catalogued as FL208. Since then, many cultures and isolates have been determined to be $G$. intraradices. Analyses of their rDNA region showed that they belong within the Glomus Group Ab (GlGrAb) (Schwarzott et al., 2001; Jansa et al., 2002b; Börstler et al., 2008). Both DAOM197198 and BEG195 have been identified as $G$. intraradices, but there appears to be no published work comparing them with the original description, the type material, or FL208. Therefore, these 
cultures might represent one species, but they may instead also belong to a cohort of related species. This element of doubt stimulated a re-examination of the molecular evidence in relation to the species $G$. intraradices.

A fungal species is defined by its nomenclatural type, although as such it is a preserved sample and thus not available for study as a living entity. However, being its descendant, the culture $G$. intraradices FL208 can provide 'living evidence' of the true nature of the species. Subculture of FL208, herein termed 'ex-type' or 'type-culture', are available for such comparative study, so it is possible to investigate whether other AMF in the Glomus Group Ab (Schwarzott et al., 2001) may be other species rather than $G$. intraradices. Strictly speaking, the Botanical Code defines an 'ex-type culture' as being obtained from type material permanently preserved in a metabolically inactive state, but for convenience we extend this here to include cultures such as FL208, derived from the 'type culture' through a series of living subcultures.

We compared the $G$. intraradices isotype with ex-type specimens from pot cultures of FL208. Ex-type material was then compared by partial nuclear small subunit (SSU), internal transcribed spacer (ITS) and partial nuclear large subunit (LSU) rDNA region sequencing with three other cultures: a new isolate from the type locality corresponding morphologically to $G$. intraradices (now cultured as ROC in the GINCO collection, http://emma.agro.ucl.ac.be/ginco-bel, as MUCL49410), DAOM197198 (from Pont Rouge, Canada); and BEG195 (from Germany). The aim of this research was to determine if these organisms indeed all correspond to $G$. intraradices.

A secondary aim was to contribute to strategies that might be used for species determination based on DNA sequences. Such identification, termed 'DNA barcoding', must be accurate, rapid, cost-effective, culture-independent, universally accessible, and usable by nonexperts (Frézal \& Leblois, 2008). For animal DNA barcoding, the mitochondrial cytochrome $c$ oxidase I $(C O I)$ gene is widely used. In fungi, COI possesses length variation $(0.64-12.3 \mathrm{~kb}$; Seifert et al., 2007) too large to fulfil barcoding requirements. Because the molecular identification of fungi has been based mainly on the ITS rDNA region (Nilsson et al., 2008; http://unite.ut.ee) the ITS region will most likely become the primary barcode for fungi. The Barcoding of Life Database (BOLD, http://www.barcodinglife.org) already supports the storage and analysis of ITS sequences, and we therefore intended also to study, using GlGrAb sequences from public databases, whether the ITS region alone can be used to resolve species in the Glomeromycota.

\section{Materials and Methods}

\section{Fungal type material}

The isotype of G. intraradices, voucher OSC40255, was borrowed from Oregon State University herbarium (OSC). It consisted of spores and stained roots on dried-out microscope slides, and spores and blue-stained roots preserved in lactophenol. It was examined microscopically by accepted methods (Walker et al., 2007).

\section{Cultures}

All pot cultures were established as closed systems in Sunbags (Sigma-Aldrich, Germany) (Walker \& Vestberg, 1994).

Ex-type cultures Pot culture substrate of FL208 was obtained on 23 March 2007 from INVAM (http:// www.invam.caf.wvu.edu, where in the 'accessions details page' it is described as 'subculture of the original isotype'). A subculture attempt (Att) number (Att4-36) was assigned to this material on receipt (Att4-0 is the identifier in our database for the original, root fragment, open pot culture of S. Nemec, established in autumn 1974). Replicate ex-type pot cultures were established in Germany (Att4-37, Att4-39Att4-43), England (Att4-38) and Belgium (Att4-44). Moreover, a ROC (Declerck et al., 1998) was established in Belgium (Att4-45) on transformed carrot (Daucus carota) roots (from one root fragment of Att4-44). From this, one spore cluster on a single hypha was taken to establish Att4-46 (MUCL49413 in GINCO-BEL) on transformed chicory (Chichorium intybus) root (Fontaine et al., 2004). Material from a subsequent chicory ROC (Att4-64) was used for DNA extraction in Germany.

New isolate from the type locality A sample was provided by S. Nemec, collected in Florida, USA, from the type locality of $G$. intraradices (a citrus plantation between Clermont and Minneola close to Highway 27). From the description of the locality, an approximate latitude and longitude was estimated $\left(28^{\circ} 33^{\prime} 41^{\prime \prime} \mathrm{N}, 81^{\circ} 44^{\prime} 40^{\prime \prime} \mathrm{W}\right)$ using Google Earth. A trap culture with roots and soil was established with Plantago lanceolata as host (Att1102-0, 14 October 2001) in disinfested $3: 1$ (v:v) horticultural sand-expanded attapulgite clay (Oil-Dri Corp., Chicago, IL, USA). Voucher samples determined as $G$. intraradices growing in the culture were made on 9 August 2002 (W4064), 17 March 2003 (W4344), and 3 March 2004 (W4598). From the 2004 sampling, a single spore was germinated on a filter fragment (Brundrett \& Juniper, 1995) and successfully used to establish Att1102-7 with $P$. lanceolata. Spores formed in this culture corresponded broadly to the type material of $G$. intraradices. They were found abundantly singly in the substrate, in loose clusters of 2 to $>100$, attached to fine, hyaline mycelium around roots. The fungus also sporulated heavily in the root cortex. On 6 June 2006, a single spore ROC was established (Att1102-9, MUCL49410) and subsequently subcultured as part of the GINCO collection.

Descendants of DAOM197198 Several cultures corresponding to DAOM197198 (originally collected in Pont Rouge, Canada) were examined. DAOM181602 is an earlier voucher 
number for a sample from an ancestral pot culture taken in 1981, before the fungus was transferred to the company Premier Tech Ltée. (Québec, Canada). The ROC widely used in AM research (Chabot et al., 1992) was initiated from a pot culture vouchered as DAOM197198 in 1987. Details about the culturing history of this fungus will be provided in a subsequent publication. As is common in many studies we use DAOM197198 as organism identifier, but stress that it is actually a voucher number of the herbarium in Ottawa and thus defines what was present in the culture at the time of sampling. We obtained ROC cultures of this fungus from several sources. (1) Att1192-44 originated from a ROC culture traced back to the laboratory of G. Becard (France), from where it was sent to the laboratory of I. Sanders (Switzerland), then to the laboratory of U. Paszkowski (Switzerland). In 2007 it was sent to the laboratory of M. Parniske (Germany) and from there to our laboratory. (2) Att1192-27 was obtained from the laboratory of P. Bonfante (Italy) in 2007, via the laboratory of P. Lammers (USA), where it was established from material produced by Premier Tech for the genome sequencing project (http://www.jgi.doe.gov/genomeprojects/). (3) Att1192-53 was sent to us in 1996 by Y. Piché and spores were stored at $-80^{\circ} \mathrm{C}$. (4) Att690-23 was obtained via the University of Western Australia by C. Walker in November 2006 and established as a closed pot culture in Munich (March 2007). All this material purportedly stems from the same ROC established in the early 1990s (Chabot et al., 1992).

BEG195 This fungus originally was sampled from an agricultural field with winter cereals near Hannover (Germany). It was cultured at the University of Marburg, passed to the Sainsbury Laboratory (Norwich, UK) and then to the laboratory of M. Parniske (Munich, Germany), and thence, from Att1485-12, to our subculture (Att1485-13) used for DNA extraction.

Glomus proliferum (MUCL41827) This AMF was cultured from banana plantation in Guadeloupe. It was described by Declerck et al., (2000) and is available as ROC from GINCO.

Identifiers used in this publication To distinguish the different cultures and isolates studied here, we refer to them by using the most common descriptors. It should be borne in mind that these correspond either to vouchers (DAOM197198), organisms (INVAM FL208, MUCL49410, BEG195), or to individual subculture attempts (Att). DAOM197198 is used for the Canadian fungus from Pont Rouge (the fungus used in the AMF genome sequencing project), FL208 for the extype cultures from Florida, and MUCL49410 (Att1102-12 and descendants) for the new isolate from the type locality. BEG195 (as Att1485-13) was included in the analysis to represent a $G$. intraradices-like fungus from Europe.
DNA extraction, PCR amplification, cloning and sequencing

DNA extraction and PCR amplification Spores were cleaned and DNA extracted as described in Schwarzott \& Schüßler (2001). In a first PCR, an amplicon containing a part of the SSU, the whole ITS1-5.8S-ITS2 region, and a part of the LSU rDNA were amplified with two different primer pairs (Table 1), using the Phusion High-Fidelity PCR Mastermix (Finnzymes, Espoo, Finland). As template $5 \mu \mathrm{l}$ of DNA extract (except for Att1 192-27 and G. proliferum, where $2 \mu$ were used) were used in $20-\mu$ final reaction volumes. The final primer concentration was $0.5 \mu \mathrm{M}$ of each primer. For primers SSUmAf (Krüger et al., 2009) and LR4+2 (ACCAGAGTTTCCTCTGGCT; modified LR4 primer, http://www.aftol.org) the PCR parameters were: $5 \mathrm{~min}$ initial denaturation at $99^{\circ} \mathrm{C}$; 40 cycles of: $10 \mathrm{~s}$ at $99^{\circ} \mathrm{C}, 30 \mathrm{~s}$ at $59^{\circ} \mathrm{C}, 1 \mathrm{~min}$ at $72^{\circ} \mathrm{C}$; final elongation $10 \mathrm{~min}$ at $72^{\circ} \mathrm{C}$. The cycling parameters for the SSUmAf and LSUmAr (Krüger et al., 2009) PCR mix were identical, except for the annealing $\left(15 \mathrm{~s}\right.$ at $\left.60^{\circ} \mathrm{C}\right)$ and elongation $\left(45 \mathrm{~s}\right.$ at $72^{\circ} \mathrm{C}$ ) parameters.

When the first PCR did not result in visible bands after gel electrophoresis of $6 \mu \mathrm{l}$ of PCR product, a second (nested) PCR was performed. The PCR reactions were initiated as for the first PCR with $0.1 \mu \mathrm{l}, 0.2 \mu \mathrm{l}, 0.5 \mu \mathrm{l}$ or $1 \mu \mathrm{l}$ from the first PCR used as template. Either the primer combination SSUGlom1 (Renker et al., 2003) and NDL22 (van Tuinen et al., 1998) or the AMF specific primers SSUmCf and LSUmBr (Krüger et al., 2009) were used for the nested PCR. The cycling regime for SSUGlom1-NDL22 was: $5 \mathrm{~min}$ at $98^{\circ} \mathrm{C}$; 30 cycles of: $10 \mathrm{~s}$ at $98^{\circ} \mathrm{C}, 30 \mathrm{~s}$ at $65^{\circ} \mathrm{C}$ and $1 \mathrm{~min}$ at $72^{\circ} \mathrm{C}$; final elongation $10 \mathrm{~min}$ at $72^{\circ} \mathrm{C}$. For SSUmCf-LSUmBr it was: $5 \mathrm{~min}$ at $99^{\circ} \mathrm{C} ; 30$ cycles of $10 \mathrm{~s}$ at $99^{\circ} \mathrm{C}, 15 \mathrm{~s}$ at $63^{\circ} \mathrm{C}$ and $45 \mathrm{~s}$ at $72^{\circ} \mathrm{C}$; final elongation $10 \mathrm{~min}$ at $72^{\circ} \mathrm{C}$. Nested PCR amplifications for Att1192-44 (pHS059) were performed with Taq DNA polymerase (Peqlab, Erlangen, Germany) and for Att4-38 (pHS080) with Top-Taq polymerase (Qiagen, Hilden, Germany), using the primer pair SSUGlom1-NDL22. In these cases the PCR program was $5 \mathrm{~min}$ at $94^{\circ} \mathrm{C} ; 30$ cycles of: $30 \mathrm{~s}$ at $94^{\circ} \mathrm{C}, 30 \mathrm{~s}$ at $58^{\circ} \mathrm{C}$ and $2 \mathrm{~min}$ at $72^{\circ} \mathrm{C}$; final elongation of $10 \mathrm{~min}$ at $72^{\circ} \mathrm{C}$.

Cloning and sequencing The PCR products were cloned with the TOPO TA or the Zero Blunt TOPO PCR Cloning Kit (Invitrogen) according to manufacturer's protocol, except that all components were used as $1 / 3$ volume (except SOC medium for initial bacterial growth, which was used as full volume). The pHS113 clones (G. proliferum) were obtained using the StrataClone Blunt PCR Cloning Kit (Stratagene Agilent Technologies, La Jolla, CA, USA) according to the manual. Clones were analysed using colony PCR and products showing correct fragment size were used for RFLP with MboI, Hinfl and RsaI. Selected clones were grown in liquid Terrific Broth media and plasmids isolated with the NucleoSpin 
New

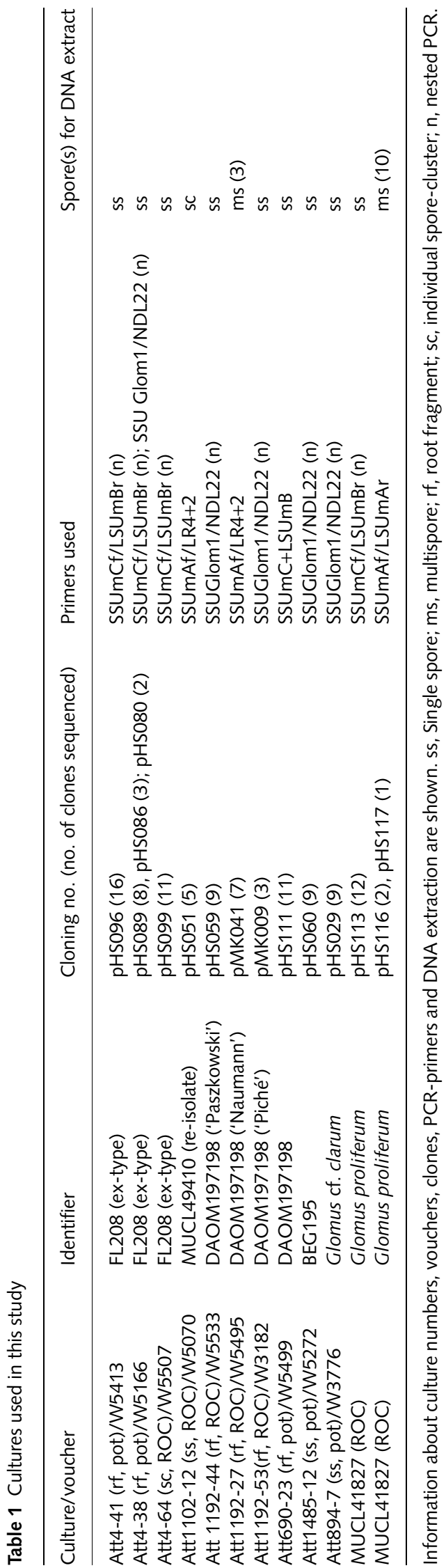

Multi-8 Plasmid kit (Macherey \& Nagel, Düren, Germany). Alternatively, a 'quick and easy' method modified after Ganguly et al. (2005) was used. Sanger sequencing was performed by the LMU Sequencing Service Unit on an ABI capillary sequencer using BIGDYE v3.1 sequencing chemistry. The new rDNA sequences derived from this study were deposited in the EMBL/GenBank/DDBJ databases with the accession numbers FM865536-FM865617 and FM992377FM992402.

\section{Phylogenetic analysis}

The $3^{\prime}$ partial SSU rDNA, the ITS region, and the $5^{\prime}$ partial LSU rDNA were either analysed for the sequences derived from this study together with some selected shorter sequences of characterized AMF from the database, or the ITS region alone was used for comparison with public database sequences. Sequences were assembled and proof-read with the program SEQASSEM and aligned with ALIGN (both from http://www.sequentix.de). Sequence divergences in per cent (uncorrected pairwise distances) were calculated by using BIOEDIT (Hall, 1999) and based on alignments containing either sequences of $G$. intraradices-related species or of Ambispora spp., including all positions. The alignment of the maximal common length (representing the SSUGlom1-NDL22 fragment) sequences comprised 1555 sites, 1387 of which could be unambiguously aligned and were used for the analyses.

When sequences derived from the same PCR reaction were identical after excluding ambiguous sites from the alignment, only one was included in phylogenetic analyses and accession numbers of the other sequences were later annotated to the corresponding clade. The analyses of database sequences included identical ones, because it is difficult to interpret whether they came from the same or different spores, PCR reactions or even cultures. Phylogenetic analysis was performed with PHYLIP (Felsenstein, 1989), RAxML (Stamatakis \& Hoover, 2008), TREE-PUZZLE (Schmidt et al., 2002) and MRBAYes (Ronquist \& Huelsenbeck, 2003). Consensus trees were constructed after 1000-fold bootstrapped neighbour-joining (NJ, based on Kimura-2-parameter model with PHYLIP 3.8; Felsenstein, 1989) analyses. RAxML was set to a maximum likelihood (ML) search for best-scoring tree after 1000 bootstraps and the proportion of invariable sites was estimated by the program. The ML quartet puzzling (MLQP) analyses were performed with TREE-PUZZLE 5.2 (based on GTR model), estimating nucleotide frequencies and gamma distributed heterogeneous rates from the dataset. As an alternative approach, the sequences (SSUGlom1-NDL22 fragment) were aligned automatically using the MAFFT online server (http:// align.bmr.kyushu-u.ac.jp/mafft/online/server/), for comparison with the results from the manual alignment. The iterative refinement option of MAFFT was set to FFT-NS-i (Katoh et al., 2002). Phylogenetic analysis was performed by RAxML with settings as above. 
For the ITS region analyses, public database sequences labelled as $G$. intraradices and such of closely related species were included. Analyses were based on a manually made alignment. Identical ITS region sequences were excluded and afterwards annotated to the appropriate clade. In total 395 sites could be unambiguously aligned. Phylogenetic analyses were performed with PHYLIP (NJ) and RAXML (ML). The two sequence alignments (SSU + ITS + LSU rDNA sequences from this study and ITS region including database sequences) are available from http://www.amf-phylogeny.com.

\section{Results}

The isotype material of G. intraradices is in relatively poor condition. It appears heavily parasitized and the spore wall structure was difficult to determine. It was also much darkened in colour because of storage in lactophenol. However, it was possible to see characteristics used by the original authorities to describe the species, along with other details that were not published in the protologue, and to compare them with those of DAOM197198. We do not show the detailed morphological comparisons here, since a detailed re-description including designation of an epitype of G. intraradices is currently in preparation for publication elsewhere.

To characterize the 'model AMF' DAOM197198 at the molecular level, we studied several cultures, including some from single-spore isolates. The phylogenetic analyses comprising the partial SSU, entire ITS region, and the partial LSU rDNA sequences show a clear separation into two clades (Fig. 1). The first clade includes the ex-type culture of $G$. intraradices, FL208 (Att4-38, Att4-41, Att4-64) and the new isolate from the type locality, MUCL49410 (Att1102-12). The second clade contains DAOM197198 (Att690-23, Att1192-27, Att1192-44, Att1192-50) and BEG195 (Att1485-12). Shorter sequences of $G$. irregulare, a $G$. intraradices-like species (Błaszkowski et al., 2008), and isolates from Switzerland were included in the analyses and also cluster in the latter clade. When using a fully automated MAFFT alignment as a base for the phylogenetic analyses, the same, distinct clades were resolved. Later, we named the clade containing FL208 and MUCL49410 as the ' $G$. intraradices clade' and the clade containing DAOM197198, BEG195, G. irregulare and the Swiss isolates as the 'G. irregulare clade'. A separation of these clades also existed when using only the ITS1 region, the partial LSU sequences, or the combined partial SSU + 5.8S + partial LSU (without ITS1 + ITS2) fragment (RAXML bootstrap support $>70 \%$, for all three options; data not shown). However, analyses of only the ITS2, or the ITS1 + 5.8S + ITS2 region resulted in a monophyletic grouping for the $G$. irregulare clade sequences, but the $G$. intraradices clade appeared paraphyletic. This indicated that the ITS2 region alone carries conflicting phylogenetic signal or too much noise, hindering resolution. Further ITS region analyses including database sequences (see below) also show that this region is not suitable to resolve species in GlGrAb.
The maximal pairwise uncorrected distance values ( $\mathrm{p}$ distances) within the G. irregulare clade were $9.3 \%$ for the newly obtained SSU + ITS + LSU rDNA sequences. The divergence in the G. intraradices clade was up to $14.1 \%$. An overlap of highest intraspecific p-distances in the $G$. intraradices clade with the lowest interspecific (relating to the $G$. irregulare clade) p-distance values was observed for the full-length sequences and ITS region, indicating the lack of a so called 'barcode gap' (http://www.barcoding.si.edu/). The variation in the partial LSU sequences only was $7.8 \%$ for the $G$. irregulare clade and $11.8 \%$ for the $G$. intraradices clade.

The most variable ITS region showed p-distances of up to $16.3 \%$ for the G. irregulare clade and up to $23.1 \%$ for the $G$. intraradices clade. This enormous ITS region variability was found within one FL208 ex-type culture spore from Att441 (Fig. 1) and is the highest ever recorded for an individual AMF spore. Within this spore the maximal p-distance for the SSU + ITS + LSU rDNA sequence is $13.9 \%$.

Analysing the ITS region including database sequences revealed several clades. Most ITS-region sequences designated as $G$. intraradices fell within the $G$. irregulare clade, including those of BEG158, BEG195 and the known ITS sequences of the genotypes (II, VI, XII, XV, XVII, XVIII; Croll et al., 2008; Croll \& Sanders, 2009) of isolates from a field site in Switzerland (Jansa et al., 2002a; Koch et al., 2004). The FL208 sequences from the public database (Börstler et al., 2008, Sudarshana P. et al., unpublished), as well as KS906 (AF185669-73) cluster together with the FL208 sequences from our analysis. Three new sequences (FM865546 from pHS051-20, FM865599 from pHS099-16 and FM865604 from pHS099-41) that stem from ROC of either a G. intraradices FL208 descendant or the new isolate (MUCL49410) cluster distantly from the main clade (Fig. 2). Sequences from the recently described $G$. irregulare, which was studied together with a fungus identified as $G$. intraradices isolated from the same trap culture (Błaszkowski et al., 2008), clearly fall into subclades containing DAOM197198 + BEG195 sequences (Figs 1, 2).

The analyses of database sequences solely from the ITS region indicated that some that were annotated as G. intraradices are resolved to belong to separated, highly supported clades. One of these clades is represented by EY118 + INVAM GR104 (AF185684, AF185686 and AF185651) and another one by INVAM VA110 + INVAM CA502 (AM980854-59) (see also Börstler et al., 2008). However, further VA110 sequences (AF185674-6) group within the G. intraradices FL208 + MUCL49410 clade. Another closely related clade is represented by sequences of Glomus cf. clarum Att894-7 and the G. clarum (CL883A) database sequences AJ243275 and AJ239123. A very distinct cluster of sequences (AJ517450-61; EnvGrA in Fig. 2) annotated as G. intraradices (Renker et al., 2005) is clearly separated from both, the G. intraradices and $G$. irregulare clades. 
New

Phytologist

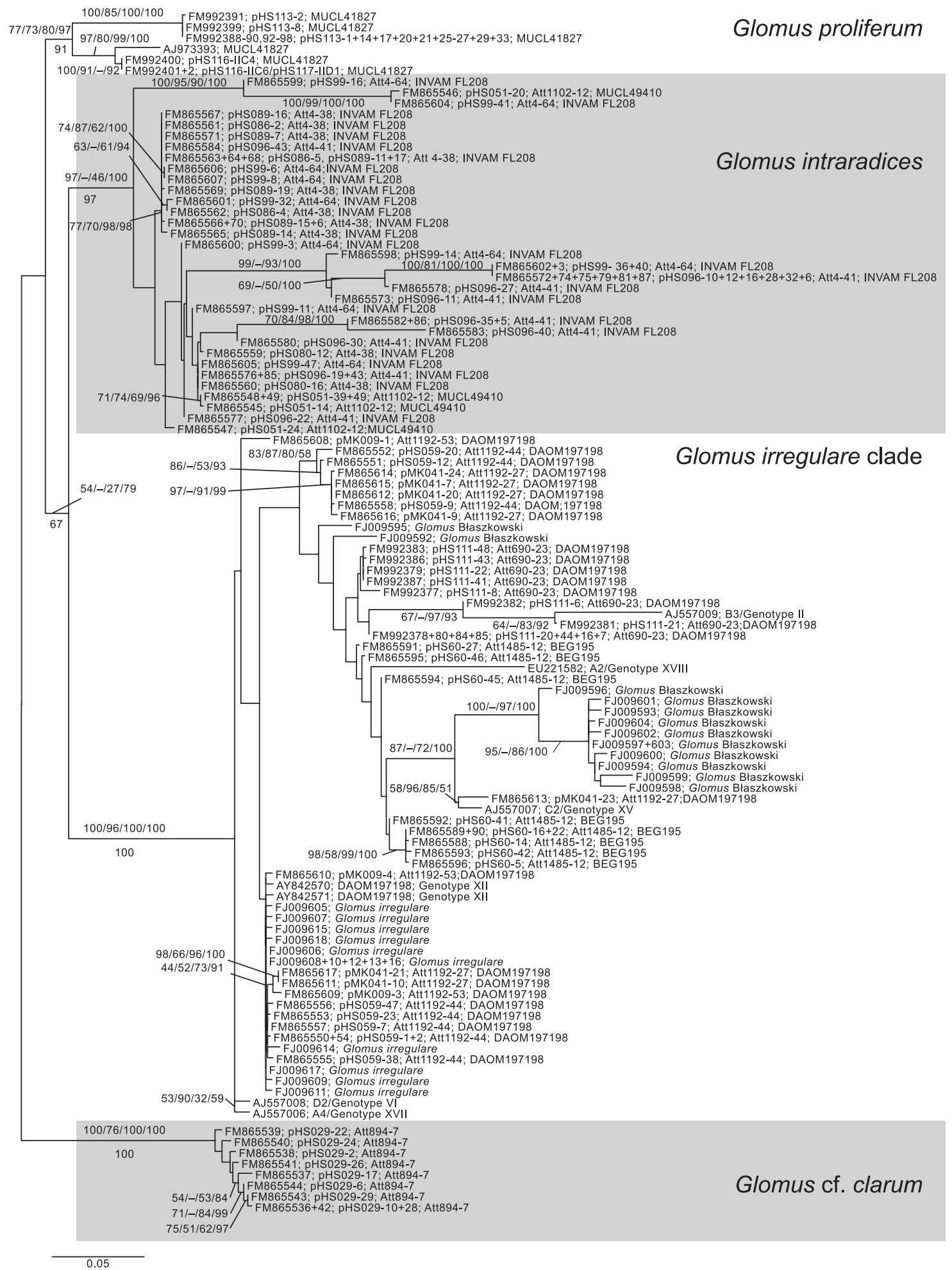

Fig. 1 Phylogenetic tree (partial small subunit (SSU), internal transcribed spacer (ITS) region, partial large subunit (LSU) rDNA sequences of approx. $1.5 \mathrm{~kb}$ ) of Glomus cultures analysed, with Glomus cf. clarum (Att894-7) sequences as outgroup. DAOM197198, BEG195 and Glomus irregulare cluster together. The ex-type cultures of Glomus intraradices (FL208 and descendants) and the new isolate from the type location (MUCL49410) form a clearly separated clade. Distances of the phylogenetic tree are derived from a RAXML analysis. The values above the branches correspond to supports from RAXML/MLQP/NJ/Bayesian analyses. Support values are not shown if lower than $50 \%$ in more than one analysis, except for some main clades. Performing RAXML analysis based on a MAFF alignment using the complete sequence length resulted in the same main topology, with even more strongly supported main clades (values below branches). 


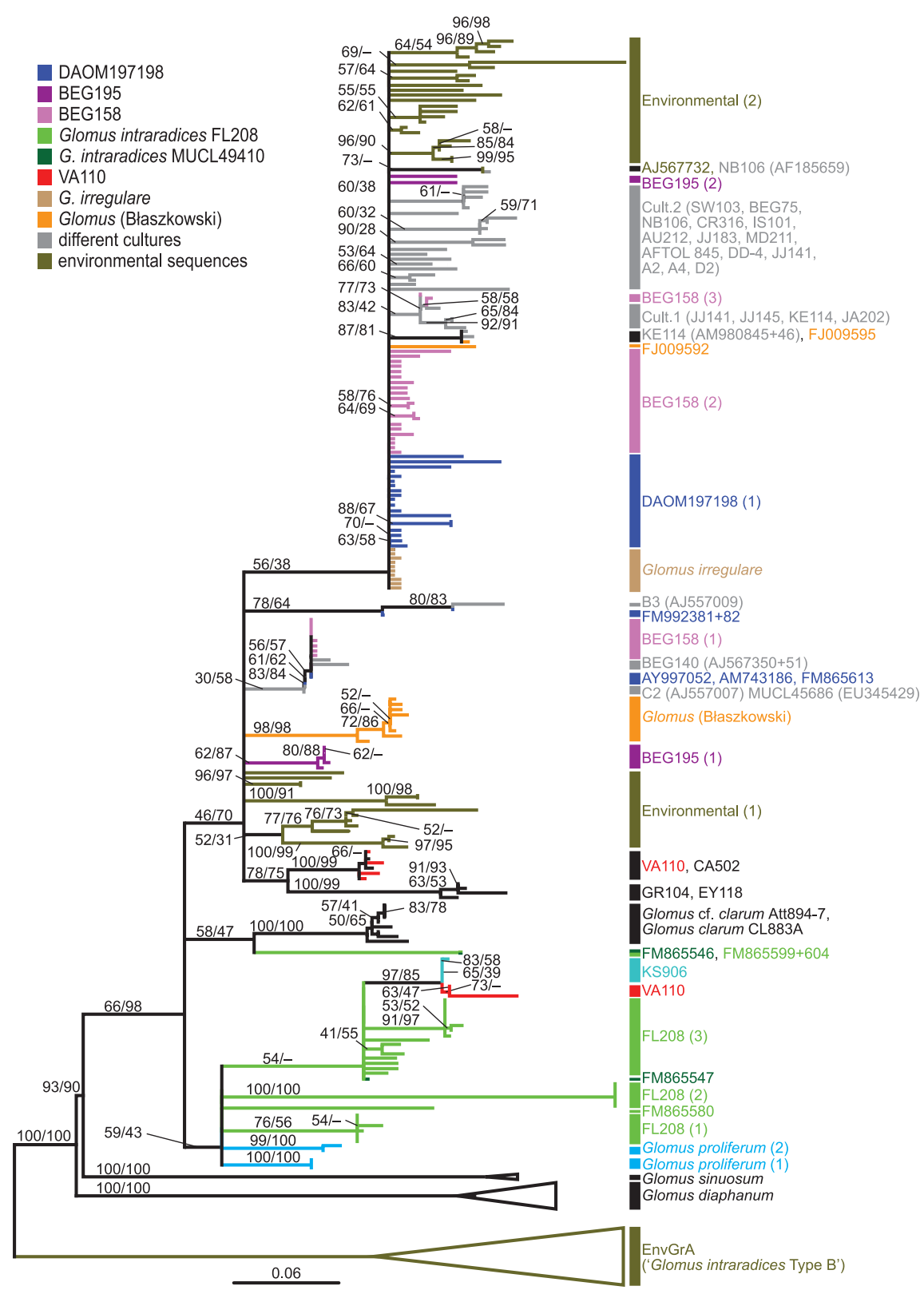

Fig. 2 Simplified phylogenetic tree of a RAXML analysis of 285 internal transcribed spacer (ITS) region sequences that are annotated as Glomus intraradices, and related species. Clades with support values $<50$ in both analyses were collapsed to polytomies. For simplicity, some well supported clades were collapsed to triangles whose sizes correspond to the respective sequence number contained. The values above the branches correspond to supports from RAXML and neighbour-joining (NJ) analyses. Accession numbers of clades or groups (code for the clade or group underlined, additional information written in brackets) are as follows: Environmental Group A (EnvGrA), AJ517450-61; Glomus diaphanum, AJ972457-63; Glomus sinuosum, AJ437105-6; Glomus proliferum (1), FM992388-99; G. proliferum (2), FM992400-2, AJ973393; FL208 (1), FM865545, 548-549;559-560, FM865573, 576, 577, 585, 597-598, 600, 605, AM980862-63; FL208 (2), FM865572, 574, 575, 579, 581, 583, 586-87, 602-3; FL208 (3), FM865547, 61-71, 78, 84, 601, 606-7, AF185661-64, AF185667-68; VA110, AF185674-76; KS906, AF185669-73; Glomus cf. clarum Att894-7, FM865536-44; CL883A, AJ239123, AJ243275; GR104, AF185651; EY118, AF185684-86; VA110, CA502, AM980854-59; Environmental (1), EF989103-05, AJ567352, EF989109-12; EF989106, 108; AJ567773, AJ968411; AJ567769-70; BEG195 (1), FM865588-90, 92-94, 96; Glomus Błaszkowski, FJ009593-94, FJ009596-604; BEG158 (1), AF394752-53, 58, 67, 72-73, 78, 81; Glomus irregulare, FJ009605-18; DAOM197197 (1), FM992377-80, 83-87, FM865550-58,

FM865608-12, FM865614-17, AM980836, AY842570-71; BEG158 (2), AF394750-51, 54, 56, 57, 59-64, 69-71, 74, 77, 79, 80, AY035641; Cultures 1 (Cult.1), AF197917, 20 (SW103) AF197919 (MD211), AJ968410 (BEG75), AM980834 (JJ141), 37,38 (CR316), 39 (DD-4), 40, 41 (JJ183), 42, 43 (AU212), AF185652, 53, 55, 56 (IS101), 60 (NB106), AY997054 (AFTOL 845), AJ557006 (A4,XVI),8 (D2,V), EU221582 (A2, XVIII); BEG158 (3), AF394765, 68, 76; Cult. 2, AM980835 (JA202), AM980833, AY035639 (JJ141), AM980844 (JJ145), AM980846 (KE114); BEG195 (2), FM865591, 95; Environmental (2), AJ517773-75, 77, 79-80, AJ504622, 28-29, AJ416417, AJ968411-12, AJ567733, 35-39, $61-62,64,66-68$. 


\section{Discussion}

The species $G$. intraradices is defined from its type material and the accompanying protologue. Unfortunately, the latter, while perhaps being adequate at the time it was written, does not describe characteristics in the detail required by recent species descriptions for glomeromycotan organisms. Indeed, defining morphospecies within the clade in which $G$. intraradices is placed by molecular analysis (GlGrAb, Schwarzott et al., 2001) seems to be difficult. Glomus intraradices produces spores both in the roots and in the substrate. The presence of intraradical spores itself is not a species-specific character but a symplesiomorphy shared with other AMF species. These intraradical spores have considerable variation in size, shape, subtending hyphal characteristics and reaction to Melzer's reagent, and generally a similar wall structure. The extraradical spores are predominantly globose to subglobose. A detailed description of the morphological characteristics of the species is currently in preparation for publication elsewhere, based on a re-examination of the type and study of both ex-type material and a new isolate obtained in pot culture and ROC from the type locality.

\section{Organisms described as $G$. intraradices encompass more than one species}

Our results revealed that many cultures or isolates frequently used in AM research and named $G$. intraradices very likely do not correspond to that species. In particular, the model fungus DAOM197198 cannot be phylogenetically resolved as G. intraradices (Fig. 1). This is in agreement with recently published studies dealing with mtLSU and nuc5.8S-ITS2 sequence data (Börstler et al., 2008) and analyses of nucITS2 sequences (Jansa et al., 2002b), although these studies did not focus on the species concept of $G$. intraradices. Based on our analyses, the name $G$. intraradices should only be applied for the INVAM FL208 descendants (ex-type), MUCL49410 (new isolate from the type locality) and other AMF that share the same phylogenetic and morphological characteristics. Because the recently described species $G$. irregulare clearly clusters with DAOM197198, although this was not shown in the original publication (Błaszkowski et al., 2008), we use the label ' $G$. irregulare clade' for this group also containing sequences from BEG195 and well investigated isolates from a field site in Switzerland. The published G. irregulare sequences form a weakly supported cluster within that clade (Fig. 1). This is most likely caused by sequencing only one main ITS rDNA variant, because the ITS variability in the published sequences of $G$. irregulare is only c. $1 \%$ and exceptionally low for $\mathrm{GlGrAb}$. This raises questions of how to define species in such a complex clade. The answer to this question will require extensive further detailed analyses.

It can, however, be deduced that the $G$. irregulare clade $(\mathrm{DAOM} 197198+\mathrm{BEG} 195+G$. irregulare + Swiss isolates $)$ and the G. intraradices clade (FL208 + MUCL49410) represent distinct AMF species, because:

- despite the large intraspecific sequence variability, DAOM197198 sequences from AMF cultures that were widely separated in space and time all cluster together in the $G$. irregulare clade, clearly separated from the $G$. intraradices clade showing even larger intraspecific (and intrasporal) variability;

- BEG195 (from Europe) sequences are embedded within the DAOM197198 (from North America) sequences, and thus within the $G$. irregulare clade;

- no isolate gave rise to any sequence (including those from the database) that cluster with members of the other clade, indicating that no rRNA gene flow takes place between the two clades. If the $G$. irregulare and the $G$. intraradices clades would be conspecific, we would expect at least some sequences crossing the borders of the phylogenetic clades. This expectation is supported by recently published evidence for genetic recombination between $G$. irregulare clade members (Croll \& Sanders, 2009);

- the $G$. intraradices and the $G$. irregulare clades separate clearly from each other and from those representing closely related species ( $G$. proliferum, $G$. clarum).

Conclusively, the new isolate (MUCL49410) from the type-locality corresponds phylogenetically to the $G$. intraradices FL208 ex-type culture. This is an indication that FL208 had not been contaminated over the years and should be accepted as indeed corresponding with the type. From these results, the earlier morphological identification of DAOM197198 and BEG195 as G. intraradices, while perhaps satisfying earlier morphological criteria, is shown to be incorrect by our molecular evidence.

\section{Morphological, phylogenetic and biological species concepts}

A morphological species concept is historically used for AMF, but a biological concept is preferable if it can be defined. A phylogenetic concept based on nonparalogous molecular markers may be congruent with a biological concept. It might be characterized by using just a single marker but only if such a marker coincides with the species boundaries.

With these concepts in mind, we have investigated some closely related AMF morphospecies in the past, to find out if they can be distinguished by their rDNA sequences. For example, morphological identification was difficult in the family Ambisporaceae in which some species form both acaulosporoid and glomoid spores. Molecular analyses proved that they were well separated from either the Acaulosporaceae or the Glomeraceae and ITS region analyses allowed separation of what were interpreted as different species, improving the morphological concept (Sawaki et al., 1998; Redecker et al., 2000; Walker et al., 2007). Nevertheless, the resolution of the ITS region seems to be limited, and in GlGrAb the situation 
is complicated. On one hand, isolates in this group were named as G. intraradices (e.g. DAOM197198, BEG195 and isolates from Switzerland) but are phylogenetically clearly separated from the clade that actually includes $G$. intraradices (FL208). On the other hand, G. irregulare seems morphologically different from both DAOM197198 and BEG195 (Błaszkowski et al., 2008), although from the molecular evidence presented here, they might be interpreted as being conspecific.

How can we explain such a situation? One simple reason could be morphological plasticity making it difficult to distinguish species microscopically in this group of AMF. Glomus irregulare is described from supposedly consistent morphological characteristics, which are not shared by DAOM197198. However, the DAOM197198 descendent Att690-23 is also morphologically different from other DAOM197198 cultures, but supposedly shares the same ancestry. There is, moreover, some preliminary evidence that plasticity may relate to host plant species or culture conditions (Walker, 2008). It is thus possible that morphological differences in this group do not consistently correlate with phylogeny, but we cannot yet draw final conclusions about these aspects.

Possible plasticity may be correlated with the theory of conspecificity of different genotypes of Swiss AMF from one field site belonging to the $G$. irregulare clade. Some of these showed different growth characteristic phenotypes (Koch et al., 2004) and analyses indicated recombination events, at least for the studied genotypes II (isolate B3) and VI (isolate D2), between isolates (Croll \& Sanders, 2009). Anastomosis compatibility experiments using five isolates from that field site indicated that isolates with different genotypes $(\mathrm{A} 4=\mathrm{XVIII}, \mathrm{B} 3=\mathrm{II}$, $\mathrm{C} 2=\mathrm{XV}, \mathrm{C} 3=\mathrm{XVII}, \mathrm{D} 1=\mathrm{VIII})$ can anastomose and that some progenies of $\mathrm{C} 2$ and $\mathrm{C} 3$ were genetically recombinant (Croll et al., 2009). It is possible that G. irregulare and DAOM197198-like fungi may be in one anastomosis compatibility group. To answer such questions, AMF must be cultured as isolates.

Regarding a phylogenetic concept for GlGrAb, species cannot reliably be separated by analyses of the ITS region (Fig. 2). For $G$. intraradices, a phylogenetic signal in the ITS2 region, which was not found in earlier works analysing either 5.8S + ITS2 or ITS2 only (Jansa et al., 2002b; Börstler et al., 2008), hindered phylogenetic resolution. However, when using the full-length (including the $3^{\prime}$ SSU and $5^{\prime}$ LSU rDNA region) fragments, the $G$. intraradices and $G$. irregulare clades were clearly separated. Our species concept is also in line with mitochondrial marker analyses (Börstler et al., 2008). We cannot yet conclude whether sequences clustering as more ancestral in a subclade may represent pseudogenes, but if this were to be the case they evolved after speciation because the full-length fragment carries the phylogenetic signal separating the clades. However, it is evident that concerted evolution of the rDNA repeats is extremely relaxed in members of GlGrAb.

\section{Sequence variability and DNA barcoding}

For the SSU + ITS + LSU rDNA fragment sequences the phylogenetic analyses resulted in a well-supported tree topology separating $G$. intraradices and the $G$. irregulare clade. We obtained the same results with a manual alignment and after fully automated alignment with MAFFT (Fig. 1), showing that a relatively simple, automated phylogenetic approach could resolve these two AMF subclades, interpreted as containing different species. We cannot yet conclude whether the fungi in the $G$. irregulare clade indeed are all conspecific, but from the molecular evidence this may well be the case.

The current discussion about fungal DNA barcoding (species identification) focuses on the ITS region, because of its historical use for identification of fungi (Nilsson et al., 2008). An important question is: 'how can AMF species be distinguished and identified by potential DNA barcoding methods?' This question is directly related to a species concept and the enormous intraspecific rDNA variability in AMF. In their recent publication about suitability of different rDNA regions for fungal DNA barcoding Nilsson et al. (2008) calculated an average glomeromycotan ITS variability of $7.5 \%$. However, most data on Glomeromycota published therein will require thorough reinterpretation because of inaccurate species definition. For example, from 36 ITS sequences used to calculate $7.6 \%$ intraspecific ITS variability for $G$. versiforme, three are from a well-defined culture (BEG47), three are most likely from the same organism (although without identifiers in the public database) and the remaining $30(>83 \%)$ sequences analysed stem from environmental roots or spores without any reliable species affiliation. There is even evidence that the different $G$. versiforme sequences encompass distinct species (Gamper et al., 2009). Another dataset is composed of 12 sequences from six different Paraglomus occultum cultures, but because the species concept among Paraglomus is not yet well defined it is unclear whether these cultures indeed are conspecific. For the members of the G. irregulare clade, Nilsson et al. (2008) report $8.7 \%$, intraspecific ITS variability and Jansa et al. (2002b) up to $18 \%$ for $G$. sp. BEG158 (Fig. 2) intrasporal ITS variability. For one $G$. intraradices FL208 spore we could show $>23 \%$ variability. Some further values reported for AMF are $9 \%$ for Gigaspora margarita (Lanfranco et al., 1999), 6\% for Glomus mosseae (Lloyd-Macgilp et al., 1996), and $13.4 \%$ (when calculated based on the alignment of Walker et al., 2007) to $9.8 \%$ (median of absolute uncorrected (Hamming) distances calculated after automated pairwise alignments; Nilsson et al., 2008) for Ambispora leptoticha.

Although these values cannot yet be conclusively compared because of the different of clones or variants, general sampling densities, alignments and calculation methods, it appears that G. intraradices-related AMF in the clade GlGrAb show considerable sequence variability within the Glomeromycota. The LSU variability reported here is also higher than in most 
other studies, especially in the G. intraradices FL208 type culture (11.8\%). The uncorrected p-distances for the diversisporacean Glomus aurantium, Glomus eburneum and Diversispora celata are 6.6, 1.4 and 2.5\%, respectively, in the partial LSU region sequences analysed (Gamper et al., 2009). Generally, our results show that it will be necessary to include the $5^{\prime} \mathrm{LSU}$ region in addition to the ITS region for DNA barcoding of AMF.

\section{How many sequence variants in one species?}

Assuming that Saccharomyces, Aspergillus and Neurospora spp. have 45-200 rDNA repeats (Kobayashi, 1998; Simon \& Weiss, 2008) and the AMF Scutellospora castanea 75 (Hosny et al., 1999), fewer than $200 \mathrm{rDNA}$ repeats would be expected within a nucleus of the AMF investigated here. It is still debated whether AMF are homokaryotic (Pawlowska \& Taylor, 2004) or heterokaryotic (Hijri \& Sanders, 2005), but the data presented here cannot resolve this question (see later). There are at least 149 ITS sequence variants from the different cultures and isolates in the G. irregulare clade (Fig. 2). For DAOM197198, we found 23 different ITS variants in the 30 sequences published here. From the public database, five additional sequences were identified for the complete ITS region, and further four covering ITS1 only. This makes 32 variants for DAOM197198, but the total number will be higher. This variability is derived from different cultures, which means that it potentially includes variants derived from recombination in different culturing lineages and may be higher than the number present in one spore. The variability found is not too high to be encoded within one nucleus. An interesting question is whether the very high variability in the $\mathrm{GlGrAb} \mathrm{rDNA}$ is also reflected in other parts of the genome, which might be a problem when using members of this AMF lineage as genetic model systems.

\section{Other subclades comprising G. intraradices-like AMF species}

There are several other species known in the GlGrAb clade, and it was recently indicated that the only published G. proliferum sequence might cluster as a sister lineage to G. intraradices FL208 (Börstler et al., 2008). However, the longer sequences of $G$. proliferum published here form a clade separated from the G. intraradices and G. irregulare clades, although not with high bootstrap support. Based on the analyses of the ITS region alone further, well-separated clades could be considered as likely to represent distinct species. The cluster EnvGrA, named as 'G. intraradices Type B' (Renker et al., 2005), represents a distinct species, being more distant from G. intraradices than from species such as Glomus diaphanum and Glomus sinuosum.

For some of the AMF investigated, phylogenetic relationships cannot be satisfactory interpreted, such as for INVAM
VA110. Some VA110 sequenced cluster with FL208, as already indicated by Börstler et al. (2008). These were submitted to the database in 1999 as part of a $G$. intraradices dataset that obviously included many contaminant sequences, as shown by their phylogenetic placement in different AMF orders. On the INVAM website it is noted that VA110 was derived from a mixed culture containing several species. VA110 is listed there as Glomus sp. on the 'Accessions Culture Information' pages and it is likely that sequences appearing in distinct phylogenetic clades actually represent different organisms. In general, sequence data from mixed cultures should be interpreted with caution.

In this study, we showed that $G$. intraradices (FL208 ex-type culture and MUCL49410 isolated from the type locality) clearly separates from the AMF in the G. irregulare-clade (DAOM197198 + BEG195 + Swiss isolates). Further, even more distant clades (e.g. EnvGrA) that were annotated as $G$. intraradices represent different, possibly undescribed AMF species. The model fungus used in AM research, DAOM197198, does not represent $G$. intraradices and is closely related to or perhaps even conspecific with $G$. irregulare.

\section{Acknowledgements}

We thank R. Halse, the curator of OSC for the loan of the type material, S. Nemec for providing the sample from the type locality, D. Redecker for discussions during the TRACEAM meeting held in January 2008, and J. Morton at INVAM for the provision of FL208. We thank M. and C. Krüger for critical reading and providing some unpublished data, and the GINCO for subculturing the FL208 and Att1102-9 descendants. Thanks to all who supplied samples. Work in Germany and the grant for H.S. were funded by the Marie Curie Early Stage Research Training Fellowship of the European Community's Sixth framework Programme (MESTCT-2005-021016) and A.S. was funded by the German Research Foundation (DFG).

\section{References}

Błaszkowski J, Czerniawska B, Wubet T, Schäfer T, Buscot F, Renker C. 2008. Glomus irregulare, a new arbuscular mycorrhizal fungus in the Glomeromycota. Mycotaxon 106: 247-267.

Börstler B, Raab PA, Thiéry O, Morton JB, Redecker D. 2008. Genetic diversity of the arbuscular mycorrhizal fungus Glomus intraradices as determined by mitochondrial large subunit rRNA gene sequences is considerably higher than previously expected. New Phytologist 180 : 452-465.

Brundrett M, Juniper S. 1995. Nondestructive assessment of spore germination of VAM fungi and production of pot cultures from single spores. Soil Biology and Biochemistry 27: 85-91.

Chabot S, Becard G, Piche Y. 1992. Life cycle of Glomus intraradix in root organ culture. Mycologia 84: 315-321.

Corkidi L, Allen EB, Merhaut D, Allen MF, Downer J, Bohn J, Evans M. 2004. Assessing the infectivity of commercial mycorrhizal inoculants in plant nursery conditions. Journal of Environmental Horticulture 22: 149-154. 
Croll D, Sanders IR. 2009. Recombination in Glomus intraradices, a supposed ancient asexual arbuscular mycorrhizal fungus. $B M C$ Evolutionary Biology 9: 13.

Croll D, Giovannetti M, Koch AM, Sbrana C, Ehinger M, Lammers PJ, Sanders IR. 2009. Nonself vegetative fusion and genetic exchange in the arbuscular mycorrhizal fungus Glomus intraradices. New Phytologist 181: 924-937.

Croll D, Wille L, Gamper HA, Mathimaran N, Lammers PJ, Corradi N, Sanders IR. 2008. Genetic diversity and host plant preferences revealed by simple sequence repeat and mitochondrial markers in a population of the arbuscular mycorrhizal fungus Glomus intraradices. New Phytologist 178: 672-687.

Declerck S, Cranenbrouck S, Dalpé Y, Séguin S, Grandmougin-Ferjani A, Fontaine J, Sancholle M. 2000. Glomus proliferum sp. nov.: a description based on morphological, biochemical, molecular and monoxenic cultivation data. Mycologia 92: 1178-1187.

Declerck S, Strullu DG, Plenchette C. 1998. Monoxenic culture of the intraradical forms of Glomus sp. isolated from a tropical ecosystem: a proposed methodology for germplasm collection. Mycologia $\mathbf{9 0 :}$ 579-585.

Felsenstein J. 1989. PHYLIP: phylogeny inference package (version 3.2). Cladistics 5: 164-166.

Fontaine J, Grandmougin-Ferjani A, Glorian V, Durand R. 2004. 24Methyl/methylene sterols increase in monoxenic roots after colonization by arbuscular mycorrhizal fungi. New Phytologist 163: 159-167.

Frézal L, Leblois R. 2008. Four years of DNA barcoding: current advances and prospects. Infection, Genetics and Evolution 8: 727-736.

Gamper HA, Walker C, Schüßler A. 2009. Diversispora celata sp. nov: molecular ecology and phylotaxonomy of an inconspicuous arbuscular mycorrhizal fungus. New Phytologist 182: 495-506.

Ganguly T, Chen P, Teetsel R, Zhang LP, Papaioannou E, Cianciarulo J. 2005. High-throughput sequencing of high copy number plasmids from bacterial cultures by heat lysis. BioTechniques 39: 304-308.

Hall T. 1999. BIOEDIT: a user-friendly biological sequence alignment editor and analysis program for Windows 95/98/NT. Nucleic Acids Symposium Series 41: 95-98.

Helber N, Requena N. 2008. Expression of the fluorescence markers DsRed and GFP fused to a nuclear localization signal in the arbuscular mycorrhizal fungus Glomus intraradices. New Phytologist 177: 537-548.

Hijri M, Sanders IR. 2005. Low gene copy number shows that arbuscular mycorrhizal fungi inherit genetically different nuclei. Nature 433: $160-163$.

Hosny M, Hijri M, Passerieux E, Dulieu H. 1999. rDNA units are highly polymorphic in Scutellospora castanea (Glomales, Zygomycetes). Gene 266: 61-71.

Jansa J, Mozafar A, Anken T, Ruh R, Sanders IR, Frossard E. 2002a. Diversity and structure of AMF communities as affected by tillage in a temperate soil. Mycorrhiza 12: 225-234.

Jansa J, Mozafar A, Banke S, McDonald BA, Frossard E. 2002b. Intra- and intersporal diversity of ITS rDNA sequences in Glomus intraradices assessed by cloning and sequencing, and by SSCP analysis. Mycological Research 106: 670-681.

Katoh K, Misawa K, Kuma KI, Miyata T. 2002. MAFFT: a novel method for rapid multiple sequence alignment based on fast Fourier transform. Nucleic Acids Research 30: 3059-3066.

Kobayashi T, Heck DJ, Nomura M, Horiuchi T. 1998. Expansion and contraction of ribosomal DNA repeats in Saccharomyces cerevisiae: requirement of replication fork blocking (Fob1) protein and the role of RNA polymerase I. Genes \& Development 12: 3821-3830.

Koch AM, Kuhn G, Fontanillas P, Fumagalli L, Goudet J, Sanders IR. 2004. High genetic variability and low local diversity in a population of arbuscular mycorrhizal fungi. Proceedings of the National Academy of Sciences, USA 101: 2369-2374.
Krüger M, Stockinger H, Krüger C, Schüßler A. 2009. DNA-based detection of Glomeromycota: one PCR primer set for all arbuscular mycorrhizal fungi. New Phytologist. doi: 10.1111/j.1469-

8137.2009.02835.x

Lanfranco L, Delpero M, Bonfante P. 1999. Intrasporal variability of ribosomal sequences in the endomycorrhizal fungus Gigaspora margarita. Molecular Ecology 8: 37-45.

Lloyd-Macgilp SA, Chambers SM, Dodd JC, Fitter AH, Walker C, Young JPW. 1996. Diversity of the ribosomal internal transcribed spacers within and among isolates of Glomus mosseae and related mycorrhizal fungi. New Phytologist 133: 103-111.

Martin F, Gianinazzi-Pearson V, Hijri M, Lammers P, Requena N, Sanders IR, Shachar-Hill Y, Shapiro H, Tuskan GA, Young JPW. 2008. The long hard road to a completed Glomus intraradices genome. New Phytologist 180: 747-750

Nilsson RH, Kristiansson E, Ryberg M, Hallenberg N, Larsson KH. 2008. Intraspecific ITS variability in the kingdom fungi as expressed in the international sequence databases and its implications for molecular species identification. Evolutionary Bioinformatics 4: 193-201.

Pawlowska TE, Taylor JW. 2004. Organization of genetic variation in individuals of arbuscular mycorrhizal fungi. Nature 427 : 733-737.

Redecker D, Morton JB, Bruns TD. 2000. Ancestral lineages of arbuscular mycorrhizal fungi (Glomales). Molecular Phylogenetics and Evolution 14: 276-284.

Renker C, Blanke V, Buscot F. 2005. Diversity of arbuscular mycorrhizal fungi in grassland spontaneously developed on area polluted by a fertilizer plant. Environmental Pollution 135: 255-266.

Renker C, Heinrichs J, Kaldorf M, Buscot F. 2003. Combining nested PCR and restriction digest of the internal transcribed spacer region to characterize arbuscular mycorrhizal fungi on roots from the field. Mycorrhiza 13: 191-198.

Ronquist F, Huelsenbeck JP. 2003. MRBAYEs 3: Bayesian phylogenetic inference under mixed models. Bioinformatics 19: 1572-1574.

Sawaki H, Sugawara K, Saito M. 1998. Phylogenetic position of an arbuscular mycorrhizal fungus, Acaulospora gerdemannii, and its synanamorph Glomus leptotichum, based upon $18 \mathrm{~S}$ rRNA gene sequence. Mycoscience 39: 477-480.

Schenck NC, Smith GS. 1982. Additional new and unreported species of mycorrhizal fungi (Endogonaceae) from Florida. Mycologia 74: 77-92.

Schmidt HA, Strimmer K, Vingron M, von Haeseler A. 2002. TREe-PUZZLE: maximum likelihood phylogenetic analysis using quartets and parallel computing. Bioinformatics 18: 502-504.

Schüßler A, Schwarzott D, Walker C. 2001. A new fungal phylum, the Glomeromycota: phylogeny and evolution. Mycological Research 105: 1413-1421.

Schwarzott D, Schüßler A. 2001. A simple and reliable method for SSU rRNA gene DNA extraction amplification and cloning from single AM fungal spores. Mycorrhiza 10: 203-207.

Schwarzott D, Schüßler A, Walker C. 2001. Glomus, the largest genus of the arbuscular mycorrhizal fungi (Glomales), is nonmonophyletic. Molecular Phylogenetics and Evolotion 21: 190-197.

Seifert KA, Samson RA, deWaard JR, Houbraken J, Levesque C, Moncalvo JM, Louis-Seize G, Hebert PD. 2007. Prospects for fungus identification using CO1 DNA barcodes, with Penicillium as a test case. Proceedings of the National Academy of Sciences, USA 104: 3901-3906.

Simon UK, Weiss M. 2008. Intragenomic variation of fungal ribosomal genes is higher than previously thought. Molecular Biology and Evolution 25: 2251-2254.

Smith SE, Read DJ. 2008. Mycorrhizal symbiosis. Cambridge, UK: Academic Press.

Stamatakis A, Hoover P. 2008. A rapid bootstrap algorithm for the RAXML web-servers. Systematic Biology 75: 758-771. 
New

van Tuinen D, Zhao B, Gianinazzi-Pearson V. 1998. PCR in studies of AM fungi: from primers to application. In: Varma A, ed. Mycorhiza Manual. Berlin, Germany: Springer, 387-399.

Walker C. 2008. Quality control through record keeping and vouchers and a tale of confusion with Glomus intraradices. In: Baar J, Estuan V, Ortas I, Orfanoudakis M, Alifragis D, eds. Mycorrhiza application in sustainable agriculture and natural systems. Thessaloniki, Greece: Aristotle University of Thessaloniki, 29-34.
Walker C, Vestberg M. 1994. A simple and inexpensive method for producing and maintaining closed pot cultures of arbuscular mycorrhizal fungi. Agricultural Science in Finland 3: 233-240.

Walker C, Vestberg M, Demircik F, Stockinger H, Saito M, Sawaki H, Nishmura I, Schüßler A. 2007. Molecular phylogeny and new taxa in the Archaeosporales (Glomeromycota): Ambispora fennica gen. sp. nov., Ambisporaceae fam. nov., and emendation of Archaeospora and Archaeosporaceae. Mycological Research 111: 137-153.

\section{Pabout New Phytologist}

- New Phytologist is owned by a non-profit-making charitable trust dedicated to the promotion of plant science, facilitating projects from symposia to open access for our Tansley reviews. Complete information is available at www.newphytologist.org.

- Regular papers, Letters, Research reviews, Rapid reports and both Modelling/Theory and Methods papers are encouraged. We are committed to rapid processing, from online submission through to publication 'as-ready' via Early View - our average submission to decision time is just 29 days. Online-only colour is free, and essential print colour costs will be met if necessary. We also provide 25 offprints as well as a PDF for each article.

- For online summaries and ToC alerts, go to the website and click on 'Journal online'. You can take out a personal subscription to the journal for a fraction of the institutional price. Rates start at $£ 139$ in Europe/\$259 in the USA \& Canada for the online edition (click on 'Subscribe' at the website).

- If you have any questions, do get in touch with Central Office (newphytol@lancaster.ac.uk; tel +44 1524 594691) or, for a local contact in North America, the US Office (newphytol@ornl.gov; tel +1 865576 5261). 
DNA-based species level detection of Glomeromycota: one PCR primer set for all arbuscular mycorrhizal fungi. 


\section{DNA barcoding of arbuscular mycorrhizal fungi}

The content of this chapter was submitted to the journal New Phytologist at the 14.12.2009.

Stockinger H, Krüger M, Schüßler A. DNA barcoding for arbuscular mycorrhizal fungi. 


\subsection{Abstract}

- $\quad$ Currently, no official DNA barcode region is defined for the Fungi. The genes COX1 and mtLSU turned out to be difficult to apply, and the ITS region, the primary candidate for a fungal DNA barcode, was shown not to resolve closely related species of arbuscular mycorrhizal fungi (AMF).

- $\quad$ DNA barcoding analyses were performed with datasets from several phylogenetic lineages of the Glomeromycota. We tested an approx. $1500 \mathrm{bp}$ fragment of the nuclear ribosomal DNA, covering approx. $240 \mathrm{bp}$ of the SSU and $800 \mathrm{bp}$ of the LSU rRNA genes and the complete ITS region, for species resolving power. Moreover, the complete ITS region, the 800 bp LSU rDNA, as well as three shorter fragments, spanning the ITS2 and 5.8S rRNA gene, the LSU-D1 rDNA domain, or the LSU-D2 domain, were analysed.

- The results show, that only the longest fragment resolves all analysed species. All other, shorter fragments failed to distinguish some closely related species.

- We recommend using the 1500 bp fragment as a base for phylogenetic DNA barcoding of AMF. This will also allow future identification of AMF at species level using shorter DNA amplicons, e.g. from deep sequencing approaches.

\subsection{Introduction}

The aim of the present study was the definition of a DNA barcoding region for arbuscular mycorrhizal fungi (AMF), which is also useful for molecular in-field community studies. Despite the fact, that AMF are perhaps the most important fungi in terrestrial ecosystems, forming intimate, mutualistic symbioses with approximately $80 \%$ of land plants (Brundrett, 2009), much of their biology still is enigmatic. The asexual, obligate symbiotic and below ground lifestyle makes AMF difficult to study and, e.g., the nutrients transport capabilities and efficiencies in different AMFplant associations, formed by individual species or species combinations, are little understood. Different functional traits and mechanisms regarding plant nutrition by AMF are expected to exist, but it is mostly unknown which AMF (communities) preferentially associate with which plants, and under which environmental conditions. As long as AMF species cannot be reliably identified and monitored in the field, such questions are difficult to answer and the lack of such basic data will hinder the exploration of functional and causal aspects for differential AMF-plant associations. Moreover, a better understanding of AMF-plant associations and preferences may also directly 
impact human life, e.g. by improvement of sustainable management practices in agriculture and forestry, making use of efficient AMF-plant combinations.

\subsubsection{Identification of AM fungal species from the field}

All AMF belong to the phylum Glomeromycota (Schüßler et al., 2001). Historically, species recognition was mainly through spore morphology, but modern molecular methods revealed cryptic species and, on the other hand, spore types that were affiliated to distinct families turned out to be of conspecific origin. A well known example are the spore morphs of Ambispora leptoticha, which were thought to represent different species but in fact are an example of spore dimorphism (Sawaki et al., 1998; Redecker et al., 2000; Walker et al., 2007). Many AMF community analyses are based on morphologically monitoring AMF spore occurrences in the soil (e.g., Oehl et al., 2009; Robinson-Boyer et al., 2009). However, such assays use resting stages and consequently do not necessarily reflect the AMF that are physiologically active in the soil and plant roots (Sanders, 2004). Also, relatively little is known about the AMF sporulation behaviour, which may depend on season, environment, or host plant, and change over both space and time (Walker et al. 1982).

To overcome such drawbacks, molecular methods were developed to detect AMF directly within roots. The most frequently used markers are one or more of the nuclear rRNA genes, e.g. the widely used SSU rRNA gene (Helgason et al., 1999; Wubet et al., 2006; Lee et al., 2008; Öpik et al., 2009), the ITS rDNA region including the 5.8S rRNA gene (Wubet et al., 2004; Hempel et al., 2007; Sýkorová et al., 2007), and a part of the LSU rRNA gene (Turnau et al., 2001; Gollotte et al., 2004; Gamper \& Leuchtmann, 2007; Pivato et al., 2007). However, also many molecular analyses are biased, as often only parts of the AMF community are detected with the used primers and the taxon-resolution level is uncertain. Moreover, neither a single molecular marker suitable for species level resolution of all AMF, nor a comprehensive and validated sequence database is yet available. Nevertheless, recent research shows that species level community analyses should be feasible based on rDNA regions (Gamper et al., 2009; Krüger et al., 2009; Stockinger et al., 2009).

\subsubsection{DNA barcoding for species definition and identification}

DNA barcoding is presently defined as the analysis of an easily amplifiable PCR fragment for sequence based identification of species. Identifications must be accurate, rapid, cost-effective, culture-independent, universally accessible, and usable by non-experts (Frézal \& Leblois, 2008). In addition, cryptic species could be recognized, and organisms can be identified in life cycle stages 
not suited for morphological identification (Gilmore et al., 2009).

In DNA barcoding, species are separated by a 'barcode gap' analysis or by fast phylogenetic analysis. A barcode gap is based on the difference between the maximum intraspecific sequence variation of a species and the minimum interspecific variation. If the minimum interspecific variation is bigger than the maximum intraspecific variation, a barcode gap exists. Alternatively, phylogenetic neighbour joining analysis based on Kimura two-parameter $(\mathrm{K} 2 \mathrm{P}=\mathrm{K} 80)$ distances are often used. Though these are the currently preferred methods, in future more sophisticated phylogenetic methods will probably be developed.

For animals, a part of the mitochondrial cytochrome c oxidase 1 (COXI) gene has become the first official DNA barcode (Hebert et al., 2004) (http://www.barcoding.si.edu/) and a barcoding system for plants was established recently, based on the $r b c L$ and matK loci (Hollingsworth et al., 2009).

\subsubsection{DNA barcode(s) for fungi}

There is not yet an officially agreed DNA barcoding method for fungi. Such a DNA based species identification system would be very useful, as most fungi cannot be identified in their vegetative, hyphal growth phase. There are approximately 100000 named fungal species (Kirk et al., 2008), and estimates suggest there may be as many as 1.5-3.5 million species in existence (Hawksworth, 2001; O'Brien et al., 2005), many of them perhaps will only be accessible by molecular methods, in future.

The nuclear ITS rDNA region is commonly used for fungi since long (White et al., 1990; Gardes \& Bruns, 1993) and will probably be proposed to the Consortium for the Barcode of Life (CBOL, www.barcoding.si.edu) as a fungal barcode (Seifert et al., 2009). Unfortunately, quality problems exist for fungal barcoding, as sequence data are often derived from inaccurately identified material (Ryberg et al., 2008), the lack of vouchers precludes verification (Agerer et al., 2000), and third party annotations in sequence database as GenBank are not possible (Bidartondo et al., 2008). Initiatives like UNITE (http://unite.ut.ee) were established to provide validated and curated data, but such data are still lacking for most fungi, AMF inclusive.

\subsubsection{COX1 is not suited as general fungal barcode}

A prerequisite for not using the COX1 region, according to the CBOL standards, should be the demonstration that it is unsuitable for easy species identification. Although this region showed promise for Penicillium spp. (Seifert et al., 2007), the length of fungal COX1 is highly variable 
(from 1.6 to $22 \mathrm{~kb}$ ). The shortest potential barcoding region varies in length from $642 \mathrm{bp}$ to $>12 \mathrm{~kb}$ (Seifert, 2009), presenting difficulties for PCR-amplification and sequencing. Moreover fungal species level discrimination with COX1 genes is inaccurate (Chase \& Fay, 2009) and in Fusarium and the Aspergillus niger complex multiple paralogous copies hinder species level resolution (Geiser et al., 2007; Gilmore et al., 2009). For AMF, the barcoding region of COX1 in Glomus sp. FACE\#494 spans 2200 bp and contains introns (Lee \& Young, 2009). Land and Hijri (2009) stated that the mtDNA of Glomus diaphanum contains a COX1 intron with high sequences similarity to a corresponding COX1 intron detected in plants and Rhizopus oryzae. The plant intron probably originated by horizontal gene transfer (HGT) from fungi (Vaughn et al., 1995; Lang \& Hijri, 2009), further questioning the general usability of $C O X 1$ as a barcode for fungi, and also plants.

As COX1 seems unsuited for Glomeromycota, the mitochondrial large subunit (mtLSU) rRNA gene was considered as an alternative. Unfortunately it also seems inapplicable because introns create very variable fragment sizes even in closely related species (Börstler et al., 2008).

\subsubsection{Defining a DNA barcoding region for AMF}

The goal of the present study was to compare different nuclear rRNA gene regions with the ITS rDNA region for use as a general DNA barcode for Glomeromycota, and to make recommendations based on the analyses of new rDNA sequence datasets. This directly relates to the applicability of environmental deep sequencing approaches using the 454 GS-FLX Titanium system, currently allowing approx. $400 \mathrm{bp}$ average read lengths (www.454.com). It was already demonstrated, that the highly variable ITS rDNA region cannot discriminate some closely related species, e.g. in Glomus Group $\mathrm{Ab}$ ('Gl. intraradices group'), which includes the model AMF Glomus sp. DAOM197198 (Stockinger et al., 2009).

For convenience, we further on abbreviate the nuc SSU rRNA gene, as SSU, the nuc LSU rRNA gene, as LSU, and the 5.8S rRNA gene, as 5.8S; the term ITS region is used for the complete ITS15.8S-ITS2 rDNA (Fig. 3). In this study, a DNA fragment of approx. $1500 \mathrm{bp}$ was sequenced from species in divergent AMF clades, covering approx. 240 bp of the SSU, the complete ITS region, and approx. $800 \mathrm{bp}$ of the LSU. We compared the complete fragment (1420-1602 bp), the ITS-region (400-526 bp), the LSU-region (776-852 bp), and three 400-500 bp fragments, covering the 5.8S+ITS2, LSU-D1, or LSU-D2, respectively, for species resolving power and suitability as DNA barcodes. 


\subsection{Material \& Methods}

\subsubsection{Taxa and public sequences used for analyses}

The 'core dataset' sequences investigated in this study (Table 1) cover the partial SSU, the ITSregion, and the partial LSU, at least corresponding to a fragment spanning the region amplified with primers SSU-Glom1 (Renker et al., 2003) and NDL22 (van Tuinen et al., 1998). For all AMF analysed, a culture identifier or a voucher deposited in a herbarium (W-numbers) are known, for most both information is available. The attempt (Att) numbers refer to the collection of Christopher Walker, BEG identifiers to the 'International bank for the Glomeromycota' (http://www.kent.ac.uk/bio/beg), INVAM to the international culture collection of (vesicular) arbuscular mycorrhizal fungi (http://invam.caf.wvu.edu) and MUCL to the Glomeromycota in vitro collection (GINCO; http://emma.agro.ucl.ac.be/ginco-bel/). In addition some other identifiers are listed for certain AMF species (Table 1).

For analysis of the five AMF species analysed in the AFTOL project (James et al., 2006), the individual SSU, ITS and LSU sequences of each species were assembled to a consensus sequence. For the 'extended dataset' analyses of the Ambisporaceae, Diversisporaceae and Glomus Group Aa, additional public database sequences were included (Table S1-S5) Sequences indicated in Schüßler et al. (2003) as probably derived from contaminants were not used. 
DNA barcoding of arbuscular mycorrhizal fungi

Table 1: Sequences used to assemble the core dataset. Number of spores used for DNA extraction is shown, if known (ss, single spore; ms, multi-spore), as well as cloning numbers (in parentheses, following the number of sequences) and the primers used for the new sequences published here (in parentheses, following the accession numbers; [n], amplified by nested PCR).

\begin{tabular}{|c|c|c|c|c|}
\hline Identifier, culture/voucher & Species name & $\begin{array}{l}\text { No. of } \\
\text { sequences }\end{array}$ & $\begin{array}{l}\text { DNA } \\
\text { extraction }\end{array}$ & Acc Nos. \\
\hline BEG12, Att109-20/W5147 & Glomus mosseae & $\begin{array}{l}8(\mathrm{pHS} 101) \\
7(\mathrm{pHS} 110)\end{array}$ & $1 \times \mathrm{ss}$ & $\begin{array}{l}\text { FN547474-6,82-93 (SSUmCf-LSUmBr } \\
[\mathrm{n}])\end{array}$ \\
\hline WUM3, Att15-5/W2939 & Glomus sp. WUM3 & 5 (pMK23) & ss & FN547477-81 (SSUGlom1-NDL22 [n]) \\
\hline MUCL41827, -/- & Glomus proliferum & 2 (pHS113) & ss & FN547500-1(SSUmCf-LSUmBr [n]) \\
\hline BEG13, -/W5258 & Acaulospora laevis & 7 (pHS054) & ss & FN547507-12, 16 (SSUmAf-LR4+2) \\
\hline Att423-4/W3077 & Acaulospora cf. laevis & 6 (pHS032) & ss & FN547502-6,17 (SSUmAf-LR4+2) \\
\hline BEG26, -/- & Acaulospora cf. laevis & 5 (pHS030) & ss & $\begin{array}{l}\text { FN547513-5,18,19 (SSUGlom1- } \\
\text { NDL22[n]) }\end{array}$ \\
\hline $\begin{array}{l}\text { INVAM TW111, Att1499- } \\
\text { 9/W5346 }\end{array}$ & Kuklospora kentinensis & 4 (pHS098) & ss & FN547520-3 (SSUmCf-LSUmBr [n]) \\
\hline Att1235-2/W5156 & Ambispora appendicula & 11 (pMK096) & $\begin{array}{l}\mathrm{ms} \\
(3 \text { spores })\end{array}$ & FN547524-34 (SSUmAf-LSUmAr) \\
\hline Att200-23/W4752 & Ambispora fennica & $12(\mathrm{pMK} 094)$ & ss & FN547535-46 (SSUmCf-LSUmBr [n]) \\
\hline BEG34, -/- & Gigaspora margarita & 24 (pHS108) & ss & FN547547-70 (SSUmAf-LSUmAr) \\
\hline $\begin{array}{l}\text { DAOM194757, Att1509- } \\
\text { 20/W5384 }\end{array}$ & Gigaspora rosea & $\begin{array}{l}6(\mathrm{pHS} 106), \\
18(\mathrm{pHS} 105), \\
3(\mathrm{pHS} 104)\end{array}$ & $1 \mathrm{x} \mathrm{ss}$ & FN547571-97 (SSUmCf-LSUmBr [n]) \\
\hline $\begin{array}{l}\text { FCPC1145, Att590- } \\
\text { 16/W5342 }\end{array}$ & Scutellospora gilmorei & $\begin{array}{l}21(\mathrm{pHS} 107) \\
5(\mathrm{pHS} 103)\end{array}$ & $1 \mathrm{x} \mathrm{ss}$ & FN547598-622 (SSUmCf-LSUmBr [n]) \\
\hline Att1505-8/W5347 & Glomus etunicatum & $12(\mathrm{pHS} 112)$ & ss & FN547623-34 (SSUGlom1-NDL22 [n]) \\
\hline BEG20, Att263-15/W3294 & Glomus caledonium & 6 (pHS031) & ss & FN547494-9 (SSUGlom1-NDL22 [n]) \\
\hline BEG47, Att475-45/W5165 & Glomus versiforme & 2 (pHS034) & ss & FN547635-6 (SSUGlom1-NDL22 [n]) \\
\hline BEG47, Att475-22/W3180 & Glomus versiforme & $\begin{array}{l}10(\mathrm{pMK} 73) \\
6(\mathrm{pMK} 72)\end{array}$ & $2 \mathrm{x} \mathrm{ss}$ & FN547666-81 (SSUmAf-LR4+2) \\
\hline Att1296-0/W4728 & Glomus aurantium & 11 (pHS109) & ss & FN547655-65 (SSUmCf-LSUmBr [n]) \\
\hline Att246-18/W4119 & Diversispora spurca & 18 (pHS100) & ss & FN547637-54 (SSUmCf-LSUmBr [n]) \\
\hline WUM18, Att869-3/- & Acaulospora sp. WUM18 & $2^{1}$ & ss & FM876792-3 \\
\hline BEG33, Att209-37/- & Acaulospora scrobiculata & $4^{1}$ & ss & FM876788-91 \\
\hline BEG231, FACE\#234 & Diversispora celata & $3^{2}$ & $\mathrm{~ms}$ & AM713402-4 \\
\hline $\begin{array}{l}\text { INVAM AZ420A, Att1290- } \\
\text { 5/W4729 }\end{array}$ & Glomus eburneum & $12^{2}$ & $\mathrm{~ms}$ & AM713405-16 \\
\hline BEG28, Att108-7/- & Glomus coronatum & $5^{1}$ & ss & FM876794-8 \\
\hline WUM3, Att15-5/W2940 & Glomus sp. WUM3 & $1^{1}$ & ss & FM876813 \\
\hline INVAM SA101, Att676-5/- & Glomus luteum & $5^{1}$ & ss & FM876808-12 \\
\hline Att565-11/W3349 & Glomus sp. W3349 & $4^{1}$ & ss & FM876804-7 \\
\hline WUM11, Att862-7/W2928 & Acaulospora laevis & $8^{1}$ & ss & FM876780-7 \\
\hline Att894-7/- & Glomus cf. clarum & $9^{3}$ & ss & FM865536-44 \\
\hline $\begin{array}{l}\text { DAOM197198 related, - } \\
\text { /W5533, W5495, W3182, } \\
\text { W5499; BEG195, -/W5272 }\end{array}$ & Glomus sp. 'irregulare-like' & $39^{3}$ & $\begin{array}{l}4 \times \mathrm{ss} \\
1 \times \mathrm{ms} \\
(3 \mathrm{spores})\end{array}$ & $\begin{array}{l}\text { FM865550-8, FM865588-96, } \\
\text { FM865608-17, FM992377-87 }\end{array}$ \\
\hline $\begin{array}{l}\text { INVAM FL208, -/W5413, } \\
\text { W5166, W5507; } \\
\text { MUCL49410, -/W5070 }\end{array}$ & Glomus intraradices & $45^{3}$ & $4 \times$ ss & $\begin{array}{l}\text { FM865545-49, FM865559-87, } \\
\text { FM865597-607 }\end{array}$ \\
\hline -/W4545 & Pacispora scintillans & $2^{1}$ & ss & FM876831-2 \\
\hline $\begin{array}{l}\text { INVAM TW111, } \\
\text { Att1499-9/W5346 }\end{array}$ & Kuklospora kentinensis & $10^{1}$ & ss & FM876821-30 \\
\hline MUCL41827, -/- & Glomus proliferum & $15^{3}$ & $\begin{array}{l}1 \mathrm{x} \text { ss, } 1 \mathrm{x} \\
\mathrm{ms}\end{array}$ & FM992388-402 \\
\hline -/W3009 & Scutellospora spinosissima & $3^{1}$ & ss & FM876834-6 \\
\hline
\end{tabular}


DNA barcoding of arbuscular mycorrhizal fungi

\begin{tabular}{|c|c|c|c|c|}
\hline$\overline{\mathrm{BEG} 35, \text { Att334-16/- }}$ & Scutellospora heterogama & $3^{1}$ & ss & FM876837-9 \\
\hline BEG47, Att475-45/W5165 & Glomus versiforme & $7^{1}$ & ss & FM876814-20 \\
\hline $\begin{array}{l}\text { AFTOL-139/ } \\
\text { INVAM UT101 }\end{array}$ & Glomus mosseae & $1^{4}$ & unknown & $\begin{array}{l}\text { Consensus AY635833 + AY997053 + } \\
\text { DQ273793 }\end{array}$ \\
\hline $\begin{array}{l}\text { AFTOL-845/ } \\
\text { 4695rac-11G2 }\end{array}$ & Glomus sp. 'irregulare-like' & $1^{4}$ & unknown & $\begin{array}{l}\text { Consensus DQ273828 + DQ322630 + } \\
\text { AY997054 }\end{array}$ \\
\hline $\begin{array}{l}\text { AFTOL-48/ } \\
\text { DAOM181602 }\end{array}$ & Glomus sp. 'irregulare-like' & $1^{4}$ & $\mathrm{~ms}$ & $\begin{array}{l}\text { Consensus AY635831 + AY997052 + } \\
\text { DQ273790 }\end{array}$ \\
\hline $\begin{array}{l}\text { AFTOL-138/ } \\
\text { INVAM FL225 }\end{array}$ & Scutellospora heterogama & $1^{4}$ & unknown & $\begin{array}{l}\text { Consensus AY635832 + AY997088 + } \\
\text { DQ273792 }\end{array}$ \\
\hline $\begin{array}{l}\text { AFTOL-844/ } \\
\text { INVAM IA702 }\end{array}$ & Paraglomus occultum & $1^{4}$ & unknown & $\begin{array}{l}\text { Consensus DQ322629 + DQ273827 + } \\
\text { AY997069 }\end{array}$ \\
\hline
\end{tabular}

${ }^{1}$ Krüger et al. 2009, ${ }^{2}$ Gamper et al. 2009, ${ }^{3}$ Stockinger et al. 2009, ${ }^{4}$ James et al. 2006 


\subsubsection{DNA extraction, PCR amplification, cloning and sequencing}

Spores were cleaned and DNA was extracted as described in Schwarzott \& Schüßler (2001). Some spores were crushed in 5x PCR buffer according to Lumini et al. (2007). As PCR template, $5 \mu 1$ of the DNA extract were used in $20 \mu 1$ final reaction volume. In the early phase of the study, PCR was performed using the primers SSU-Glom1 and NDL22 or LR4+2 (Stockinger et al., 2009). Most AMF cultures studied later were characterised by the nested PCR approach with AMF specific primers (Krüger et al., 2009; see Table 1). PCR using the Phusion High Fidelity DNA polymerase (Finnzymes, Espoo, Finland), cloning, RFLP analyses and sequencing were performed as described in Krüger et al. (2009), with exception of Gl. caledonium BEG20 which was amplified using a Taq DNA polymerase (Peqlab, Erlangen, Germany) and some clones which were obtained using the StrataClone Blunt PCR Cloning Kit (Stratagene Agilent Technologies, La Jolla, CA, USA), according to the manual. Sequences were assembled and proofread with SeqAssem (http://www.sequentix.de) and deposited in the EMBL/GenBank/DDBJ databases with the accession numbers FN547474-FN547681.

\subsubsection{Phylogenetic and sequence divergence analyses}

The $3^{\prime}$ partial SSU, the ITS region, and the 5' partial LSU sequences from this study and public database sequences covering the same regions were analysed for their species resolving power (Table 1). Data were mainly from characterized AMF species, from single spore DNA extractions or single spore isolates. Regions were separated either by the gene borders, or by frequently used primer binding sites. The ITS region (400-526 bp) including the 5.8S was cut at the border to SSU and LSU rRNA genes; the LSU fragment (776-852 bp) covering the 5' LSU rRNA gene region until the binding site of primer LSUmBr (Krüger et al., 2009); the ITS2 fragment (352-430 bp) corresponds to an ITS3-ITS4 (White et al., 1990) amplicon and includes most of the 5.8S rRNA gene and the complete ITS2 region; the LSU-D1 fragment (281-394 bp) corresponds to a LR1FLR3reverse amplicon (van Tuinen et al., 1998), whereas FLR3 was designed as a forward primer (Gollotte et al., 2004); the LSU-D2 fragment (370-436 bp) corresponds to an FLR3-LSUmBr amplicon (Fig. 3).

For three AMF families, the ITS region or a part of the LSU was analysed after adding shorter or less well defined sequences from the database. Those were aligned to the core dataset with Align (http://www.sequentix.de) or ARB (Ludwig et al., 2004; http://www.arb-home.de). The resulting 
dataset is referred to as 'extended dataset'. Sequence divergences were calculated based on the K2P model (Kimura, 1980) with pairwise deletion of gaps, using the APE package of R (Paradis et al., 2004). To illustrate the sequence divergences within and between species, TaxonGap2.3 (Slabbinck et al., 2008) was used.

The analyses of database sequences included identical sequences, when it was unclear if these originated from the same or different spores or even cultures. Phylogenetic analyses were performed with PHYLIP3.6 (Felsenstein, 2004), using the neighbour joining method (based on K2P model). A consensus tree was calculated from 1000-fold bootstrapped analyses with SumTrees (Sukumaran \& Holder, 2008) and the bootstrap (BS) values were mapped on the neighbour joining tree. As an alternative approach, the sequences were aligned automatically using the MAFFT online server (MAFFT version 6; http://align.bmr.kyushu-u.ac.jp/mafft/online/server/), for comparison with the results from the manual alignment. The iterative refinement option of MAFFT was set to FFT-NS-i (Katoh et al., 2002). Phylogenetic trees were processed with TreeGraph2 (treegraph.bioinfweb.info), TreeViewJ (Peterson \& Colosimo, 2007), and Treedyn (Chevenet et al., 2006) and refined with Adobe Illustrator CS3.

Figure 3: Schematic representation of the nuclear ribosomal DNA regions studied. Positions of priming sites that were used as borders for in silico analyses of the fragments are shown as black triangles. Black lines indicate the fragments analysed.

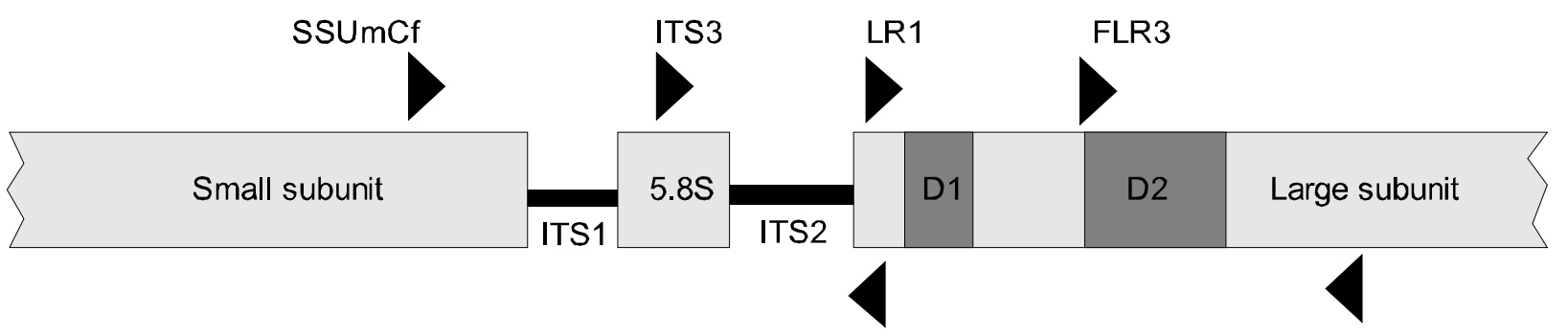

SSUmCf-LSUmBr

ITS4

LSUmBr

ITS region

LSU region

ITS2 fragment

LSU-D1 fragment

LSU-D2 fragment 


\subsection{Results}

\subsubsection{Intraspecific rDNA sequence variation}

No general intraspecific percentage of sequence variation (K2P distance) could be defined as a threshold to separate AMF species, even within individual families in the Glomeromycota. For the longest DNA fragment studied, SSUmCf-LSUmBr (approx. 1500 bp, see Table S6, corresponding to the core dataset), the variation ranged from $0.47-10.8 \%$. When taking only the seven species into account for which at least 24 sequence variants are available (Ac. laevis, Gi. margarita, Gi. rosea, Sc. gilmorei, Gl. intraradices. Glomus sp. 'irregulare-like' and Gl. versiforme) the minimum intraspecific variation was $1.55 \%$. The highest value of $10.8 \%$ was found in Gl. intraradices (cultures FL208 and MUCL49410).

The ITS region revealed a variation of $0.23-14.6 \%$, or $2.96-14.6 \%$ when only analysing the seven species with at least 24 variants of the SSUmCf-LSUmBr fragment available, respectively. Glomus intraradices (FL208 and MUCL49410) again showed the highest intraspecific variation with $14.6 \%$. Interestingly, the highest maximum intraspecific variation of $15.7 \%$, for Gl. intraradices, was found in the LSU-D2 fragment (FLR3-LSUmBr). The range of variation in this region was 0$15.7 \%$ (2.8-15.7\% for species with at least 24 variants known).

For the LSU-D1 fragment (LR1-FLR3), five species lacked intraspecific variation (number of distinct sequences in parentheses): Glomus sp. WUM3 (6), Gl. caledonium (3), Acaulospora scrobiculata (4), Gl. luteum (5), Diversispora celata (3). In general, this region showed the lowest intraspecific variation for most species analysed, but with exceptions. For Kuklospora kentinensis (14) a variation of $0.5 \%$ was found in the LSU-D1 fragment but the ITS2 fragment (ITS3-ITS4) showed no variation at all for this species.

\subsubsection{Barcode gap analyses}

A barcode gap is not a prerequisite for DNA barcoding, but may be helpful to distinguish species without the need of phylogenetic analyses (e.g., Hebert et al., 2004). Comparison of the different regions, regardless of the alignment method used (Table S6, Figure 4), showed that the complete fragment (SSUmCf-LSUmBr) had the lowest number (4) of species without a barcode gap, followed by the complete ITS region with 5 species and the LSU region with 7. Analysis of the LSU-D2 fragment resulted in 7 species lacking a barcode gap, whereas the less variable LSU-D1 fragment revealed 12 species without a barcode gap. The ITS2 fragment (covering most of the 5.8S) 
resulted in 8 species without a barcode gap. For the complete fragment, the size of the existing barcode gaps varied from only $0.1 \%$ to $22 \%$.

Figure 4: Barcode gap analyses of the rDNA regions studied. The SSUmCf-LSUmBr fragment was aligned either manually or automated (MAFFT). Light bar: maximum intraspecific variation, dark bar: minimum interspecific variation; to the right of the bar the closest species is given, respectively. Scale on top is \% variation based on K2P distances. Vertical line indicates the minimal interspecific variation. 

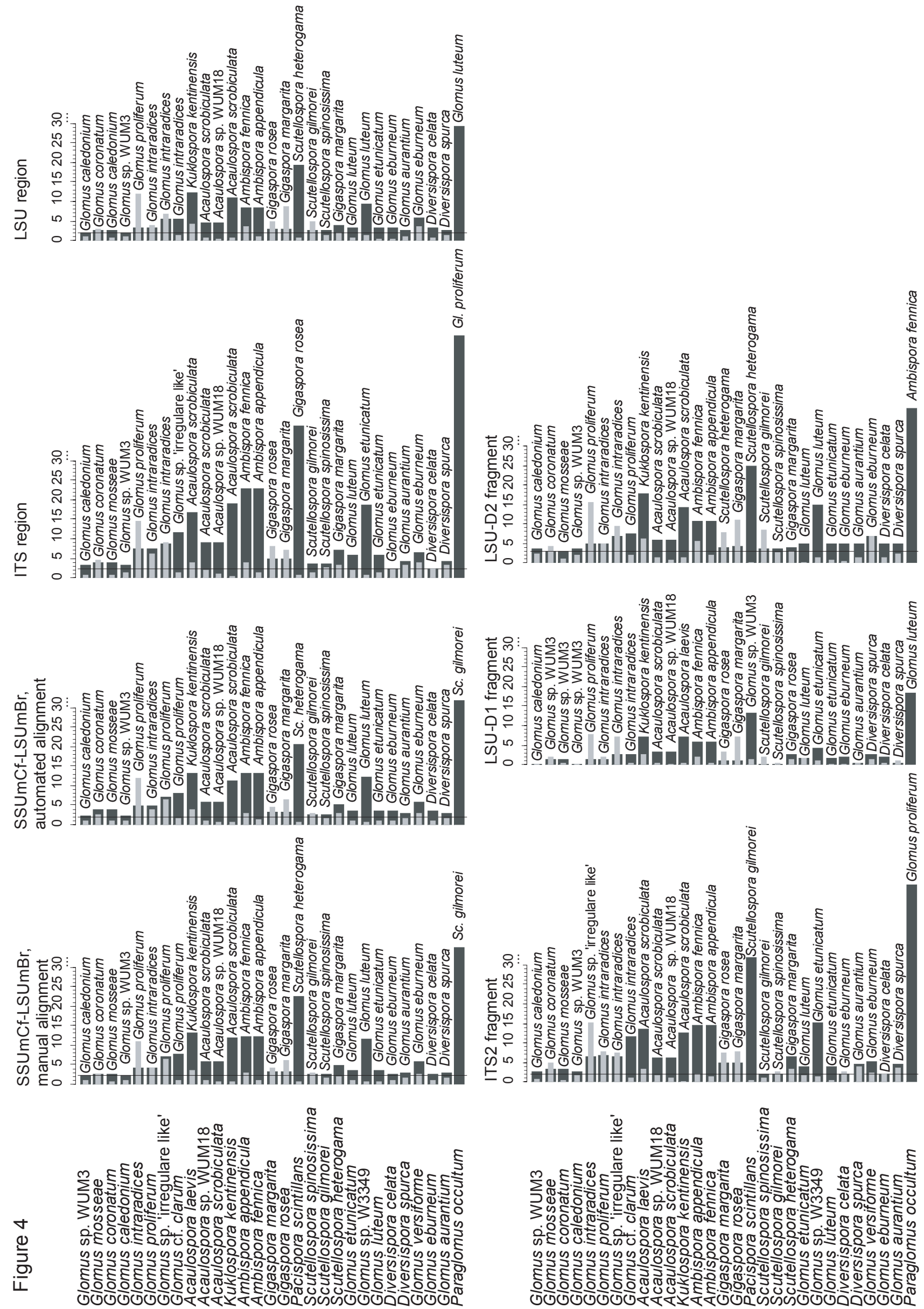


\subsubsection{Phylogenetic analyses of the core dataset}

The Gigasporaceae, Acaulosporaceae, Diversisporaceae, Ambisporaceae, Glomus Group B, Glomus Group Aa and Glomus Group Ab were analysed separately, as the high variation in the ITS region made it impossible to align across family level groups. For each group, five defined regions covered by the SSUmCf-LSUmBr fragment were analysed (Figure 3). All positions in the alignment were included in the phylogenetic analyses (Figure 5, Supplementary Figs S1-S6), as summarized in Table 2 for the core dataset (Figure 5 and Supplementary Figs S1-S6).

Using the complete fragment (SSUmCf-LSUmBr) resulted in the best discriminatory power. Each of the known species was resolved with bootstrap support of at least $72 \%$, for most species of $>90 \%$. Almost all species studied could be separated using the complete ITS region, except $G l$. intraradices and its close relatives. Similarly, maximum likelihood analyses of this region did not resolve sequences of $G l$. intraradices (FL208 and MUCL49410) and related species as monophyletic clades (Stockinger et al., 2009).

Analyses of the LSU region resulted in the similar problems regarding lacking resolution of $G l$. intraradices and its close relatives. Two other species, Scutellospora spinosissima (3 sequences) and $\mathrm{Gl}$. proliferum (15 sequences), were not resolved as monophyletic. In addition, the Gigaspora rosea clade (27 sequences) had bootstrap support below $50 \%$; the other species were separated with support values of at least $55 \%$. When the three shorter ITS2, LSU-D1 and LSU-D2 fragments were analysed separately, the LSU-D1 fragment performed worst. Sequences from 11 of the 25 species did not form monophyletic clades. The ITS2 and LSU-D2 fragments performed better, but still could not resolve two species (Gl. proliferum, 15 sequences; Gl. intraradices FL208 and MUCL49410, together 47 sequences), respectively. Gigaspora margarita BEG34 did not form a well supported clade for either fragment. The third species not resolved as monophyletic in the LSU-D2 analysis was Sc. spinosissima (3 sequences). The AFTOL sequences of Gl. mosseae and Sc. heterogama cluster with other sequences of the corresponding species, whereas the AFTOL Glomus sp. 'intraradices' sequences, derived either from culture MUCL43194 (=DAOM197198, =DAOM181602; used for the Glomus genome sequencing project) or from "GINCO \#4695rac11G2", clearly cluster with Glomus irregulare in the 'Gl. irregulare-clade', confirming the evidence of Stockinger et al. (2009). 
Table 2: Neighbour joining analyses (based on K2P distances, 1000 bootstraps) of six different regions (complete SSUmCf-LSUmBr fragment, complete ITS region, ITS2, LSU, LSU-D1 and LSU-D2 fragments). Respective bootstrap values supporting species as monophyletic are shown.

\begin{tabular}{|c|c|c|c|c|c|c|}
\hline & $\begin{array}{l}\text { SSUmCf- } \\
\text { LSUmBr }\end{array}$ & $\begin{array}{l}\text { ITS } \\
\text { region }\end{array}$ & LSU & $\begin{array}{c}\text { ITS2 } \\
\text { (ITS3-ITS4) }\end{array}$ & $\begin{array}{c}\text { LSU-D1 } \\
\text { (LR1-FLR3) }\end{array}$ & $\begin{array}{c}\text { LSU-D2 } \\
\text { (FLR3-LSUmBr) }\end{array}$ \\
\hline Gigaspora margarita & 88 & 75 & 55 & 47 & & 34 \\
\hline Gigaspora rosea & 100 & 90 & 48 & 90 & & 59 \\
\hline Scutellospora gilmorei & 100 & 99 & 88 & 100 & & 69 \\
\hline Scutellospora spinosissima & 92 & 96 & & 95 & & \\
\hline Scutellospora heterogama & 100 & 100 & 100 & 100 & 97 & 98 \\
\hline Length of alignment (positions) & 1505 & 468 & 795 & 394 & 398 & 376 \\
\hline Acaulospora laevis & 100 & 100 & 100 & 100 & 100 & 100 \\
\hline Acaulospora scrobiculata & 100 & 100 & 100 & 100 & 100 & 100 \\
\hline Acaulospora sp. WUM18 & 100 & 100 & 100 & 100 & 100 & 100 \\
\hline Kuklospora kentinensis & 100 & 100 & 100 & 100 & 100 & 100 \\
\hline Length of alignment (positions) & 1591 & 525 & 826 & 436 & 403 & 401 \\
\hline Diversispora celata & 100 & 95 & 100 & 70 & 99 & 100 \\
\hline Diversispora spurca & 100 & 96 & 100 & 97 & & 100 \\
\hline Glomus aurantium & 100 & 100 & 94 & 95 & & 94 \\
\hline Glomus eburneum & 100 & 75 & 100 & 72 & 99 & 93 \\
\hline Glomus versiforme & 100 & 100 & 100 & 100 & 100 & 100 \\
\hline Length of alignment (positions) & 1600 & 497 & 860 & 407 & 398 & 440 \\
\hline $\begin{array}{l}\text { Glomus cf. clarum } \\
\text { Glomus intraradices }\end{array}$ & $\begin{array}{c}100 \\
72\end{array}$ & 100 & 100 & 100 & 100 & 100 \\
\hline Glomus sp. 'irregulare-like' & 100 & 96 & 99 & 53 & & 95 \\
\hline Glomus proliferum & 94 & 80 & & & & \\
\hline Length of alignment (positions) & 1644 & 540 & 863 & 437 & 400 & 440 \\
\hline Glomus mosseae & 100 & 97 & 100 & 93 & 98 & 99 \\
\hline Glomus sp. WUM3 & 100 & 97 & 100 & 98 & & 100 \\
\hline Glomus caledonium & 100 & 100 & 96 & 99 & & 97 \\
\hline Glomus coronatum & 100 & 100 & 96 & 100 & 99 & 99 \\
\hline Length of alignment (positions) & 1664 & 565 & 862 & 448 & 397 & 442 \\
\hline Glomus etunicatum & 100 & 99 & 100 & 90 & 96 & 100 \\
\hline Glomus sp. W3349 & 100 & 100 & 100 & 100 & 100 & 100 \\
\hline Glomus luteum & 100 & 100 & 100 & 100 & 96 & 93 \\
\hline Length of alignment (positions) & 1624 & 539 & 843 & 433 & 392 & 430 \\
\hline
\end{tabular}

Figure 5: Phylogenetic tree computed from all approx. 1500 bp SSUmCf-LSUmBr fragment sequences analysed (core dataset), demonstrating species level resolution. Neighbour joining analyses (1000 BS) with BS support displayed down to the level of species. Note that the BS support values differ from those given in Table 2, because an unambiguous alignment of ITS1 and ITS2 sequences between families, as computed here, in fact is impossible. Therefore, the BS values shown here are biased by ambiguously aligned sites in the highly variable regions and for species level comparison the values from Table 2 should be referred to. Left of each cluster the corresponding species is written. For better readability every second cluster is highlighted in grey 


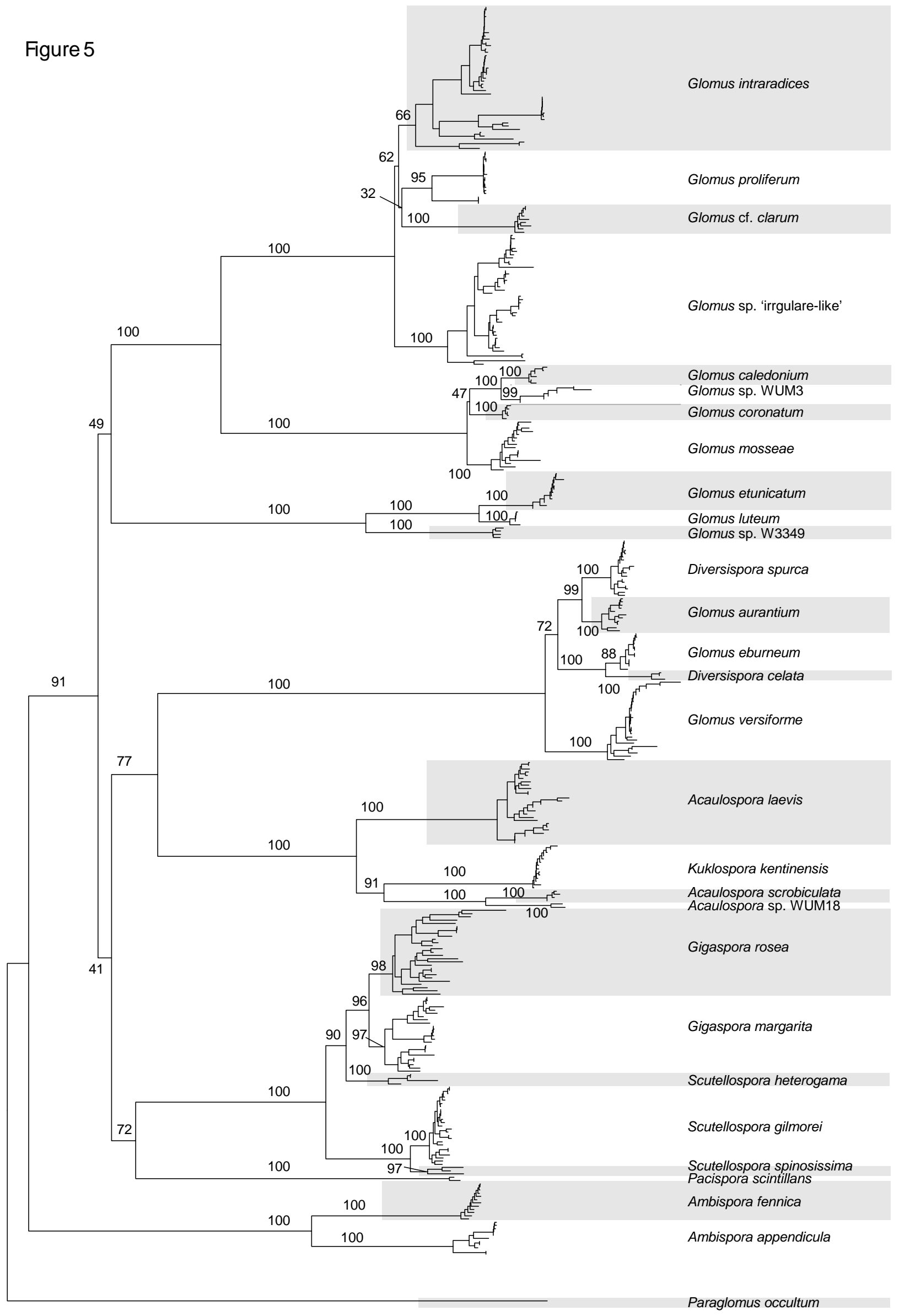




\subsubsection{Phylogenetic analyses of the extended dataset}

Shorter sequences from the public database were included in some analyses, selected according to their assigned name or culture identifier. Additionally, some environmental sequences were included, predominantly from the Ambisporaceae, Diversisporaceae and Glomus Group Aa.

\subsubsection{Analyses of Ambisporaceae}

Whereas only for two Ambisporaceae species the SSUmCf-LSUmBr fragment is available (Table S6, Figure 4), for the ITS region five Ambispora species and several environmental sequences could be analysed. All were phylogenetically well separated, with bootstrap support of at least $82 \%$ (Figure S8). The ITS2 fragment analysis showed a very similar result, with environmental sequences not matching any of the characterized Ambispora species. The environmental sequences (number in parentheses) from Taxus baccata (6), Prunus africana (1) or Plantago lanceolata (1) roots form well separated branches, as already shown before (Walker et al., 2007). For all of them the distance to the closest related species or clade is two to three-times higher than the minimal intraspecific distances within Am. appendicula (11 sequences), Am. leptoticha (26), and Am. callosa (34). The intraspecific variation in the ITS region was 2.3-7.3\%. The barcode gap analysis showed that Am. leptoticha, with $7.3 \%$ intraspecific variation, lacked a barcode gap to Am. appendicula (Figure S7), but not vice versa. The phylogenetic analysis clearly separated both species from each other.

\subsubsection{Analyses of Diversisporaceae}

The ITS analyses of the Diversisporaceae using the extended dataset (Figure S9) did not reveal any fundamental differences to the analyses of the core dataset (Figure S5). It was already known, that Gl. fulvum (5 sequences), Gl. megalocarpum (2), and Gl. pulvinatum (2) form a clade much apart from the other Diversisporaceae species and together probably represent a distinct taxon at the genus level (Redecker et al., 2007). Some additional ITS database sequences formed separated clades, one of them containing sequences from the INVAM cultures AZ237B from Arizona (4 sequences) together with NB101 from Namibia (4 sequences). These eight sequences are most likely conspecific and represent the closest known relative to Di. celata (3 sequences), as already stated by Gamper et al. (2009). At this point it should be mentioned that several Glomus species have not yet been formally transferred to the genus Diversispora and therefore carry the 'wrong' 
genus name. The naming of sequences also is misleading for a set of 30 environmental sequences that are annotated as Gl. versiforme but separate from Gl. versiforme BEG47 (31 sequences) in several sub clades. From our analyses, they should be annotated as unknown Diversispora species. The ITS region of Gl. fulvum (5 sequences) showed the highest intraspecific variation in the Diversisporaceae, with about $15 \%$. This is caused by sequence AM818544, which originated from a field collected specimen different from the other sequences. Perhaps AM818544 is a different species. Excluding AM818544, Gl. fulvum showed an intraspecific variation of $9.8 \%$. All other characterized species in the Diversisporaceae had a variation below $7 \%$.

For the LSU analyses (Figure S10), the four database sequences (AM947664,65, AY842573,74) from Gl. versiforme BEG47 clustered with the sequences of the core dataset of Gl. versiforme BEG47 (25 sequences). The sequence EU346868 from a 'Gl. versiforme' culture HDAM-4 and that of BEG47 were widely separated, and they are unlikely to have originated from a conspecific fungus. However, further sequences from such cultures are needed for more detailed analyses. The database sequences EF067886-88 clustered with the Gl. eburneum sequences, consistent with the fact that all sequences refer to the same culture identifier, INVAM AZ420A. The LSU sequences of Di. celata (Gamper et al., 2009) clustered with those of our core dataset. There are three $G l$. aurantium LSU database sequences (EF581860,62,63), derived from trap cultures, which clustered with the Gl. aurantium sequences from our core dataset. However, two additional Gl. aurantium sequences (EF581861,64) form a distinct clade. All five sequences, linked to voucher W4728, originate from the same trap culture setup with material collected near Tel Aviv in Israel (J. Błaszkowski, personal communication 21.9.2009). As trap cultures usually contain several species, it is not certain that the sequences were indeed derived from conspecific organisms. Without cultures established as isolates such questions can hardly be answered. The inclusion of the public sequences increased the intraspecific variation of $\mathrm{Di}$. celata to $2.6 \%$ (26 sequences), of $\mathrm{Gl}$. versiforme to $4.1 \%$ (29 sequences), and of Gl. aurantium to $1.9 \%$ (14 sequences). When including the outliers (EU346868, isolate HDAM-4) for Gl. versiforme the variation raised to $9.1 \%$ and in the case of Gl. aurantium (EF581861,64) to $8.1 \%$, whereas both species lost the barcode gap to their neighbours (Figure S7).

\subsubsection{Analyses of Glomus Group Aa ('GI. mosseae group')}

Analysis of our core dataset of this group showed clear separation of species with the ITS region, the ITS2 fragment, and the LSU fragments analysed. However, the situation changed considerably when including additional database sequences for the 'extended dataset'. 
For the ITS region, Glomus sp. WUM3 (6 sequences), Gl. caledonium (10 sequences) and Gl. geosporum (31 sequences) were well separated, but the ex-type of Gl. coronatum BEG28 (16 sequences) clade clustered in-between the two Gl. mosseae clades (Figure 6). Both Gl. mosseae clades were well supported by $80 \%$ and $100 \%$ bootstrap (BS) values, respectively. All new Gl. mosseae sequences from the present study, those from Avio et al. (2009), and from the databases being annotated as Gl. mosseae cluster together in the major clade (109 sequences). The smaller clade consists of seven sequences derived from field sampled spores with identifiers GMO2 and GMO3. One sequence (AF161058) characterised from spore GMO2 clusters in this minor clade while all the other ones (AF161055-57, AF166276) cluster within the major Gl. mosseae clade.

The ITS sequences in Glomus Group Aa reveal more discrepancies. Glomus monosporum (IT102: AF004689; FR115: AF004690, AF125195), Gl. dimorphicum (BEG59: X96838-41), and 'Gl. fasciculatum' BEG58 (X96842,43, but see below) sequences cluster in the major Gl. mosseae clade. Another species that has two sequences in the Gl. mosseae clade is Gl. fasciculatum BEG58. This species' morphology is very distinct from Gl. mosseae, as already discussed in Lloyd-Macglip et al. (1996), and in contrast to the BEG58 ITS sequences a SSU sequence from Gl. fasciculatum BEG53 clusters in the Glomus Group Ab (Schwarzott et al., 2001), which is consistent with morphological data. The phylogenetic analysis of the ITS2 fragment revealed a similar separation of the analysed species, but, e.g., the support value for the clade of Gl. caledonium decreased from $90 \%$ to insignificant $41 \%$.

For the Gl. mosseae major clade, when taking only the sequences into account that are annotated under this species name, the intraspecific variation of the complete ITS region is $12.1 \%$ (100 sequences). When assuming that, although annotated with distinct names (Gl. monosporum, Gl. fasciculatum BEG58, Gl. dimorphicum), all sequences clustering within the major Gl. mosseae clade are conspecific, but excluding the single outlier sequence from GMO2 and all sequences of GMO3 (minor clade), the variation only marginally increased to $12.2 \%$ (109 sequences). The variation rose to $20.0 \%$ (140 sequences) when adding the GMO2 and GMO3 'outlier' sequences. The intraspecific variation of all other well characterized and supported species within Glomus Group Aa varied between 0.8 and $2.8 \%$.

The LSU-D2 fragment analysis resulted in clear separation into several well supported clades (Figure 6). However, also here, some clades contain sequences from more than one species. One $G l$. fragilistratum sequence clusters within the Gl. caledonium clade. One Gl. coronatum BEG49 sequence is far apart from those of ex-type Gl. coronatum BEG28 (=Att108). Glomus coronatum BEG49 clusters with Glomus sp. WUM3, but also a Gl. constrictum BEG130 sequence falls in this clade. Within the Gl. mosseae clade, 12 sequences form a separated subclade (AY639159,61,62,65, 
AY639270,71,74,78,80,81, DQ469126, AF396788; upper subclade in Fig. 6). Interestingly, LSUD2 sequences from single spore isolates (H. Gamper isolates 209 and BEG224; J. Jansa isolate 243) can be found in both of the Gl. mosseae subclades. The major clade (lower subclade in Fig. 6) also harbours all sequences of Gl. mosseae analysed by Rosendahl et al. (2009), representing cultures from six continents. For all Gl. mosseae sequences together, the intraspecific variation of the LSUD2 fragment is $19.4 \%$ (170 sequences). The major clade had a variation of $15.8 \%$ (158 sequences) and the smaller clade of $11.2 \%$ (12 sequences). All other species in the clade showed an intraspecific variation between 1.2-5.0\% (5-28 sequences). 


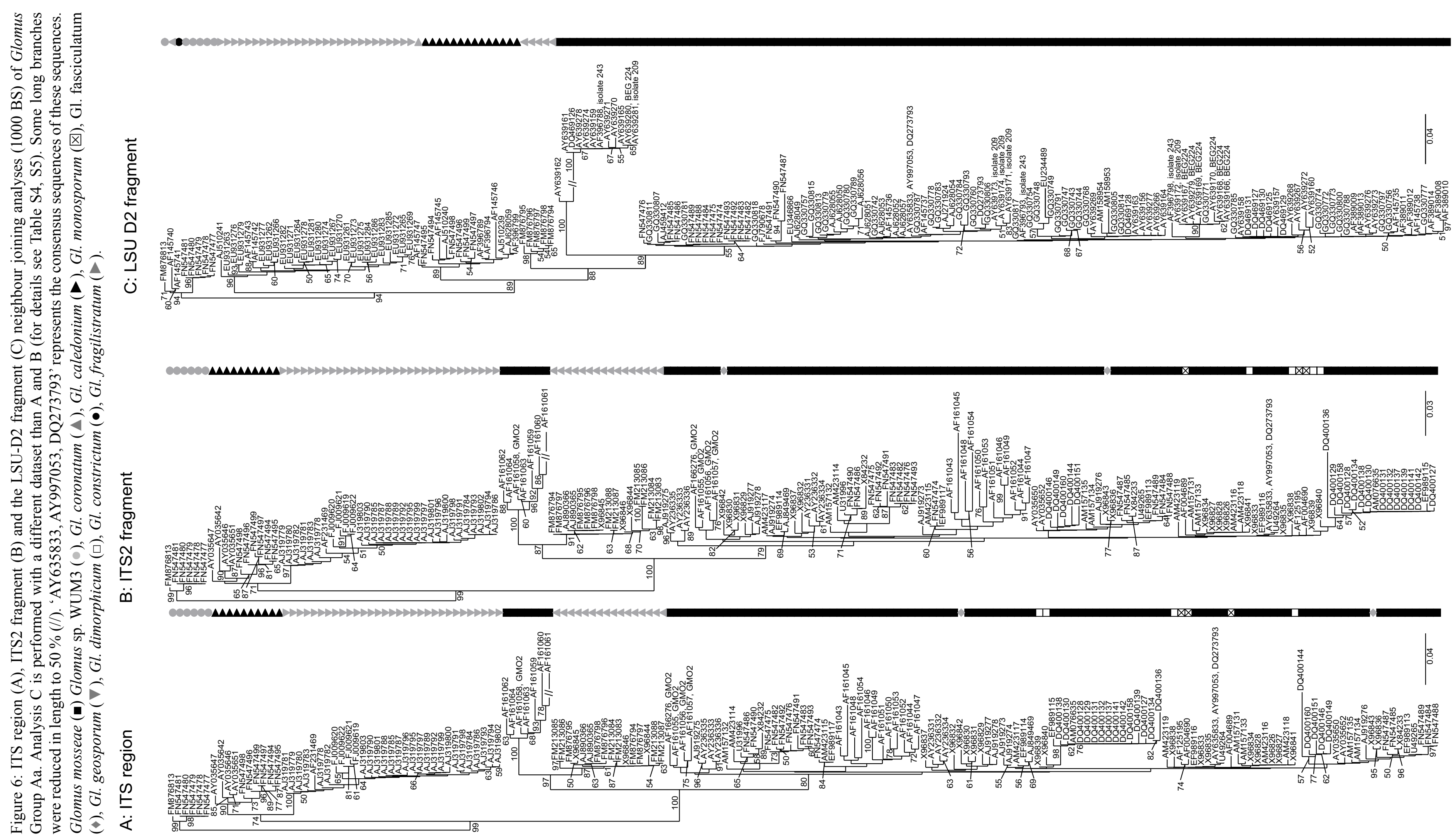




\subsection{Discussion}

We analysed several regions of the nuclear rDNA region as possible candidates for DNA barcoding of AMF, including the widely used ITS region, which probably will become an official barcode for fungi (Seifert, 2009). However, Stockinger et al. (2009) already demonstrated that the ITS region is unsuitable to resolve some closely related AMF species, which could be resolved analysing a longer fragment, covering a part of the SSU, the ITS region and part of the LSU. Therefore, we used this approx. 1500 bp long and easily PCR amplifiable PCR fragment (Krüger et al., 2009) as a baseline for the present study. Based on this, shorter DNA fragments were studied for their power for species resolution (DNA barcoding). This was also done with respect to potential species monitoring by 454 GS-FLX Titanium pyrosequencing (www.454.com; Valentini et al., 2009).

\subsubsection{Intraspecific rDNA variation}

Analyses presented in earlier publications (e.g., Lloyd-Macglip et al., 1996; Jansa et al., 2002; Walker et al., 2007) showed variable nuclear rDNA sequences to exist within one AMF spore, which holds true for all nuclear rDNA regions studied, but at different levels. One individual spore of Gl. intraradices (FL208) contains approximately the same extent of variation within the ITS region as found in two Gl. intraradices isolates from the same field site, but with 20 years inbetween (Stockinger et al., 2009). Based on that result, a single spore isolate or single spore DNA extractions could be interpreted as being valid to roughly define the intraspecific variability, but this will have to be proven in future, also with respect to differences in different phylogenetic lineages. The intraspecific and intrasporal variation varied considerably between the studied AMF species, for all regions analysed. This may only partly caused by different sampling density, as also when only AMF species with at least 24 known sequence variants were taken into account, the extent of intraspecific variation was diverse. In the present study, we followed the CBOL barcoding rules (www.barcoding.si.edu). This has to be mentioned, as the numbers for sequence variation differ significantly, depending on the method used for estimation. As an example, for Gl. intraradices (cultures FL208 and MUCL49410, together 47 sequences) the variation based on K2P distances is $14.6 \%$ in the ITS region, whereas a calculation based on uncorrected distances including gaps as a fifth character (Stockinger et al., 2009) raises the value to more than $23 \%$. Similarly high K2P distances were found, for the ITS region, of Gl. mosseae (12.2\%, 109 sequences) and Gl. fulvum (15\%, 5 sequences), including database sequences. The Gl. mosseae variation increased to 
enormous $20.3 \%$ when outlier sequences were included, but it is unlikely that these are from the same species. In comparison, the intrasporal ITS variation of Gl. mosseae analysed in this study was $4.6 \%$ (16 sequences) and only slightly increased to $5.3 \%$ when adding 45 sequences from $G l$. mosseae cultures with geographically widespread origin (Avio et al. 2009). Based on these data, there is some doubt whether all public database sequences annotated as Gl. mosseae are from the same species.

The intraspecific variation of the complete LSU region was intermediate between that of the LSUD1 and the LSU-D2 fragment, with the highest variation (in the LSU-D2 core dataset) in $G l$. intraradices (15.7\%; FL208 and MUCL49410). When including public database and outlier sequences, Gl. mosseae reached an intraspecific variation of $19.4 \%$ (170 sequences in total), whereas without outliers the variation is $15.8 \%$. As for the ITS data, also here it is impossible to be sure about the conspecific origin of the database sequences annotated as Gl. mosseae.

In general, the simple use of a \% variation value as threshold to define and cluster molecular operational taxonomic units (MOTUs) for species identification must be considered inapplicable.

\subsubsection{Barcode gap analyses}

The comparison of the maximum intraspecific and the minimum interspecific variation revealed that none of the studied DNA fragments allowed absolute AMF species separation from a simple barcode gap analysis. Barcode gaps may often be an artefact of insufficient taxon sampling (Wiemers \& Fiedler, 2007) and the likely existence of a large number of undescribed and uncharacterised species (Sýkorová et al., 2007; Kottke et al., 2008; Öpik et al., 2009) adds further complexity to the topic. Evidently, this method cannot be applied to AMF, when based on the rDNA regions.

\subsubsection{Phylogenetic analyses}

A barcode gap is not necessarily needed for a barcode-based identification of species, which can also be derived from phylogenetic inference. The phylogenetic analysis of the complete fragment (SSUmCf-LSUmBr) resulted in the strongest support for species. All species, where sequence data were available, could be separated by using simple neighbour joining analysis based on K2P distance. The about 1500 bp long sequences resulted in a clear distinction between Gl. proliferum, Gl. cf. clarum (Att894-7), Gl. intraradices (FL208, MUCL49410) and the closely related species or species complex represented by the Gl. irregulare-clade, in Glomus Group Ab. Maximum 
likelihood analyses resulted in the same separation, with even higher support of the topology (Stockinger et al., 2009). The species concept is indirectly supported by the fact that also the mitochondrial LSU rDNA as a marker distinguishes between $G l$. intraradices and sequences from the Gl. irregulare-clade (Börstler et al., 2008). It should be mentioned that the species description of Gl. irregulare did not compare all morphologically similar species and Gl. irregulare therefore may be a synonym of earlier described species (Walker, 2009).

\subsubsection{The ITS region}

The ITS region resolved many of the known species, but not the closely related members within Glomus Groups Ab and Aa, respectively. The intraspecific ITS variation is extremely high in these species and it is unclear how such highly divergent sequences can persist in an organism, even under relaxed concerted evolution. On the other hand, the ITS region resolved relatively closely related species in the Ambisporaceae (Walker et al., 2007), including Am. appendicula, which was earlier discussed as possibly being conspecific with Am. gerdemannii and Am. leptoticha (Morton \& Redecker, 2001). Another example are the environmental ITS sequences labelled as Gl. versiforme, which do not cluster with the Gl. versiforme BEG47 and most likely represent distinct species, exemplifying that assigning environmental sequences to species should be done with care.

For Glomus Group Aa, sequences with uncertain assignment to species are, e.g., from Gl. dimorphicum and Gl. monosporum, which were, on morphological grounds, discussed as possibly conspecific with Gl. mosseae (Walker, 1992). Further difficulties result from sequences originated from mixed cultures. For example, the fungus identified as Gl. monosporum INVAM FR115 was in a mixed culture that additionally contained spores of Gl. mosseae and Paraglomus occultum. The culture Gl. monosporum INVAM IT102 additionally contained Gl. mosseae and Gl. etunicatum spores (http://invam.caf.wvu.edu, 24.11.2009). It can neither be ruled out that the spores identified as Gl. mosseae and Gl. monosporum are conspecific, nor that contaminant sequences (Schüßler, 1999) gave rise to wrong affiliations. In general, the Gl. mosseae sequences form two distinct clades, whereas the minor clade consists of sequences from two field sampled spores (GMO2 and GMO3). All GMO3 sequences (AF161059-64) and one GMO2 sequence (AF161058) fall in the minor clade, the remaining GMO2 sequences all fall in the major clade. Sequence AF161058 might be interpreted as a contaminant originating from spore GMO3 and sequences AF161058 and AF161059-64, consequently, might be interpreted as derived from an unidentified species, as discussed by Antoniolli et al. (2000). However, also here it is not possible to draw final conclusions, as the existing intrasporal ITS variation is unknown. In particular when including the database ITS 
sequences it seems impossible to state whether the Gl. mosseae clade consists of one species or several species that cannot be separated. Analysing the complete fragment (SSUmCf-LSUmBr) for more cultures might solve this question.

\subsubsection{The LSU region}

Using the 800 bp LSU region resulted in more unresolved species in our neighbour joining analyses than using the ITS region. The reason could be 'noise' carried by the LSU-D1 fragment, which behaved worst with regard to resolving species, also for the core dataset. This could explains that the LSU-D2 fragment alone resolved species better than the complete 800 bp LSU region, with approximately the same species resolution power as the ITS region. Sequences of the cultures analysed by Rosendahl (2009), with geographically widespread origin, all fell into the main $G l$. mosseae subclade (Fig. 6, lower clade). The authors suggested, based on the genetic variability found in the LSU and in two FOX2 and TOR gene introns that the geographical widespread isolates are closely related and the panglobal distribution likely is caused by anthropogenic dispersal. Our analyses may support this interpretation, but it should also be mentioned that three single spore isolates (HG isolate 209, BEG224, JJ isolate 243) gave rise to sequence variants in both, the major and the minor Gl. mosseae subclades. This indicates that the LSU variation reported in some studies may be an underestimate, caused by a lack of perhaps rare sequence types (represented by the upper LSU-D2 subclade in Figure 6).

\subsubsection{Database sequences}

It is clear that there are many inaccurate species determinations in the public sequence databases. For example, some ITS and SSU sequences annotated as of glomeromycotan origin were demonstrated to be from an ascomycete (Redecker et al. 1999; Schüßler, 1999). But also AMF contaminants sequences cannot be ruled when using spores from mixed species cultures. Some database sequences seem to be assigned to the wrong species. For example, Glomus fasciculatum sequences of two cultures (BEG53 and BEG58) cluster in two different groups, BEG53 in Glomus Group Ab and BEG58 in Glomus Group Aa. From a morphological viewpoint, it is very unlikely that BEG58 sequences X96842 and X96843 indeed belong to Gl. fasciculatum. A third party annotation facility in GenBank (as proposed by many mycologists, e.g., Bidartondo et al., 2008) or well defined and curated databases like UNITE would help to resolve sequence annotation problems in the Glomeromycota. 


\subsubsection{DNA fragments for 454 GS-FLX Titanium pyrosequencing technology}

The 454 GS-FLX Titanium pyrosequencing technology currently allows an average read length of approx. 350-450 bp and offers great potential for ecological studies. Our data indicate that a read length of $400 \mathrm{bp}$ will not be sufficient to identify all AMF species with certainty, based on neighbour joining analyses using such a short fragment only. However, there are alternative phylogenetic approaches that may overcome this lack of resolution when taking an alignment based on longer sequences as a 'backbone' for the phylogenetic inference. For example, the program RAxML 7.2.2 (http://wwwkramer.in.tum.de/exelixis/software.html) includes a new algorithm that offers likelihood values for phylogenetic positions of short sequences within a robust tree topology computed from longer sequences. We show the LSU-D2 and ITS2 fragments to be good candidates for species identification by 454 pyrosequencing. The LSU-D2 region may be preferred if AMF should be specifically amplified from roots or soil and it may have a slightly superior species resolution power. In studies where other groups of fungi are investigated together with the AMF diversity, the ITS2 fragment is a good alternative and can be amplified with established primers. We did not test the AM1-NS31 SSU fragment, used in many environmental studies including a recent 454 GS-FLX sequencing approach, because the AM1 primer evidently discriminates many AMF taxa and this region clearly lacks species resolution power.

\subsubsection{Conclusion}

We show that, based on the rDNA regions studied, there is no barcode gap for many AMF species. The intraspecific variation is heterogeneous and exceptionally high in some phylogenetic groups. Neighbour joining analyses of the approx. 1500 bp SSUmCf-LSUmBr rDNA fragment distinguished all investigated species, whereas shorter rDNA fragments did not allow a separation of very closely related species. Regarding high throughput 454 GS-FLX Titanium pyrosequencing technology, the LSU-D2 and ITS2 fragments appear most suitable. However, beside purely methodological aspects, species recognition is mainly hampered by the lack of a comprehensive and accurate baseline dataset. For future analyses, a 'quantitative world of community analysis' beyond 454 GS-FLX Titanium amplicon sequencing may soon become feasible by affordable high throughput sequencing of even longer DNA fragments (Pacific Biosciences www.pacificbiosciences.com; Eid et al., 2009). This may be taken as another argument in favour of using longer DNA barcodes for easier species resolution. 
We propose the sequencing of the easily amplifiable SSUmCf-LSUmBr $1.5 \mathrm{~kb}$ fragment variants, covering the partial SSU, the ITS region and a part of the LSU, as a DNA barcoding region for Glomeromycota. We also recommend that such a molecular characterisation should be included as a prerequisite to AMF species description whenever possible. Such validated sequence data will be important for comprehensive molecular studies of AMF-plant associations in the field and they will help to uncover and study preferential associations, which are still mostly hidden.

\subsection{Acknowledgements}

The grant for H.S. was funded by the Marie Curie Early Stage Research Training Fellowship of the European Community's Sixth Framework Programme (MEST-CT-2005-021016, 'TRACEAM'). The grants for M.K. and A.S. were financed by the German Research Foundation (DFG). Thanks to all who supplied samples.

\subsection{References}

Agerer R, Ammirati J, Blanz P, Courtecuisse R, Desjardin DE, Gams W, Hallenberg N, Halling R, Hawksworth DL, Horak E, et al. 2000. Always deposit vouchers. Mycological Research 104: 642-644.

Antoniolli Z, Schachtman D, Ophel-Keller K, Smith S. 2000. Variation in rDNA ITS sequences in Glomus mosseae and Gigaspora margarita spores from a permanent pasture. Mycological Research 104: 708-715.

Avio L, Cristani C, Strani P, Giovannetti M. 2009. Genetic and phenotypic diversity of geographically different isolates of Glomus mosseae. Canadian Journal of Microbiology 55: 242253.

Bidartondo MI, Bruns TD, Blackwell M, Edwards I, Taylor AFS, Horton T, Zhang N, Kõljalg U, May G, Kuyper TW, et al. 2008. Preserving Accuracy in GenBank. Science 319: 1616.

Börstler B, Raab PA, Thiéry O, Morton JB, Redecker D. 2008. Genetic diversity of the arbuscular mycorrhizal fungus Glomus intraradices as determined by mitochondrial large subunit rRNA gene sequences is considerably higher than previously expected. New Phytologist 180: 452465.

Brundrett M. 2009. Mycorrhizal associations and other means of nutrition of vascular plants: understanding the global diversity of host plants by resolving conflicting information and developing reliable means of diagnosis. Plant and Soil 320: 37-77.

Chase MW, Fay MF. 2009. Barcoding of Plants and Fungi. Science 325: 682-683.

Chevenet F, Brun C, Banuls A, Jacq B, Christen R. 2006. TreeDyn: towards dynamic graphics and annotations for analyses of trees. BMC Bioinformatics 7: 439.

Eid J, Fehr A, Gray J, Luong K, Lyle J, Otto G, Peluso P, Rank D, Baybayan P, Bettman B, et al. 2009. Real-Time DNA sequencing from single polymerase molecules. Science 323: 133-138. 
Felsenstein J. 2004. PHYLIP (Phylogeny Inference Package) version 3.6. Distributed by the author. Department of Genome Sciences, University of Washington, Seattle.

Frézal L, Leblois R. 2008. Four years of DNA barcoding: Current advances and prospects. Infection, Genetics and Evolution 8: 727-736.

Gamper H, Leuchtmann A. 2007. Taxon-specific PCR primers to detect two inconspicuous arbuscular mycorrhizal fungi from temperate agricultural grassland. Mycorrhiza 17: 145-152.

Gamper HA, Walker C, Schüßler A. 2009. Diversispora celata sp. nov: molecular ecology and phylotaxonomy of an inconspicuous arbuscular mycorrhizal fungus. New Phytologist 182: 495-506.

Gardes M, Bruns TD. 1993. ITS primers with enhanced specificity for Basidiomycetes application to the identification of mycorrhizae and rusts. Molecular Ecology Notes 2: 113-118.

Geiser DM, Klich M, Frisvad J, Peterson S, Varga J, Samson R. 2007. The current status of species recognition and identification in Aspergillus. Studies in Mycology 59: 1-10.

Gilmore SR, Gräfenhahn T, Louis-Seize G, Seifert KA. 2009. Multiple copies of cytochrome oxidase 1 in species of the fungal genus Fusarium. Molecular Ecology Resources 9: 90-98.

Gollotte A, van Tuinen D, Atkinson D. 2004. Diversity of arbuscular mycorrhizal fungi colonising roots of the grass species Agrostis capillaris and Lolium perenne in a field experiment. Mycorrhiza 14: 111-117.

Hawksworth DL. 2001. The magnitude of fungal diversity: the 1.5 million species estimate revisited. Mycological Research 105: 1422-1432.

Hebert PD, Stoeckle MY, Zemlak TS, Francis CM. 2004. Identification of birds through DNA barcodes. PLoS Biology 2: e312.

Helgason T, Fitter AH, Young JPW. 1999. Molecular diversity of arbuscular mycorrhizal fungi colonising Hyacinthoides non-scripta (bluebell) in a seminatural woodland. Molecular Ecology 8: 659-666.

Hempel S, Renker C, Buscot F. 2007. Differences in the species composition of arbuscular mycorrhizal fungi in spore, root and soil communities in a grassland ecosystem. Environmental Microbiology 9: 1930-1938.

Hollingsworth PM, Forrest LL, Spouge JL, Hajibabaei M, Ratnasingham S, van der Bank M, Chase MW, Cowan RS, Erickson DL, Fazekas AJ, et al. 2009. A DNA barcode for land plants. Proceedings of the National Academy of Sciences 106: 12794-12797.

James TY, Kauff F, et al. 2006. Reconstructing the early evolution of Fungi using a six-gene phylogeny. Nature 443: 818-822.

Jansa J, Mozafar A, Banke S, McDonald BA, Frossard E. 2002. Intra- and intersporal diversity of ITS rDNA sequences in Glomus intraradices assessed by cloning and sequencing, and by SSCP analysis. Mycological Research 106: 670-681.

Katoh K, Misawa K, Kuma KI, Miyata T. 2002. MAFFT: a novel method for rapid multiple sequence alignment based on fast Fourier transform. Nucleic Acids Research 30: 3059-3066.

Kimura M. 1980. A simple method for estimating evolutionary rates of base substitutions through comparative studies of nucleotide sequences. Journal of Molecular Evolution 16: 111-120.

Kirk PM, Cannon PF, Minter DW, Stalpers JA. 2008. Dictionary of the Fungi, 10th ed. Wallingford, UK: CABI.

Kottke I, Haug I, Setaro S, Suarez JP, Weiß M, Preußing M, Nebel M, Oberwinkler F. 2008. Guilds of mycorrhizal fungi and their relation to trees, ericads, orchids and liverworts in a neotropical mountain rain forest. Basic and Applied Ecology 9: 13-23.

Krüger M, Stockinger H, Krüger C, Schüßler A. 2009. DNA-based species level detection of Glomeromycota: one PCR primer set for all arbuscular mycorrhizal fungi. New Phytologist 183: 212-223.

Lang BF, Hijri M. 2009. The complete Glomus intraradices mitochondrial genome sequence - a milestone in mycorrhizal research. New Phytologist 183: 3-6. 
Lee J, Lee S, Young JPW. 2008. Improved PCR primers for the detection and identification of arbuscular mycorrhizal fungi. FEMS Microbiology Ecology 65: 339-349.

Lee J, Young JPW. 2009. The mitochondrial genome sequence of the arbuscular mycorrhizal fungus Glomus intraradices isolate 494 and implications for the phylogenetic placement of Glomus. New Phytologist 183: 200-211.

Lloyd-Macglip SA, Chambers SM, Dodd J, Fitter AH, Walker C, Young JW. 1996. Diversity of the ribosomal internal transcribed spacers within and among isolates of Glomus mosseae and related mycorrhizal fungi. New Phytologist 133: 103-111.

Ludwig W, Strunk O, Westram R, Richter L, Meier H, Yadhukumar, Buchner A, Lai T, Steppi S, Jobb G, et al. 2004. ARB: a software environment for sequence data. Nucleic Acids Research 32: 1363-1371.

Lumini E, Bianciotto V, Jargeat P, Novero M, Salvioli A, Faccio A, Bécard G, Bonfante P. 2007. Presymbiotic growth and sporal morphology are affected in the arbuscular mycorrhizal fungus Gigaspora margarita cured of its endobacteria. Cellular Microbiology 9: 1716-1729.

Morton JB, Redecker D. 2001. Two new families of Glomales, Archaeosporaceae and Paraglomaceae, with two new genera Archaeospora and Paraglomus, based on concordant molecular and morphological characters. Mycologia 93: 181-195.

O'Brien HE, Parrent JL, Jackson JA, Moncalvo JM, Vilgalys R. 2005. Fungal community analysis by large-scale sequencing of environmental samples. Applied and Environmental Microbiology 71: 5544-5550.

Oehl F, Sieverding E, Ineichen K, Mäder P, Wiemken A, Boller T. 2009. Distinct sporulation dynamics of arbuscular mycorrhizal fungal communities from different agroecosystems in longterm microcosms. Agriculture, Ecosystems \& Environment 134: 257-268.

Öpik M, Metsis M, Daniell TJ, Zobel M, Moora M. 2009. Large-scale parallel 454 sequencing reveals host ecological group specificity of arbuscular mycorrhizal fungi in a boreonemoral forest. New Phytologist 184: 424-437.

Paradis E, Claude J, Strimmer K. 2004. APE: Analyses of Phylogenetics and Evolution in R language. Bioinformatics 20: 289-290.

Peterson MW, Colosimo ME. 2007. TreeViewJ: An application for viewing and analyzing phylogenetic trees. Source Code for Biology and Medicine 2: 7.

Pivato B, Mazurier S, Lemanceau P, SiblotS, Berta G, Mougel G, van Tuinen D. 2007. Medicago species affect the community composition of arbuscular mycorrhizal fungi associated with roots. New Phytologist 176: 197-210.

Redecker D, Hijri M, Dulieu H, Sanders IR. 1999. Phylogenetic analysis of a dataset of fungal 5.8S rDNA sequences shows that highly divergent copies of internal transcribed spacers reported from Scutellospora castanea are of ascomycete origin. Fungal Genetics and Biology 28: 238-244.

Redecker D, Morton JB, Bruns TD. 2000. Ancestral lineages of arbuscular mycorrhizal fungi (Glomales). Molecular Phylogenetics and Evolution 14: 276-284.

Redecker D, Raab PA, Oehl F, J.Camacho F, Court R. 2007. A novel clade of sporocarp-forming species of glomeromycotan fungi in the Diversisporales lineage. Mycological Progress 6: 35-44.

Renker C, Heinrichs J, Kaldorf M, Buscot F. 2003. Combining nested PCR and restriction digest of the internal transcribed spacer region to characterize arbuscular mycorrhizal fungi on roots from the field. Mycorrhiza 13: 191-198.

Robinson-Boyer L, Grzyb I, Jeffries P. 2009. Shifting the balance from qualitative to quantitative analysis of arbuscular mycorrhizal communities in field soils. Fungal Ecology 2: 1-9.

Rosendahl S, McGee P, Morton JB. 2009. Lack of global population genetic differentiation in the arbuscular mycorrhizal fungus Glomus mosseae suggests a recent range expansion which may have coincided with the spread of agriculture. Molecular Ecology 18: 4316-4329. 
Ryberg M, Nilsson RH, Kristiansson E, Topel M, Jacobsson S, Larsson E. 2008. Mining metadata from unidentified ITS sequences in GenBank: A case study in Inocybe (Basidiomycota). BMC Evolutionary Biology 8: 50.

Sanders IR. 2004. Plant and arbuscular mycorrhizal fungal diversity: Are we looking at the relevant levels of diversity and are we using the right techniques? New Phytologist 164: 415-418.

Sawaki H, Sugawara K, Saito M. 1998. Phylogenetic position of an arbuscular mycorrhizal fungus, Acaulospora gerdemannii, and its synanamorph Glomus leptotichum, based upon $18 \mathrm{~S}$ rRNA gene sequence. Mycoscience 39: 477-480.

Schüßler A. 1999. Glomales SSU rRNA gene diversity. New Phytologist 144: 205-207.

Schüßler A, Schwarzott D, Walker C. 2001. A new fungal phylum, the Glomeromycota: phylogeny and evolution. Mycological Research 105: 1413-1421.

Schüßler A, Schwarzott D, Walker C. 2003. Glomeromycota rRNA genes-the diversity of myths? Mycorrhiza 13: 233-236.

Schwarzott D, Schüßler A. 2001. A simple and reliable method for SSU rRNA gene DNA extraction, amplification, and cloning from single AM fungal spores. Mycorrhiza 10: 203-207.

Schwarzott D, Walker C, Schüßler A. 2001. Glomus, the largest genus of the arbuscular mycorrhizal fungi (Glomales), Is nonmonophyletic. Molecular Phylogenetics and Evolution 21: 190-197.

Seifert KA. 2009. Progress towards DNA barcoding of fungi. Molecular Ecology Resources 9: 8389.

Seifert KA, Samson RA, deWaard JR, Houbraken J, Levesque C, Moncalvo JM, Louis-Seize G, Hebert PD. 2007. Prospects for fungus identification using CO1 DNA barcodes, with Penicillium as a test case. Proceedings of the National Academy of Sciences 104: 3901-3906.

Slabbinck B, Dawyndt P, Martens M, De Vos P, De Baets B. 2008. TaxonGap: a visualization tool for intra- and inter-species variation among individual biomarkers. Bioinformatics 24: 866-867. Stockinger H, Walker C, Schüßler A. 2009. 'Glomus intraradices DAOM197198', a model fungus in arbuscular mycorrhiza research, is not Glomus intraradices. New Phytologist 183: 1176-1187.

Sukumaran J, Holder MT. 2008. SumTrees: Summarization of split support on phylogenetic trees. Version 1.0.2. Part of the DendroPy Phylogenetic Computation Library Version 2.1.3 (http://pypi.python.org/pypi/DendroPy).

Sýkorová Z, Wiemken A, Redecker D. 2007. Cooccurring Gentiana verna and Gentiana acaulis and their neighboring plants in two swiss upper montane meadows harbor distinct arbuscular mycorrhizal fungal communities. Applied and Environmental Microbiology 73: 5426-5434.

van Tuinen D, Zhao B, Gianinazzi-Pearson V. 1998. PCR in studies of AM fungi: from primers to application. Mycorrhiza Manual. Berlin, Heidelberg: Springer, 387-400.

Turnau K, Ryszka R, Gianinazzi-Pearson V, van Tuinen D. 2001. Identification of arbuscular mycorrhizal fungi in soils and roots of plants colonizing zinc wastes in southern Poland. Mycorrhiza 10: 169-174.

Valentini A, Pompanon F, Taberlet P. 2009. DNA barcoding for ecologists. Trends in Ecology \& Evolution 24: 110-117.

Vaughn JC, Mason MT, Sper-Whitis GL, Kuhlman P, Palmer JD. 1995. Fungal origin by horizontal transfer of a plant mitochondrial group I intron in the chimeric COXI gene of Peperomia. Journal of Molecular Evolution 41: 563-572.

Walker C. 2009. Importance of taxonomy for inoculum labelling and the Glomus intraradices story. pp 14-16 in Anon, From production to application of arbuscular mycorrhizal fungi in agricultural systems: a multidisciplinary approach. Proceeding of COST 870 Working Groups II \& III, 14-15 Sept 2009, Université Catholique de Louvain, Belgium.

Walker C, Mize CW, McNabb HS. 1982. Populations of endogonaceous fungi at two locations in central Iowa. Canadian Journal of Botany 60:2518-2519. 
Walker C. 1992. Systematics and taxonomy of the arbuscular endomycorrhizal fungi (Glomales)- a possible way forward. Agronomie 12: 887-897.

Walker C, Vestberg M, Demircik F, Stockinger H, Saito M, Sawaki H, Nishmura I, Schüßler A. 2007. Molecular phylogeny and new taxa in the Archaeosporales (Glomeromycota): Ambispora fennica gen. sp. nov., Ambisporaceae fam. nov., and emendation of Archaeospora and Archaeosporaceae. Mycological Research 111: 137-153.

White T, Bruns T, Lee S, Taylor J. 1990. Amplification and direct sequencing of fungal ribosomal RNA genes for phylogenies. PCR protocols: a guide to methods and applications. San Diego, California: Academic Press, 315-322.

Wiemers M, Fiedler K. 2007. Does the DNA barcoding gap exist? - a case study in blue butterflies (Lepidoptera: Lycaenidae). Frontiers in Zoology 4: 8.

Wubet T, Weiß M, Kottke I, Teketay D, Oberwinkler F. 2004. Molecular diversity of arbuscular mycorrhizal fungi in Prunus africana, an endangered medicinal tree species in dry Afromontane forests of Ethiopia. New Phytologist 161: 517-528.

Wubet T, Weiß M, Kottke I, Teketay D, Oberwinkler F. 2006. Phylogenetic analysis of nuclear small subunit rDNA sequences suggests that the endangered African Pencil Cedar, Juniperus procera, is associated with distinct members of Glomeraceae. Mycological Research 110: 10591069. 


\section{General discussion}

The aim of my thesis was to develop and establish tools for the molecular characterisation and 'molecular tracing' of AMF species in ecosystems. As a base, different genes and DNA regions had to be characterised and analysed for their potential use as DNA barcodes for AMF. DNA barcoding uses relatively short and standardized DNA marker sequences to determine species accurately, rapidly and cost efficiently (Frézal \& Leblois, 2008). Ideally, DNA barcodes must be applicable for non-experts, culture independent and universally accessible. For AMF, DNA barcode identification would contribute significantly to biological research and agronomic field analyses as AMF are hidden in the soil, but known to increase plant biomass in varying degrees, depending on the AMFplant species combinations (van der Heijden et al., 2003; Klironomos, 2003; Smith \& Read, 2008). A suitable AMF DNA barcode would help to determine the effects of particular AMF species to plants, in the field. The present work focused on the characterisation of a potential DNA barcode by using parts of widely studied rDNA sequences. The SSU rDNA region is largely giving the current molecular baseline for the higher AMF taxonomy (Schüßler et al., 2001), but often does not allow resolution at species level. Different regions of the rDNA were therefore analysed and evaluated for species resolution and identification power on several exemplary datasets. A summary of these analyses and results is shown in Figure 7. This included the in silico analysis of approximately $400 \mathrm{bp}$ fragments with regard to 454 GS-FLX Titanium sequencing. This new technology produces up to approx. 400000 sequences with read lengths of approx. $400 \mathrm{bp}$ in one run, which makes it suitable for environmental barcoding studies (Valentini et al., 2009). 


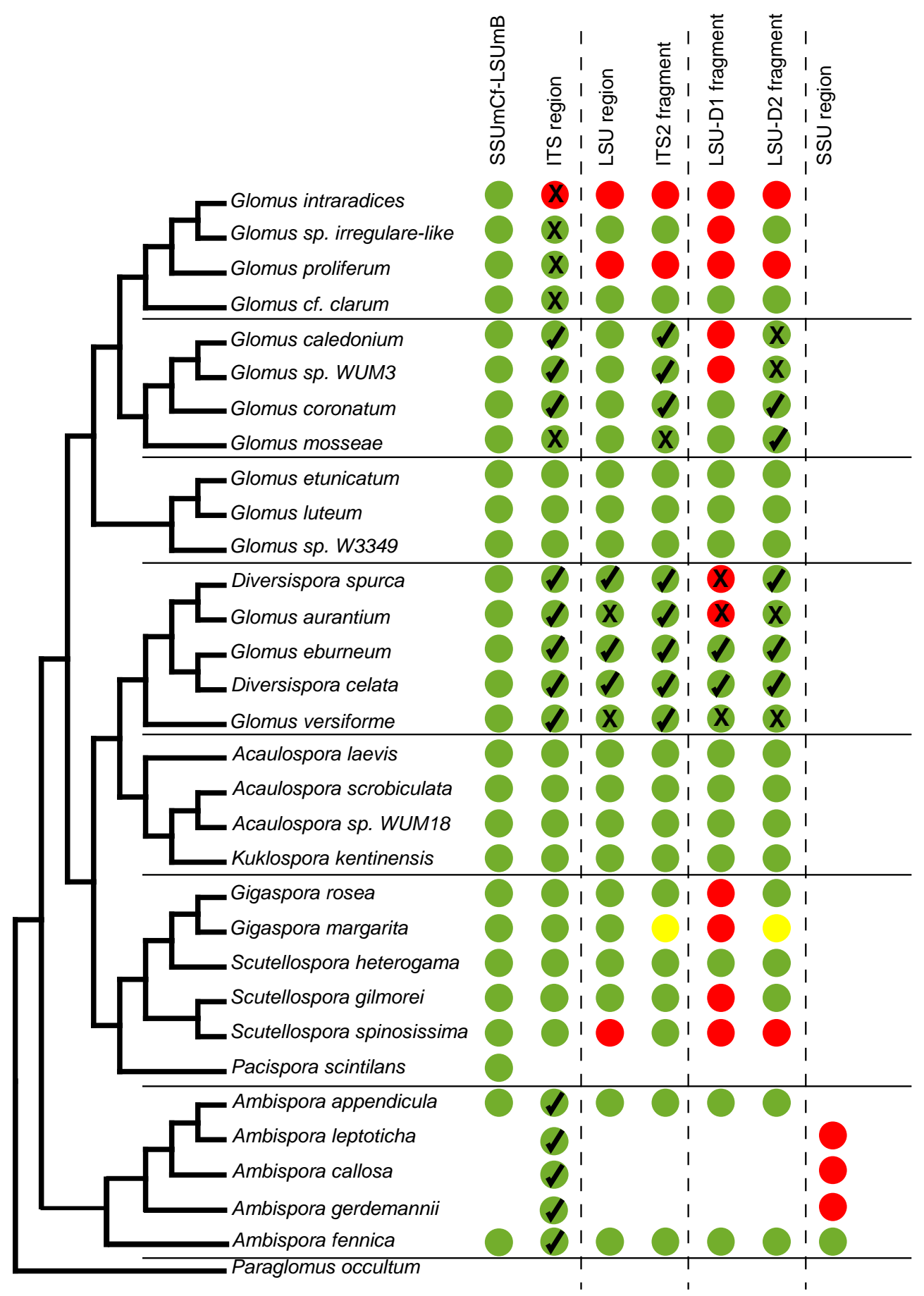

Figure 7: Overview summarizing the main results of this thesis. A schematic phylogenetic tree is shown to the left. Analyses from sequences generated within this thesis are marked as coloured circles. The rDNA fragments analysed are displayed at the top. In relation to species resolution using neighbour joining analyses, sequences from one species form a monophyletic clade with a bootstrap support higher than 50 are indicated in green, sequences from one species form a monophyletic clade with a bootstrap support below 50 in yellow and sequences from one species, which do not form a monophyletic clade are shown in red. When analyses used additional sequences taken from databases the circles are marked with $\sqrt{ }$ or $X$. $\sqrt{ }$ marks successful species resolution after including additional database sequences, $\mathrm{X}$ marks lacking species resolution resulting after addition of database sequences for the given species. 


\subsection{AMF species resolution using the SSU rDNA}

In a first approach, the SSU rDNA was analysed for species resolution of AMF from the Ambisporaceae (chapter 4). Many glomeromycotan species have corresponding sequences of the SSU rDNA in the public databases, but not all are correctly identified. In the meanwhile, most AMF sequences in the databases are unidentified and of environmental origin. The results in chapter 4 showed that analyses of the SSU rDNA do not allow resolving all Ambispora species. Members of this genus are known to produce dimorphic spores (both glomoid and acaulosporoid), which makes identification difficult when using purely morphological methods, particularly as some are thought to produce only glomoid spores. The limited resolution of the SSU rDNA is in agreement with a later study of Gamper et al. (2009) in which it proved impossible for members of the Diversisporaceae to separate all species. Another example are two closely related species, Gl. caledonium and Gl. geosporum, only showing a difference of 2-3 bp in this marker region (Rosendahl, 2008), which may be problematic when the quality of sequences is insufficient. Phylogenetic analyses of selected soil fungal species within Ascomycota and Zygomycota using partial SSU sequences only showed $52 \%$ success rate for species identification (Molitor et al., 2009). Bruns et al. (1991) already indicated that the SSU rDNA may not be suitable to separate fungi to species level, although at this time fewer sequences were available.

Nevertheless, SSU or partial SSU fragments are widely used in characterizing AMF communities (Helgason et al., 1999; Wubet et al., 2006; Öpik et al., 2009). These analyses cannot be interpreted at species level and the comparison of such studies is difficult, a situation not changing principally with the introduction of operational taxonomic units (OTUs), molecular OTUs (MOTUs) or 'virtual taxa'. The concept of OTUs follows that of bacteria, where OTUs are widely used based on a $3 \%$ threshold of the SSU rDNA divergence to separate at species level (Quince et al., 2008). A similar transfer of the $3 \%$ threshold to AMF SSU analyses would, for instance, combine Gl. caledonium and $G l$. geosporum to one species.

Many unidentified AMF sequence types and clusters have been found in various ecological studies using parts of the SSU rDNA (e.g. Kottke et al., 2008; Öpik et al., 2009) highlighting the possible existence of many unknown AMF species. However, such sequence types or clusters (or OTUs) may contain more than one species, as exemplified in chapter 4 for Am. callosa, Am. gerdemannii and Am. leptoticha. On the other hand, several sequence clusters interpreted as distinct OTUs may correspond to one species. Due to the lack of species resolution, the SSU rDNA and the application of OTUs based on the SSU clearly are unsuitable for DNA barcoding. 


\subsection{AMF species resolution using the ITS region}

The ITS region is one of the most widely used markers for identification of fungi and has recently been considered to be a de-facto barcode for fungi (Seifert 2009). The ITS region was therefore chosen as the consequent promising marker sequence for AMF DNA barcoding. The first study (chapter 4) with a phylogenetic approach using the ITS region appeared promising. It was not only suited to resolve all well defined Ambisporaceae species tested, but also cryptic species. In addition, the ITS region separated species with very similar spore morphology. The ITS region was also used to separate AMF species in other families (Redecker et al., 2007; Gamper et al., 2009). Our subsequent research then focused on separating closely related species within the Glomus Group $\mathrm{Ab}$, which contains the major model organism for AMF research, Glomus sp. DAOM197198. Although this organism was called Gl. intraradices, our studies (chapter 6) have shown it to be a different species more closely related to or perhaps conspecific with Gl. irregulare. However, in this case the ITS region alone was not suited to separate the closely related species, irrespective whether a simple neighbour joining or a more sophisticated maximum likelihood phylogenetic analysis was used. This partly is caused by the high intraspecific ITS region variation of up to $14.6 \% \mathrm{~K} 2 \mathrm{P}$ distance. High intraspecific ITS variation, such as uncorrected distances, within the Glomus Group Ab was already reported by Jansa et al. (2002b). The ITS region was also unsuited to distinguish all analysed species in some non-AMF fungal groups, e.g. the genus Cladosporium (Molitor et al. 2009). Although for non-AMF the intraspecific variation can also reach relatively high levels, e.g. in Xylaria hypoxylon (Ascomycota, 24.2\%) and Rhizoctonia bataticola (Basidiomycota, 17.3\%), but is generally much lower than in glomeromycotan species (Nilsson et al., 2008). However, it should be noted that these values cannot be directly compared to the intraspecific variation reported in our and many other studies, because of methodological differences in pairwise distance calculation (see chapter 7).

An analysis within this thesis (chapter 6) revealed that for Gl. intraradices FL208 a single AMF spore may contain approx. the same sequence variation as found within the two isolates available for this fungus (descendants from the FL208 'type culture' and from a 20 years later re-isolation from the type locality). This high variation within a species and within an individual spore is remarkable and exceptional. Some studies argue that one AMF coenocyte contain genetically different nuclei (are heterokaryotic; Kuhn et al., 2001), though this is still moot (Pawlowska \& Taylor, 2004). If the highly variable ITS sequences are located within one nucleus, a highly relaxed concerted evolution, which usually homogenizes the different repeats of rDNA, is indicated. Concerted evolution was demonstrated to be very efficient in some fungal species (Ganley \& 
Kobayashi, 2007) but e.g. relaxed in some species of cacti (Harpke \& Peterson, 2006) and the grasshopper Podisma pedestris (Keller et al., 2006). This study (chapter 7) demonstrates, that not only AMF from Glomus group Ab, but also several species from other clades show a very high intraspecific ITS region (and also the LSU) variation. Therefore, relaxed concerted evolution seems widespread in Glomeromycota.

The functional relevance of the numerous variants is still not clear, but some of them may represent pseudogenes. Such rDNA pseudogenes were detected in other organisms, for example in a fish $(\mathrm{Xu}$ et al., 2009), a coral (Marquez et al., 2003) and a cactus species (Hartmann et al., 2001).

The high intraspecific variation makes DNA barcoding for AMF even more complex because for analyses it is desirable to have highly similar sequences within a species (Valentini et al., 2009). The distance between the maximum intraspecific and the minimum interspecific variation (K2P distances), defined as barcode gap (Hollingsworth et al., 2009; www.barcoding.si.edu), is very low in the ITS region of AMF species and overlaps in some closely related species (chapter 7). Species identification based on this simple method was therefore not successful for AMF. For rapid detection of species, Hebert et al. (2004) proposed that the minimum interspecific variation should be 10 times of the maximum intraspecific variation analysed with COXI for animals. The ITS region of AMF clearly does not fulfil this criterion, but the ITS region could be used to distinguish most, but not all, of the AMF species analysed here by phylogenetic methods.

\subsection{AMF species resolution using the LSU region}

Another widely used rDNA part for AMF species identification is the LSU region. Like the ITS region, this region has also been used for AMF species identification and community analyses (van Tuinen et al., 1998; Kjøller \& Rosendahl, 2000; Gollotte et al., 2004; Pivato et al., 2007; Gamper et al., 2009). Most studies used the first $800 \mathrm{bp}$ or even smaller parts of the 5' region of the LSU rRNA gene. Two variable regions, D1 and D2, exist within the first $800 \mathrm{bp}$ of the LSU, which are of great interest for species identification. Our study therefore focused on this fragment, and on two sub-fragments containing either the D1 or the D2 region. Gamper et al. (2009) demonstrated successful separation of species in the Diversisporaceae using a partial LSU fragment. These analyses are in agreement with our results, except for some potentially misannotated sequences from the database. The species identification using the $800 \mathrm{bp}$ part of the LSU was not successful for some members of Glomus Group Ab and the Gigasporaceae. In some other fungal groups, for example in the Lecanoromycetes (Ascomycota; Hofstetter et al., 2007) and rusts (Vialle et al., 
2009), the LSU also was not suited to resolve all species, whereas the LSU species resolution was better than that of four studied mitochondrial genes, for the rusts. For their studies on AMF, Gollotte et al. (2004) excluded the D1 by using PCR primers amplifying only the D2 domain. This seems very reasonable, as in the present work the LSU-D1 fragment analyses could not correctly separate about half of the species studied and, moreover, the analysis of the D2 performed as good as the analyses of the D1 and D2 regions together, indicating a high amount of 'phylogenetic noise' in the D1 domain. Analysing a LSU fragment covering the D2 domain, Rosendahl et al. (2009) showed very little sequence differences of max. $6 \mathrm{bp}$ for Gl. mosseae isolates from several continents. The variation within their analysed Gl. mosseae isolates is smaller, compared to the one Gl. mosseae isolate Att109-20/BEG12 analysed here (chapter 7). Rosendahl et al. (2009) argue that the small variation of the LSU and two other genes analysed indicate an anthropogenic dispersal of the geographically very widespread isolates.

\subsection{Species resolution with ITS region and partial LSU sequences}

The longest fragment (SSUmCf-LSUmBr, approx. $1500 \mathrm{bp}$ ) used for our analyses covers approx. $240 \mathrm{bp}$ of the SSU, the complete ITS region, and approx. $800 \mathrm{bp}$ of LSU. This fragment allowed separating all species analysed by a simple phylogenetic method (chapter 7). In addition, our analyses showed that the model organism Glomus sp. 'irregulare-like' DAOM197198 (formerly called Gl. intraradices) is not conspecific with Gl. intraradices, which is in agreement with mtLSU analyses of sequences of Glomus Group Ab (Börstler et al., 2008).

The successful resolution by using the longer SSUmCf-LSUmBr fragment highlights the often ignored aspect that longer sequences usually have better phylogenetic resolution (Nei et al., 1998; Rokas \& Carroll, 2005), if carrying additional phylogenetically informative regions. The conserved regions in the LSU can help to affiliate unknown sequences, because they provide higher-level taxonomic information and are also easier to align unambiguously. Because our study was the first using both the ITS and the LSU region for detailed phylogenetic analyses of AMF, a comparison of the longest fragment (SSUmCf-LSUmBr) for a wide range of AMF species is not yet possible. Some ectomycorrhizal community studies were carried out on the ITS and partial LSU region together to identify species (Tedersoo et al., 2008), whereas the additional use of the ITS region enhanced species resolution (Smith et al., 2007).

The phylogenetic analyses of the longest fragment (SSUmCf-LSUmBr) clearly separated all species analysed in this study, but such separation could not be revealed with a simple barcode gap analysis. 
Generally, barcode gaps may often represent an artefact caused by insufficient taxon sampling, as discussed by Wiemers and Fiedler (2007). Our results clearly indicate that simple barcode gap analyses are impossible for AMF, when based on the rDNA fragments, and that phylogenetic methods are needed for species resolution.

\subsection{Evaluation of short rDNA fragments for new sequencing technologies}

New sequencing technologies such as 454 sequencing (www.454.com) allow the generation of up to 400000 sequences per run with an average read length of approx. 400 bp (Valentini et al., 2009) and are promising tools to overcome the labour and cost intensive cloning approach for analyses of organism communities. When testing the power of such relatively short fragments to separate AMF species, it turned out that in particular the LSU-D1 (LR1-FLR3) fragment was the least useful of the tested regions (chapter 7). The ITS2 fragment and the LSU-D2 (FLR3-LSUmBr) fragment performed better. In some 454 studies the ITS1 was used as target region for fungal community analyses (Buée et al., 2009; Jumpponen \& Jones, 2009), but Nilsson et al. (2009) have shown that the results of BLAST search based on the ITS1 or ITS2 disagree in $40 \%$ over the taxonomic affiliation of the query sequence, which is a fundamental problem. Hence the right selection of the fragment and the use of high quality annotate sequences will be crucial for comparability of 454 analyses.

In the 454 sequencing approach of Öpik et al. (2009), a part of the SSU rDNA was sequenced with approx. $250 \mathrm{bp}$ average read lengths. However, the maximum resolution of such studies, after $97 \%$ clustering to 'virtual taxa', clearly is above species level. One virtual taxon defined and detected by the criteria published may in fact represent a number of different species. In the Ambisporaceae, the full length SSU is not suited to distinguish species (chapter 4). Care has to be taken to avoid overinterpretation of data, and using the term 'virtual taxa' for MOTUs is misleading, as the taxonomic or even the phylogenetic level is not defined.

Other next-generation sequencing systems, such as Genetic Analyzer/Solexa (Illumina), SOLiD DNA Sequencer (Applied Biosystems) and Heliscope (Helicos) produce even more sequences, but with maximal read length of 75 bases (Valentini et al., 2009; www.illumina.com). Such short read lengths seem to be insufficient for AMF determination, because even the $400 \mathrm{bp}$ analysed here failed to identify all species. However, species identification based on 400 bp sequences could be considerably improved by phylogenetic classification using a 'backbone' based on the analysis of 
longer fragments. Such tools are already available, as e.g. implementation in the RAxML software (http://wwwkramer.in.tum.de/exelixis/software.html).

A recently published paper describes another promising next-generation sequencing technology (Pacific Bioscience www.pacificbiosciences.com; Eid et al., 2009). With this method sequencing of long DNA fragments from environmental DNA samples may become feasible without prior PCR amplification, and the longest fragment (SSUmCf-LSUmBr) analysed here could be used for community analyses of AMF.

\subsection{Arbuscular mycorrhizal fungi DNA barcoding - a conclusion}

DNA barcodes, by definition, should be applicable to identify species. The long fragment (approx. $1500 \mathrm{bp}$ ) analysed here fulfils this requirement, as shown by phylogenetic analyses (chapter 6 and 7). The fragment contains the ITS region, which is a proposed DNA barcode region for fungi (Seifert, 2009). Even closely related species could be separated, which was also supported by independent mitochondrial LSU marker analyses (Börstler et al., 2008). The minimal length of DNA barcodes was proposed to be 500 bp (Frézal \& Leblois, 2008; Seifert, 2009). On the other hand, for analysing herbarium specimens DNA barcodes should be short enough to allow the amplification of degraded DNA, which is difficult for more than $150 \mathrm{bp}$ (Valentini et al., 2009). In this case, the maximum barcode length is limited by technical considerations. When DNA barcoding was first attempted, Sanger sequencing technology allowed read lengths of approx. $700 \mathrm{bp}$, which perhaps was one of the reasons for the size of the first official barcode (COX1) of about $650 \mathrm{bp}$. However, Hajibabaei et al. (2006) had to increase the barcode length of COX1 to $1500 \mathrm{bp}$ to resolve two chimpanzee species.

The ITS region as a common fungal barcode did work for all, except some AMF species examined here for our datasets (chapter 7). However, this must be seen on the background that only a part of the known AMF was analysed. Environmental studies done with the ITS region or the SSU region reveal many new AMF sequence types, which at least partly will turn out to be uncharacterised species (Renker et al., 2005; Sýkorová et al., 2007b; Öpik et al., 2009; Wubet et al., 2009). Ryberg et al. (2009) reported that the genus Glomus had a high proportion of insufficiently identified sequences. Such unknown species may reduce the resolution of the ITS barcode. Incorporating sequences from the database in the ITS region analyses resulted in reduced species resolution, although this could also be an effect of misannotated sequences. Nilsson et al. (2006) showed that up to $20 \%$ of fungal sequences in the public databases may be incorrectly identified at species 
level. Feau et al. (2009) also highlighted misidentified Melampsora rust species in herbarium and sequence databases. Such problem sequences emphasize the necessity of curated databases, as for example BOLD (Ratnasingham \& Hebert, 2007) or UNITE (Kõljalg et al., 2005). Alternatively, a third party annotation in the public databases (GenBank, EMBL, DDBJ) would help to overcome this problem (Bidartondo et al., 2008), but currently this is not allowed.

All AMF species analysed in the present thesis could be separated if the proposed, relatively long SSUmCf-LSUmBr fragment was used. In general, DNA regions of AMF analysed in this work showed a very high intraspecific variation. In birds, the COXI intraspecific variation is about $2 \%$ (Hebert et al., 2003), whereas in AMF the ITS region variation may be up to $14.6 \%$. Interestingly, one AMF spore can harbour approx. the entire degree of variability of two independent isolates, as shown for Gl. intraradices (chapter 6).

Regarding the DNA barcode region for AMF proposed here, new primers (SSUmCf-LSUmBr; SSUmAf-LSUmAr) were designed and tested for both AMF spores and environmental root samples (chapter 5). DNA barcoding primers should optimally be universal to higher taxa, for example, the entire fungal kingdom. However, this kingdom is huge and contains estimated 1.5-3.5 million species (Hawksworth, 2001; O'Brien et al., 2005). For many gene regions it will perhaps not be possible to design primers covering all fungi. The new primers described in chapter 5 are designed specifically for AMF and therefore allow analyses from contaminated and root material. In some former studies, ascomycotan sequences were assigned as of glomeromycotan origin, as demonstrated in Schüßler (1999) and Redecker et al. (1999). It later turned out that even healthy looking and surface-sterilized spores were colonized and therefore contaminated by other fungi (Hijri et al., 2002). An important application for AMF specific primers is the PCR-amplification of AMF DNA from plant roots. Such roots are not only colonized by AMF, but also by other fungi such as pathogens and many endophytes. The DNA amplified with these new primers includes the priming sites for the widely used primer pair ITS4 and ITS5, which is often used to identify fungal species and may be used as a general fungal DNA barcoding primer pair (Seifert, 2009). Therefore, the DNA barcode proposed here for AMF also covers and is compatible with the one suggested as a general fungal barcode. Beside the better species separation power of the long fragment, it will also allow to affiliate LSU sequences to their species if the ITS region fails to match to a sequence in the database. In AMF, use of the combined ITS region and partial LSU regions currently seems unavoidable for species separation, when based on rDNA. 


\subsection{Outlook}

AMF DNA barcodes provide a powerful and useful tool to identify species and provide a complementary method to classical morphological analyses. In the near future it will be desirable to generate more DNA barcodes for a greater coverage of AMF species. Morphologically well characterized AMF species and cultures are urgently needed to build up such a database, and AMF cultures should also be made available to the scientific community. Additionally, the DNA barcoding region should be analysed for all newly described species and the sequences should be deposited in a public database, similar to the classical need of conserving vouchers in a herbarium. For AMF several divergent sequences from a given species should be included. As indicated in chapter 6 for Gl. intraradices FL208, the analysis of a single spore may already cover a significant part of the intraspecific variability.

The combined application of plant and AMF DNA barcodes will create an opportunity for analysing AMF-plant associations from root samples. The identification of the host and the symbiont could simultaneously be established from the same sample. Information about AMF species preferentially associated with certain plants may, e.g., be important for restoration and reforestation success (Wubet et al., 2009; Urgiles et al., 2009). This minimal destructive sampling method would also allow sampling of rare and endangered species.

In phylogenetic analyses of AMF with molecular biological tools, individual sequences are often used to determine the identity. For short sequences, this in many cases may be insufficient for the species level, which is partly due to limited information content, partly to the high intraspecific variation (especially when analysing closely related species). On the other hand, a characterisation of intraspecific sequence variation of the longer fragment (SSUmCf-LSUmBr) proposed here as barcode will facilitate the separation of species based on shorter fragments (ITS or LSU) in future, at least to some extent.

DNA barcode identification for AMF appears to offer a significant contribution to biological research and agronomic field analyses in the near future. In general, AMF supply phosphorus and other nutrients to plants, influence the plant and soil water relations and can stabilise soil through their hyphal network and secreted glycoproteins. These multifunctional beneficial effects on plant are gaining more interest because of the increasing demand for food and other plant materials, and for sustainable agricultural systems. Traditionally, plant production is promoted in high input systems by high amounts of fertilizers, but rock phosphate resources are depleting (Cordell et al., 2009) and the increases in energy prices raise costs for nitrogen fertilizers (Huang, 2007). The application of AMF can help to reduce the fertilizer requirements for plant production (Sharma \& 
Adholeya, 2004). Therefore it is imporant to identify the most 'suitable' AMF species in the field or in nurseries. Molecular tools, such as DNA barcoding, are needed to characterise the efficient plantfungus combinations. Already a decade ago, van der Heijden et al. (1998) showed that plant species respond differently to various AMF species combinations. In addition, AMF species identification will play a role in approaches to breed plant cultivars with higher responsiveness to AM (Boomsma \& Vyn, 2008). Another applied aspect is the fact that a standardized species classification system (DNA barcodes) will help inoculum producers to improve their quality control systems and to define their used AMF species. In addition, the use of a general fungal barcode allows the screening of inoculum for pathogenic fungi. DNA barcoding would eventually also reduce costs and time when compared to microscopical examination (von Alten et al., 2002; Gianinazzi \& Vosátka, 2004). The importance of quality control in AMF production was emphasized at the formation of a working group within the COST action 870, which focuses on this topic (www.cost870.eu/cost.htm). Besides of being useful in laboratory research and for inoculum producers, a DNA barcode will facilitate AMF identification for quarantine and control agencies. An accurate AMF DNA barcode will moreover, at least in certain cases, allow tracing of introduced AMF in the field and the verification of the successful establishment and survival of applied AMF inoculum.

Molecular tools are the only possibility to analyse the AMF species colonizing plant roots and to answer related ecological questions in AMF research. Several studies have been done on biodiversity and community analyses of AMF with molecular tools (Renker et al., 2005; Wubet et al., 2006; Hempel et al., 2007; Sýkorová et al., 2007b; Öpik et al., 2009). Most of the used DNA regions, however, lack species resolution. Furthermore, the primers used were often selective for subgroups within AMF and not covering the complete community (Schüßler, 2001). With both the newly designed primers presented in this work (chapter 5), targeting all Glomeromycota, and the knowledge of the intra- and interspecific sequence variation, species identification should be possible, also for AMF species communities. Although differences between two different types of AMF communities could be shown working with 'virtual taxa' (Öpik et al., 2009), such types of analyses would be much improved if performed at species or individual organismic level.

It has been shown here that DNA barcoding in AMF is possible (chapter 7), but it is by far not as straightforward as barcoding in animals (e.g. Hebert et al., 2004). It is desirable that such a barcode is compatible with that used for other fungi. Although it would be a great improvement to use a uniform DNA barcode, such as the ITS region, for all fungi, the region on its own is not sufficiently accurate for robust species delineation and should be extended for Glomeromycota. This thesis contributes significantly to the discussion and evaluation of DNA barcodes for fungi and offers 
improvements with regard to selected primers and detailed analyses of barcoding regions for AMF. The approx. 1500 bp SSUmCf-LSUmBr fragment is proposed as an extended DNA barcode for AMF, whereas the ITS2 and the LSU-D2 regions both are proposed as shorter barcodes for analyses making use of 454GS-FLX Titanium sequencing approaches. This and other deep sequencing methods will offer the potential of a rapid screening and monitoring of AMF communities in close future. However, robust deep sequencing data interpretation will strongly depend on well characterised and annotated 'hand made' sequences as a fundamental baseline, which in turn depends on the availability of diverse and well characterised AMF isolates. 


\section{References}

Akiyama K, Matsuzaki K, Hayashi H. 2005. Plant sesquiterpenes induce hyphal branching in arbuscular mycorrhizal fungi. Nature 435: 824-827.

von Alten H, Blal B, Dodd J, Feldmann F, Vosatka M. 2002. Quality control of arbuscular mycorrhizal fungi inoculum. Mycorrhizal technology in agriculture. Birkhäuser, 223-234.

Aroca R, Porcel R, Ruiz-Lozano JM. 2007. How does arbuscular mycorrhizal symbiosis regulate root hydraulic properties and plasma membrane aquaporins in Phaseolus vulgaris under drought, cold or salinity stresses? New Phytologist 173: 808-816.

Augé RM. 2004. Arbuscular mycorrhizae and soil/plant water relations. Canadian Journal of Soil Science 84: 373-381.

Augé RM. 2001. Water relations, drought and vesicular-arbuscular mycorrhizal symbiosis. Mycorrhiza 11: 3-42.

Augé RM, Toler H, Sams C, Nasim G. 2008. Hydraulic conductance and water potential gradients in squash leaves showing mycorrhiza-induced increases in stomatal conductance. Mycorrhiza 18: 115-121.

Bago B, Pfeffer PE, Abubaker J, Jun J, Allen JW, Brouillette J, Douds DD, Lammers PJ, Shachar-Hill Y. 2003. Carbon export from arbuscular mycorrhizal roots involves the translocation of carbohydrate as well as lipid. Plant Physiology 131: 1496-1507.

Besserer A, Puech-Pagès V, Kiefer P, Gomez-Roldan V, Jauneau A, Roy S, Portais J, Roux C, Bécard G, Séjalon-Delmas N. 2006. Strigolactones stimulate arbuscular mycorrhizal fungi by activating mitochondria. PLoS Biology 4: e226.

Bever JD, Schultz PA, Pringle A, Morton JB. 2001. Arbuscular mycorrhizal fungi: More diverse than meets the eye, and the ecological tale of why. Bioscience 51: 923 - 931.

Bever JD, Richardson SC, Lawrence BM, Holmes J, Watson M. 2009. Preferential allocation to beneficial symbiont with spatial structure maintains mycorrhizal mutualism. Ecology Letters 12: 1321.

Bianciotto V, Barbiero G, Bonfante P. 1995. Analysis of the cell cycle in an arbuscular mycorrhizal fungus by flow cytometry and bromodeoxyuridine labelling. Protoplasma 188: 161169.

Bianciotto V, Bonfante P. 1992. Quantification of the nuclear DNA content of two arbuscular mycorrhizal fungi. Mycological Research 96: 1071-1076.

Bidartondo MI, Redecker D, Hijri I, Wiemken A, Bruns TD, Dominguez L, Sersic A, Leake JR, Read DJ. 2002. Epiparasitic plants specialized on arbuscular mycorrhizal fungi. Nature 419: 389-392. 
Bidartondo MI, Bruns TD, Blackwell M, Edwards I, Taylor AFS, Horton T, Zhang N, Kõljalg U, May G, Kuyper TW, et al. 2008. Preserving accuracy in GenBank. Science 319: 1616.

Boomsma CR, Vyn TJ. 2008. Maize drought tolerance: Potential improvements through arbuscular mycorrhizal symbiosis? Field Crops Research 108: 14-31.

Börstler B, Raab PA, Thiéry O, Morton JB, Redecker D. 2008. Genetic diversity of the arbuscular mycorrhizal fungus Glomus intraradices as determined by mitochondrial large subunit rRNA gene sequences is considerably higher than previously expected. New Phytologist 180: 452465.

Brundrett M. 2009. Mycorrhizal associations and other means of nutrition of vascular plants: understanding the global diversity of host plants by resolving conflicting information and developing reliable means of diagnosis. Plant and Soil 320: 37-77.

Bruns TD, White TJ, Taylor JW. 1991. Fungal molecular systematics. Annual Review of Ecology and Systematics 22: 525-564.

Buée M, Reich M, Murat C, Morin E, Nilsson RH, Uroz S, Martin F. 2009. 454 Pyrosequencing analyses of forest soils reveal an unexpectedly high fungal diversity. New Phytologist 184;279-282.

Bürkert B, Robson A. 1994. 65Zn uptake in subterranean clover (Trifolium subterraneum L.) by three vesicular-arbuscular mycorrhizal fungi in a root-free sandy soil. Soil Biology and Biochemistry 26: 1117-1124.

Burleigh SH, Kristensen BK, Bechmann IE. 2003. A plasma membrane zinc transporter from Medicago truncatula is up-regulated in roots by $\mathrm{Zn}$ fertilization, yet down-regulated by arbuscular mycorrhizal colonization. Plant Molecular Biology 52: 1077-1088.

Cavagnaro TR, L-L. Gao, F. A. Smith, S. E. Smith. 2001. Morphology of arbuscular mycorrhizas is influenced by fungal identity. New Phytologist 151: 469-475.

Cordell D, Drangert J, White S. 2009. The story of phosphorus: Global food security and food for thought. Global Environmental Change 19: 292-305.

Corradi N, Hijri M, Fumagalli L, Sanders IR. 2004a. Arbuscular mycorrhizal fungi (Glomeromycota) harbour ancient fungal tubulin genes that resemble those of the chytrids (Chytridiomycota). Fungal Genetics and Biology 41: 1037-1045.

Corradi N, Kuhn G, Sanders IR. 2004b. Monophyly of B-tubulin and H+-ATPase gene variants in Glomus intraradices: consequences for molecular evolutionary studies of AM fungal genes. Fungal Genetics and Biology 41: 262-273.

Croll D, Giovannetti M, Koch AM, Sbrana C, Ehinger M, Lammers PJ, Sanders IR. 2008. Nonself vegetative fusion and genetic exchange in the arbuscular mycorrhizal fungus Glomus intraradices. New Phytologist 181: 924-937.

Croll D, Sanders I. 2009. Recombination in Glomus intraradices, a supposed ancient asexual arbuscular mycorrhizal fungus. BMC Evolutionary Biology 9: 13. 
Croll D, Wille L, Gamper HA, Mathimaran N, Lammers PJ, Corradi N, Sanders IR. 2008. Genetic diversity and host plant preferences revealed by simple sequence repeat and mitochondrial markers in a population of the arbuscular mycorrhizal fungus Glomus intraradices. New Phytologist 178: $672-687$.

Daft MJ, Nicolson T. 1966. Effect of Endogone mycorrhiza on plant growth. New Phytologist 65 : 343-350.

Daft MJ, Nicolson T. 1969a. Effect of Endogone mycorrhiza on plant growth. II. Influence of soluble phosphate on endophyte and host in maize. New Phytologist 68: 945-952.

Daft MJ, Nicolson T. 1969b. Effect of Endogone mycorrhiza on plant growth. III. Influence of inoculum concentration on growth and infection in tomato. New Phytologist 68: 953-963.

Dickson S. 2004. The Arum-Paris continuum of mycorrhizal symbioses. New Phytologist 163: 187200.

Dickson S, Smith F, Smith S. 2007. Structural differences in arbuscular mycorrhizal symbioses: more than 100 years after Gallaud, where next? Mycorrhiza 17: 375-393.

Douhan GW, Petersen C, Bledsoe CS, Rizzo DM. 2005. Contrasting root associated fungi of three common oak-woodland plant species based on molecular identification: host specificity or nonspecific amplification? Mycorrhiza 15: 365-372.

Eid J, Fehr A, Gray J, Luong K, Lyle J, Otto G, Peluso P, Rank D, Baybayan P, Bettman B, et al. 2009. Real-Time DNA sequencing from single polymerase molecules. Science 323: 133-138.

Feau N, Vialle A, Allaire M, Tanguay P, Joly DL, Frey P, Callan BE, Hamelin RC. 2009. Fungal pathogen (mis-) identifications: A case study with DNA barcodes on Melampsora rusts of aspen and white poplar. Mycological Research 113: 713-724.

Fitter AH. 2005. Darkness visible: Reflections on underground ecology. Journal of Ecology 93: 231-243.

Frank B. 2005. On the nutritional dependence of certain trees on root symbiosis with belowground fungi (an English translation of A.B. Frank's classic paper of 1885). Mycorrhiza 15: 267-275.

Fransson A, van Aarle IM, Olsson PA, Tyler G. 2003. Plantago lanceolata L. and Rumex acetosella L. differ in their utilisation of soil phosphorus fractions. Plant and Soil 248: 285-295.

Frézal L, Leblois R. 2008. Four years of DNA barcoding: Current advances and prospects. Infection, Genetics and Evolution 8: 727-736.

Gamper HA, Walker C, Schüßler A. 2009. Diversispora celata sp. nov: molecular ecology and phylotaxonomy of an inconspicuous arbuscular mycorrhizal fungus. New Phytologist 182: 495-506.

Gange AC, Brown VK, Farmer L. 1990. A test of mycorrhizal benefit in an early successional plant community. New Phytologist 115: 85-91. 
Ganley AR, Kobayashi T. 2007. Highly efficient concerted evolution in the ribosomal DNA repeats: Total rDNA repeat variation revealed by whole-genome shotgun sequence data. Genome Research 17: 184-191.

Gallaud I. 1905. Études sur les mycorrhizes endotrophes. Revue Générale de Botanique 17, 5-48, 66-83, 123-135, 223-239, 313-325, 425-433, 479-500.

Geiser DM, Klich M, Frisvad J, Peterson S, Varga J, Samson R. 2007. The current status of species recognition and identification in Aspergillus. Studies in Mycology 59: 1-10.

Genre A, Chabaud M, Faccio A, Barker DG, Bonfante P. 2008. Prepenetration apparatus assembly precedes and predicts the colonization patterns of arbuscular mycorrhizal fungi within the root cortex of both Medicago truncatula and Daucus carota. Plant Cell 20: 1407-1420.

Genre A, Chabaud M, Timmers T, Bonfante P, Barker DG. 2005. Arbuscular mycorrhizal fungi elicit a novel intracellular apparatus in Medicago truncatula root epidermal cells before infection. Plant Cell 17: 3489-3499.

Gerdemann JW. 1965. Vesicular-arbuscular mycorrhizae formed on Maize and Tuliptree by Endogone fasciculata. Mycologia 57: 562-575.

Gianinazzi S, Vosátka M. 2004. Inoculum of arbuscular mycorrhizal fungi for production systems: Science meets business. Canadian Journal of Botany 82: 1264-1271.

Gildon A, Tinker PB. 1983. Interactions of vesicular-arbuscular mycorrhizal infections and heavy metals in plants. II. The effects of infection on uptake of copper. New Phytologist 95: 263-268.

Gilmore SR, Gräfenhahn T, Louis-Seize G, Seifert KA. 2009. Multiple copies of cytochrome oxidase 1 in species of the fungal genus Fusarium. Molecular Ecology Resources 9: 90-98.

Gnekow M, Marschner H. 1989. Role of VA-mycorrhiza in growth and mineral nutrition of apple (Malus pumila var. domestica) rootstock cuttings. Plant and Soil 119: 285-293.

Gollotte A, van Tuinen D, Atkinson D. 2004. Diversity of arbuscular mycorrhizal fungi colonising roots of the grass species Agrostis capillaris and Lolium perenne in a field experiment. Mycorrhiza 14: 111-117.

Govindarajulu M, Pfeffer PE, Jin H, Abubaker J, Douds DD, Allen JW, Bucking H, Lammers PJ, Shachar-Hill Y. 2005. Nitrogen transfer in the arbuscular mycorrhizal symbiosis. Nature 435: 819-823.

Grace EJ, Cotsaftis O, Tester M, Smith FA, Smith SE. 2009. Arbuscular mycorrhizal inhibition of growth in barley cannot be attributed to extent of colonization, fungal phosphorus uptake or effects on expression of plant phosphate transporter genes. New Phytologist 181: 938-949.

Graham J, Abbott L. 2000. Wheat responses to aggressive and non-aggressive arbuscular mycorrhizal fungi. Plant and Soil 220: 207-218.

Grime JP, Mackey JML, Hillier SH, Read DJ. 1987. Floristic diversity in a model system using experimental microcosms. Nature 328: 420-422. 
Hajibabaei M, Singer GA, Hickey DA. 2006. Benchmarking DNA barcodes: An assessment using available primate sequences. Genome 49: 851-854.

Harley J, Harley E. 1987. A check-list of mycorrhiza in the British Flora. New Phytologist 105: 1102.

Harpke D, Peterson A. 2006. Non-concerted ITS evolution in Mammillaria (Cactaceae). Molecular Phylogenetics and Evolution 41: 579-593.

Hartmann S, Nason JD, Bhattacharya D. 2001. Extensive ribosomal DNA genic variation in the columnar cactus Lophocereus. Journal of Molecular Evolution 53: 124-134.

Hart MM, Trevors JT. 2005. Microbe management: Application of mycorrhizal fungi in sustainable agriculture. Frontiers in Ecology and the Environment 3: 533-539.

Hartnett DC, Wilson GWT. 1999. Mycorrhizae influence plant community structure and diversity in tallgrass prairie. Ecology 80: 1187-1195.

Hawksworth DL. 2001. The magnitude of fungal diversity: the 1.5 million species estimate revisited. Mycological Research 105: 1422-1432.

Hayman DS, Mosse B. 1971. Plant growth responses to vesicular-arbuscular mycorrhiza I. Growth of Endogone-inoculated plants in phosphate-deficient soils. New Phytologist 70: 19-27.

Hayman DS, Mosse B. 1972. Plant growth responses to vesicular-arbuscular mycorrhiza III. Increased uptake of labile P from soil. New Phytologist 71: 41-47.

Hebert PD, Stoeckle MY, Zemlak TS, Francis CM. 2004. Identification of birds through DNA barcodes. PLoS Biology 2: e312.

Hebert PD, Cywinska A, Ball SL, deWaard JR. 2003. Biological identifications through DNA barcodes. Proceedings of the Royal Society of London. Series B: Biological Sciences 270: 313-321.

Heckman DS, Geiser DM, Eidell BR, Stauffer RL, Kardos NL, Hedges BS. 2001. Molecular evidence for the early colonisation of land by fungi and plants. Science 293: 1129-1133.

van der Heijden MGA. 2004. Arbuscular mycorrhizal fungi as support systems for seedling establishment in grassland. Ecology Letters 7: 293-303.

van der Heijden MGA, Klironomos JN, Ursic M, Moutoglis P, Streitwolf-Engel R, Boller T, Wiemken A, Sanders IR. 1998. Mycorrhizal fungal diversity determines plant biodiversity, ecosystem variability and productivity. Nature 396: 69-72.

van der Heijden MGA, Streitwolf-Engel R, Riedl R, Siegrist S, Neudecker A, Ineichen K, Boller T, Wiemken A, Sanders IR. 2006. The mycorrhizal contribution to plant productivity, plant nutrition and soil structure in experimental grassland. New Phytologist 172: 739-752.

van der Heijden MGA, Wiemken A, Sanders IR. 2003. Different arbuscular mycorrhizal fungi alter coexistence and resource distribution co-occurring plant. New Phytologist 157: 569-578. 
Helgason T, Daniell T, Husband R, Fitter A, Young JPW. 1998. Ploughing up the wood-wide web? Nature 394: 431.

Helgason T, Fitter AH, Young JPW. 1999. Molecular diversity of arbuscular mycorrhizal fungi colonising Hyacinthoides non-scripta (bluebell) in a seminatural woodland. Molecular Ecology 8: 659-666.

Helgason T, Merryweather J, Denison J, Wilson P, Young JPW, Fitter A. 2002. Selectivity and functional diversity in arbuscular mycorrhizas of co-occurring fungi and plants from a temperate deciduous woodland. Journal of Ecology 90: 371-384.

Hempel S, Renker C, Buscot F. 2007. Differences in the species composition of arbuscular mycorrhizal fungi in spore, root and soil communities in a grassland ecosystem. Environmental Microbiology 9: 1930-1938.

Hijri M, Redecker D, Petetot JAM, Voigt K, Wostemeyer J, Sanders IR. 2002. Identification and isolation of two ascomycete fungi from spores of the arbuscular mycorrhizal fungus Scutellospora castanea. Applied and Environmental Microbiology 68: 4567-4573.

Hijri M, Sanders IR. 2004. The arbuscular mycorrhizal fungus Glomus intraradices is haploid and has a small genome size in the lower limit of eukaryotes. Fungal Genetics and Biology 41: 253-261.

Hijri M, Sanders IR. 2005. Low gene copy number shows that arbuscular mycorrhizal fungi inherit genetically different nuclei. Nature 433: 160-163.

Hofstetter V, Miadlikowska J, Kauff F, Lutzoni F. 2007. Phylogenetic comparison of proteincoding versus ribosomal RNA-coding sequence data: A case study of the Lecanoromycetes (Ascomycota). Molecular Phylogenetics and Evolution 44: 412-426.

Hollingsworth PM, Forrest LL, Spouge JL, Hajibabaei M, Ratnasingham S, van der Bank M, Chase MW, Cowan RS, Erickson DL, Fazekas AJ, et al. 2009. A DNA barcode for land plants. Proceedings of the National Academy of Sciences, USA 106: 12794-12797.

Hosny M, Gianinazzi-Pearson V, Dulieu H. 1998. Nuclear DNA content of 11 fungal species in Glomales. Genome 41: 422-428.

Huang W. 2007. Impact of rising natural gas prices on U.S. ammonia supply / WRS-0702. USDA.

Jakobsen I, Rosendahl S. 1990. Carbon flow into soil and external hyphae from roots of mycorrhizal cucumber plants. New Phytologist 115: 77-83.

Jansa J, Mozafar A, Frossard E. 2003. Long-distance transport of $P$ and $Z n$ through the hyphae of an arbuscular mycorrhizal fungus in symbiosis with maize. Agronomie 23: 481-488.

Jansa J, Mozafar A, Anken T, Ruh R, Sanders IR, Frossard E. 2002a. Diversity and structure of AMF communities as affected by tillage in a temperate soil. Mycorrhiza 12: 225-234.

Jansa J, Mozafar A, Banke S, McDonald BA, Frossard E. 2002b. Intra- and intersporal diversity of ITS rDNA sequences in Glomus intraradices assessed by cloning and sequencing, and by SSCP analysis. Mycological Research 106: 670-681. 
Johnson NC, Graham JH, Smith FA. 1997. Functioning of mycorrhizal associations along the mutualism; parasitism continuum. New Phytologist 135: 575-585.

Jumpponen A, Jones KL. 2009. Massively parallel 454 sequencing indicates hyperdiverse fungal communities in temperate Quercus macrocarpa phyllosphere. The New Phytologist 184:279-282

Keller I, Chintauan-Marquier IC, Veltsos P, Nichols RA. 2006. Ribosomal DNA in the grasshopper Podisma pedestris: escape from concerted evolution. Genetics 174: 863-874.

Kirk PM, Cannon PF, Stalpers J. 2008. Dictionary of the Fungi. Wallingford, UK: CABI.

Kjøller R, Rosendahl S. 2000. Detection of arbuscular mycorrhizal fungi (Glomales) in roots by nested PCR and SSCP (Single Stranded Conformation Polymorphism). Plant and Soil 226: 189196.

Klironomos JN, McCune J, Hart M, Neville J. 2000. The influence of arbuscular mycorrhizae on the relationship between plant diversity and productivity. Ecology Letters 3: 137-141.

Klironomos JN. 2002. Feedback with soil biota contributes to plant rarity and invasiveness in communities. Nature 417: 67-70.

Klironomos JN. 2003. Variation in plant response to native and exotic arbuscular mycorrhizal fungi. Ecology 84: 2292-2301.

Kõljalg U, Larsson K, Abarenkov K, Nilsson R, Alexander I, Eberhardt U, Erland S, Høiland $\mathbf{K}$, Kjøller R, Larsson E, et al. 2005. UNITE: a database providing web-based methods for the molecular identification of ectomycorrhizal fungi. New 166: 1063-1068.

Kottke I, Haug I, Setaro S, Suarez JP, Weiß M, Preußing M, Nebel M, Oberwinkler F. 2008. Guilds of mycorrhizal fungi and their relation to trees, ericads, orchids and liverworts in a neotropical mountain rain forest. Basic and Applied Ecology 9: 13-23.

Kubota M, McGonigle TP, Hyakumachi M. 2005. Co-occurrence of Arum- and Paris-type morphologies of arbuscular mycorrhizae in cucumber and tomato. Mycorrhiza 15: 73-77.

Kucey R, Janzen H. 1987. Effects of VAM and reduced nutrient availability on growth and phosphorus and micronutrient uptake of wheat and field beans under greenhouse conditions. Plant and Soil 104: 71-78.

Kuhn G, Hijri M, Sanders IR. 2001. Evidence for the evolution of multiple genomes in arbuscular mycorrhizal fungi. Nature 414: 745-748.

Lanfranco L, Delpero M, Bonfante P. 1999. Intrasporal variability of ribosomal sequences in the endomycorrhizal fungus Gigaspora margarita. Molecular Ecology 8: 37-45.

Lang BF, Hijri M. 2009. The complete Glomus intraradices mitochondrial genome sequence - a milestone in mycorrhizal research. New Phytologist 183: 3-6. 
Lee J, Lee S, Young JPW. 2008. Improved PCR primers for the detection and identification of arbuscular mycorrhizal fungi. FEMS Microbiology Ecology 65: 339-349.

Lee J, Young JPW. 2009. The mitochondrial genome sequence of the arbuscular mycorrhizal fungus Glomus intraradices isolate 494 and implications for the phylogenetic placement of Glomus. New Phytologist 183: 200-211.

Li L, Li T, Zhao Z. 2007. Differences of arbuscular mycorrhizal fungal diversity and community between a cultivated land, an old field, and a never-cultivated field in a hot and arid ecosystem of southwest China. Mycorrhiza 17: 655-665.

Li X, Marschner H, George E. 1991. Acquisition of phosphorus and copper by VA-mycorrhizal hyphae and root-to-shoot transport in white clover. Plant and Soil 136: 49-57.

Li X, Christie P. 2001. Changes in soil solution $\mathrm{Zn}$ and $\mathrm{pH}$ and uptake of $\mathrm{Zn}$ by arbuscular mycorrhizal red clover in Zn-contaminated soil. Chemosphere 42: 201-207.

Lloyd-Macglip SA, Chambers S, Dodd J, Fitter AH, Walker C, Young JW. 1996. Diversity of the ribosomal internal transcribed spacers within and among isolates of Glomus mosseae and related mycorrhizal fungi. New Phytologist 133: 103-111.

Mäder P, Vierheilig H, Streitwolf-Engel T, Boller T, Frey P, Christie P, Wiemken A. 2000. Transport of $15 \mathrm{~N}$ from a soil compartment separated by a polytetrafluoroethylene membrane to plant roots via the hyphae of arbuscular mycorrhizal fungi. New Phytologist 146: 155-161.

Marler MJ, Zabinski CA, Callaway RM. 1999. Mycorrhizae indirectly enhance competitive effects of an invasive forb on a native Bunchgrass. Ecology 80: 1180-1186.

Marquez LM, Miller DJ, MacKenzie JB, van Oppen MJH. 2003. Pseudogenes contribute to the extreme diversity of nuclear ribosomal DNA in the hard coral Acropora. Molecular Biology and Evolution 20: 1077-1086.

Marschner P, Baumann K. 2003. Changes in bacterial community structure induced by mycorrhizal colonisation in split-root maize. Plant and Soil 251: 279-289.

Marschner P, Timonen S. 2005. Interactions between plant species and mycorrhizal colonization on the bacterial community composition in the rhizosphere. Applied Soil Ecology 28: 23-36.

Martin F, Gianinazzi-Pearson V, Hijri M, Lammers P, Requena N, Sanders IR, Shachar-Hill Y, Shapiro H, Tuskan GA, Young JPW. 2008. The long hard road to a completed Glomus intraradices genome. New Phytologist 180: 747-750.

Marulanda A, Azcón R, Ruiz-Lozano JM. 2003. Contribution of six arbuscular mycorrhizal fungal isolates to water uptake by Lactuca sativa plants under drought stress. Physiologia Plantarum 119: 526-533.

Mathimaran N, Falquet L, Ineichen K, Picard C, Redecker D, Boller T, Wiemken A. 2008. Microsatellites for disentangling underground networks: Strain-specific identification of Glomus intraradices, an arbuscular mycorrhizal fungus. Fungal Genetics and Biology 45: 812-817. 
Molitor C, Inthavong B, Sage L, Geremia RA, Mouhamadou B. 2009. Potentiality of the cox 1 gene in the taxonomic resolution of soil fungi. FEMS Microbiology Letters 302: 76-84.

Mosse B. 1957. Growth and chemical composition of mycorrhizal and non-mycorrhizal apples. Nature 179: 922-924.

Mosse B, Hayman DS. 1971. Plant growth responses to vesicular-arbuscular mycorrhiza. New Phytologist 70: 29-34.

Msiska Z, Morton J. 2009. Phylogenetic analysis of the Glomeromycota by partial $\beta$-tubulin gene sequences. Mycorrhiza 19: 1432-1890.

Nei M, Kumar S, Takahashi K. 1998. The optimization principle in phylogenetic analysis tends to give incorrect topologies when the number of nucleotides or amino acids used is small. Proceedings of the National Academy of Sciences, USA 95: 12390-12397.

Newsham KK, Fitter AH, Watkinson AR. 1995. Multi-functionality and biodiversity in arbuscular mycorrhizas. Trends in Ecology \& Evolution 10: 407-411.

Nilsson RH, Kristiansson E, Ryberg M, Hallenberg N, Larsson K. 2008. Intraspecific ITS variability in the kingdom fungi as expressed in the international sequence databases and its implications for molecular species identification. Evolutionary Bioinformatics Online 4: 193-201.

Nilsson RH, Ryberg M, Kristiansson E, Abarenkov K, Larsson K, Kõljalg U. 2006. Taxonomic reliability of DNA sequences in public sequence databases: A fungal perspective. PLoS ONE 1: e59.

Nilsson RH, Ryberg M, Abarenkov K, Sjökvist E, Kristiansson E. 2009. The ITS region as a target for characterization of fungal communities using emerging sequencing technologies. FEMS Microbiology Letters 296: 97-101.

O'Brien HE, Parrent JL, Jackson JA, Moncalvo J, Vilgalys R. 2005. Fungal community analysis by large-scale sequencing of environmental samples. Applied and Environmental Microbiology 71: 5544-5550.

O'Connor PJ, Smith SE, Smith A. 2002. Arbuscular mycorrhizas influence plant diversity and community structure in a semiarid herbland. New Phytologist 154: 209-218.

Oehl F, Sieverding E, Ineichen K, Mader P, Boller T, Wiemken A. 2003. Impact of land use intensity on the species diversity of arbuscular mycorrhizal fungi in agroecosystems of Central Europe. Applied and Environmental Microbiology 69: 2816-2824.

Oehl F, Sieverding E, Ineichen K, Ris E, Boller T, Wiemken A. 2005. Community structure of arbuscular mycorrhizal fungi at different soil depths in extensively and intensively managed agroecosystems. New Phytologist 165: 273-283.

Öpik M, Metsis M, Daniell TJ, Zobel M, Moora M. 2009. Large-scale parallel 454 sequencing reveals host ecological group specificity of arbuscular mycorrhizal fungi in a boreonemoral forest. New Phytologist 184: 424-437. 
Öpik M, Moora M, Zobel M, Saks Ü, Wheatley R, Wright F, Daniell T. 2008. High diversity of arbuscular mycorrhizal fungi in a boreal herb-rich coniferous forest. New Phytologist 179: 867-876.

Parniske M. 2008. Arbuscular mycorrhiza: the mother of plant root endosymbioses. Review Nature Reviews Microbiology 6: 763-775.

Pawlowska TE, Taylor JW. 2004. Organization of genetic variation in individuals of arbuscular mycorrhizal fungi. Nature 427: 733-737.

Pivato B, Mazurier S, Lemanceau P, Siblot S, Berta G, Mougel C, van Tuinen D. 2007. Medicago species affect the community composition of arbuscular mycorrhizal fungi associated with roots. New Phytologist 176: 197-210.

Pringle A, Bever JD. 2008. Analogous effects of arbuscular mycorrhizal fungi in the laboratory and a North Carolina field. New Phytologist 180: 162-175.

Quince C, Curtis TP, Sloan WT. 2008. The rational exploration of microbial diversity. The ISME Journal 2: 997-1006.

Raab PA, Brennwald A, Redecker D. 2005. Mitochondrial large ribosomal subunit sequences are homogeneous within isolates of Glomus (arbuscular mycorrhizal fungi, Glomeromycota). Mycological Research 109: 1315-1322.

Ratnasingham S, Hebert PDN. 2007. BOLD: The Barcode of Life Data System. Molecular Ecology Notes 7: 355 - 364.

Redecker D. 2000. Specific PCR primers to identify arbuscular mycorrhizal fungi within colonized roots. Mycorrhiza 10: 73-80.

Redecker D, Hijri M, Dulieu H, Sanders IR. 1999. Phylogenetic analysis of a dataset of fungal 5.8S rDNA sequences shows that highly divergent copies of internal transcribed spacers reported from Scutellospora castanea are of ascomycete origin. Fungal Genetics and Biology 28: 238-244.

Redecker D, Kodner R, Graham LE. 2000a. Glomalean fungi from the Ordovician. Science 289: 1920-1921.

Redecker D, Morton JB, Bruns TD. 2000b. Ancestral lineages of arbuscular mycorrhizal fungi (Glomales). Molecular Phylogenetics and Evolution 14: 276-284.

Redecker D, Raab PA, Oehl F, J.Camacho F, Court R. 2007. A novel clade of sporocarp-forming species of glomeromycotan fungi in the Diversisporales lineage. Mycological Progress 6: 35-44.

Remy W, Taylor TN, Hass H, Kerp H. 1994. Four hundred-million-year-old vesicular arbuscular mycorrhizae. Proceedings of the National Academy of Sciences 91: 11841-11843.

Renker C, Blanke V, Buscot F. 2005. Diversity of arbuscular mycorrhizal fungi in grassland spontaneously developed on area polluted by a fertilizer plant. Environmental Pollution 135: 255266. 
Renker C, Heinrichs J, Kaldorf M, Buscot F. 2003. Combining nested PCR and restriction digest of the internal transcribed spacer region to characterize arbuscular mycorrhizal fungi on roots from the field. Mycorrhiza 13: 191-198.

Reynolds HL, Anne E. Hartley, Keith M. Vogelsang, Bever JD, P. A. Schultz. 2005. Arbuscular mycorrhizal fungi do not enhance nitrogen acquisition and growth of old-field perennials under low nitrogen supply in glasshouse culture. New Phytologist 167: 869-880.

Rillig MC. 2004. Arbuscular mycorrhizae, glomalin, and soil aggregation. Canadian Journal of Soil Science 84: 355-363.

Rodríguez-Echeverría S, Freitas H. 2006. Diversity of AMF associated with Ammophila arenaria ssp. arundinacea in Portuguese sand dunes. Mycorrhiza 16: 543-552.

Rokas A, Carroll SB. 2005. More genes or more taxa? The relative contribution of gene number and taxon number to phylogenetic accuracy. Molecular Biology and Evolution 22: 1337-1344.

Rosendahl S, Taylor JW. 1997. Development of multiple genetic markers for studies of genetic variation in arbuscular mycorrhizal fungi using AFLP. Molecular Ecology 6: 821-829.

Rosendahl S, McGee P, Morton JB. 2009. Lack of global population genetic differentiation in the arbuscular mycorrhizal fungus Glomus mosseae suggests a recent range expansion which may have coincided with the spread of agriculture. Molecular Ecology 18: 4316-4329.

Rosendahl S. 2008. Communities, populations and individuals of arbuscular mycorrhizal fungi. New Phytologist 178: 253-266.

Ryberg M, Kristiansson E, Sjökvist E, Nilsson RH. 2009. An outlook on the fungal internal transcribed spacer sequences in GenBank and the introduction of a web-based tool for the exploration of fungal diversity. New Phytologist 181: 471-477.

Sanders FE, P. Bernard Tinker. 1973. Phosphate flow into mycorrhizal roots. Pesticide Science 4: 385-395.

Sanders IR, Alt M, Groppe K, Boller T, Wiemken A. 1995. Identification of ribosomal DNA polymorphisms among and within spores of the Glomales: application to studies on the genetic diversity of arbuscular mycorrhizal fungal communities. New Phytologist 130: 419-427.

Sanders IR, Koch A, Kuhn G. 2003. Arbuscular mycorrhizal fungi: genetics of multigenomic, clonal networks and its ecological consequences. Biological Journal of the Linnean Society 79: 5960 .

Santos-Gonzalez JC, Finlay RD, Tehler A. 2007. Seasonal dynamics of arbuscular mycorrhizal fungal communities in roots in a seminatural grassland. Applied and Environmental Microbiology 73: $5613-5623$.

Sawaki H, Sugawara K, Saito M. 1998. Phylogenetic position of an arbuscular mycorrhizal fungus, Acaulospora gerdemannii, and its synanamorph Glomus leptotichum, based upon $18 \mathrm{~S}$ rRNA gene sequence. Mycoscience 39: 477-480. 
Schüßler A. 1999. Glomales SSU rRNA gene diversity. New Phytologist 144: 205-207.

Schüßler A. 2001. Analysis of partial Glomales SSU rRNA genes: implications for primer design and phylogeny. Mycological research 105: 5-15.

Schüßler A, Schwarzott D, Walker C. 2001. A new fungal phylum, the Glomeromycota: phylogeny and evolution. Mycological Research 105: 1413-1421.

Schwarzott D, Walker C, Schüßler A. 2001. Glomus, the largest genus of the arbuscular mycorrhizal fungi (Glomales), is nonmonophyletic. Molecular Phylogenetics and Evolution 21: 190-197.

Seif E, Leigh J, Liu Y, Roewer I, Forget L, Lang BF. 2005. Comparative mitochondrial genomics in zygomycetes: bacteria-like RNase P RNAs, mobile elements and a close source of the group I intron invasion in angiosperms. Nucleic Acids Research 33: 734-744.

Seifert KA. 2009. Progress towards DNA barcoding of fungi. Molecular Ecology Resources 9: 8389.

Seifert KA, Samson RA, deWaard JR, Houbraken J, Levesque C, Moncalvo JM, Louis-Seize G, Hebert PD. 2007. Prospects for fungus identification using CO1 DNA barcodes, with Penicillium as a test case. Proceedings of the National Academy of Sciences, USA 104: 3901-3906.

Sharma MP, Adholeya A. 2004. Effect of arbuscular mycorrhizal fungi and phosphorus fertilization on the post vitro growth and yield of micropropagated strawberry grown in a sandy loam soil. Canadian Journal of Botany 82: 322-328.

Simon L, Lalonde M, Bruns TD. 1992. Specific amplification of $18 \mathrm{~S}$ fungal ribosomal genes from vesicular-arbuscular endomycorrhizal fungi colonizing roots. Applied and Environmental Microbiology 58: 291-295.

Simon L, Bousquet J, Lévesque RC, Lalonde M. 1993. Origin and diversification of endomycorrhizal fungi and coincidence with vascular land plants. Nature 363: 67-69.

Smith FA, Grace EJ, Smith SE. 2009. More than a carbon economy: nutrient trade and ecological sustainability in facultative arbuscular mycorrhizal symbioses. New Phytologist 182: 347-358.

Smith ME, Douhan GW, Rizzo DM. 2007. Ectomycorrhizal community structure in a xeric Quercus woodland based on rDNA sequence analysis of sporocarps and pooled roots. The New Phytologist 174: 847-863.

Smith SE, Read DJ. 2008. Mycorrhizal symbiosis. Amsterdam; Boston: Academic Press.

Smith SE, SmithFA, Jakobsen I. 2004. Functional diversity in arbuscular mycorrhizal (AM) symbioses: the contribution of the mycorrhizal $\mathrm{P}$ uptake pathway is not correlated with mycorrhizal responses in growth or total P uptake. New Phytologist 162: 511-524.

Smith SE, Smith FA, Jakobsen I. 2003. Mycorrhizal fungi can dominate phosphate supply to plants irrespective of growth responses. Plant Physiology 133: 16-20. 
Sýkorová Z, Ineichen K, Wiemken A, Redecker D. 2007a. The cultivation bias: different communities of arbuscular mycorrhizal fungi detected in roots from the field, from bait plants transplanted to the field, and from a greenhouse trap experiment. Mycorrhiza 18: 1-14.

Sýkorová Z, Wiemken A, Redecker D. 2007b. Cooccurring Gentiana verna and Gentiana acaulis and their neighboring plants in two Swiss upper montane meadows harbor distinct arbuscular mycorrhizal fungal communities. Applied and Environmental Microbiology 73: 5426-5434.

Tawaraya K. 2003. Arbuscular mycorrhizal dependency of different plant species and cultivars. Soil Sciences and Plant Nutrition 49: 655-668.

Tedersoo L, Jairus T, Horton BM, Abarenkov K, Suvi T, Saar I, Kõljalg U. 2008. Strong host preference of ectomycorrhizal fungi in a Tasmanian wet sclerophyll forest as revealed by DNA barcoding and taxon-specific primers. New Phytologist 180: 479-490.

Thompson JP. 1990. Soil sterilization methods to show VA-mycorrhizae aid P and Zn nutrition of wheat in vertisols. Soil Biology and Biochemistry 22: 229-240.

van Tuinen D, Jacquot E, Zhao B, Gollotte A, Gianinazzi-Pearson V. 1998. Characterization of root colonization profiles by a microcosm community of arbuscular mycorrhizal fungi using $25 \mathrm{~S}$ rDNA-targeted nested PCR. Molecular Ecology 7: 879-887.

Urgiles N, Lojan P, Aguirre N, Blaschke H, Guenter S, Stimm B. Kottke I. 2009. Application of mycorrhizal roots improves growth of tropical tree seedlings in the nursery: a step towards reforestation with native species in the Andes of Ecuador. New Forests 38: 229-239

Valentini A, Pompanon F, Taberlet P. 2009. DNA barcoding for ecologists. Trends in Ecology \& Evolution 24: 110-117.

Vaughn JC, Mason MT, Sper-Whitis GL, Kuhlman P, Palmer JD. 1995. Fungal origin by horizontal transfer of a plant mitochondrial group I intron in the chimeric coxI gene of Peperomia. Journal of Molecular Evolution 41: 563-572.

Vialle A, Feau N, Allaire M, Didukh M, Martin F, Moncalvo J, Hamelin RC. 2009. Evaluation of mitochondrial genes as DNA barcode for Basidiomycota. Molecular Ecology Resources 9: 99113.

Viera A, Glenn MG. 1990. DNA content of vesicular-arbuscular mycorrhizal fungal spores. Mycologia 82: 263-267.

Wang B, Qiu Y. 2006. Phylogenetic distribution and evolution of mycorrhizas in land plants. Mycorrhiza 16: 299-363.

Wiemers M, Fiedler K. 2007. Does the DNA barcoding gap exist? - A case study in blue butterflies (Lepidoptera: Lycaenidae). Frontiers in Zoology 4: 8.

Wubet T, Kottke I, Teketay D, Oberwinkler F. 2009. Arbuscular mycorrhizal fungal community structures differ between co-occurring tree species of dry Afromontane tropical forest, and their seedlings exhibit potential to trap isolates suited for reforestation. Mycological Progress 8: 317-318. 
Wubet T, Weiß M, Kottke I, Teketay D, Oberwinkler F. 2006. Phylogenetic analysis of nuclear small subunit rDNA sequences suggests that the endangered African Pencil Cedar, Juniperus procera, is associated with distinct members of Glomeraceae. Mycological Research 110: 10591069.

Xu J, Zhang Q, Xu X, Wang Z, Qi J. 2009. Intragenomic variability and pseudogenes of ribosomal DNA in Stone flounder Kareius bicoloratus. Molecular Phylogenetics and Evolution 52: 157-166.

Zhu Y, Christie P, Scott Laidlaw A. 2001. Uptake of Zn by arbuscular mycorrhizal white clover from Zn-contaminated soil. Chemosphere 42: 193-199. 


\section{Acknowledgement}

Numerous people have generously spent time, supervision, encouragement and help during the research resulting in this thesis. Following people I would like to thank in particularly:

My supervisor Arthur Schüßler is thanked for all his support, the fruitful discussions and the possibility to work in his lab.

Manuela and Claudia Krüger are acknowledged for an enjoyable and productive working atmosphere, for help of any kind and for the delicious lunches.

Gertrud Strobel is thanked for her help with cloning and other lab affairs.

I am grateful to Chris Walker for his essential help in morphological analyses of AMF spores and all the interesting discussions not only about AMF spores.

I acknowledge David Cohen for the good and interesting working time in Darmstadt and for nice distractions in the Cafe Chaos.

Stéphane Declerck, Sylvie Cranenbrouck, Marleen IJdo and the GINCO-Bel team is thanked for introducing me into root organ cultures and for the material they provided.

I would like to thank Martin Parniske and his group for interesting discussions, their help and their open-minded environment.

I would like to thank Maria Naumann for the enjoyable collaboration in Louvain-la-Neuve, Turino and Munich, and for her critical thinking of all imaginable topics.

I am very grateful to Chris Walker, Maria Naumann, Magdalena Eder and Dadhichi Paretkar who had the patience to proofread parts of my thesis.

I would like to thank my family and friends for their motivation, help, advice and distraction.

Especially, I am very grateful to Magdalena for all her love, patience, support and inspiration.

This work was supported by funding from the Marie Curie Research Training Network in the EU Sixth Framework for the TRACEAM (TRACEability of Arbuscular Mycorrhizal fungi as plantbeneficial micro-organisms in agro-environments) project, MEST-CT-2005-021016. 


\section{Appendix}

\subsection{Supplementary data}

The following data are supplementary material of the submitted publication "DNA barcoding of arbuscular mycorrhiza fungi” (chapter 7).

Table S1: Sequences used for analysis of the Ambisporaceae ITS region and ITS2 fragment (see Figure S8).

Accession Species

FN547524 Ambispora appendicula FN547525 Ambispora appendicula FN547526 Ambispora appendicula FN547527 Ambispora appendicula FN547528 Ambispora appendicula FN547529 Ambispora appendicula FN547530 Ambispora appendicula FN547531 Ambispora appendicula FN547532 Ambispora appendicula FN547533 Ambispora appendicula FN547534 Ambispora appendicula AB048656 Ambispora callosa AB048657 Ambispora callosa AB048658 Ambispora callosa AB048659 Ambispora callosa AB048660 Ambispora callosa AB048661 Ambispora callosa AB048662 Ambispora callosa AB048663 Ambispora callosa AB048664 Ambispora callosa AB048665 Ambispora callosa AB048666 Ambispora callosa AB048667 Ambispora callosa AB048668 Ambispora callosa AB048669 Ambispora callosa AB048670 Ambispora callosa AB048671 Ambispora callosa AB048672 Ambispora callosa AB048673 Ambispora callosa AB048674 Ambispora callosa AB048675 Ambispora callosa AB048676 Ambispora callosa AB048677 Ambispora callosa AB048678 Ambispora callosa AB048679 Ambispora callosa AB048680 Ambispora callosa AB048681 Ambispora callosa
Culture/voucher

Att1235-2/W5156

Att1235-2/W5156

Att1235-2/W5156

Att1235-2/W5156

Att1235-2/W5156

Att1235-2/W5156

Att1235-2/W5156

Att1235-2/W5156

Att1235-2/W5156

Att1235-2/W5156

Att1235-2/W5156

MAFF520057/W4769

MAFF520057/W4769

MAFF520057/W4769

MAFF520057/W4769

MAFF520057/W4769

MAFF520057/W4769

MAFF520057/W4769

MAFF520057/W4769

MAFF520057/W4769

MAFF520057/W4769

MAFF520057/W4769

MAFF520057/W4769

MAFF520057/W4769

MAFF520057/W4769

MAFF520057/W4769

MAFF520058/W4771

MAFF520058/W4771

MAFF520058/W4771

MAFF520058/W4771

MAFF520058/W4771

MAFF520058/W4771

MAFF520058/W4771

MAFF520058/W4771

MAFF520058/W4771

MAFF520058/W4771

MAFF520058/W4771 
AB048682 Ambispora callosa AB259840 Ambispora callosa AB259841 Ambispora callosa AB259842 Ambispora callosa AB259843 Ambispora callosa AB259844 Ambispora callosa AB259845 Ambispora callosa AB259846 Ambispora callosa AM268197 Ambispora fennica AM268198 Ambispora fennica AM268199 Ambispora fennica AM268200 Ambispora fennica AM268201 Ambispora fennica AM268202 Ambispora fennica AM268203 Ambispora fennica FN547535 Ambispora fennica FN547536 Ambispora fennica FN547537 Ambispora fennica FN547538 Ambispora fennica FN547539 Ambispora fennica FN547540 Ambispora fennica FN547541 Ambispora fennica FN547542 Ambispora fennica FN547543 Ambispora fennica FN547544 Ambispora fennica FN547545 Ambispora fennica FN547546 Ambispora fennica AM743187 Ambispora gerdemannii AB048630 Ambispora leptoticha AB048631 Ambispora leptoticha AB048632 Ambispora leptoticha AB048633 Ambispora leptoticha AB048634 Ambispora leptoticha AB048635 Ambispora leptoticha AB048636 Ambispora leptoticha AB048637 Ambispora leptoticha AB048638 Ambispora leptoticha AB048639 Ambispora leptoticha AB048640 Ambispora leptoticha AB048641 Ambispora leptoticha AB048642 Ambispora leptoticha AB048643 Ambispora leptoticha AB048644 Ambispora leptoticha AB048645 Ambispora leptoticha AB048646 Ambispora leptoticha AB048647 Ambispora leptoticha AB048648 Ambispora leptoticha AB048649 Ambispora leptoticha AB048650 Ambispora leptoticha AB048651 Ambispora leptoticha
MAFF520058/W4771

OK-m1/W4768

OK-m1/W4768

OK-m1/W4768

OK-m1/W4768

MAFF520073/W4752

MAFF520073/W4752

MAFF520073/W4752

Att200-11/W3569

Att200-23/W4752

Att200-11/W3569

Att200-11/W3569

Att200-11/W3569

Att200-11/W3569

Att200-23/W4752

Att200-23/W4752

Att200-23/W4752

Att200-23/W4752

Att200-23/W4752

Att200-23/W4752

Att200-23/W4752

Att200-23/W4752

Att200-23/W4752

Att200-23/W4752

Att200-23/W4752

Att200-23/W4752

Att200-23/W4752

INVAM AU215

MAFF520055/W4770

MAFF520055/W4770

MAFF520055/W4770

MAFF520055/W4770

MAFF520055/W4770

MAFF520055/W4770

MAFF520055/W4770

MAFF520055/W4770

MAFF520055/W4770

MAFF520055/W4770

MAFF520055/W4770

MAFF520055/W4770

MAFF520055/W4770

MAFF520055/W4770

MAFF520055/W4770

MAFF520055/W4770

MAFF520055/W4770

MAFF520055/W4770

MAFF520055/W4770

MAFF520055/W4770

MAFF520055/W4770

MAFF520055/W4770 
AB048652 Ambispora leptoticha AB048653 Ambispora leptoticha AB048654 Ambispora leptoticha AB048655 Ambispora leptoticha AJ567807 Am. sp. from Plantago lanceolata environmental roots

AY236277 Am. sp. from Prunus africana AY174701 Am. sp. from Taxus baccata AY174702 Am. sp. from Taxus baccata AY174703 Am. sp. from Taxus baccata AY174707 Am. sp. from Taxus baccata AY174708 Am. sp. from Taxus baccata AY174710 Am. sp. from Taxus baccata
MAFF520055/W4770

MAFF520055/W4770

MAFF520055/W4770

MAFF520055/W4770

environmental environmental environmental environmental environmental environmental environmental 
Table S2: Sequences used for analyses of the Diversisporaceae ITS region and ITS2 fragment (see Figure S9).

Accession Species

AM713402 Diversispora celata

AM713403 Diversispora celata

AM713404 Diversispora celata

FN547637 Diversispora spurca

FN547638 Diversispora spurca

FN547639 Diversispora spurca

FN547640 Diversispora spurca

FN547641 Diversispora spurca

FN547642 Diversispora spurca

FN547643 Diversispora spurca

FN547644 Diversispora spurca

FN547645 Diversispora spurca

FN547646 Diversispora spurca

FN547647 Diversispora spurca

FN547648 Diversispora spurca

FN547649 Diversispora spurca

FN547650 Diversispora spurca

FN547651 Diversispora spurca

FN547652 Diversispora spurca

FN547653 Diversispora spurca

FN547654 Diversispora spurca

AM418549 Glomus pulvinatum

AM418550 Glomus pulvinatum

AJ849468 Glomus aurantium

FN547655 Glomus aurantium

FN547656 Glomus aurantium

FN547657 Glomus aurantium

FN547658 Glomus aurantium

FN547659 Glomus aurantium

FN547660 Glomus aurantium

FN547661 Glomus aurantium

FN547662 Glomus aurantium

FN547663 Glomus aurantium

FN547664 Glomus aurantium

FN547665 Glomus aurantium

AM713405 Glomus eburneum

AM713406 Glomus eburneum

AM713407 Glomus eburneum

AM713408 Glomus eburneum

AM713409 Glomus eburneum

AM713410 Glomus eburneum

AM713411 Glomus eburneum

AM713412 Glomus eburneum

AM713413 Glomus eburneum

AM713414 Glomus eburneum

AM713415 Glomus eburneum
Culture/voucher

FACE234; BEG231

FACE234; BEG231

FACE234; BEG231

Att246-18/W4119

Att246-18/W4119

Att246-18/W4119

Att246-18/W4119

Att246-18/W4119

Att246-18/W4119

Att246-18/W4119

Att246-18/W4119

Att246-18/W4119

Att246-18/W4119

Att246-18/W4119

Att246-18/W4119

Att246-18/W4119

Att246-18/W4119

Att246-18/W4119

Att246-18/W4119

Att246-18/W4119

Att246-18/W4119

environmental

environmental

Holotype. Błaszkowski J., 2444 (DPP)

Att1296-0/W4728

Att1296-0/W4728

Att1296-0/W4728

Att1296-0/W4728

Att1296-0/W4728

Att1296-0/W4728

Att1296-0/W4728

Att1296-0/W4728

Att1296-0/W4728

Att1296-0/W4728

Att1296-0/W4728

AZ420A/W4729

AZ420A/W4729

AZ420A/W4729

AZ420A/W4729

AZ420A/W4729

AZ420A/W4729

AZ420A/W4729

AZ420A/W4729

AZ420A/W4729

AZ420A/W4729

AZ420A/W4729 
AM713416 Glomus eburneum

AM418544 Glomus fulvum

AM418545 Glomus fulvum

AM418546 Glomus fulvum

AM418547 Glomus fulvum

AM418548 Glomus fulvum

AM418551 Glomus megalocarpum

AM418552 Glomus megalocarpum

AF185677 Glomus sp.

AF185679 Glomus sp.

AF185680 Glomus sp.

AF185681 Glomus sp.

AF185682 Glomus sp.

AF185690 Glomus sp.

AF185693 Glomus sp.

AF185694 Glomus sp.

AJ504642 Glomus sp. 'versiforme'

AJ504643 Glomus sp. 'versiforme'

AJ504644 Glomus sp. 'versiforme'

AJ516922 Glomus sp. 'versiforme'

AJ516923 Glomus sp. 'versiforme'

AJ516924 Glomus sp. 'versiforme'

AJ516925 Glomus sp. 'versiforme'

AJ516926 Glomus sp. 'versiforme'

AJ516927 Glomus sp. 'versiforme'

AJ516928 Glomus sp. 'versiforme'

AJ516929 Glomus sp. 'versiforme'

AJ516930 Glomus sp. 'versiforme'

AJ516931 Glomus sp. 'versiforme'

AJ516932 Glomus sp. 'versiforme'

AJ516933 Glomus sp. 'versiforme'

AJ516934 Glomus sp. 'versiforme'

AJ516935 Glomus sp. 'versiforme'

AJ517781 Glomus sp. 'versiforme'

AM076636 Glomus sp. 'versiforme'

AM076637 Glomus sp. 'versiforme'

AM076638 Glomus sp. 'versiforme'

DQ400187 Glomus sp. 'versiforme'

DQ400194 Glomus sp. 'versiforme'

DQ400197 Glomus sp. 'versiforme'

DQ400198 Glomus sp. 'versiforme'

DQ400212 Glomus sp. 'versiforme'

DQ400223 Glomus sp. 'versiforme'

DQ400225 Glomus sp. 'versiforme'

DQ400227 Glomus sp. 'versiforme'

DQ400229 Glomus sp. 'versiforme'

AF246141 Glomus versiforme

AF246142 Glomus versiforme

AF246143 Glomus versiforme

AY842567 Glomus versiforme
AZ420A/W4729

environmental

environmental

environmental

environmental

environmental

environmental

environmental

INVAM AZ237B

INVAM AZ237B

INVAM AZ237B

INVAM AZ237B

INVAM NB101

INVAM NB101

INVAM NB101

INVAM NB101

environmental

environmental

environmental

environmental

environmental

environmental

environmental

environmental

environmental

environmental

environmental

environmental

environmental

environmental

environmental

environmental

environmental

environmental

environmental

environmental

environmental

environmental

environmental

environmental

environmental

environmental

environmental

environmental

environmental

environmental

BEG47

BEG47

BEG47

BEG47 
AY842568 Glomus versiforme

AY842569 Glomus versiforme

FM876814 Glomus versiforme

FM876815 Glomus versiforme

FM876816 Glomus versiforme

FM876817 Glomus versiforme

FM876818 Glomus versiforme

FM876819 Glomus versiforme

FM876820 Glomus versiforme

FN547635 Glomus versiforme

FN547636 Glomus versiforme

FN547666 Glomus versiforme

FN547667 Glomus versiforme

FN547668 Glomus versiforme

FN547669 Glomus versiforme

FN547670 Glomus versiforme

FN547671 Glomus versiforme

FN547672 Glomus versiforme

FN547673 Glomus versiforme

FN547674 Glomus versiforme

FN547675 Glomus versiforme

FN547676 Glomus versiforme

FN547677 Glomus versiforme

FN547678 Glomus versiforme

FN547679 Glomus versiforme

FN547680 Glomus versiforme

FN547681 Glomus versiforme
BEG47

BEG47

BEG47/W5165

BEG47/W5165

BEG47/W5165

BEG47/W5165

BEG47/W5165

BEG47/W5165

BEG47/W5165

BEG47/W5165

BEG47/W5165

BEG47/W3180

BEG47/W3180

BEG47/W3180

BEG47/W3180

BEG47/W3180

BEG47/W3180

BEG47/W3180

BEG47/W3180

BEG47/W3180

BEG47/W3180

BEG47/W3180

BEG47/W3180

BEG47/W3180

BEG47/W3180

BEG47/W3180

BEG47/W3180 
Table S3: Sequences used for analyses of the Diversisporaceae LSU region, LSU-D1 and LSU-D2 fragment (see Figure S10).

\begin{tabular}{|c|c|c|}
\hline Accession & Species & Culture/voucher \\
\hline AM713402 & Diversispora celata & BEG231 (FACE234) \\
\hline AM713403 & Diversispora celata & BEG231 (FACE234) \\
\hline AM713404 & Diversispora celata & BEG231 (FACE234) \\
\hline AM713405 & Glomus eburneum & AZ420A/W4729 \\
\hline AM713406 & Glomus eburneum & AZ420A/W4729 \\
\hline AM713407 & Glomus eburneum & AZ420A/W4729 \\
\hline AM713408 & Glomus eburneum & AZ420A/W4729 \\
\hline AM713409 & Glomus eburneum & AZ420A/W4729 \\
\hline AM713410 & Glomus eburneum & AZ420A/W4729 \\
\hline AM713411 & Glomus eburneum & AZ420A/W4729 \\
\hline AM713412 & Glomus eburneum & AZ420A/W4729 \\
\hline AM713413 & Glomus eburneum & AZ420A/W4729 \\
\hline AM713414 & Glomus eburneum & AZ420A/W4729 \\
\hline AM713415 & Glomus eburneum & AZ420A/W4729 \\
\hline AM713416 & Glomus eburneum & AZ420A/W4729 \\
\hline FN547635 & Glomus versiforme & BEG47/W5165 \\
\hline FN547636 & Glomus versiforme & BEG47/W5165 \\
\hline FM876814 & Glomus versiforme & BEG47/W5165 \\
\hline FM876815 & Glomus versiforme & BEG47/W5165 \\
\hline FM876816 & Glomus versiforme & BEG47/W5165 \\
\hline FM876817 & Glomus versiforme & BEG47/W5165 \\
\hline FM876818 & Glomus versiforme & BEG47/W5165 \\
\hline FM876819 & Glomus versiforme & BEG47/W5165 \\
\hline FM876820 & Glomus versiforme & BEG47/W5165 \\
\hline FN547637 & Diversispora spurca & Att246-18/W4119 \\
\hline FN547638 & Diversispora spurca & Att246-18/W4119 \\
\hline FN547639 & Diversispora spurca & Att246-18/W4119 \\
\hline FN547640 & Diversispora spurca & Att246-18/W4119 \\
\hline FN547641 & Diversispora spurca & Att246-18/W4119 \\
\hline FN547642 & Diversispora spurca & Att246-18/W4119 \\
\hline FN547643 & Diversispora spurca & Att246-18/W4119 \\
\hline FN547644 & Diversispora spurca & Att246-18/W4119 \\
\hline FN547645 & Diversispora spurca & Att246-18/W4119 \\
\hline FN547646 & Diversispora spurca & Att246-18/W4119 \\
\hline FN547647 & Diversispora spurca & Att246-18/W4119 \\
\hline FN547648 & Diversispora spurca & Att246-18/W4119 \\
\hline FN547649 & Diversispora spurca & Att246-18/W4119 \\
\hline FN547650 & Diversispora spurca & Att246-18/W4119 \\
\hline FN547651 & Diversispora spurca & Att246-18/W4119 \\
\hline FN547652 & Diversispora spurca & Att246-18/W4119 \\
\hline FN547653 & Diversispora spurca & Att246-18/W4119 \\
\hline FN547654 & Diversispora spurca & Att246-18/W4119 \\
\hline FN547655 & Glomus aurantium & Att1296-0/W4728 \\
\hline FN547656 & Glomus aurantium & Att1296-0/W4728 \\
\hline FN547657 & Glomus aurantium & Att1296-0/W4728 \\
\hline FN547658 & Glomus aurantium & Att1296-0/W4728 \\
\hline
\end{tabular}


FN547659 Glomus aurantium

FN547660 Glomus aurantium

FN547661 Glomus aurantium

FN547662 Glomus aurantium

FN547663 Glomus aurantium

FN547664 Glomus aurantium

FN547665 Glomus aurantium

FN547666 Glomus versiforme

FN547667 Glomus versiforme

FN547668 Glomus versiforme

FN547669 Glomus versiforme

FN547670 Glomus versiforme

FN547671 Glomus versiforme

FN547672 Glomus versiforme

FN547673 Glomus versiforme

FN547674 Glomus versiforme

FN547675 Glomus versiforme

FN547676 Glomus versiforme

FN547677 Glomus versiforme

FN547678 Glomus versiforme

FN547679 Glomus versiforme

FN547680 Glomus versiforme

FN547681 Glomus versiforme

AY842574 Glomus versiforme

AY842573 Glomus versiforme

EF067888 Glomus eburneum

EF067887 Glomus eburneum

EF067886 Glomus eburneum

AM947665 Glomus versiforme

AM947664 Glomus versiforme

EU346868 Glomus versiforme

AY639306 Diversispora celata

AY639235 Diversispora celata

AY639234 Diversispora celata

AY639233 Diversispora celata

AY639241 Diversispora celata

AY639240 Diversispora celata

AY639239 Diversispora celata

AY639238 Diversispora celata

AY639237 Diversispora celata

AY639236 Diversispora celata

DQ350448 Diversispora celata

DQ350449 Diversispora celata

DQ350450 Diversispora celata

DQ350451 Diversispora celata

DQ350452 Diversispora celata

DQ350453 Diversispora celata

AY639232 Diversispora celata

AY639231 Diversispora celata

AY639230 Diversispora celata
Att1296-0/W4728

Att1296-0/W4728

Att1296-0/W4728

Att1296-0/W4728

Att1296-0/W4728

Att1296-0/W4728

Att1296-0/W4728

BEG47/W3180

BEG47/W3180

BEG47/W3180

BEG47/W3180

BEG47/W3180

BEG47/W3180

BEG47/W3180

BEG47/W3180

BEG47/W3180

BEG47/W3180

BEG47/W3180

BEG47/W3180

BEG47/W3180

BEG47/W3180

BEG47/W3180

BEG47/W3180

BEG47/W3180

BEG47/W3180

INVAM AZ420A

INVAM AZ420A

INVAM AZ420A

BEG47

BEG47

HDAM-4

BEG231 (FACE234)

BEG231 (FACE234)

BEG231 (FACE234)

BEG231 (FACE234)

BEG232 (FACE272)

BEG232 (FACE272)

BEG232 (FACE272)

BEG232 (FACE272)

BEG232 (FACE272)

BEG232 (FACE272)

BEG233 (FACE410)

BEG233 (FACE410)

BEG233 (FACE410)

BEG233 (FACE410)

BEG233 (FACE410)

BEG233 (FACE410)

BEG230 (FACE83)

BEG230 (FACE83)

BEG230 (FACE83) 


$\begin{array}{lll}\text { AY639229 } & \text { Diversispora celata } & \text { BEG230 (FACE83) } \\ \text { AY639228 } & \text { Diversispora celata } & \text { BEG230 (FACE83) } \\ \text { AY639227 } & \text { Diversispora celata } & \text { BEG230 (FACE83) } \\ \text { AY639226 } & \text { Diversispora celata } & \text { BEG230 (FACE83) } \\ \text { EF581864 } & \text { Glomus aurantium } & \text { Att1296-0/W4728 } \\ \text { EF581863 } & \text { Glomus aurantium } & \text { Att1296-0/W4728 } \\ \text { EF581862 } & \text { Glomus aurantium } & \text { Att1296-0/W4728 } \\ \text { EF581861 } & \text { Glomus aurantium } & \text { Att1296-0/W4728 } \\ \text { EF581860 } & \text { Glomus aurantium } & \text { Att1296-0/W4728 }\end{array}$


Table S4: Sequences used for analysis of the Glomus Group Aa ITS region and ITS2 fragment (see Figure 6).

\begin{tabular}{|c|c|c|}
\hline Accession & Species & Culture/voucher \\
\hline X96842 & Glomus cf. fasciculatum & BEG58 \\
\hline X96843 & Glomus cf. fasciculatum & BEG58 \\
\hline AY035642 & Glomus caledonium & JJ36 \\
\hline AY035646 & Glomus caledonium & $\mathrm{JJ} 40$ \\
\hline AY035647 & Glomus caledonium & JJ41 \\
\hline AY035651 & Glomus caledonium & BEG161 \\
\hline FN547494 & Glomus caledonium & BEG20/W3294 \\
\hline FN547495 & Glomus caledonium & BEG20/W3294 \\
\hline FN547496 & Glomus caledonium & BEG20/W3294 \\
\hline FN547497 & Glomus caledonium & BEG20/W3294 \\
\hline FN547498 & Glomus caledonium & BEG20/W3294 \\
\hline FN547499 & Glomus caledonium & BEG20/W3294 \\
\hline AJ890365 & Glomus coronatum & IMA3 \\
\hline AJ890366 & Glomus coronatum & IMA3 \\
\hline FM213083 & Glomus coronatum & environmental \\
\hline FM213084 & Glomus coronatum & environmental \\
\hline FM213085 & Glomus coronatum & environmental \\
\hline FM213086 & Glomus coronatum & environmental \\
\hline FM213087 & Glomus coronatum & environmental \\
\hline FM213088 & Glomus coronatum & environmental \\
\hline FM876794 & Glomus coronatum & BEG28 (Att108-7) \\
\hline FM876795 & Glomus coronatum & BEG28 (Att108-7) \\
\hline FM876796 & Glomus coronatum & BEG28 (Att108-7) \\
\hline FM876797 & Glomus coronatum & BEG28 (Att108-7) \\
\hline FM876798 & Glomus coronatum & BEG28 (Att108-7) \\
\hline X96844 & Glomus coronatum & BEG28 \\
\hline X96845 & Glomus coronatum & BEG28 \\
\hline X96846 & Glomus coronatum & BEG28 \\
\hline X96838 & Glomus dimorphicum & BEG59 \\
\hline X96839 & Glomus dimorphicum & BEG59 \\
\hline X96840 & Glomus dimorphicum & BEG59 \\
\hline X96841 & Glomus dimorphicum & BEG59 \\
\hline AF231469 & Glomus geosporum & unknown \\
\hline AJ319778 & Glomus geosporum & unknown \\
\hline AJ319779 & Glomus geosporum & unknown \\
\hline AJ319780 & Glomus geosporum & unknown \\
\hline AJ319781 & Glomus geosporum & unknown \\
\hline AJ319782 & Glomus geosporum & unknown \\
\hline AJ319783 & Glomus geosporum & unknown \\
\hline AJ319784 & Glomus geosporum & unknown \\
\hline AJ319785 & Glomus geosporum & unknown \\
\hline AJ319786 & Glomus geosporum & unknown \\
\hline AJ319787 & Glomus geosporum & unknown \\
\hline AJ319788 & Glomus geosporum & unknown \\
\hline AJ319789 & Glomus geosporum & unknown \\
\hline AJ319790 & Glomus geosporum & unknown \\
\hline
\end{tabular}




\begin{tabular}{|c|c|c|}
\hline AJ319791 & Glomus geosporum & unknown \\
\hline AJ319792 & Glomus geosporum & unknown \\
\hline AJ319793 & Glomus geosporum & unknown \\
\hline AJ319794 & Glomus geosporum & unknown \\
\hline AJ319795 & Glomus geosporum & unknown \\
\hline AJ319796 & Glomus geosporum & unknown \\
\hline AJ319797 & Glomus geosporum & unknown \\
\hline AJ319798 & Glomus geosporum & unknown \\
\hline AJ319799 & Glomus geosporum & unknown \\
\hline AJ319800 & Glomus geosporum & unknown \\
\hline AJ319801 & Glomus geosporum & unknown \\
\hline AJ319802 & Glomus geosporum & unknown \\
\hline AJ319803 & Glomus geosporum & unknown \\
\hline FJ009619 & Glomus geosporum & unknown \\
\hline FJ009620 & Glomus geosporum & unknown \\
\hline FJ009621 & Glomus geosporum & unknown \\
\hline FJ009622 & Glomus geosporum & unknown \\
\hline AF004689 & Glomus monosporum & INVAM IT102 \\
\hline AF004690 & Glomus monosporum & INVAM FR115 \\
\hline AF125195 & Glomus monosporum & INVAM FR115 \\
\hline AF161043 & Glomus mosseae & environmental (GMO1a) \\
\hline AF161044 & Glomus mosseae & environmental (GMO1b) \\
\hline AF161045 & Glomus mosseae & environmental (GM01c) \\
\hline AF161046 & Glomus mosseae & environmental (GMO1d) \\
\hline AF161047 & Glomus mosseae & environmental (GMO1e) \\
\hline AF161048 & Glomus mosseae & environmental (GMO1f) \\
\hline AF161049 & Glomus mosseae & environmental (GMO1g) \\
\hline AF161050 & Glomus mosseae & environmental (GMO1h) \\
\hline AF161051 & Glomus mosseae & environmental (GMO1i) \\
\hline AF161052 & Glomus mosseae & environmental (GMO1j) \\
\hline AF161053 & Glomus mosseae & environmental (GMO11) \\
\hline AF161054 & Glomus mosseae & environmental (GMO1) \\
\hline AF161055 & Glomus mosseae & environmental (GMO2a) \\
\hline AF161056 & Glomus mosseae & environmental (GMO2b) \\
\hline AF161057 & Glomus mosseae & environmental (GMO2c) \\
\hline AF161058 & Glomus mosseae & environmental (GMO2e) \\
\hline AF161059 & Glomus mosseae & environmental (GMO3a) \\
\hline AF161060 & Glomus mosseae & environmental (GMO3b) \\
\hline AF161061 & Glomus mosseae & environmental (GMO3c) \\
\hline AF161062 & Glomus mosseae & environmental (GM03d) \\
\hline AF161063 & Glomus mosseae & environmental (GM03e) \\
\hline AF161064 & Glomus mosseae & environmental (GM03f) \\
\hline AF166276 & Glomus mosseae & environmental (GMO2d) \\
\hline AJ849469 & Glomus mosseae & unknown \\
\hline AJ919273 & Glomus mosseae & INVAM AZ225C \\
\hline AJ919274 & Glomus mosseae & INVAM AZ225C \\
\hline AJ919275 & Glomus mosseae & INVAM NB114 \\
\hline AJ919276 & Glomus mosseae & INVAM IN101C \\
\hline AJ919277 & Glomus mosseae & INVAM FL156 \\
\hline AJ919278 & Glomus mosseae & INVAM FL156 \\
\hline
\end{tabular}




\begin{tabular}{|c|c|c|}
\hline AM076635 & Glomus mosseae & environmental \\
\hline AM157131 & Glomus mosseae & ISCB13 \\
\hline AM157132 & Glomus mosseae & ISCB17 \\
\hline AM157133 & Glomus mosseae & ISCB22 \\
\hline AM157134 & Glomus mosseae & ISCB19 \\
\hline AM157135 & Glomus mosseae & ISCB20 \\
\hline AM423114 & Glomus mosseae & IMA1 \\
\hline AM423115 & Glomus mosseae & IMA1 \\
\hline AM423116 & Glomus mosseae & BEG25 \\
\hline AM423117 & Glomus mosseae & BEG25 \\
\hline AM423118 & Glomus mosseae & BEG25 \\
\hline AM423119 & Glomus mosseae & BEG25 \\
\hline AY035650 & Glomus mosseae & BEG160 \\
\hline AY035652 & Glomus mosseae & BEG161 \\
\hline AY236331 & Glomus mosseae & SP301 \\
\hline AY236332 & Glomus mosseae & SP302 \\
\hline AY236333 & Glomus mosseae & SP303 \\
\hline AY236334 & Glomus mosseae & SP304 \\
\hline AY236335 & Glomus mosseae & SP305 \\
\hline AY236336 & Glomus mosseae & SP306 \\
\hline AY997053 & Glomus mosseae & INVAM UT101 (AFTOL-ID 139) \\
\hline DQ400127 & Glomus mosseae & environmental \\
\hline DQ400128 & Glomus mosseae & environmental \\
\hline DQ400129 & Glomus mosseae & environmental \\
\hline DQ400130 & Glomus mosseae & environmental \\
\hline DQ400131 & Glomus mosseae & environmental \\
\hline DQ400132 & Glomus mosseae & environmental \\
\hline DQ400134 & Glomus mosseae & environmental \\
\hline DQ400136 & Glomus mosseae & environmental \\
\hline DQ400137 & Glomus mosseae & environmental \\
\hline DQ400138 & Glomus mosseae & environmental \\
\hline DQ400139 & Glomus mosseae & environmental \\
\hline DQ400141 & Glomus mosseae & environmental \\
\hline DQ400142 & Glomus mosseae & environmental \\
\hline DQ400144 & Glomus mosseae & environmental \\
\hline DQ400146 & Glomus mosseae & environmental \\
\hline DQ400149 & Glomus mosseae & environmental \\
\hline DQ400151 & Glomus mosseae & environmental \\
\hline DQ400158 & Glomus mosseae & environmental \\
\hline DQ400160 & Glomus mosseae & environmental \\
\hline EF989113 & Glomus mosseae & environmental \\
\hline EF989114 & Glomus mosseae & environmental \\
\hline EF989115 & Glomus mosseae & environmental \\
\hline EF989116 & Glomus mosseae & environmental \\
\hline EF989117 & Glomus mosseae & environmental \\
\hline FN547474 & Glomus mosseae & BEG12 \\
\hline FN547475 & Glomus mosseae & BEG12 \\
\hline FN547476 & Glomus mosseae & BEG12 \\
\hline FN547482 & Glomus mosseae & BEG12 \\
\hline FN547483 & Glomus mosseae & BEG12 \\
\hline
\end{tabular}




$\begin{array}{lll}\text { FN547484 } & \text { Glomus mosseae } & \text { BEG12 } \\ \text { FN547485 } & \text { Glomus mosseae } & \text { BEG12 } \\ \text { FN547486 } & \text { Glomus mosseae } & \text { BEG12 } \\ \text { FN547487 } & \text { Glomus mosseae } & \text { BEG12 } \\ \text { FN547488 } & \text { Glomus mosseae } & \text { BEG12 } \\ \text { FN547489 } & \text { Glomus mosseae } & \text { BEG12 } \\ \text { FN547490 } & \text { Glomus mosseae } & \text { BEG12 } \\ \text { FN547491 } & \text { Glomus mosseae } & \text { BEG12 } \\ \text { FN547492 } & \text { Glomus mosseae } & \text { BEG12 } \\ \text { FN547493 } & \text { Glomus mosseae } & \text { BEG12 } \\ \text { U31996 } & \text { Glomus mosseae } & \text { BEG 12 } \\ \text { U49264 } & \text { Glomus mosseae } & \text { UKJII8 } \\ \text { U49265 } & \text { Glomus mosseae } & \text { INVAM FL156 } \\ \text { X84232 } & \text { Glomus mosseae } & \text { BEG12 } \\ \text { X84233 } & \text { Glomus mosseae } & \text { BEG12 } \\ \text { X96826 } & \text { Glomus mosseae } & \text { BEG25 } \\ \text { X96827 } & \text { Glomus mosseae } & \text { BEG25 } \\ \text { X96828 } & \text { Glomus mosseae } & \text { BEG25 } \\ \text { X96829 } & \text { Glomus mosseae } & \text { BEG55 } \\ \text { X96830 } & \text { Glomus mosseae } & \text { BEG54 } \\ \text { X96831 } & \text { Glomus mosseae } & \text { BEG54 } \\ \text { X96832 } & \text { Glomus mosseae } & \text { BEG54 } \\ \text { X96833 } & \text { Glomus mosseae } & \text { BEG57 } \\ \text { X96834 } & \text { Glomus mosseae } & \text { BEG57 } \\ \text { X96835 } & \text { Glomus mosseae } & \text { BEG57 } \\ \text { X96836 } & \text { Glomus mosseae } & \text { BEG61 } \\ \text { X96837 } & \text { Glomus mosseae } & \text { BEG61 } \\ \text { FM876813 } & \text { Glomus } \text { sp. WUM3 } & \text { WUM3/W2940 } \\ \text { FN547477 } & \text { Glomus } \text { sp. WU3 } & \text { WUM3/W2939 } \\ \text { FN547478 } & \text { Glomus } \text { sp. WUM3 } & \text { WUM3/W2939 } \\ \text { FN547479 } & \text { Glomus sp. WUM3 } & \text { WUM3/W2939 } \\ \text { FN547480 } & \text { Glomus sp. WUM3 } & \text { WUM3/W2939 } \\ \text { FN547481 } & \text { Glomus sp. WUM3 } & \text { WUM3/W2939 }\end{array}$


Table S5: Sequences used for analysis of the Glomus Group Aa LSU-D2 fragment (see Figure 6).

\begin{tabular}{|c|c|c|}
\hline Accession & Species & Culture/voucher \\
\hline FN547474 & Glomus mosseae & BEG12/W5147 \\
\hline FN547475 & Glomus mosseae & BEG12/W5147 \\
\hline FN547476 & Glomus mosseae & BEG12/W5147 \\
\hline FN547477 & Glomus sp. & WUM3/W2939 \\
\hline FN547478 & Glomus sp. & WUM3/W2939 \\
\hline FN547479 & Glomus sp. & WUM3/W2939 \\
\hline FN547480 & Glomus sp. & WUM3/W2939 \\
\hline FN547481 & Glomus sp. & WUM3/W2939 \\
\hline N547482 & Glomus mosseae & BEG12/W5147 \\
\hline FN547483 & Glomus mosseae & BEG12/W5147 \\
\hline FN547484 & Glomus mosseae & BEG12/W5147 \\
\hline FN547485 & Glomus mosseae & BEG12/W5147 \\
\hline FN547486 & Glomus mosseae & BEG12/ \\
\hline FN547487 & Glomus mosseae & BEG12/W5147 \\
\hline FN547488 & Glomus mosseae & BEG12/W5147 \\
\hline FN547489 & Glomus mosseae & BEG12/W5147 \\
\hline FN547490 & Glomus mosseae & BEG12/W5147 \\
\hline FN547491 & Glomus mosseae & BEG12 \\
\hline FM876813 & Glomus sp. & WUM3/W2940 \\
\hline FN547492 & Glomus mosseae & BEG12/W5147 \\
\hline FN547493 & Glomus mosseae & BEG12/W5147 \\
\hline FM876798 & Glomus coronatum & BEG \\
\hline FM876796 & Glomus coronatum & BEG28 (Att108-7) \\
\hline FM876797 & Glomus coronatum & BEG28 (Att108-7) \\
\hline FM876794 & Glomus coronatum & BEG28 (Att108-7) \\
\hline FM876795 & Glomus coronatum & BEG28 (Att108- \\
\hline FN547494 & Glomus caledonium & BEG20/W3294 \\
\hline FN547495 & Glomus caledonium & BEG20/W3294 \\
\hline FN547496 & Glomus caledonium & BEG20/W3294 \\
\hline FN547497 & Glomus caledonium & BEG20/W3294 \\
\hline FN547498 & Glomus caledonium & BEG20/W3294 \\
\hline FN547499 & Glomus caledonium & BEG20/W3294 \\
\hline AF145741 & Glomus constrictum & BEG130 \\
\hline AF145747 & Glomus fragilistratum & BEG05 \\
\hline AF145735 & Glomus mosseae & BEG25 \\
\hline AF145745 & Glomus caledonium & BEG20 \\
\hline AF145740 & Glomus coronatum & BEG49 \\
\hline AF145742 & Glomus geosporum & BEG90 \\
\hline AF396789 & Glomus caledonium & RMC658 \\
\hline AF396794 & Glomus caledonium & RWC658 \\
\hline
\end{tabular}




\begin{tabular}{|c|c|c|}
\hline AF145736 & Glomus mosseae & BEG85 \\
\hline AF396799 & Glomus caledonium & SC_658 \\
\hline AJ510239 & Glomus caledonium & BEG86 \\
\hline AF396788 & Glomus mosseae & 243 \\
\hline AF396793 & Glomus mosseae & 243 \\
\hline AF396798 & Glomus mosseae & 243 \\
\hline AY639156 & Glomus mosseae & 8 \\
\hline AY639157 & Glomus mosseae & 8 \\
\hline AY639158 & Glomus mosseae & 8 \\
\hline AY639160 & Glomus mosseae & environmental \\
\hline AY639162 & Glomus mosseae & environmental \\
\hline AY639163 & Glomus mosseae & environmental \\
\hline AY639164 & Glomus mosseae & 101 \\
\hline AY639270 & Glomus mosseae & environmental \\
\hline AY639159 & Glomus mosseae & environmental \\
\hline AY639274 & Glomus mosseae & environmental \\
\hline AY639281 & Glomus mosseae & 209 \\
\hline AY639271 & Glomus mosseae & environmental \\
\hline AY639278 & Glomus mosseae & 102 \\
\hline AY639280 & Glomus mosseae & BEG224 (FACE 130) \\
\hline AY639161 & Glomus mosseae & environmental \\
\hline AY639165 & Glomus mosseae & BEG224 (FACE 130) \\
\hline AY639166 & Glomus mosseae & BEG224 (FACE 130) \\
\hline AY639167 & Glomus mosseae & BEG224 (FACE 130) \\
\hline AY639168 & Glomus mosseae & BEG224 (FACE 130) \\
\hline AY639169 & Glomus mosseae & BEG224 (FACE 130) \\
\hline AY639170 & Glomus mosseae & BEG224 (FACE 130) \\
\hline AY639171 & Glomus mosseae & 209 \\
\hline AY639172 & Glomus mosseae & 209 \\
\hline AY639173 & Glomus mosseae & 209 \\
\hline AY639174 & Glomus mosseae & 209 \\
\hline AY639266 & Glomus mosseae & 8 \\
\hline AY639267 & Glomus mosseae & 8 \\
\hline AY639268 & Glomus mosseae & 8 \\
\hline AY639269 & Glomus mosseae & 8 \\
\hline AY639272 & Glomus mosseae & environmental \\
\hline AY639273 & Glomus mosseae & environmental \\
\hline AY639276 & Glomus mosseae & environmental \\
\hline AY639277 & Glomus mosseae & 101 \\
\hline DQ469128 & Glomus mosseae & 505 \\
\hline AJ628059 & Glomus caledonium & BEG86 \\
\hline AJ510241 & Glomus geosporum & BEG11 \\
\hline DQ273793 & Glomus mosseae & INVAM UT101 (AFTOL-ID 139) \\
\hline AY639279 & Glomus mosseae & BEG224 (FACE 130) \\
\hline
\end{tabular}




\begin{tabular}{|c|c|c|}
\hline FJ790678 & Glomus mosseae & DDAM \\
\hline EU931286 & Glomus geosporum & BEG199 \\
\hline EU931285 & Glomus geosporum & BEG199 \\
\hline EU931284 & Glomus geosporum & BEG199 \\
\hline EU931283 & Glomus geosporum & BEG199 \\
\hline EU931282 & Glomus geosporum & BEG199 \\
\hline EU931281 & Glomus geosporum & BEG199 \\
\hline EU931280 & Glomus geosporum & BEG199 \\
\hline EU931279 & Glomus geosporum & BEG199 \\
\hline EU931278 & Glomus geosporum & BEG199 \\
\hline EU931277 & Glomus geosporum & BEG199 \\
\hline EU931276 & Glomus geosporum & BEG199 \\
\hline EU931275 & Glomus geosporum & BEG199 \\
\hline EU931274 & Glomus geosporum & BEG199 \\
\hline EU931273 & Glomus geosporum & BEG211 \\
\hline EU931272 & Glomus geosporum & BEG211 \\
\hline EU931271 & Glomus geosporum & BEG211 \\
\hline EU931270 & Glomus geosporum & BEG211 \\
\hline EU931269 & Glomus geosporum & BEG211 \\
\hline EU931267 & Glomus geosporum & BEG211 \\
\hline EU931266 & Glomus geosporum & BEG211 \\
\hline EU931265 & Glomus geosporum & BEG211 \\
\hline EU931264 & Glomus geosporum & BEG211 \\
\hline EU931263 & Glomus geosporum & BEG211 \\
\hline EU931262 & Glomus geosporum & BEG211 \\
\hline EU931261 & Glomus geosporum & BEG211 \\
\hline EU346866 & Glomus mosseae & HDAM-2 \\
\hline EU234489 & Glomus mosseae & BEG116 \\
\hline AM158954 & Glomus mosseae & BEG167 \\
\hline AM158953 & Glomus mosseae & BEG167 \\
\hline DQ469131 & Glomus mosseae & 505 \\
\hline DQ469130 & Glomus mosseae & 505 \\
\hline DQ469129 & Glomus mosseae & 505 \\
\hline DQ469127 & Glomus mosseae & 505 \\
\hline DQ469126 & Glomus mosseae & 505 \\
\hline DQ469125 & Glomus mosseae & 505 \\
\hline AJ459412 & Glomus mosseae & environmental \\
\hline AJ628057 & Glomus mosseae & BEG29 \\
\hline AJ628056 & Glomus mosseae & BOL3 \\
\hline AJ628055 & Glomus mosseae & BOL1 \\
\hline AJ628054 & Glomus mosseae & V150 \\
\hline AJ628053 & Glomus mosseae & V249 \\
\hline AJ628052 & Glomus mosseae & V293 \\
\hline AJ628051 & Glomus mosseae & V91 \\
\hline
\end{tabular}




\begin{tabular}{|c|c|c|}
\hline AJ628050 & Glomus mosseae & V296 \\
\hline AJ628049 & Glomus mosseae & V296 \\
\hline AF145746 & Glomus caledonium & BEG86 \\
\hline AF145743 & Glomus geosporum & BEG106 \\
\hline AF145738 & Glomus mosseae & BEG84 \\
\hline AF145737 & Glomus mosseae & BEG83 \\
\hline AJ271924 & Glomus mosseae & HM-CL1 \\
\hline AJ510240 & Glomus caledonium & BEG20 \\
\hline AF389014 & Glomus mosseae & BEG68 \\
\hline AF389013 & Glomus mosseae & BEG68 \\
\hline AF389012 & Glomus mosseae & BEG68 \\
\hline AF389011 & Glomus mosseae & BEG68 \\
\hline AF389010 & Glomus mosseae & BEG68 \\
\hline AF389009 & Glomus mosseae & BEG68 \\
\hline AF389008 & Glomus mosseae & BEG68 \\
\hline GQ330818 & Glomus mosseae & AU34 \\
\hline GQ330817 & Glomus mosseae & AU33 \\
\hline GQ330815 & Glomus mosseae & AU8 \\
\hline GQ330814 & Glomus mosseae & AU2 \\
\hline GQ330813 & Glomus mosseae & WUM16 \\
\hline GQ330811 & Glomus mosseae & Narrabii \\
\hline GQ330807 & Glomus mosseae & Bur11 \\
\hline GQ330806 & Glomus mosseae & INVAM JA205c \\
\hline GQ330805 & Glomus mosseae & BEG229 \\
\hline GQ330800 & Glomus mosseae & BEG55 \\
\hline GQ330797 & Glomus mosseae & INVAM NB103c \\
\hline GQ330793 & Glomus mosseae & INVM SF1171 \\
\hline GQ330791 & Glomus mosseae & INVAM CU134a \\
\hline GQ330789 & Glomus mosseae & DKB01D4 \\
\hline GQ330788 & Glomus mosseae & DKK04D22 \\
\hline GQ330787 & Glomus mosseae & DKGm1 \\
\hline GQ330785 & Glomus mosseae & Sp813 \\
\hline GQ330784 & Glomus mosseae & Sp6314 \\
\hline GQ330783 & Glomus mosseae & Sp4318 \\
\hline GQ330781 & Glomus mosseae & Sp2735 \\
\hline GQ330780 & Glomus mosseae & Sp1841 \\
\hline GQ330779 & Glomus mosseae & BEG128 \\
\hline GQ330778 & Glomus mosseae & BEG124 \\
\hline GQ330777 & Glomus mosseae & BEG85 \\
\hline GQ330774 & Glomus mosseae & Dk11107 \\
\hline GQ330773 & Glomus mosseae & Dk21107 \\
\hline GQ330772 & Glomus mosseae & Dk17107 \\
\hline GQ330771 & Glomus mosseae & BEG230 \\
\hline GQ330768 & Glomus mosseae & Dk23135 \\
\hline
\end{tabular}


GQ330760 Glomus mosseae

GQ330757 Glomus mosseae

GQ330756 Glomus mosseae

GQ330754 Glomus mosseae

GQ330749 Glomus mosseae

GQ330748 Glomus mosseae

GQ330747 Glomus mosseae

GQ330744 Glomus mosseae

GQ330743 Glomus mosseae

GQ330742 Glomus mosseae
INVAM WY111

INVAM MT107

INVAM OR229

INVAM SC226

INVAM MN101

INVAM MI210

INVAM ON201

INVAM WI101

INVAM NV106

INVAM IN101 
Table S6: Barcode gap analyses with TaxonGap 2.3 based on pairwise comparison of K2P listances based on a manual or automated alignment (MAFFT). Variation is given in \% $\mathrm{K} 2 \mathrm{P}$ listances. The closest species, presence or absence of a barcode gap were identical for the nanual and MAFFT alignments, respectively. Seq, number of sequences; CS, closest species; BG, barcode gap; Max. ISV, maximum intraspecific variation; Min. ISV, minimum intraspecific variation; ?, unknown.

\begin{tabular}{|c|c|c|c|c|c|c|c|c|}
\hline \multirow[b]{2}{*}{ Family } & \multirow[b]{2}{*}{ Species } & \multirow[b]{2}{*}{ Seq } & \multirow[b]{2}{*}{ CS } & \multirow[b]{2}{*}{ BG } & \multicolumn{2}{|c|}{$\begin{array}{l}\text { manual } \\
\text { alignment }\end{array}$} & \multicolumn{2}{|c|}{$\begin{array}{l}\text { MAFFT } \\
\text { alignment }\end{array}$} \\
\hline & & & & & $\begin{array}{l}\text { Max. } \\
\text { ISV }\end{array}$ & Min. & $\begin{array}{l}\text { Max. } \\
\text { ISV }\end{array}$ & Min. \\
\hline & Glomus mosseae & 16 & Gl. coronatum & Yes & 2.52 & 2.66 & 2.58 & 3.78 \\
\hline Glomeraceae & Gl. sp. WUM3 & 6 & Gl. caledonium & Yes & 0.85 & 2.1 & 0.85 & 2.09 \\
\hline (Glomus & Gl. coronatum & 5 & Gl. mosseae & Yes & 0.5 & 2.66 & 1.01 & 3.78 \\
\hline \multirow[t]{2}{*}{ Group Aa) } & Gl. caledonium & 3 & Gl. sp. WUM3 & Yes & 0.8 & 2.1 & 0.8 & 2.09 \\
\hline & Gl. intraradices & 47 & Gl. proliferum & No & 10.77 & 4.29 & 11.75 & 4.7 \\
\hline Glomeraceae & Gl. proliferum & 15 & Gl. intraradices & Yes & 4.02 & 4.29 & 3.89 & 4.7 \\
\hline (Glomus & Gl. sp. 'irregulare-like' & 39 & Gl. proliferum & Yes & 6.43 & 7 & 6.29 & 6.94 \\
\hline \multirow[t]{3}{*}{ Group Ab) } & Gl. clarum & 9 & Gl. proliferum & Yes & 1.09 & 7.58 & 1.59 & 7.96 \\
\hline & Acaulospora laevis & 26 & $\begin{array}{l}\text { Ku. Kentinensis \& } \\
\text { Ac. scrobiculata }\end{array}$ & Yes & 3.42 & 13.07 & 3.99 & 13.16 \\
\hline & Acaulospora sp. WUM18 & 2 & Ac. scrobiculata & Yes & 1.02 & 5.66 & 1.02 & 5.66 \\
\hline Acaulo- & Ac. scrobiculata & 4 & Ac. sp. WUM18 & Yes & 0.47 & 5.66 & 0.47 & 5.66 \\
\hline sporaceae & Kuklospora kentinensis & 14 & Ac. scrobiculata & Yes & 0.54 & 11.98 & 0.54 & 11.38 \\
\hline Ambi- & Ambispora appendicula & 11 & Am. fennica & Yes & 2.87 & 12.11 & 2.87 & 13.26 \\
\hline \multirow{4}{*}{ sporaceae } & Am. fennica & 12 & Am. appendicula & Yes & 1 & 12.11 & 1.14 & 13.26 \\
\hline & Gigaspora margarita & 24 & Gi. rosea & No & 4.15 & 3.26 & 4.42 & 3.34 \\
\hline & Gi. rosea & 27 & Gi. margarita & No & 6.17 & 3.26 & 6.53 & 3.34 \\
\hline & Sc. gilmorei & 25 & Sc. spinosissima & Yes & 1.55 & 2.64 & 1.62 & 2.5 \\
\hline \multirow{2}{*}{$\begin{array}{l}\text { Giga- } \\
\text { sporaceae }\end{array}$} & Sc. spinosissima & 3 & Sc. gilmorei & No & 2.84 & 2.64 & 2.84 & 2.5 \\
\hline & Sc. heterogama & 4 & Gi. margarita & Yes & 1.95 & 4.69 & 2.74 & 5.07 \\
\hline Glomeraceae & Glomus sp. W3349 & 4 & Gl. luteum & Yes & 0.77 & 11.54 & 0.71 & 12.27 \\
\hline (Glomus & Gl. etunicatum & 12 & Gl. luteum & Yes & 0.93 & 3.64 & 0.94 & 3.63 \\
\hline \multirow[t]{4}{*}{ Group B) } & Gl. luteum & 5 & Gl. etunicatum & Yes & 0.64 & 3.64 & 0.96 & 3.63 \\
\hline & Diversispora celata & 3 & Gl. eburneum & Yes & 0.9 & 2.61 & 0.83 & 3.39 \\
\hline & Gl. eburneum & 12 & Di. celata & Yes & 0.92 & 2.61 & 0.92 & 3.39 \\
\hline & Gl. versiforme & 25 & Gl. eburneum & Yes & 2.52 & 5.81 & 2.79 & 5.64 \\
\hline \multirow{2}{*}{$\begin{array}{l}\text { Diversi- } \\
\text { sporaceae }\end{array}$} & Diversispora spurca & 18 & Gl. aurantium & Yes & 1.59 & 2.73 & 1.66 & 2.87 \\
\hline & Gl. aurantium & 11 & Di. spurca & Yes & 1.71 & 2.73 & 1.71 & 2.87 \\
\hline $\begin{array}{l}\text { Para- } \\
\text { glomeraceae }\end{array}$ & Paraglomus occultum & 1 & Sc. gilmorei & $?$ & - & 34.93 & - & 31.7 \\
\hline $\begin{array}{l}\text { Paci- } \\
\text { sporaceae }\end{array}$ & Pacispora scintillans & 2 & Sc. heterogama & Yes & 0.62 & 22.59 & 0.55 & 20.55 \\
\hline
\end{tabular}



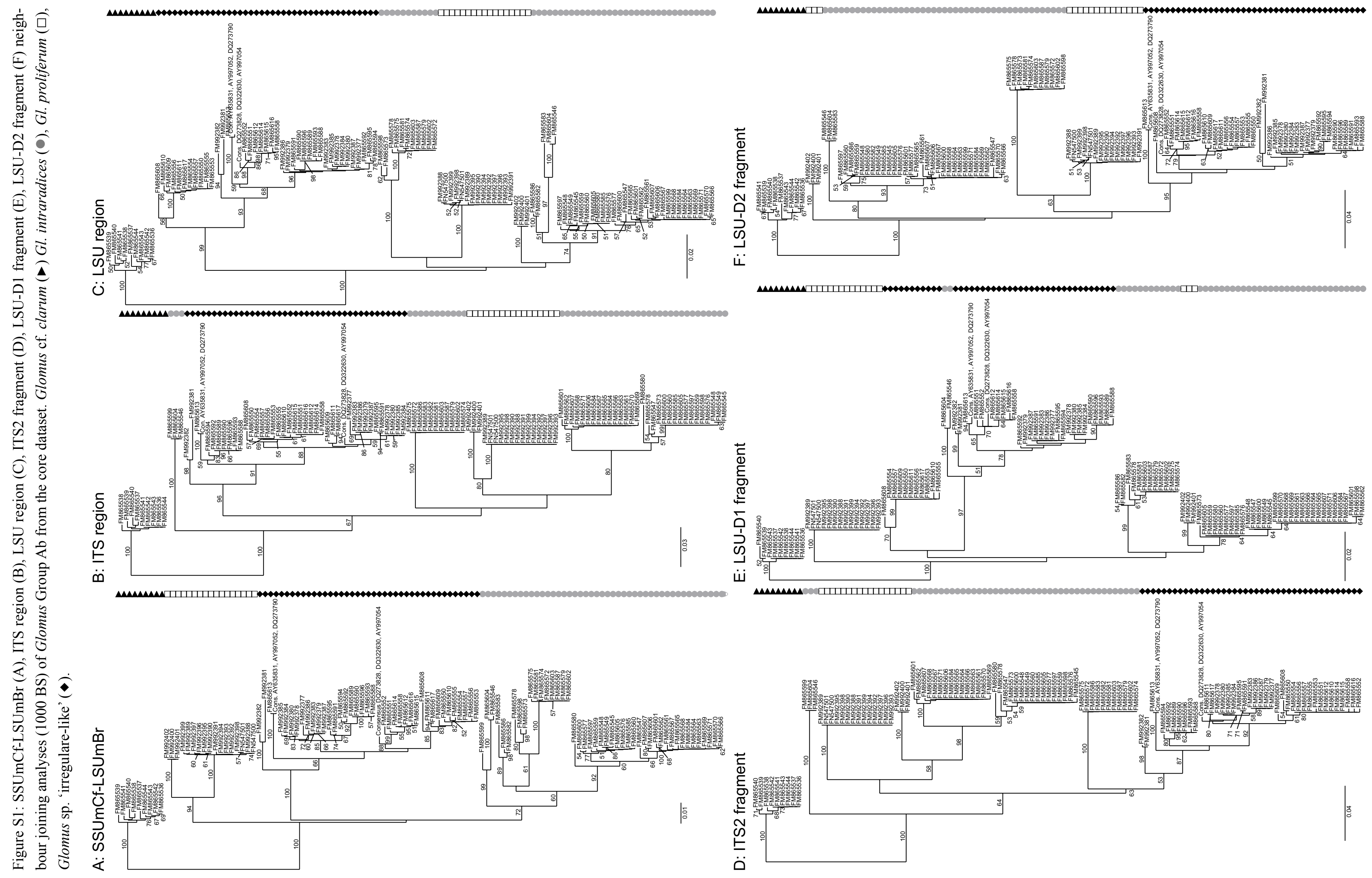

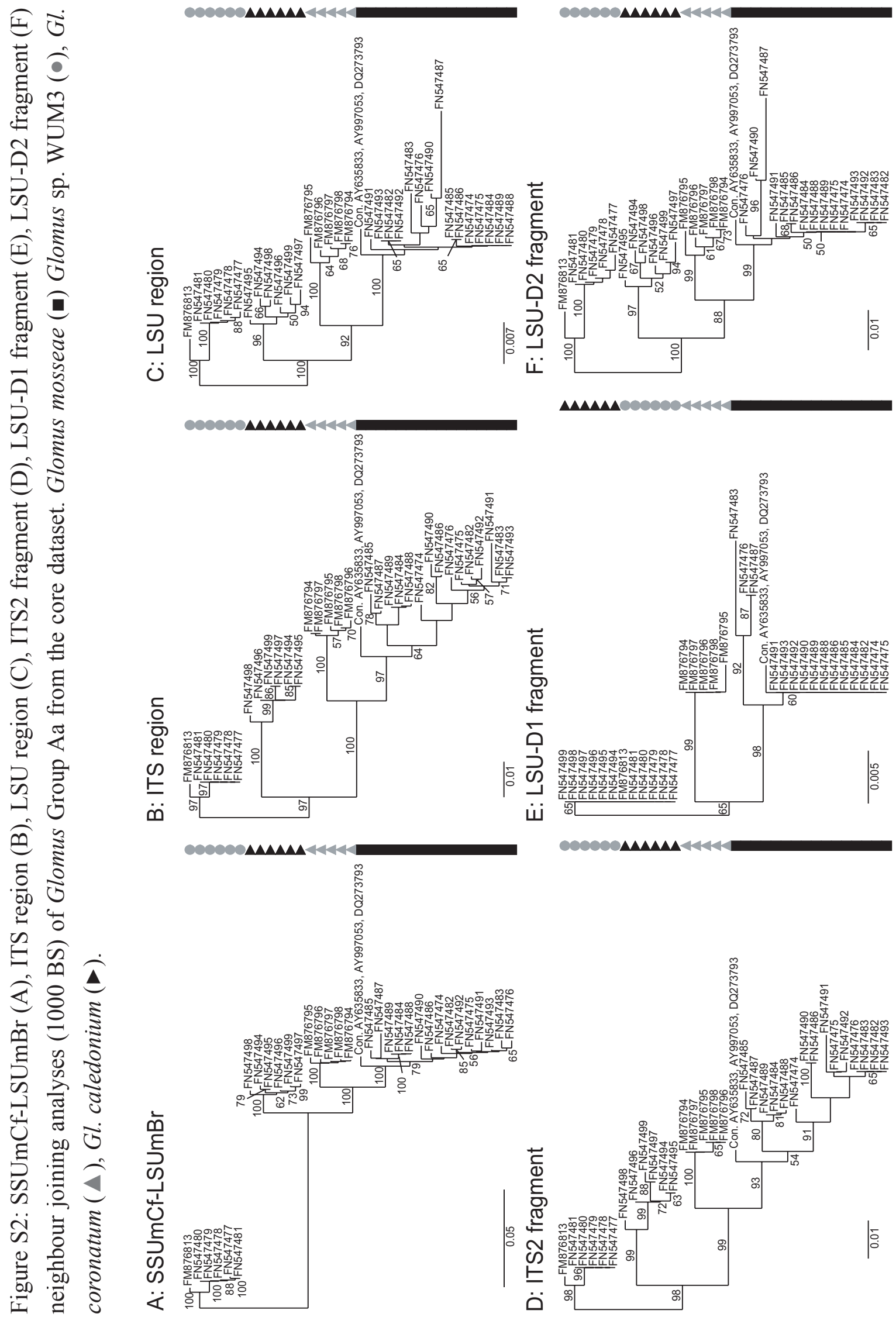
Figure S3: SSUmCf-LSUmBr (A), ITS region (B), LSU region (C), ITS2 fragment (D), LSU-D1 fragment (E), LSU-D2 fragment (F) neighbour joining analyses (1000 BS) of Acaulosporaceae from the core dataset. Kuklospora kentinensis ( ), Acaulospora sp. WUM18 (४), Ac. scrobiculata $(\square)$, Ac. laevis $(\bullet)$.

A: SSUmCf-LSUmBr

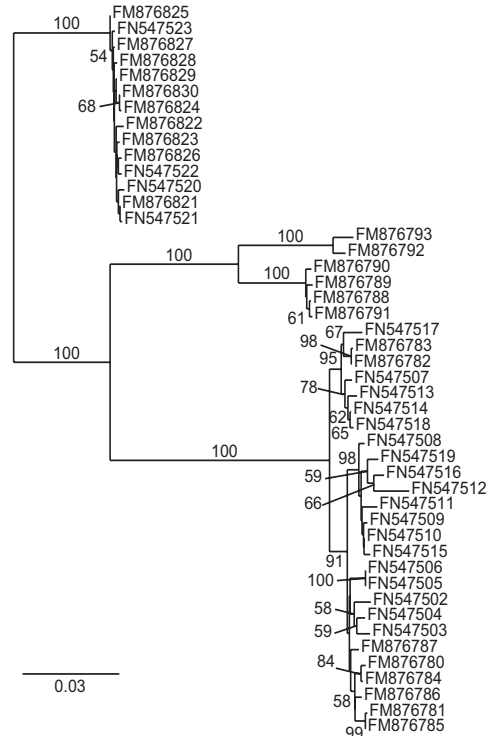

D: ITS2 fragment

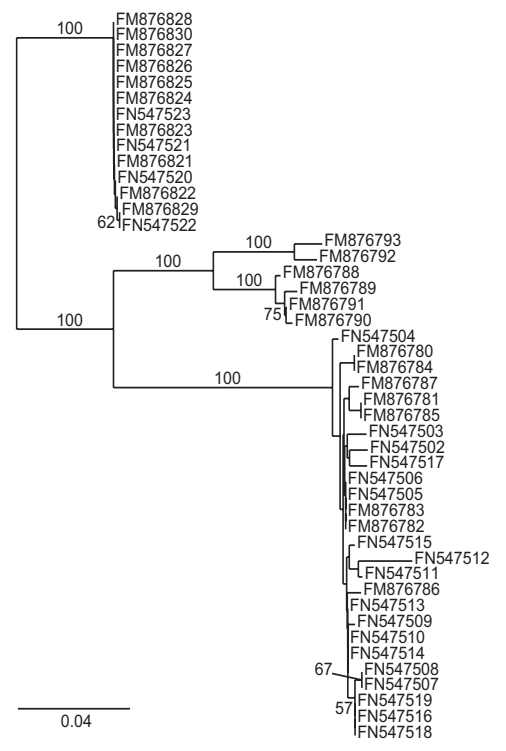

B: ITS region

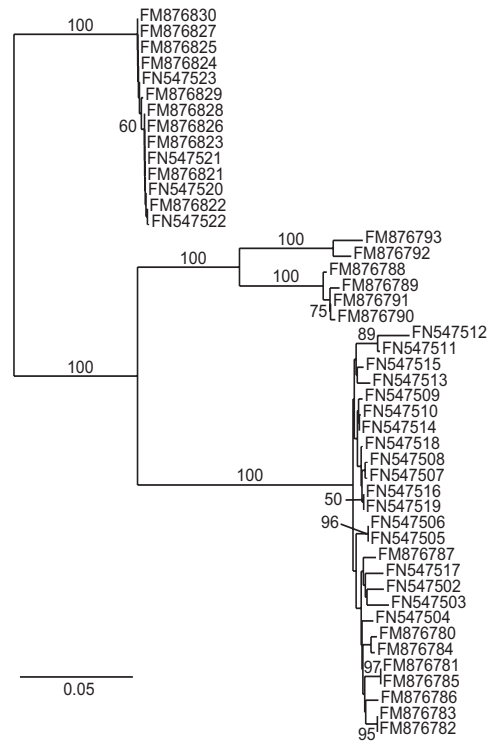

E: LSU-D1 fragment

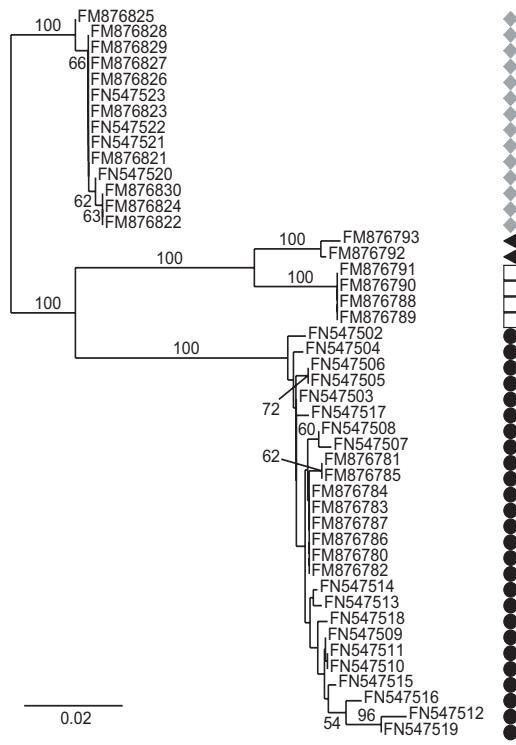

C: LSU region

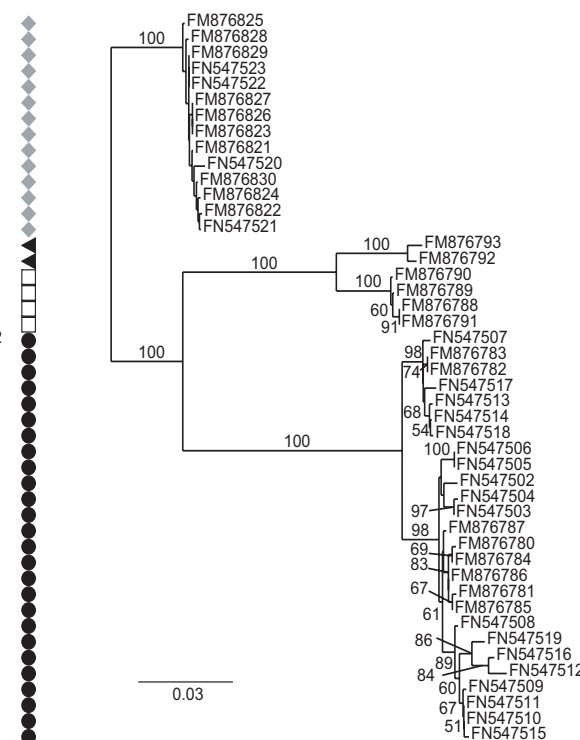

F: LSU-D2 fragment

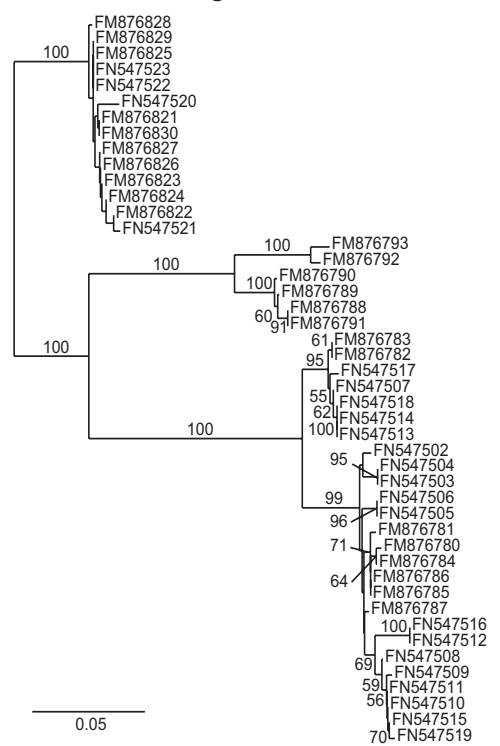


Figure S4: SSUmCf-LSUmBr (A), ITS region (B), LSU region (C), ITS2 fragment (D), LSU-D1 fragment (E), LSU-D2 fragment (F) neighbour joining analyses (1000 BS) of Glomus Group B from the core dataset. Glomus sp. W3349 (•), Glomus luteum (口), Gl. etunicatum $(\bullet)$.

A: SSUmCf-LSUmBr

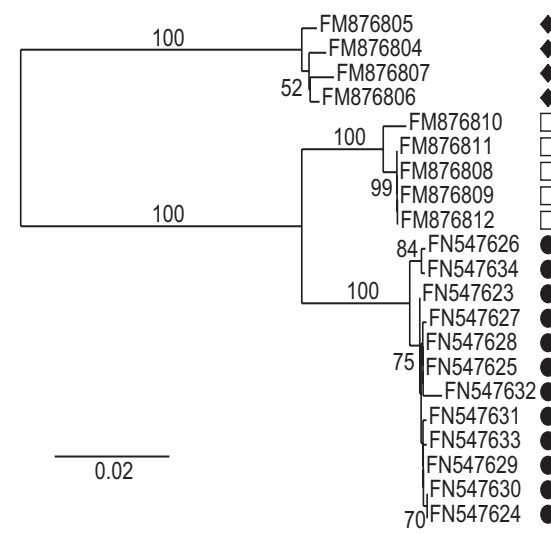

D: ITS2 fragment

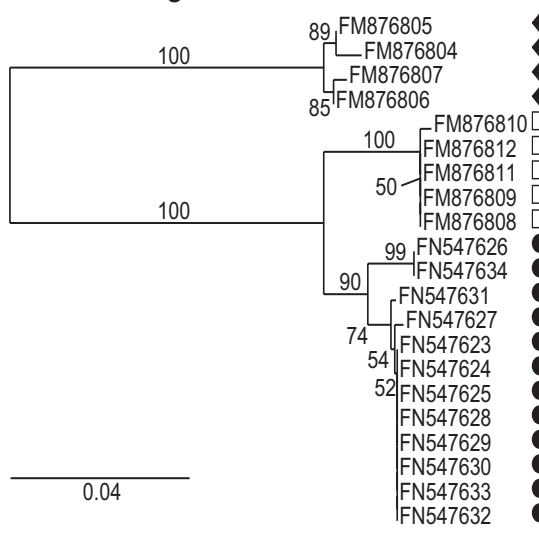

B: ITS region

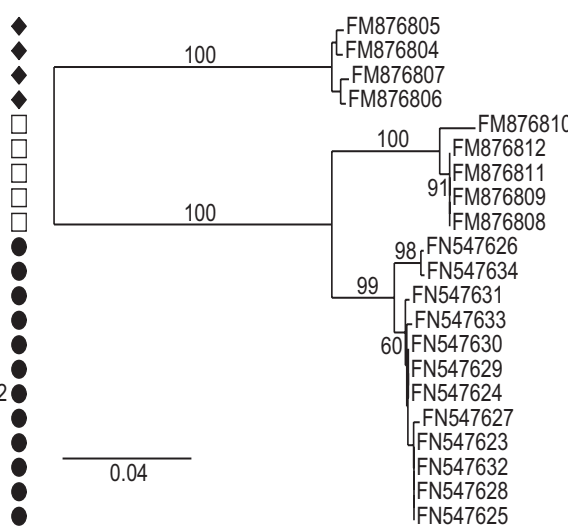

E: LSU-D1 fragment

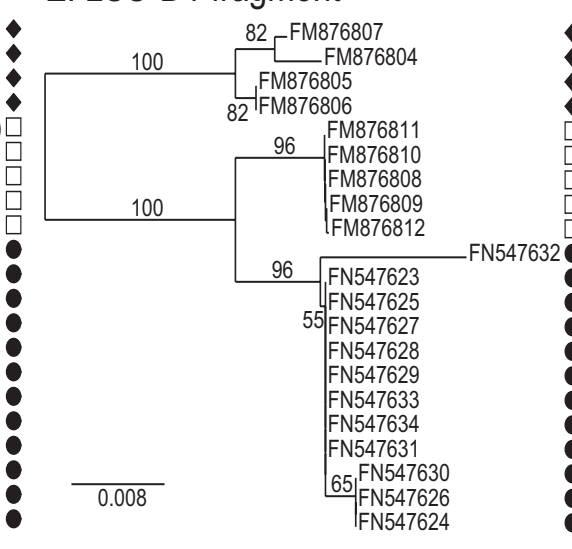

C: LSU region

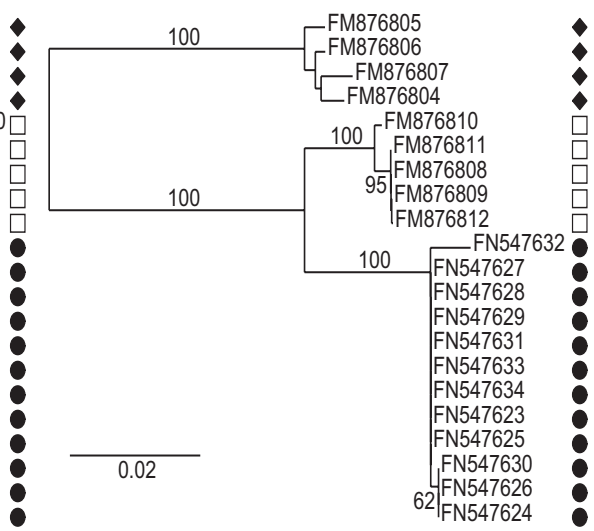

F: LSU-D2 fragment

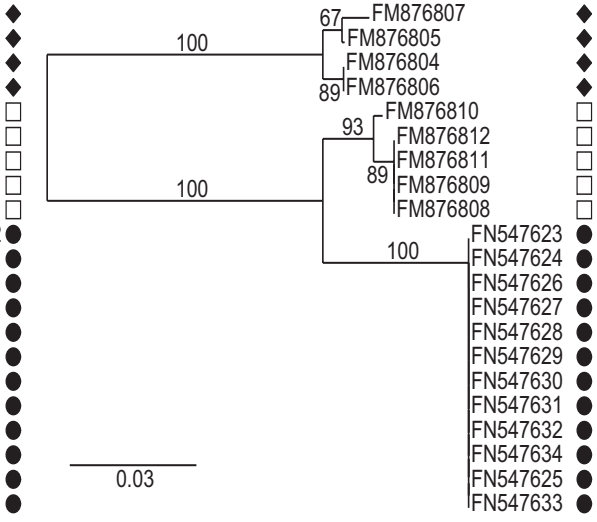


Figure S5: SSUmCf-LSUmBr (A), ITS region (B), LSU region (C), ITS2 fragment (D), LSU-D1 fragment (E), LSU-D2 fragment (F) neighbour joining analyses (1000 BS) of Diversisporaceae from the core dataset. Glomus eburneum ( $\nabla)$, Gl. aurantium $(\triangleleft), G l$. versiforme ( $\square)$, Diversispora celata (४), Di. spurca $(\boldsymbol{\nabla})$.

A: SSUmCf-LSUmBr

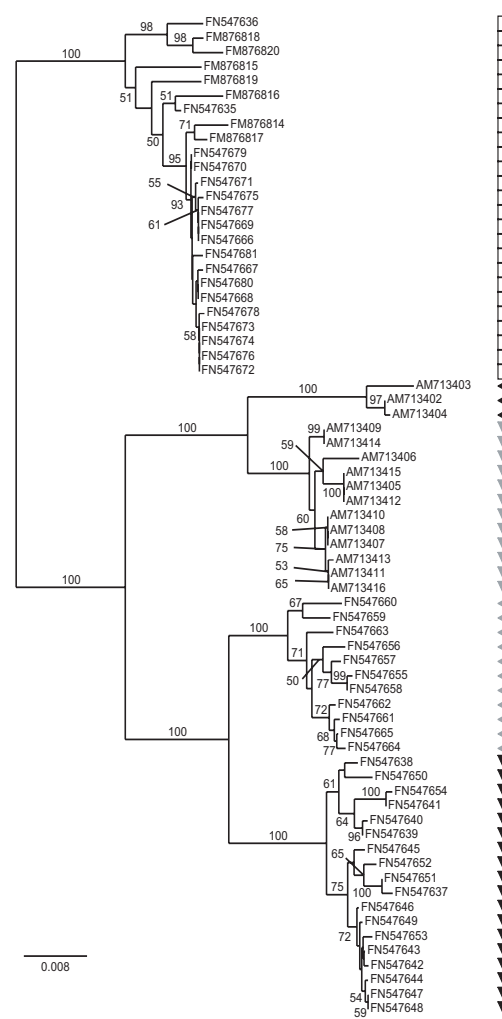

B: ITS region

D: ITS2 fragment

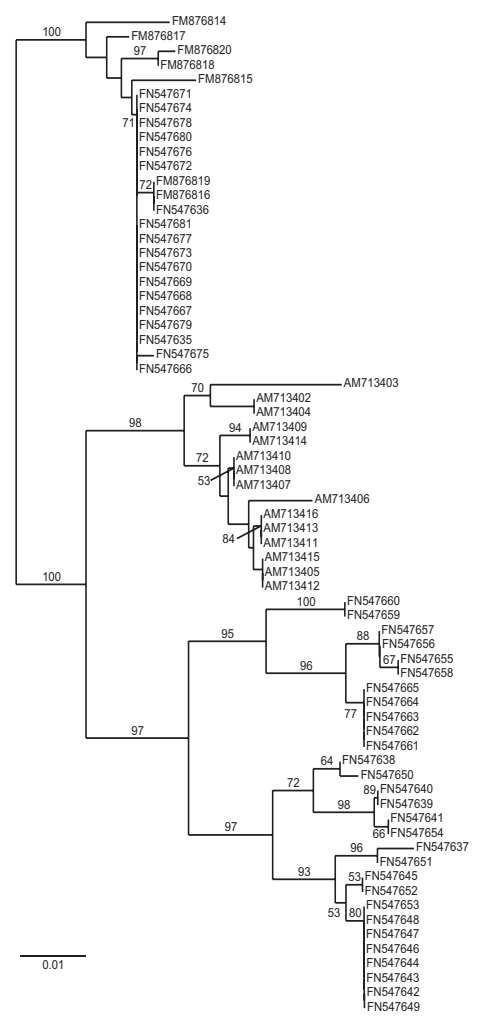

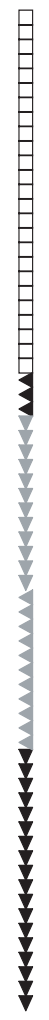

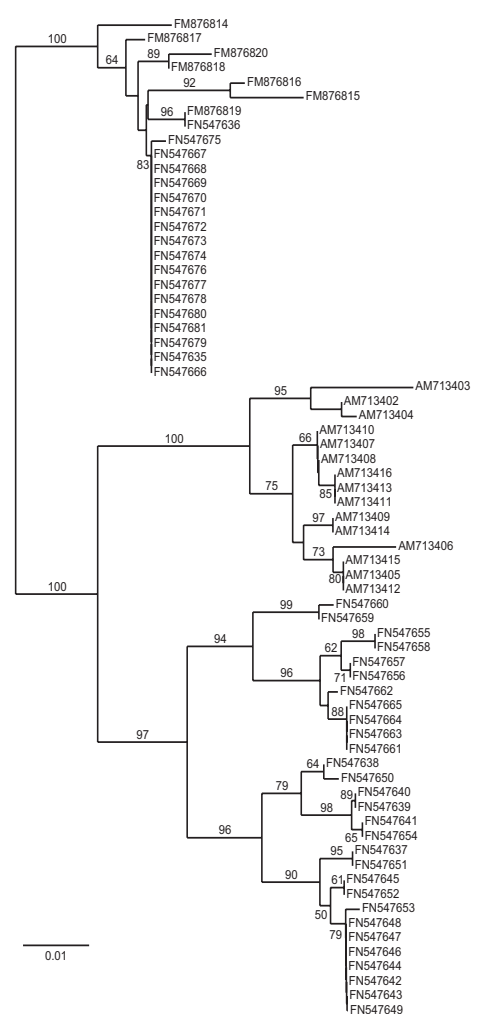

E: LSU-D1 fragment

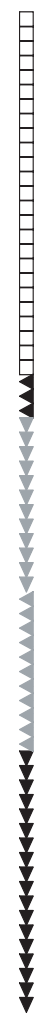

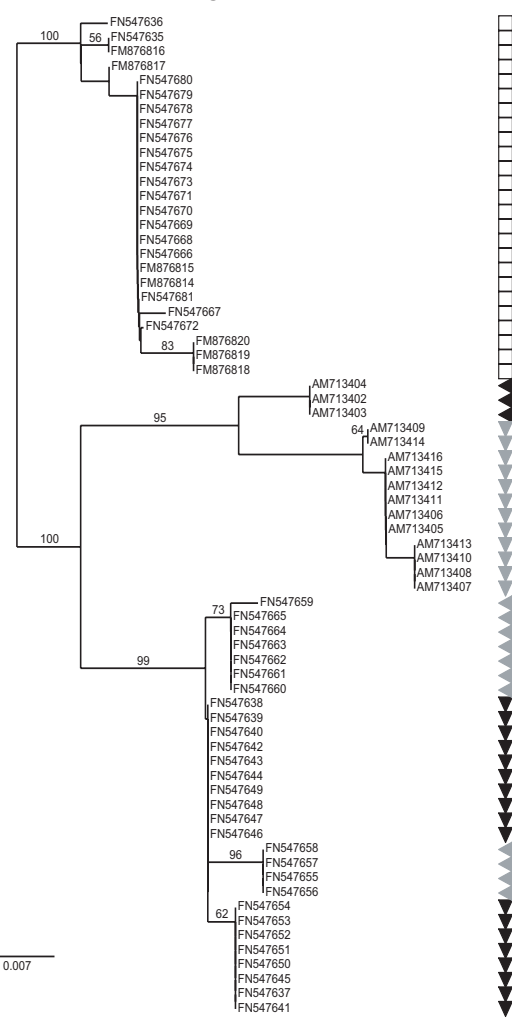

154
C: LSU region

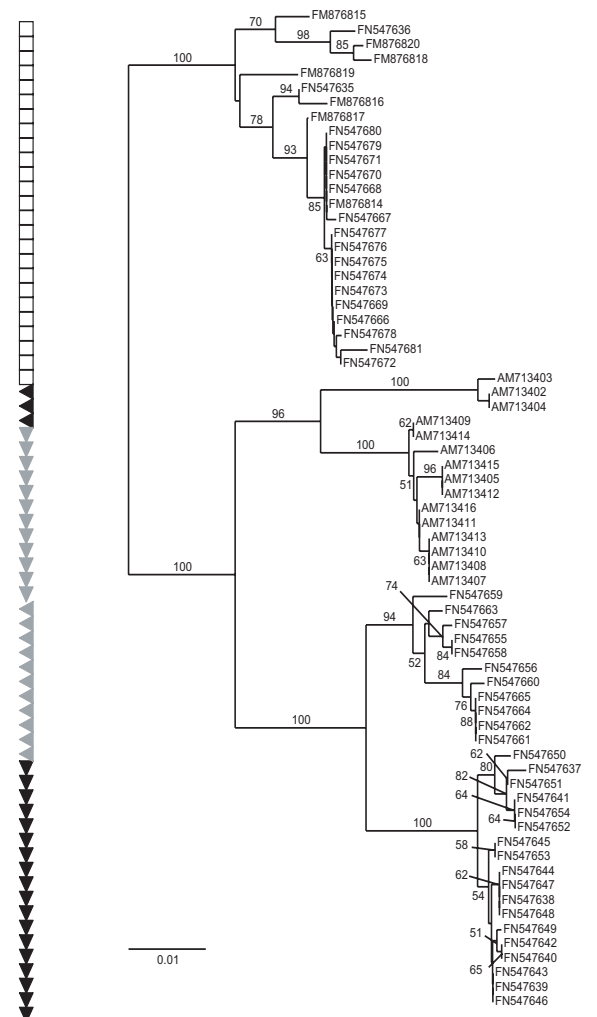

F: LSU-D2 fragment

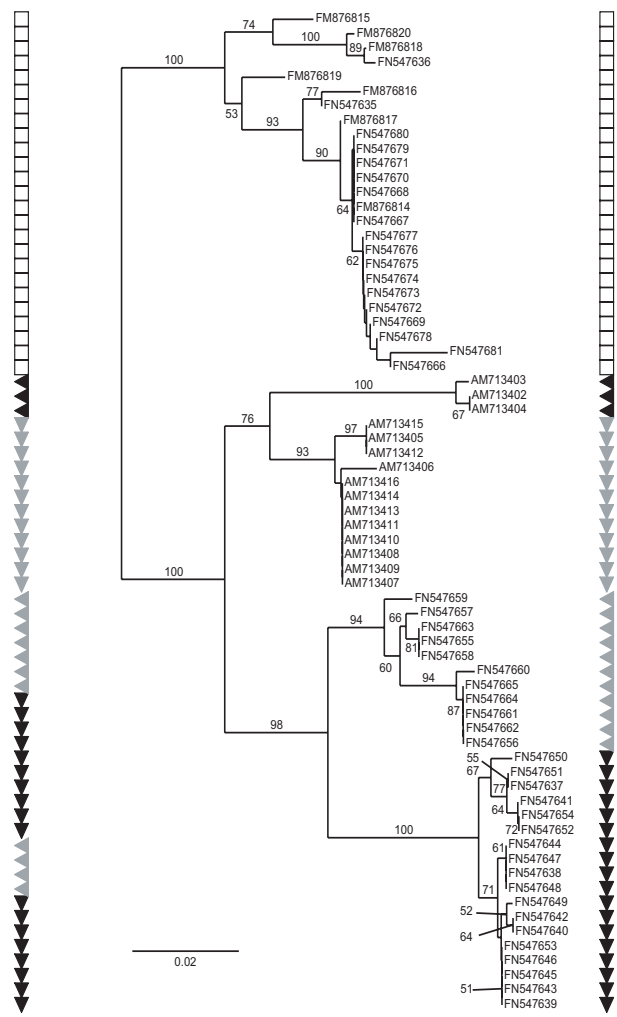


Figure S6: SSUmCf-LSUmBr (A), ITS region (B), LSU region (C), ITS2 fragment (D), LSU-D1 fragment (E), LSU-D2 fragment (F) neighbour joining analyses (1000 BS) of Gigasporaceae from the core dataset. Scutellospora spinosissima (घ), Sc. heterogama ( $\square)$, Gigaspora rosea ( $\mathbf{\nabla})$, Sc. gilmorei $(\diamond)$, Gi. margarita $(\bullet)$. 
Appendix

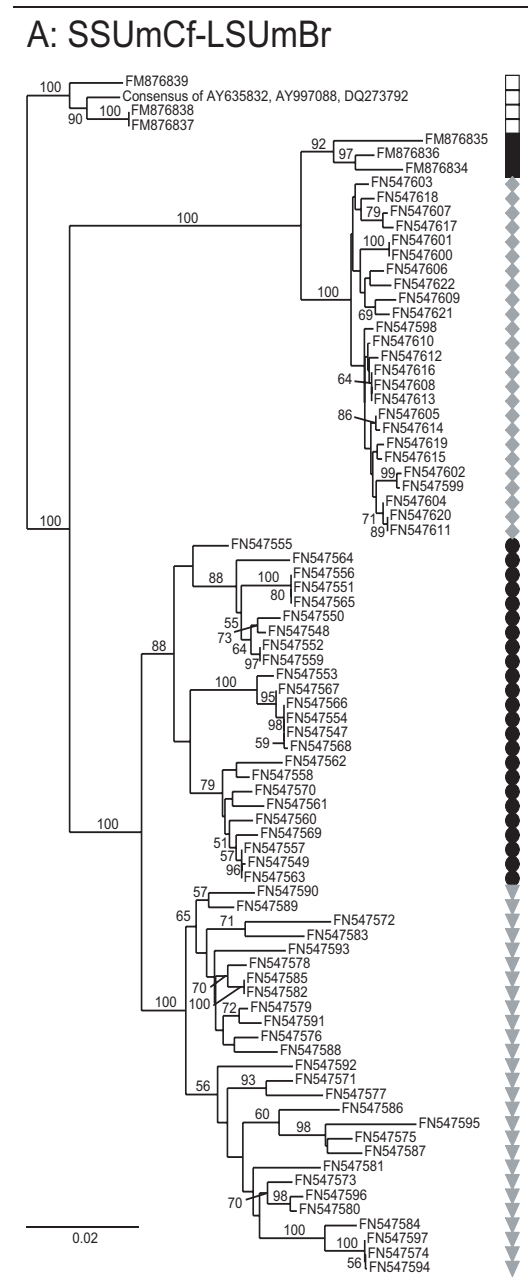

B: ITS region

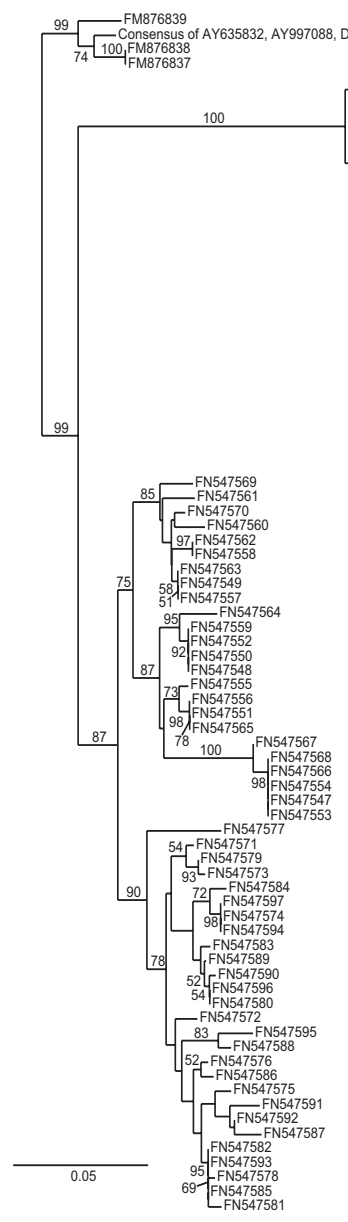

E: LSU-D1 fragment

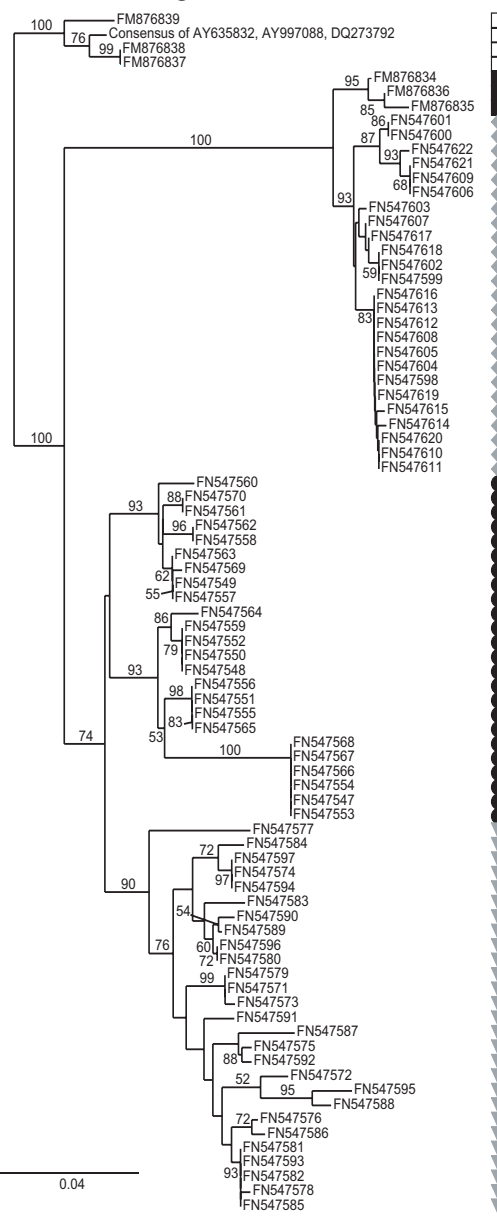

C: LSU region

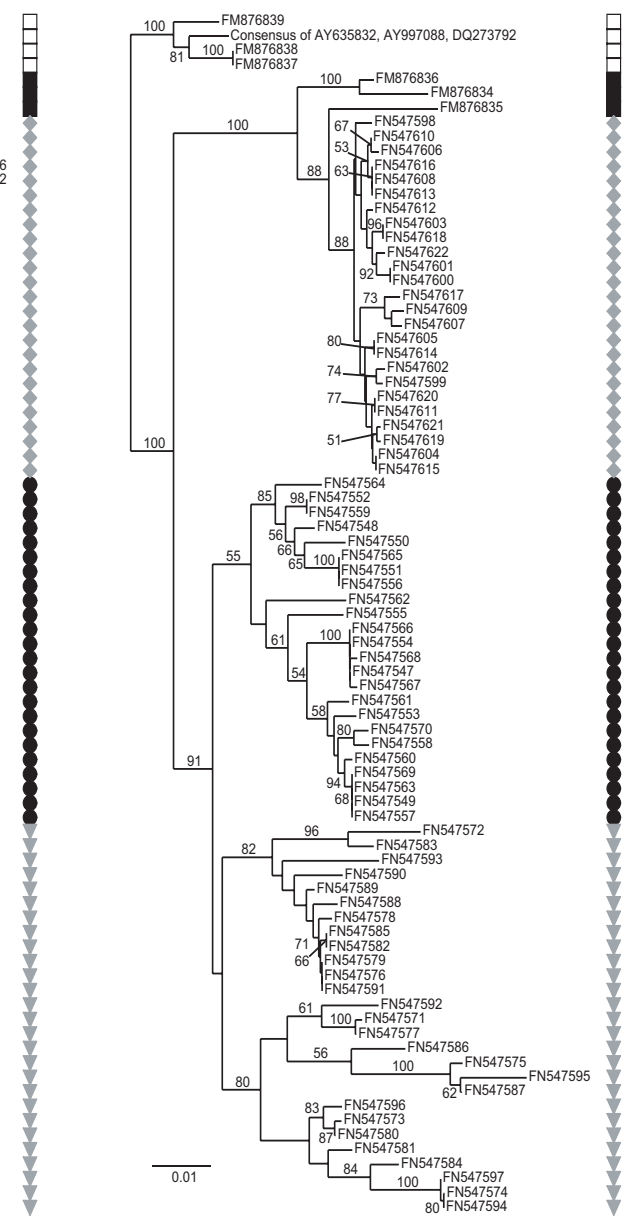

F: LSU-D2 fragment
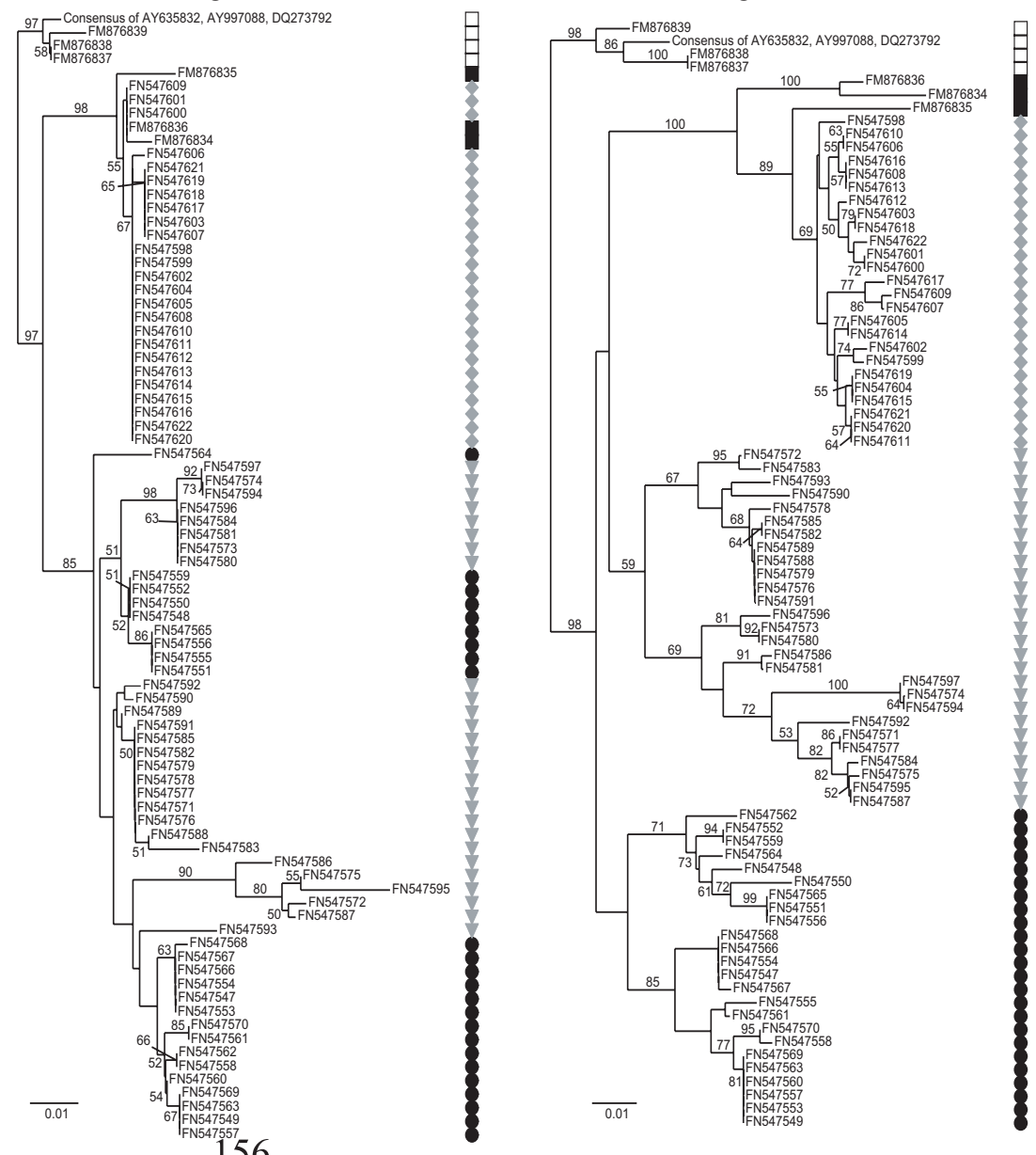

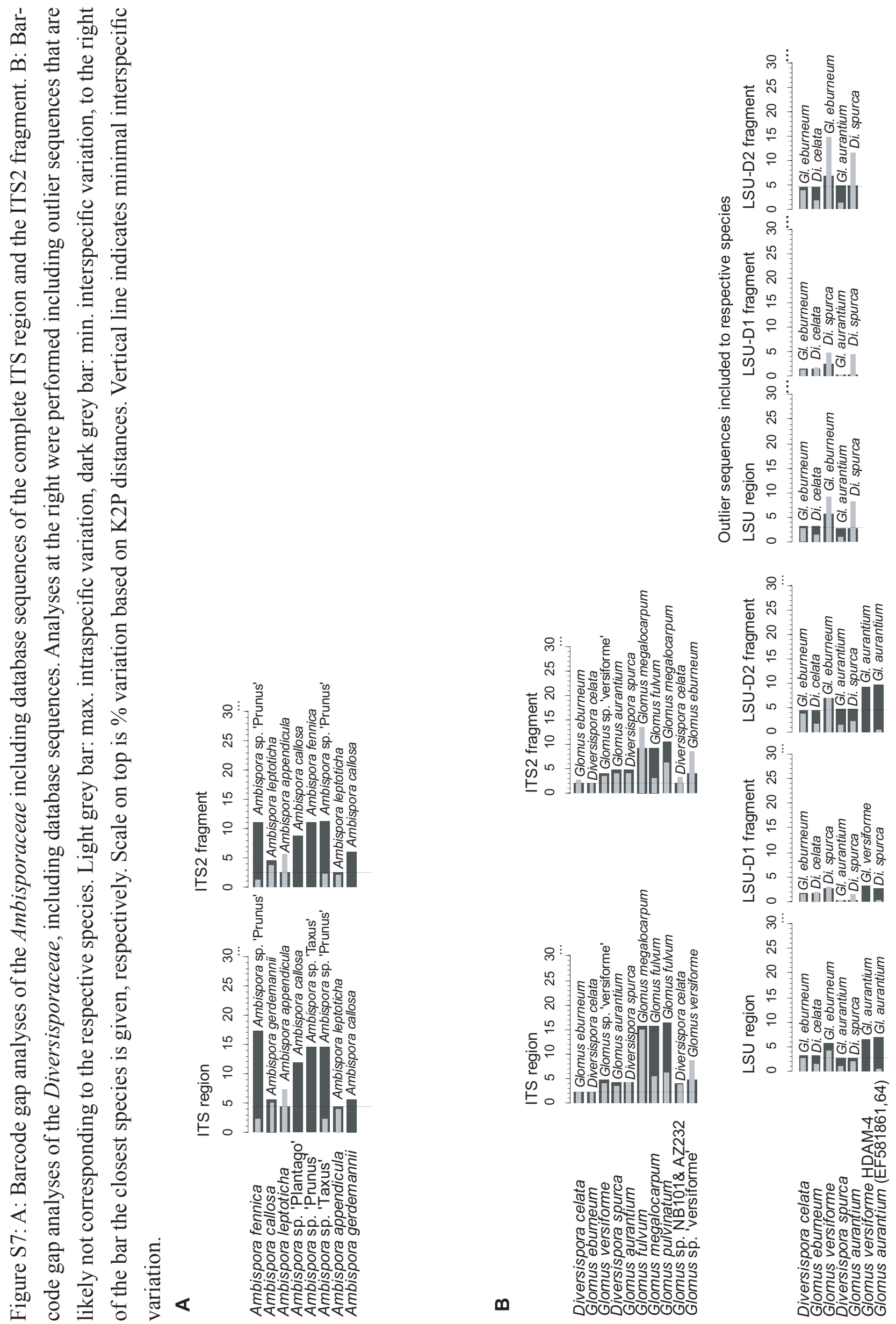
Figure S8: ITS region (A) and ITS2 fragment (B) neighbour joining analyses (1000 BS) of the Ambisporaceae. Ambispora gerdemanii ( $\nabla)$, Am. leptoticha (凶), Am. callosa (४), Am. fennica ( $\mathbf{\Delta})$, Am.

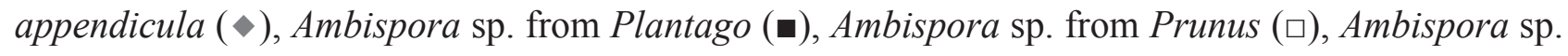
from Taxus $(\triangleright)$.

\section{A: ITS region}

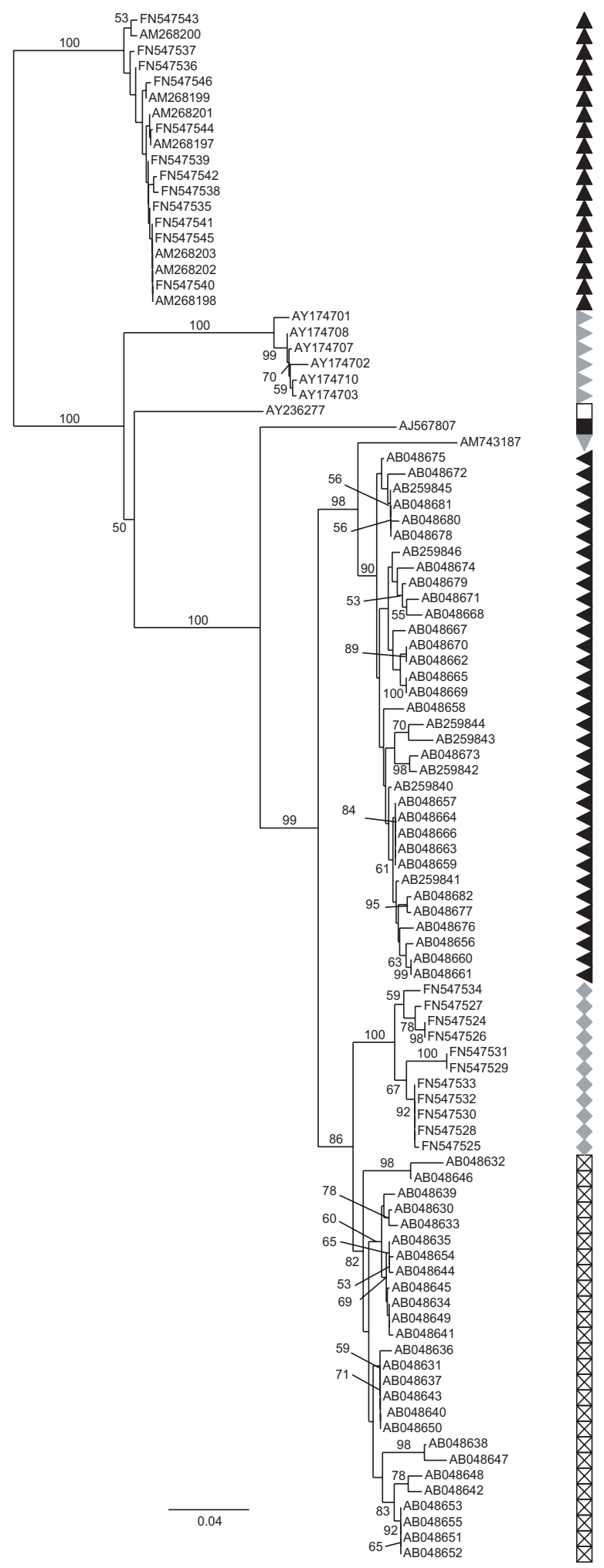

B: ITS2 fragment

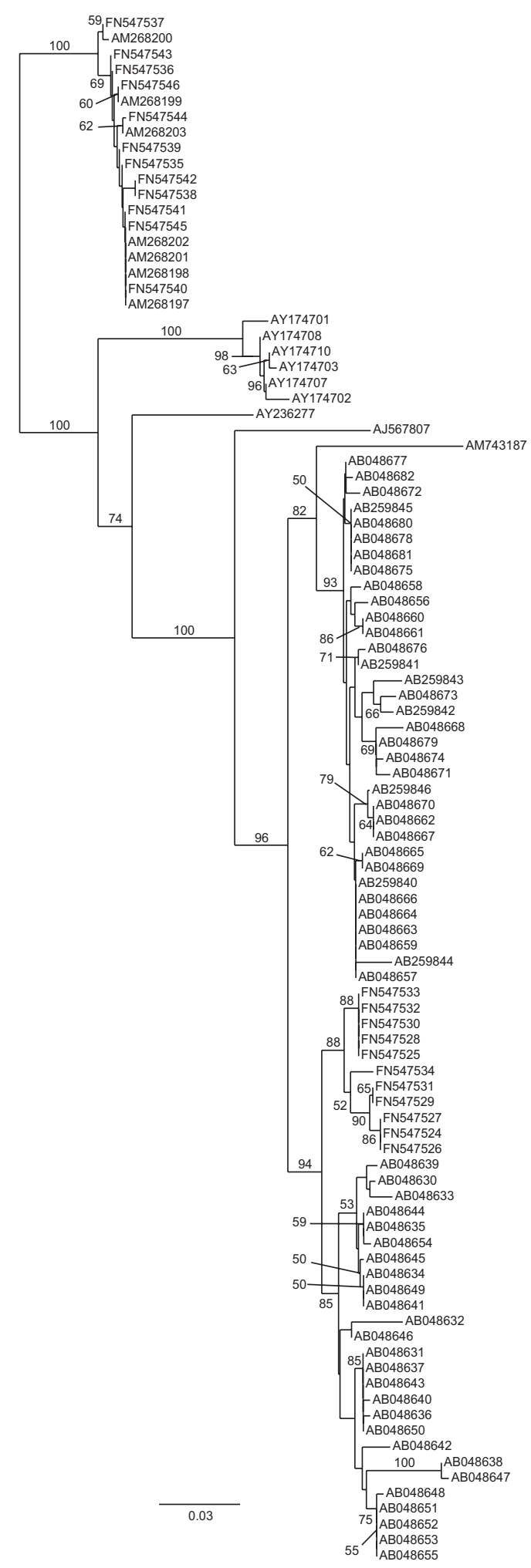


Figure S9: ITS region (A) and ITS2 fragment (B) neighbour joining analyses (1000 BS) of the Diversisporaceae. Glomus eburneum ( $\nabla)$, Gl. aurantium (४), Gl. versiforme ( $\square)$, Diversispora celata (४),

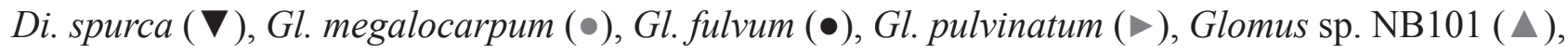
Glomus sp. AZ37B ( $\mathbf{\Delta})$, Glomus sp.’versiforme' environmental ( $\otimes)$. 


\section{A: ITS region}

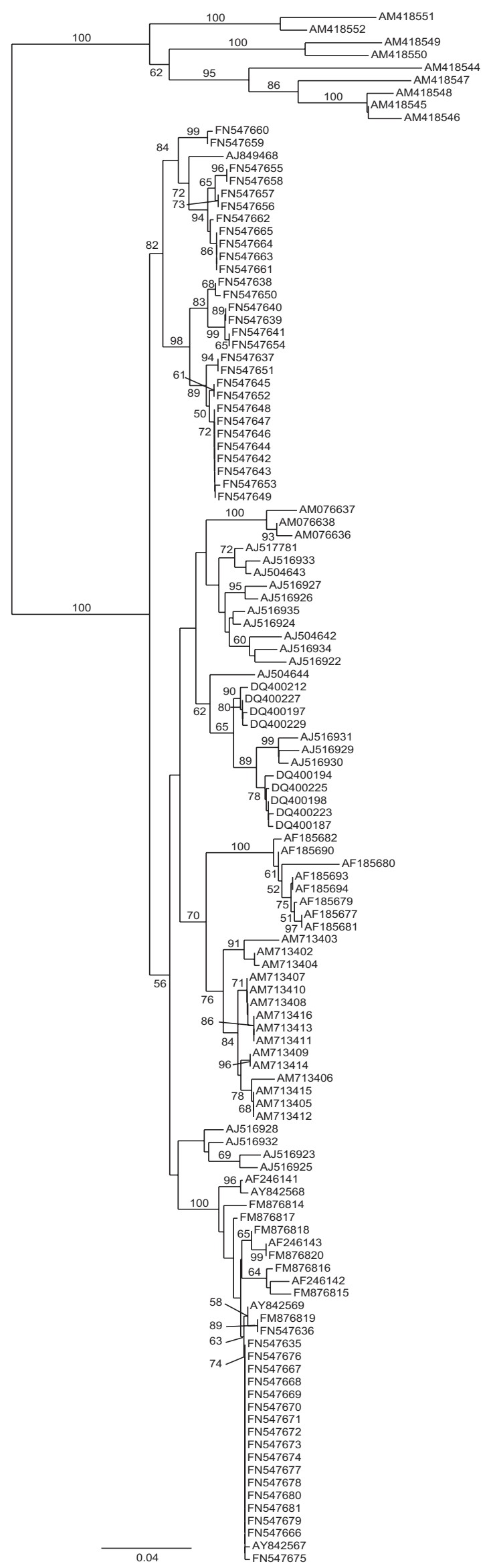

\section{B: ITS2 fragment}

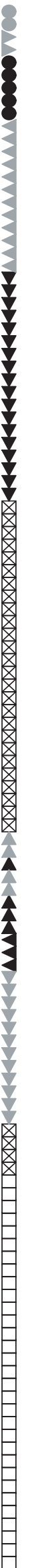

\section{B: ITS2 fragment}

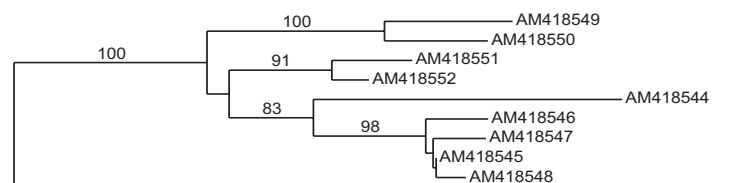

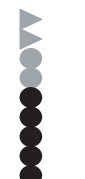

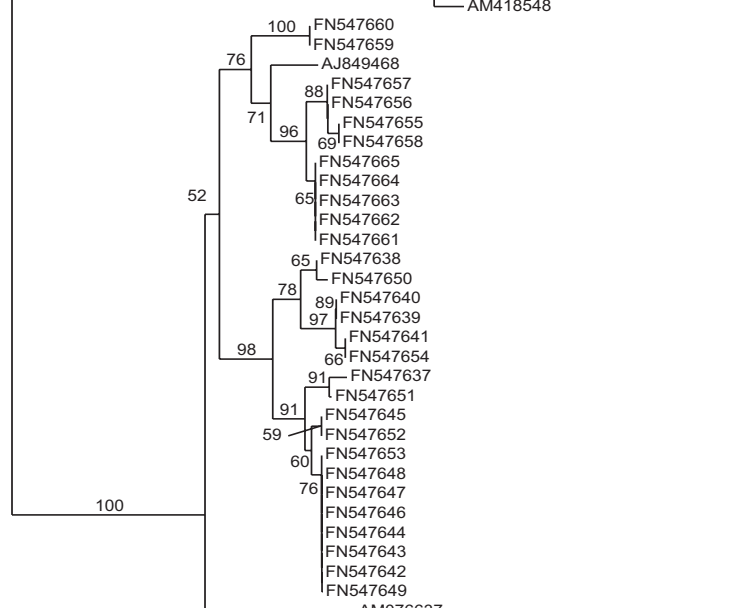


Figure S10: LSU region (A), LSU-D1 fragment (B) and LSU-D2 fragment (C) neighbour joining analyses (1000 BS) of the Diversisporaceae. Glomus eburneum ( $\nabla$ ), Gl. aurantium (४), Gl. versiforme ( $\square)$, Diversispora celata (४), Di. spurca ( $\mathbf{\nabla})$.

A: LSU region

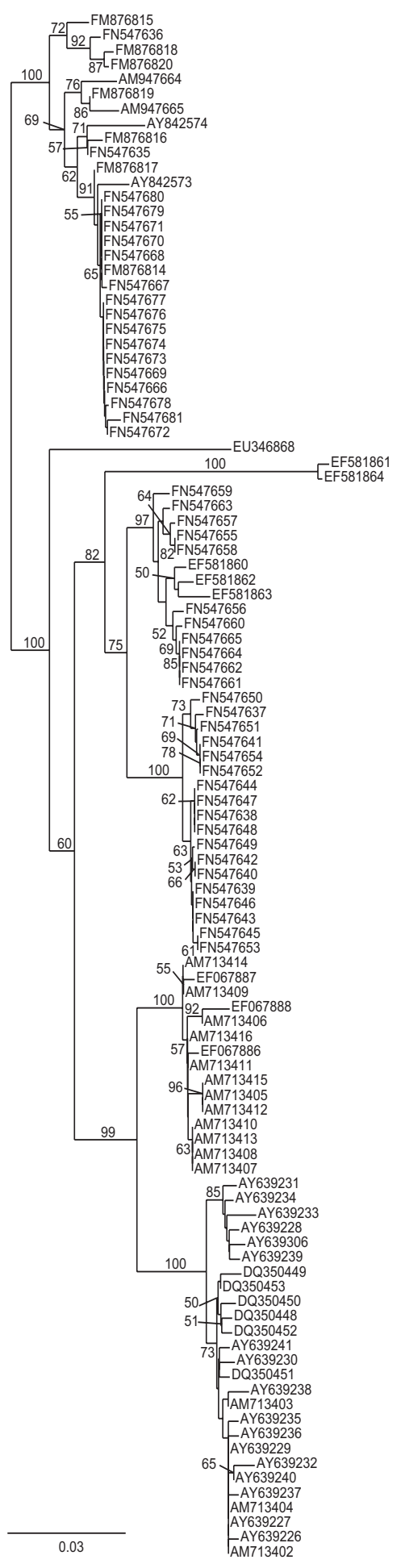

B: LSU-D1 fragment

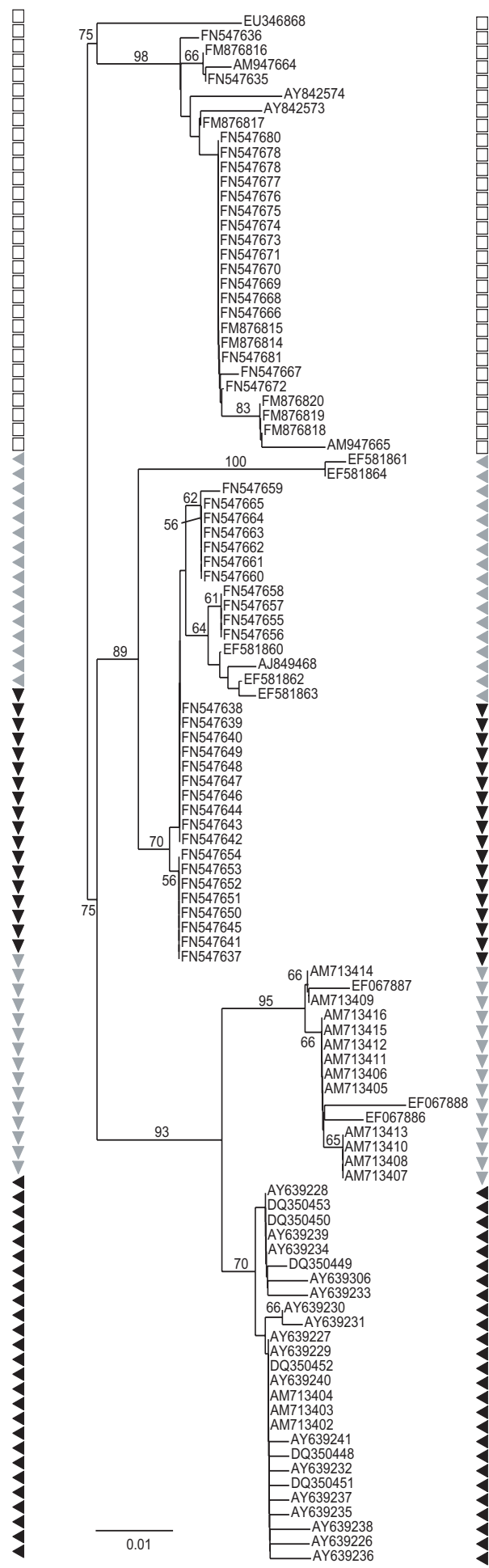

C: LSU-D2 fragment

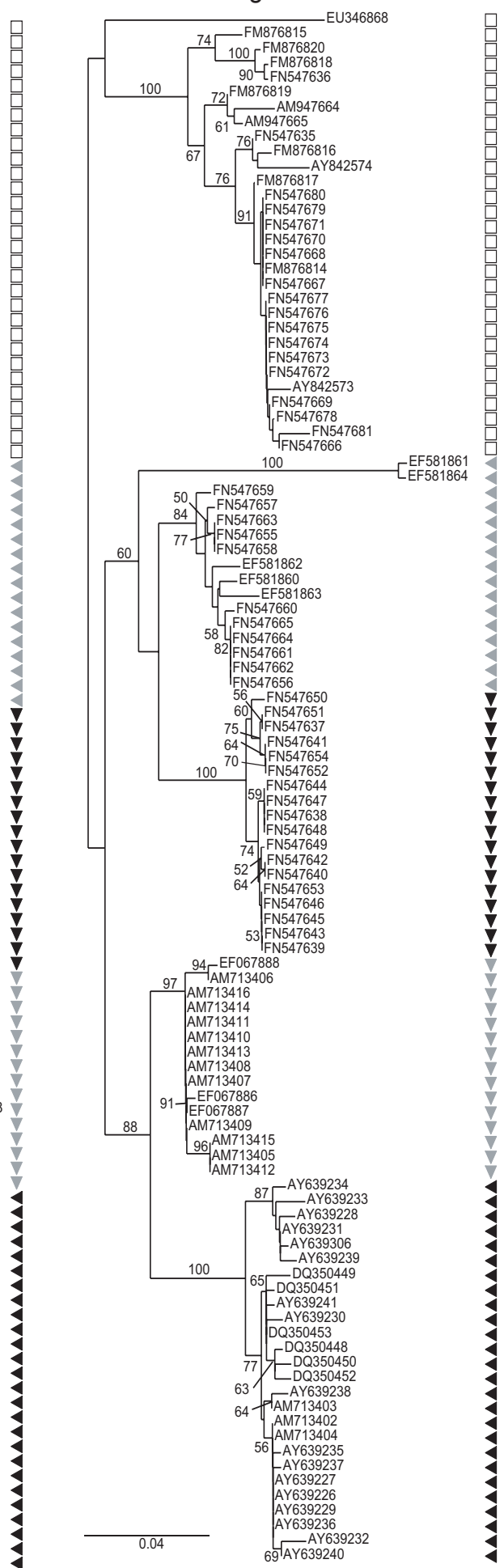




\subsection{Contribution of the author}

Walker C, Vestberg M, Demircik F, Stockinger H, Saito M, Sawaki H, Nishmura I, Schüßler A. 2007. Molecular phylogeny and new taxa in the Archaeosporales (Glomeromycota): Ambispora fennica gen. sp. nov., Ambisporaceae fam. nov., and emendation of Archaeospora and Archaeosporaceae. Mycological Research 111: 137-153.

Parts worked out by Herbert Stockinger: He contributed a part of the rDNA sequences for this analysis.

Krüger M, Stockinger H, Krüger C, Schüßler A. 2009. DNA-based species level detection of Glomeromycota: one PCR primer set for all arbuscular mycorrhizal fungi. New Phytologist 183: 212-223.

Parts worked out by Herbert Stockinger: He participated in the alignment of new and database sequences and in the design of the primers. In addition, a part of the newly published sequences were generated by him.

Stockinger H, Walker C, Schüßler A. 2009. 'Glomus intraradices DAOM197198', a model fungus in arbuscular mycorrhiza research, is not Glomus intraradices. New Phytologist 183: 1176-1187.

Parts worked out by Herbert Stockinger: He cultured many of the AMF isolates used in this study and generated the vast majority of the new sequences published in this study and he performed the phylogenetic analyses. Together with C. Walker and A. Schüßler, he wrote the manuscript.

Stockinger H, Krüger M, Schüßler A: DNA barcoding for arbuscular mycorrhiza fungi

Parts worked out by Herbert Stockinger: He generated the majority of the sequences, aligned them to the existing database. He performed all DNA barcoding analyses. A Schüßler and he wrote the manuscript.

I hereby confirm the above statements:

Herbert Stockinger

PD Dr. Arthur Schüßler 


\subsection{Curriculum vitae}

\section{Herbert Stockinger}

\section{Personal data}

Date of birth: 1 September 1977

Place of birth: Braunau am Inn, Austria

\section{Education}

$2006-$

2005

$$
\begin{aligned}
& 2003-2005 \\
& 1999-2003 \\
& 1992-1997 \\
& 1988-1992 \\
& 1984-1988
\end{aligned}
$$

PhD about "DNA barcode of arbuscular mycorrhizal fungi" in the framework of the European project TRACEAM (TRACEability of Arbuscular Mycorrhizal fungi as plant-beneficial micro-organisms in agro-environments, MEST-CT2005-021016; Technical University of Darmstadt and Ludwig Maximilian University Munich, Germany) $\rightarrow$

Master study in biology passed with distinction, final examination on 28 November 2005 Master Thesis: "Mycorrhizal status of endangered plant species: Crocus albiflorus, Euphorbia verrucosa and Hypochoeris maculata" Supervisors: Prof. Dr. Kurt Haselwandter, University of Innsbruck, \& Prof. Dr. Thomas Peer, University of Salzburg Master Student of Botany at the University of Salzburg Bachelor Student of Environmental Biology at the University of Salzburg College for agriculture in Ursprung in the county of Salzburg Secondary School in Munderfing in the county Upper Austria Elementary School Lochen in the county Upper Austria

\section{Congress Contributions}

$2009 \operatorname{Apr} 7^{\text {th }}-9^{\text {th }}$
Summer School of the Project TRACEAM with the topics: Molecular ecology, phylogeny, DNA barcoding, bioinformatics tools, AMF taxonomy, Tracing and evolution of AMF endobacteria, Production of AMF in vitro, Phylochips and 454FLX sequencing - detection of AMF from the field, Genome structure of AMF, LMU, Munich, Germany, oral presentation 
2008 Aug $2^{\text {nd }-} 8^{\text {th }}$

2008 Aug $9^{\text {th }}-13^{\text {th }}$

2008 Jan $17^{\text {th }}-19^{\text {th }}$

2007 Oct $3^{\text {rd }}-5^{\text {th }}$

2007 May $17^{\text {th }}-19^{\text {th }}$

2006 Nov $23^{\text {rd }}-25^{\text {th }}$

2006 Sep $18^{\text {th }}-20^{\text {th }}$

$2006 \mathrm{Jul} 23^{\text {rd }}-27^{\text {th }}$

2005 July $17^{\text {th }}-23^{\text {rd }}$

2005 June $2^{\text {nd }}-4^{\text {th }}$

2004 Oct $21^{\text {st }}-23^{\text {rd }}$ $93^{\text {rd }}$ Ecological Society of America Annual Meeting, Milwaukee, Wisconsin, USA. Participation on two workshops of the Fungal Environmental Sampling and Informatics Network (FESIN) - poster presentation Mycological Society of America (MSA) 2008 Annual Meeting, Penn State University, State College, Pennsylvania, USA - poster presentation Winterschool with the topic AM fungi: soil ecology, molecular identification, and endobacteria (BLOs); information exchange with the FUNGIMYC project. University of Turin (UNITO), Turin, Italy, oral presentation.

DNA Barcoding in Europe, Leiden, The Netherlands, poster presentation EMBO Workshop "Molecular Biodiversity and DNA Barcode", Roma Italy, poster presentation Mycorrhizal snapshots, Turino, Italy

IXth International Fungal Biology Conference \& 16th New Phytologist Symposium: "Impact of genomics on fungal biology“. Nancy/France, poster presentation

$5^{\text {th }}$ International Conference on Mycorrhiza "Mycorrhiza for Science and Society" Granada/Spain

XVII International Botanical Congress, Vienna/Austria, poster presentation Management Committee and Final meeting of COST Action 8.38, Dijon/France, poster presentation

8th Management Committee Meeting of COST Action 8.38, Granada/Spain, poster presentation

\section{Professional experiences}

\author{
2009 Apr \\ 2005 Aug - Dec
}

$2002-2005$

$2001 \mathrm{Jul}-\mathrm{Sep}$

$1999 \mathrm{Apr}-2000$ Oct

1998
Scientific Employee Ludwig Maximilian University (LMU) Munich, Germany Technical assistant in the project "Phylogenetic and geographical analyses of the orchid genus Bulbophyllum on Madagascar and the Mascarens", Department of Organismic Biology, University of Salzburg, funded by the Austrian Science Fund (FWF), Austria

Teaching Assistant: Bioindication, Soil ecology, Native habitats, Phytology II:

Poaceae, Juncaceae \& Cyperaceae and ecosystems \& nutrient cycles,

University of Salzburg, Austria

Practical at a farm in Dalwigksthal Hesse, Germany

Deputy Managing Director of Maschinenring Oberes Mattigtal / Upper Austria Civilian service at the Red Cross Salzburg, Austria 